\title{
Assignment and Substitution in the Labour Market
}

Citation for published version (APA):

Dupuy, A. (2004). Assignment and Substitution in the Labour Market. [Doctoral Thesis, Maastricht University]. ROA. https://doi.org/10.26481/dis.20040326ad

Document status and date:

Published: 01/01/2004

DOI:

10.26481/dis.20040326ad

Document Version:

Publisher's PDF, also known as Version of record

\section{Please check the document version of this publication:}

- A submitted manuscript is the version of the article upon submission and before peer-review. There can be important differences between the submitted version and the official published version of record.

People interested in the research are advised to contact the author for the final version of the publication, or visit the DOI to the publisher's website.

- The final author version and the galley proof are versions of the publication after peer review.

- The final published version features the final layout of the paper including the volume, issue and page numbers.

Link to publication

\footnotetext{
General rights rights.

- You may freely distribute the URL identifying the publication in the public portal. please follow below link for the End User Agreement:

www.umlib.nl/taverne-license

Take down policy

If you believe that this document breaches copyright please contact us at:

repository@maastrichtuniversity.nl

providing details and we will investigate your claim.
}

Copyright and moral rights for the publications made accessible in the public portal are retained by the authors and/or other copyright owners and it is a condition of accessing publications that users recognise and abide by the legal requirements associated with these

- Users may download and print one copy of any publication from the public portal for the purpose of private study or research.

- You may not further distribute the material or use it for any profit-making activity or commercial gain

If the publication is distributed under the terms of Article $25 \mathrm{fa}$ of the Dutch Copyright Act, indicated by the "Taverne" license above, 
Assignment and Substitution in the Labour Market 


\section{Promotores:}

Prof.dr. J.A.M. Heijke

Prof.dr. A. de Grip

\section{Co-promotor:}

Dr. A.H. Borghans

Beoordelingscommissie:

Prof.dr. J. Muysken (voorzitter)

Prof.dr. J. Hartog (Universiteit van Amsterdam)

Prof.dr. P. Mohnen 


\section{Acknowledgements}

I am deeply indebted to my promotors Hans Heijke and Andries de Grip and co-promotor Lex Borghans. From low to high frequency, my meetings with Hans have always been remarkably profitable as he always found a way to stimulate my innagination in assembling this study. For their frequent and highly pertinent comments as well as for their indispensable guidance throughout this study I thank Lex and Andries. I would also like to express my gratitude to Joan Muysken, Joop Hartog and Pierre Mohnen, the members of the assessment committee, for their valuable comments on this dissertation.

For their comments on earlier drafts of different chapters of this study, I would like to thank Paul Bingley, Frank Cörvers, Bart Golsteyn, Ben Kriechel, Philip Marey, David Margolis, Erik de Regt, Catherine Ris, Mark Sanders, Michael Sattinger, Inge Sieben, Wendy Smits, Jan Dirk Vlasbom, Bas ter Weel and Niels Westergaard-Nielsen.

I would also like to acknowledge participants at the following conferences and seminars for their contributions: the European Association of Labour Economists in Regensburg 1999, Jyvalskylä 2001, and Paris 2002, the NAKE-Dag 2000, the Econometric Society European Meeting in Lausanne 2001 and seminars at the ROA, Maastricht Economic Research institute on Innovation and Technology (MERIT) and Centre for Labour market and Social research (CLS) in Aarhus Business School, Denmark.

Chapter 5 is a modified version of Dupuy and de Grip: "Do Large Firms Have More Opportunities to Substitute Labour Than Small Firms?" This research is the result of a three-month stay at the Centre for Labour market and Social research (CLS) in Aarhus Business School, Denmark from May to July 2001. I want to thank the CLS for providing access to the Matched Employer Employee data and financial support, the Marie Curie funding for financial support and the National Centre for Register-based Research (NCRR) for workspace. I am indebted to Soren Sorensen for data assistance.

I am most grateful to Milou for her love and to my French and Dutch families for their endless support. 



\section{Contents}

Acknowledgements . . . . . . . . . . . v

1 Introduction 1

1.1 Motivation . . . . . . . . . . . . . . 1

1.2 Aim of the study and theoretical framework . . . . . . . 4

1.3 Plan of the thesis . . . . . . . . . . . . 10

1.4 Related discussions $\ldots \ldots \ldots \ldots \ldots \ldots \ldots \ldots$

1.4 .1 Labour demand . . . . . . . . . . . . . 15

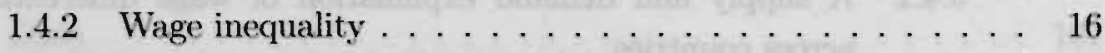

1.4.3 Effect of overeducation on productivity and wages . . . . 17

1.4 .4 Firms' heterogeneity . . . . . . . . . . . . . 19

1.4.5 General versus specific education and the educational structure ................... 20

2 Assignment models and substitution $\quad 23$

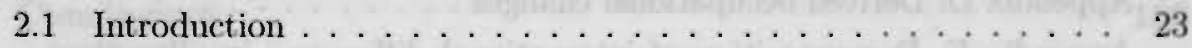

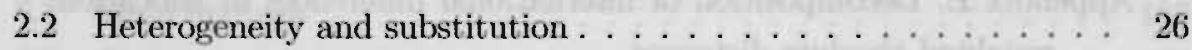

2.3 Roy's self-selection model . . . . . . . . . . . . 28

2.4 Rosen's tasks assignment model . . . . . . . . . . . . . 35

2.5 Tinbergen's allocation model . . . . . . . . . . . 40

2.6 Allocation model: A demand approach . . . . . . . 45

2.6.1 Tasks assignment model with several types of workers and occupations . . . . . . . . . . . 45

2.6.2 Tasks assignment and workers' self-selection . . . . . . 50

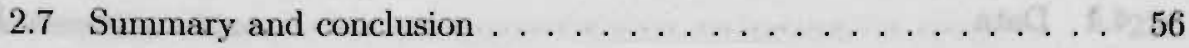

Appendix A. Elasticity of substitution and efficiency units between oc-

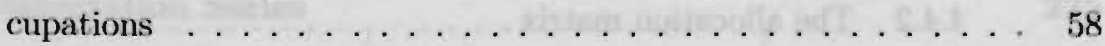


Appendix B. Elasticity of substitution and the allocation of the marginal task

3 Testing the assignment model $\quad 63$

3.1 Introduction . . . . . . . . . . . . . . 63

3.2 Data . . . . . . . . . . . . . . . . 67

3.3 Conceptual framework . . . . . . . . . . . . 72

3.3 .1 Production function $\ldots \ldots \ldots \ldots \ldots \ldots \ldots$

3.3.2 Isolating supply and demand from allocation structure effects 77

3.3 .3 Allocation structure $\ldots \ldots \ldots \ldots \ldots \ldots . \ldots . \ldots . \ldots 78$

3.3 .4 Supply and demand . . . . . . . . . . 79

3.3.5 A supply and demand explanation of wage differentials across countries . . . . . . . . . . 80

3.4 Empirical results $\ldots \ldots \ldots \ldots \ldots \ldots \ldots \ldots \ldots \ldots \ldots$

3.4.1 Estimation of the substitution elasticity parameter and relative equilibrium wages . . . . . . . . . . 82

3.4.2 A supply and demand explanation of wage differentials across countries . . . . . . . . . . 86

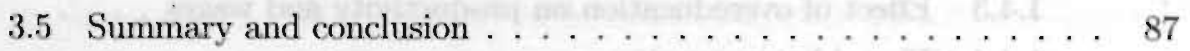

Appendix A. Cross-classification of workers' educational backgrounds and the various jobs $\ldots \ldots \ldots \ldots \ldots \ldots \ldots \ldots$

Appendix B. Wage premium by educational field and country $\ldots .90$

Appendix C. Derived educational changes . . . . . . . . . . . . . . 91

Appendix D. Derived occupational changes . . . . . . . . . . 92

Appendix E. Decomposition of international differences in allocation:

weighted absolute distances $\ldots \ldots \ldots \ldots \ldots$

4 Allocation structures $\quad 95$

4.1 Introduction . . . . . . . . . . . . . . . 95

4.2 The theoretical model $\ldots \ldots \ldots \ldots \ldots \ldots \ldots . \ldots \ldots$

4.3 Allocation structures . . . . . . . . . . . . . . . . . 104

4.3.1 Isolating allocation structures . . . . . . . . . 105

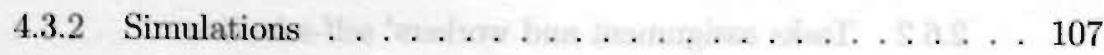

4.4 Data . . . . . . . . . . . . . . . 123

4.4 .1 Data source . . . . . . . . . . . . . 123

4.4 .2 The allocation matrix . . . . . . . . . 124 
4.4 .3 Earnings function . . . . . . . . . . . 127

4.5 Allocation structure . . . . . . . . . . . . 130

4.5.1 Quantitative methodology . . . . . . . . . 130

4.5 .2 Empirical results . . . . . . . . . . . . . . 132

4.5.3 Implications: general versus specific education . . . . . 134

4.6 Summary and conclusion . . . . . . . . . . . . . 138

Appendix A. Homogeneity restrictions . . . . . . . . . 141

Appendix B. Educational and Occupational levels . . . . . . . . . 142

Appendix C. Hamermesh's restrictions . . . . . . . . . 143

Appendix D. Derivation of the wage changes . . . . . . . 145

Appendix E. Estimated short and long run demand . . . . . . . . 148

Appendix F. Wald-test on earnings regressions specification $\ldots \ldots 149$

Appendix G. Descriptive statistics of the data . . . . . . . 150

5 Substitution at the firm-level 151

5.1 Introduction . . . . . . . . . . . . . . . . . 151

5.2 Elasticities of substitution: Four theorems . . . . . . . . 157

5.3 Data . . . . . . . . . . . . . . . . . 167

5.4 Empirical results . . . . . . . . . . . . . . 172

5.4 .1 Production function and firm size . . . . . . . . 172

5.4 .2 Elasticities of substitution . . . . . . . . . 175

5.4 .3 Robustness check . . . . . . . . . . . . . . 179

5.5 Summary and conclusion . . . . . . . . . . 186

6 Conclusions 189

6.1 Main findings . . . . . . . . . . . . . . . . . . 189

6.2 Summary . . . . . . . . . . . . . . . . 190

6.3 Future research . . . . . . . . . . . . . . . . . 194

$\begin{array}{ll}\text { References } & 199\end{array}$

$\begin{array}{ll}\text { Summary in Dutch } & 215\end{array}$

$\begin{array}{ll}\text { Conventions } & 221\end{array}$

$\begin{array}{ll}\text { Curriculum vitae } & 223\end{array}$

$\begin{array}{ll}\text { ROA Dissertation Series } & 225\end{array}$ 



\section{List of Figures}

1.1 Allocation and assignment in the labour market $\ldots \ldots \ldots \ldots$

2.1 Educational choice under hierarchical sorting. . . . . . . 32

2.2 Educational choice under non-hierarchical sorting. . . . . . . 34

2.3 Assignment of workers to jobs. . . . . . . . . . 37

2.4 The allocation problem and the mapping of abilities required and actual abilities. . . . . . . . . . . . . 44

3.1 Decomposition of wage differentials across countries. . . . . . 76

4.1 Shifts in labour demand associated to a decrease in $a, \sigma_{a}<\sigma_{e} \ldots 112$

4.2 Shifts in labour demand associated to a decrease in $a, \sigma_{o}>\sigma_{e} \ldots 112$

4.3 Shifts in labour demand associated to a decrease in $b, \sigma_{o}<\sigma_{e} \ldots 113$

4.4 Shifts in labour demand associated to a decrease in $b, \sigma_{o}>\sigma_{e} \ldots 113$

4.5 Shifts in labour demand associated to an increase in $c, \sigma_{o}<\sigma_{e} . \quad .114$

4.6 Shifts in labour demand associated to an increase in $c, \sigma_{o}>\sigma_{e}$. . 114

4.7 Shifts in labour productivity associated to a decrease in $a, \sigma_{o}<\sigma_{\epsilon} .116$

4.8 Shifts in labour productivity associated to a decrease in $a, \sigma_{\mathrm{o}}>\sigma_{e} .116$

4.9 Shifts in labour productivity associated to a decrease in $b, \sigma_{o}<\sigma_{\epsilon}$. 117

4.10 Shifts in labour productivity associated to a decrease in $b, \sigma_{o}>\sigma_{c} .117$

4.11 Shifts in labour productivity associated to an increase in $c, \sigma_{o}<\sigma_{e} .118$

4.12 Shifts in labour productivity associated to an increase in $c, \sigma_{o}>\sigma_{e} .118$

4.13 Shifts in wage dispersion associated to a decrease in $a, \sigma_{o}<\sigma_{e} . \quad 119$

4.14 Shifts in wage dispersion associated to a decrease in $a, \sigma_{o}>\sigma_{e} . \quad 119$

4.15 Shifts in wage dispersion associated to a decrease in $b, \sigma_{o}<\sigma_{e} \ldots .121$

4.16 Shifts in wage dispersion associated to a decrease in $b, \sigma_{o}>\sigma_{e} \ldots .121$

4.17 Shifts in wage dispersion associated to an increase in $c, \sigma_{\sigma}<\sigma_{\epsilon} . .122$

4.18 Shifts in wage dispersion associated to an increase in $c, \sigma_{o}>\sigma_{\epsilon} . \quad 122$

4.19 The demand for labour with general and technical education. . . 135 
4.20 Labour productivity. . . . . . . . . . . . . . . 136

4.21 Wage dispersion. . . . . . . . . . . . 137

5.1 The demand curve for input $q_{1}$ and $q_{2}$ and the relationship between the elasticity of substitution and the change in the maximum production level at given total cost associated to a decrease in one input price. . . . . . . . . . . . . . . . 159

5.2 At equivalent capital intensity, a higher elasticity of substitution between capital and labour implies a higher labour productivity. . 161

5.3 At equivalent workforce composition, a higher elasticity of substitution between skilled and unskilled workers implies a higher labour productivity. . . . . . . . . . . . . 165 


\section{List of Tables}

1.1 The allocation of graduates in higher education in 10 countries.

2.1 The structure of assignment and the marginal task. . . . . . . 38

2.2 The structure of assignment and the marginal tasks. . . . . . . . 46

2.3 The structure of assignment, the marginal worker and the marginal task. ............................. 53

2.4 The relative efficiency units between occupations and the number of tasks dealt with in each occupation. . . . . . . . . . . . .

2.5 The marginal task and the number of tasks dealt with in each

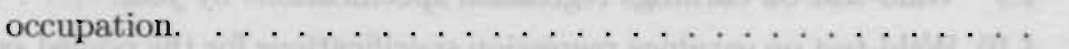

3.1 Average number of workers by education and occupation expressed in the nine countries in promile.

3.2 Variance decomposition of hourly earnings for each country. . . . 71

3.3 The relationship between allocation, wages and the allocation structure. . . . . . . . . . . . . . . . . .

3.4 Own-wage elasticities and Allen partial elasticities of substitution evaluated for the world-wide allocation and equal wages across

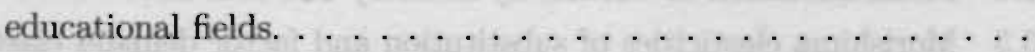

3.5 Decomposition of international differences in allocation into supply and demand effects and allocation structure effects. . . . . . . . .

3.6 Classification of educational fields and occupational fields ('required education'). . . . . . . . . . . . . . . .

3.7 Wage-premium by educational field relative to Arts-Humanities graduates for each country and absolute distances in allocation.

3.8 Education-specific changes in allocation after controlling for demand and supply differences. . . . . . . . . . . . . . 
3.9 Occupation-specific changes in allocation after controlling for demand and supply differences. . . . . . . . . . . .

3.10 Decomposition of international differences in allocation into supply and demand effects and allocation structure effects, using weighted absolute distances .

4.1 Allocation structure: some particularities.

4.2 Classification of educational and occupational fields. . . . . . . 124

4.3 Allocation matrix for the pooled sample 1994, 1995 and $1996 . \quad$. . 125

4.4 Allocation matrix in percentage of the annual total for 1994, 1995 and 1996.

4.5 Earnings function for pooled sample 1994-1995-1996, the log of net monthly income being the dependent variable.

4.6 Allocation structure estimates. . . . . . . . . . . . . . . 132

4.7 Own-wage elasticities and Allen partial elasticities of substitution. 134

4.8 The long run allocation matrix in annual percentage and the estimates reallocation matrix for 1994, 1995 and 1996.

4.9 Wald-test on earnings regression specifications by year. . . . . 149

4.10 Wald-test on earnings regression specifications for the pooled sample.149

4.11 Descriptive statistics of the data.

5.1 Firms' shares and employment shares by industry and firm-size (average 1992-'95).

5.2 Firms' labour productivity and capital intensity by industry and firm-size. . . . . . . . . . . . . . . . . . . . . 169

5.3 Workforce composition by industry and firm-size. . . . . . 170

5.4 Firms allocation of workers by industry and firm-size. . . . . . 171

5.5. Morishima elasticities of substitution and factor demand elasticities by firm-size in the Manufacturing industry, evaluated at the normalised mean share. . . . . . . . . . . . . . . . 177

5.6 Morishima elasticities of substitution and factor demand elasticities by firm-size in the Construction industry, evaluated at the normalised mean share.

5.7 Morishima elasticities of substitution and factor demand elasticities by firm-size in the Utilities industry, evaluated at the normalised. mean share. 
5.8 Productivity regressions in the manufacturing industry. . . . . 182

5.9 Productivity regressions in the utilities industry. . . . . . . . 183

5.10 Productivity regressions in the conctruction industry. . . . . . 184

5.11 Productivity growth regressions by industry. . . . . . . . 185 
LIST OF TABLES

gui very to s Tat

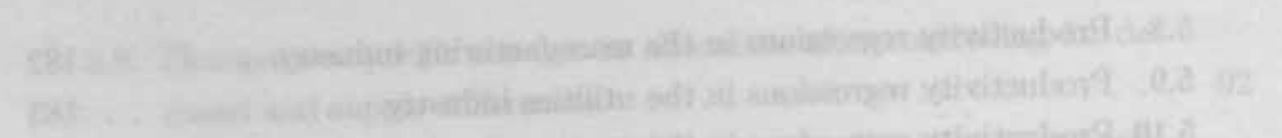




\section{Chapter 1}

\section{Introduction}

\subsection{Motivation}

Although the specialisation of labour is an important feature, in the labour market no one is irreplaceable. If a worker quits, the firm would perhaps shuffle some tasks and look for a new worker but production will be almost unaffected. In one occupation we find people with different educational backgrounds and people with the same education are employed in different occupations. As a consequence, the labour market is relatively flexible and can accommodate to shifts in the demand for and supply of the various types of workers. However, this flexibility is probably not unlimited. If for instance an engineer is replaced by an economist, especially in a large firm, a small shuffle of tasks among the workers will be enough to leave the production unaffected. However, if all engineers are replaced by economists, the level of production would undoubtedly be affected substantially. This raises the question what are the determinants of the possibilities to substitute workers with different skills. Understanding the mechanism by which tasks are divided in the labour market may contribute to our insight on why some labour markets are more flexible than others.

In this study we will analyse the flexibility of the labour market, captured by the concept of substitution, by looking at who is assigned to which task. Our approach is to consider differences between workers and differences between tasks, especially between tasks in the same occupation. We assume that firms try to find the assignment of workers to tasks that maximises production. The optimal assignment depends on the distribution of the skills of workers and the distribution of the skills required to perform the various tasks, and responds to factor 
demand and supply conditions. On the basis of this framework, we can analyse i) whether the assignment of workers to tasks influences the substitution process in the labour market, ii) how this assignment affects the distribution of wages and productivity through the substitution process, iii) how the educational system can be optimised for a flexible labour market and iv) whether the substitution process differs between firms and industries and whether these differences are related to productivity differences between firms.

To illustrate the relationship between the assignment of workers to tasks and the flexibility of the labour market, it is interesting to look at US data. In the United States, the relative employment of college graduates to high-school graduates has almost doubled between 1967 and 1987. As a result, a substitution process took place between college and high-school graduates. There is fairly well documented literature, led by Katz and Murphy (1992), that shows that the substitution process that took place in the US is consistent with an elasticity of substitution of 1.4. Such a elasticity is often interpreted as a reflection of production technology. However, if we look at the assignment of workers to tasks, our approach can be used to explain the substitution process as follows. The first extra college graduate has been assigned to the most difficult task high-school graduates performed until then, and the remaining tasks were reassigned to the remaining high-school graduates. This process is repeated when the second extra college graduate has been assigned to the most difficult task high-school graduates performed until then and the remaining tasks are reassigned to high-school graduates, etc. As a result of the increasing educational attainment of the workforce, the substitution process that takes place does not occur homogeneously across occupations but increases the number of workers finding jobs below their educational level. This mechanism actually fits quite well with the US data. Indeed, in response to a tremendous shift in the relative supply of skills, the number of college graduates working in jobs below their level of education grew from $20 \%$ in the beginning of the $60 \mathrm{~s}$ to $38 \%$ in the mid $70 \mathrm{~s} .{ }^{1}$

As Tinbergen (1975) stated, what seems to be a 'mismatch' between a person's education and the education required for his or her job is actually the result of rational behaviour.

\footnotetext{
${ }^{1}$ Source: Freeman (1976), Rumberger (1987) and Daly et al. (2000). Freeman (1976) was the first who raised the issue of the overeducated American. Figures for OECD countries on the percentage of 'overeducated' workers vary from $20 \%$ to $50 \%$ regarding the various educational levels in the late 90s (see Borghans and. De Grip (2000)) .
} 
We must make a difference between the education normally required for the execution of a given productive task and the actual education of the person engaged for that task...In a situation where fewer people of lowest (highest) education are available than could be used in the production process a rational behaviour of both the demand and the supply side of the market will imply that some workers with higher (lower) education find jobs that normally required a lower (higher) education. (Tinbergen (1975), p. 80)

Empirical evidence for the dispersion of workers' education in each occupation seems to be a universal fact. Most empirical research so far focused on the levels of education and occupation. ${ }^{2}$ Across countries, the proportion of higher educated workers who are 'overeducated' for their jobs ranges from $3 \%$ in Austria and Finland to $50 \%$ in Japan as indicated in Table 1.1.

Empirical evidence is also found in the allocation of workers with different educational fields to various fields of occupation. Table 1.1 shows $^{3}$ the percentage of higher educated workers working in higher occupations outside their own occupational field. The proportion of workers allocated outside their specific occupational field ranges from $25 \%$ in Spain to $55 \%$ in the Netherlands. At an intermediate educational level the proportion of graduates working in the corresponding occupational level but outside their own occupational field is about $23 \%$ in the Netherlands. ${ }^{4}$

Also, large firms tend to allocate relatively more workers to occupations in which workers' educational level is above the 'required' job level, as indicated by Danish Matched Employer-Employee data. ${ }^{5}$ In large firms, the proportion of workers who are overeducated for their job lies $0.5 \%$ points, $1.1 \%$ and $2.6 \%$ points above the proportion of small firms in the utilities, construction and manufacturing industry, respectively.

\footnotetext{
${ }^{2}$ See Hartog and Oosterbeek (1988), Groot (1996) and Muysken and Ruholl (2001) for empirical evidence in the Netherlands, see Muysken et al. (2003) for Germany, see Duncan and Hoffman (1981), Rumberger (1987) and Cohn and Khan (1995) for US figures, Sloane et al. (1999) for the UK, Kiker et al. (1997) for evidence in Portugal and for Spain, see Alba-Ramirez (1993).

${ }^{3}$ For more details on the dataset used see Chapter 3.

${ }^{4}$ For the US, Wilms (1974) finds that $50 \%$ of students find employment related to their field of study and Pincus (1980) reports that $40 \%$ are employed outside their own occupational field.

${ }^{5}$ See Chapter 5 for more details on the Danish Matched Employer-Employee data.
} 
Table 1.1: The allocation of graduates in higher education in 10 countries.

\begin{tabular}{l|c|c}
\hline \hline Country & \% 'overeducated' & $\begin{array}{c}\text { \% working outside } \\
\text { own occupational field }\end{array}$ \\
\hline Austria & 3 & 40 \\
Finland & 3 & 34 \\
France & 11 & 53 \\
Germany & 6 & 35 \\
Italy & 9 & 40 \\
Japan & 50 & 52 \\
The Netherlands & 7 & 55 \\
Spain & 22 & 25 \\
United Kingdom & 10 & 48 \\
US & $13^{a}$ & $41^{b}$ \\
\hline \hline
\end{tabular}

Data: CHEERS Survey

The first column indicates the percentage of higher educated workers who are overeducated for their jobs, 1998.

The second column indicates the percentage of higher educated workers in higher occupations but outside their own occupational field, 1998.

${ }^{a}$ Data source: Baccalaureate and Beyond second follow-up (B\&B 92-93).

${ }^{b}$ Weighted average of BA/BS, Associate and Certificate graduates in the USA in 1990. Source: Grubb (1997). Survey of Income and Program Participation (SIPP).

\subsection{Aim of the study and theoretical framework}

The aim of this study is twofold. One is to yield an understanding of what happens when substitution takes place in the labour market. The other is to understand why some labour markets are more flexible than others.

This study analyses the demand for (heterogeneous) labour in the context of an allocation model of workers to jobs. Therefore, the study finds its roots in both a neoclassical framework of labour demand (see Ashenfelter et al. (1986) and Hamermesh (1993)) and the assignment theory (see Sattinger (1993)). The study rests on neoclassical labour demand principles in which assignment principles are incorporated.

In his book Principles of Economics, Marshall (1920) emphasises the importance of labour demand adjustment. Marshall's view of neoclassical economics focuses on employers' decisions about how many workers to employ. The demand for labour is viewed as derived fron consumers' demands for final goods 


\subsection{AIM OF THE STUDY AND THEORETICAL FRAMEWORK}

and services:

...the direct demand for houses gives rise to a joint demand for the labour of all various building trades, and for bricks, stone, wood etc. which are factors of production of building work of all kinds, or as we may say for shortness, of new houses. The demand for any one of these, as for instance the labour of plasterers, is only an indirect or derived demand. (Marshall (1920), Book V, Chapter VI, Part 1, p.316.)

In the theory of labour demand, employers are concerned with the availability of labour and its price. Since firms can adjust both labour and capital services, the firm must choose the best combination of these two factors of production. So the demand for labour adjusts employment to current market conditions.

Adjustments in labour demand are usually measured by the elasticity of the derived demand for labour (Marshall (1920) and Hicks (1970)), that is the percentage change in labour demand corresponding to a one-percent change in the wage rate. Marshall (1920) summarised the four determinants of labour demand in four laws of derived demand. To illustrate those four laws, we shall use the well known textbook example by Filer, Hamermesh and Rees (1996) of the production of a symphony concert.

Example 1 (First Marshallian law) In order to produce a symphony concert the employer needs musicians, ushers and of course capital services (an opero house, instruments etc.). Suppose the wage of musicians increases by 10 percent. The employer would like to replace musicians by either capital services or some ushers, i.e. factors of production that become relatively cheaper, but may find it technologically difficult to do so.

The first Marshallian law stipulates that the demand for musicians will be more elastic the easier the employer can substitute musicians by other factors of production. In other words, the elasticity of substitution plays a key role in determining the magnitude of the adjustment in the demand for labour in response to changing market conditions.

Example 2 (Second Marshallian law) Suppose that the increase in the price of the concert, induced by the increase in the wage of musicians, does not change people's willingness to attend the concert. The employer would then be able to employ about as many musicians as before the wage increase. 
The second Marshallian law indicates that the less elastic the demand for the final product, the less elastic the demand for musicians. In other words, it implies that the demand for labour will change little when the employer is able to pass the wage increase on to the consumers (increase in the price of the final product) with little loss in the demand for the final product.

Example 3 (Third Marshallian law) Suppose that ushers know how to play music such that the employer finds it technologically possible to substitute ushers for musicians. The employer will actually seek to substitute ushers for musicians since ushers become relatively cheaper but may not be able to do so simply because there are no ushers available in the labour market.

The third Marshallian law of derived demand states that the elasticity of the demand for musicians will be lower the less elastic the supply of other factors of production.

Example 4 (Fourth Marshallian law) "Suppose that the wages of musicians comprise 80 percent of total costs of a symphony concert while the wages of ushers make up 5 percent of the costs. Now suppose that the wages of musicians rise 10 percent, with other costs remaining constant. To a first approximation, the cost of a concert will increase by 8 percent and there will likely be a decrease in attendance and the demand for musicians. On the other hand, if the wages of ushers rise by 10 percent, total cost will only increase by 0.5 percent. With such a small increase there will probably be just about as many people willing to attend the concert and the demand for ushers will not fall much." (Filer, Hamermesh and Rees (1996), pp. 156-\%.)

The fourth law of derived demand indicates that the demand for musicians wili be less elastic the lower the share of musicians in total cost. For this reason it is often referred to as the importance of being unimportant.

The elasticity of demand for labour is usually decomposed into two separate effects: the substitution effect in production that corresponds to the increase in labour inputs that would result from a decrease in wages holding output constant and the output scale effect in production. The output scale effect is induced by the fall in the costs of production that follows a fall in wages. With lower costs of production, the firm will increase its sales by lowering its price, which in turn enables an expansion of output. Adding both effects together sizes the total 
effect of a decrease in wages. The linear equation relating the total effect to the substitution effect and the output scale effect is known as the Slutsky equation (see Slutsky (1915)). ${ }^{6}$

The second and fourth laws refer to the output scale effect in production. The first and third laws concern the substitution effect. Provided that the supply of other factors is perfectly elastic (such that their prices are fixed), the substitution effect depends only on the elasticity of substitution between the various factors of production.

However, there is more to the elasticity of substitution than merely the substitution effect in production. Hicks (1964) shows indeed that the fourth Marshallian law is not unequivocally true and holds only under certain conditions imposed on the elasticity of substitution between factors of production, between musicians, ushers and capital.

Example 5 Suppose ushers can play music such that the employer can substitute ushers for musicians. The employer will substitute the expensive musicians by ushers resulting in a moderate increase in the total cost of a concert. With this smaller increase in the price of a concert, there will be just about as many people willing to attend the concert.

This example illustrates the important role played by the elasticity of substitution in the output scale effect. As Hicks (1964) demonstrates, the importance of being unimportant holds as long as the elasticity of product demand is greater than the elasticity of substitution between factors of production. The reverse is true whenever the elasticity of substitution is greater: "when the employer can substitute more easily (between factors of production) than the consumer (between final products), it is an advantage to labour to have a large share in the initial input mix." (Filer et al. (1996) pp. 156-7) This implies that the employer's ease to substitute between factors of production not only determines the demand for labour via the substitution effect but also via the output effect. De La Granville (1989) corroborates Hicks's (1964) finding by a graphical demonstration. De La Granville shows that the larger the elasticity of substitution between factors of production, the larger the output scale effect in production.

\footnotetext{
${ }^{6}$ The Slutsky Equation is geometrically constructed as a parallelogram-shaped area. This parallelogram becomes a diamond in the case of unit elasticity of substitution (in the case of a Cobb-Douglas production technology). This has led economists to talk about the 'Slutsky Diamond'.
} 
De La Granville considers a family of production functions that only differ by the magnitude of their elasticity of substitution and shows that the new maximum output level resulting from a decrease in one input price is higher the greater the elasticity of substitution. ${ }^{\top}$

Yet, adjustments in the demand for heterogeneous labour do not occur homogeneously across occupations. In the concert industry, substitution occurs, $a$ priori, only between ushers and musicians in the musician occupation. ${ }^{8}$ An allocation model of workers with different educational backgrounds to various occupations acknowledges the interdependence of the labour markets for different educational groups. In such a model, a downward shift in supply of a particular educational group of workers increases the associated wage rate and induces substitution between types of labour within occupations. Therefore, labour will be differentiated in this study with respect to both education and occupation.

To return to the concert industry, one might wonder how employers can substitute let say two ushers for one musician. A simple explanation is found in the theory of comparative advantage and the distribution of skills among workers and the distribution of required skills among jobs. The employer may find it interesting to substitute a usher for a musician as long as the usher, though not trained to be a musician, has fairly good musical skills. This statement implies that there are several types of skills and people are initially endowed with a certain level of each skill-type. Even then, the employer might not be willing to substitute the usher, a fairly talented flute player, for a leading pianist. The employer will probably substitute the usher in question for a flute player of minor importance.

The example emphasises the assignment of heterogeneous workers to heterogeneous jobs and the notion of workers' comparative advantage in the labour market. In order to incorporate this dimension into the analysis of the demand for heterogeneous labour, we find inspiration in the assignment literature. The

\footnotetext{
${ }^{7}$ As mentioned in footnote 6 , the Shutsky equation can be constructed as a parallelogram, the area of which is proportional to the magnitude of the elasticity of substitution. The argument used by De La Granville relies on the linear approximation made when using the Slutsky equation in its differential form instead of the true infinitesimal form. He shows that the order of the magnitude of the error made by using the linear approximation increases with the magnitude of the elasticity of substitution.

${ }^{8}$ Note that the ushers who replace the musicians are not ushers anymore but musicians. This highlights the need to distinguish between workers' actual jobs and potential jobs. This is precisely what education and occupation variables do: they separate the potential occupations (determined by education) to the actual occupation or as in Tinbergen's (1973) term required education (i.e. occupation) and actual education.
} 
assignment of workers to tasks provide a microfoundation to this study. Building on the assignment of heterogeneous workers to heterogeneous tasks, an allocation model will be developed in which several categories of education and occupation are distinguished. This model relates to those developed in Roy (1950 and 1951), Tinbergen (1956) and Rosen (1978). ${ }^{9}$ The model we will develop in this study offers the opportunity to bridge the gap between the theory of labour demand and the assignment literature. By explicitly modeling the assignment of tasks to workers and the self-selection of workers into educational profiles, an indirect production function can be used in an allocation context to model the assignment of the marginal task to the workers as well as the self-selection of the workers into education-occupation profiles.

Figure 1.1 illustrates how the microeconomic assignment of heterogeneous workers to heterogeneous tasks generates the allocation problem at the aggregate level of education and occupation. In the supply side of the labour market, individuals are endowed with different capacities. Individuals choose their educational profiles based on their initial capacities and the market wages associated with each educational background. The educational choice transforms initial endowments into skills. Since individuals are $e x$ ante heterogeneous with respect to their own endowment, within educational groups, individuals are heterogeneous with respect to their skills. By analogy to the supply side, the demand side is decomposed into several occupations. In each occupation, different tasks have to be done in order to produce output. The tasks differ from one another by the levels of the various types of skills they require. As a result, tasks are heterogeneous within each occupation. The allocation problem is characterised by the distribution of workers by education to the various occupations. This does not result into a one-to-one correspondence between education and occupation. Indeed, even if the supply of workers by education equals the demand for workers in the corresponding occupation, workers with different educational backgrounds may be observed working in the same occupation, and vice versa. This allocation pattern emerges because each educational group is composed of workers that are heterogeneous in terms of their skills and each occupational group is composed of tasks that are heterogeneous with respect to the skills they require. Therefore, the optimal assignment of the tasks belonging to each occupation to

\footnotetext{
${ }^{9}$ See also Sattinger $(1975,1978,1979,1980$ and 1993), Macdonald (1982) and Teulings (1995a, 1995b and 2002).
} 


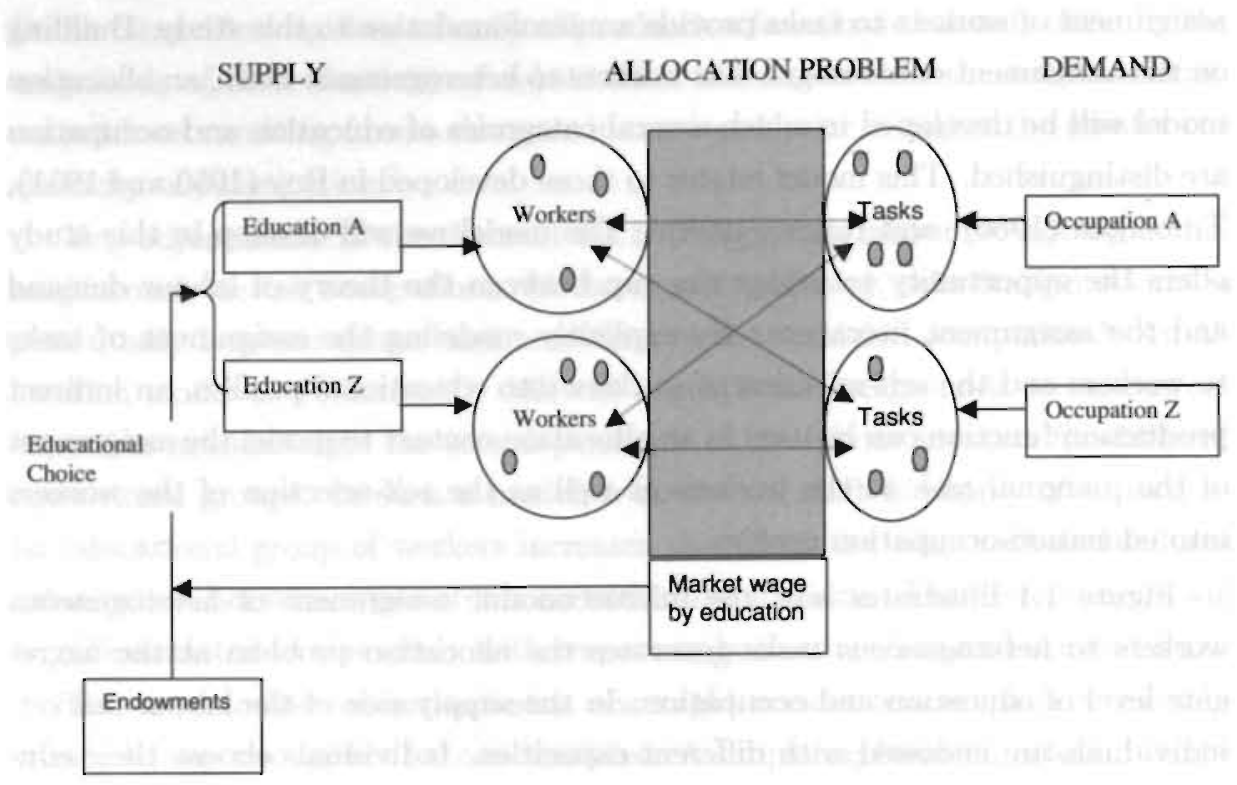

Figure 1.1: Allocation and assignment in the labour market

workers in each educational group leads to the presence of workers with different educational backgrounds in a particular occupation and the presence of workers with the same educational background in different occupations. The optimal assignment of workers to tasks depends on productivity parameters indicating the range of tasks that workers with the various educational backgrounds can perform in each occupation. In this study, the term 'allocation structure' is used to define this set of productivity parameters. The optimal assignment of tasks changes as the relative wages of the educational groups change. The assignment of workers to tasks changes through the supply and demand adjustment process, which results in allocation changes.

\subsection{Plan of the thesis}

The structure of the remaining chapters is in accordance with the following line of thought. To understand how the assignment of heterogeneous workers to heterogeneous jobs affects the substitution between groups of workers, we will develop an allocation model in Chapter 2. In Chapter 3, we will test the relevance of our 
allocation model in explaining the substitution process between different types of workers in real data. Chapter 4 follows naturally by addressing the question whether some allocation structures can lead to a substitution process that is relatively more advantageous in terms of market outcomes, i.e. higher labour productivity and lower instability. Finally, in Chapter 5 we will investigate whether different firms have different substitution possibilities. We will evaluate whether the production functions and thereby the substitution possibilities differ between firms in the same industry and whether these differences are related to the differences in allocation of workers and productivity between firms. This analysis provides an understanding of how allocation figures observed at the level of a country are generated at the level of the firm.

The allocation model developed in Chapter 2 is used throughout this study. First, an overview of the different models related to the assignment theory is presented. Roy's self-selection model, Rosen's model of the assignment of tasks to workers and Tinbergen's allocation model are detailed respectively and their restrictions with respect to the scope of this study are discussed. Building on the assignment literature, a theoretical model that offers the opportunity to bridge the gap between labour demand literature and assignment literature is developed. It is shown that indirect production functions in which different labour inputs are distinguished along education and occupation can be funded at the micro level. Moreover, the optimal assignment of workers to tasks also depends on the allocation structure, i.e. the set of productivity parameters indicating the range of tasks that workers with the various educational backgrounds can perform in each occupation. By modeling explicitly the assignment of tasks to workers and the self-selection of workers into educational profiles it will be demonstrated that an indirect production function in an allocation context can be used to model the assignment of the marginal task to workers as well as the self-selection of workers into education-occupation profiles. The parameters of the elasticity of substitution between workers with different educational backgrounds within a particular occupation and of the elasticity of substitution between occupations are shown to play a crucial role in the distribution of skills and workers to occupations.

In Chapter 3 and 4, the allocation model of workers to jobs developed in Chapter 2 is used in order to investigate the impact of differences (between countries) or changes (through time) in the range of tasks that workers with each educational background can perform in the various occupations (i.e. the allocation structure) on the substitution process. In Chapter 3, we test for the relevance of our al- 
location model in explaining the substitution process between different types of workers in real data. In the literature related to wage inequality across countries, the structure of wages is confronted with a (neo-) classical supply and demand framework. Across countries, differences in the relative supply of labour should coincide with wage differentials if the substitution process between the various types of labour occurs freely in each country. Some authors, e.g. Blau and Kahn (1996), reject the supply and demand explanation of wage differentials across countries because the magnitude of the substitution effect necessary to match supply and demand differentials with wage differentials is not plausible. Several authors, e.g. Leuven et al. (2004) and Freernan and Schettkat (2001), argue that the skill content of educational groups varies a great deal across countries which makes educational comparisons difficult. We decompose the substitution effect into an effect due to differences in the allocation structure induced by differences in the skill content of educational segments and the true substitution effect resulting from supply shifts only. The use of the allocation model developed in this study enables us to detect differences in the allocation that are not caused by supply and demand factors but caused by differences in the skill content across countries. The remaining supply and demand differential can be compared with wage differentials to measure the real substitution effect. Empirical results show that cross-country differences in allocation are to a large extent (50\%) due to differences in the allocation structure. Moreover, once these differences in the allocation structure are controlled for, wage differentials across countries coincide with at least $64 \%$ of employment differentials.

The question whether some allocation structures can lead to a substitution process that is relatively more advantageous in terms of a higher labour productivity and a lower labour market instability, is addressed in Chapter 4 . The impact of the structure of allocation on the substitution process is investigated by isolating specific allocation structures. Since workers with general education can perform a rather large range of tasks in every occupation, they can easily switch occupations. We would therefore expect that a shift in the supply of workers between two specific educational fields leads to a reciprocal change in the wage rate of these two types of workers but leaves the wage of workers with general education unchanged. We show that there is a family of allocation structures that satisfy this condition which is characterised by three productivity parameters. Simulations show that the labour productivity and wage dispersion are sensitive to the relative magnitude of the three parameters and to the relative ease to sub- 
stitute between occupational output compared to the ease to substitute between workers with different educational fields within occupations. Empirical results for the Netherlands show that the demand for workers with a general educational background is less elastic than the demand for workers with technical and social services vocational specialisation. This result suggests that a relative decrease in the supply of graduates in general educational fields can only be absorbed by a relatively large increase in its relative wage, large decrease in labour productivity and large increase in wage dispersion. The range of tasks that workers with general, technical and social services educational fields can perform in the various occupations corresponds to our ex ante expectations. The general educational field is very similar to our theoretical definition of general education and the technical and social services educational fields correspond to our theoretical definition of technical education.

From an educational policy perspective, we show that the skill content of a study in terms of specific and general skills matters for labour productivity and instability. The more specific the skills of workers the larger labour productivity. However, the more generic the skills of workers, the larger the range of tasks these workers can perform outside their own occupation and the smaller the increase in wage dispersion in case of supply shifts. Moreover, although the specialisation of labour is an important feature of the labour market, as it enhances workers' productivity in their vocational occupation, our results suggest that the flexibility of the labour market, measured by the ease to substitute between occupations and between workers with different educational backgrounds, should be accounted for when defining the skill content of the various educational fields. We show that the larger the elasticity of substitution between occupational outputs compared to the elasticity of substitution between workers, the larger the percentage change in labour productivity associated to a decrease in the range of tasks that workers with general education could perform outside general occupation but the smaller the percentage change in labour productivity associated to a decrease in the range of tasks that workers with technical and social services can perform in general occupations. Therefore countries like the Netherlands, for which the ease to substitute between occupational outputs is large compared to the ease to substitute between workers, may benefit from decreasing the range of tasks that workers with general education could perform outside general occupation, by increasing the amount of skills that contribute to their productivity in the general occupation at the expense of the general skills that contribute to their 
productivity in the other occupations.

Chapter 5 addresses the questions of whether the production functions and thereby the substitution possibilities differ between firms in the same industry and whether these differences are related to the differences in allocation of workers and productivity between firms within industries. The hypothesis is advanced that the differences in labour productivity, capital intensity and skill composition of the workforce observed between small and large firms lie in the differences in the production function. The production function of small, medium and large firms in three industries are estimated separately using matched employer-employee data for Denmark. Empirical results show that large firms have a higher elasticity of substitution between skilled and unskilled workers in skilled jobs and a higher elasticity of substitution between skilled workers in skilled jobs and capital than small firms. These differences explain the higher labour productivity and capital intensity observed in large firms. Also, under skill-biased technological change, the higher elasticity of substitution between skilled and unskilled labour in large firms explains the higher skill intensity in large firms. In turn, the higher productivity enables large firms to employ skilled workers in low-skilled jobs explaining the higher rate of overeducated workers observed in large firms. The tendency of large firms to employ a relatively overeducated workforce can be related to an 'ant versus cicada' behaviour. ${ }^{10}$ Large firms build in a reserve capacity of skilled workers in periods of surplus of skilled people in order to anticipate future demand or supply shocks in the labour market for skilled workers. Large firms are therefore affected less if the wage of skilled. workers increases, since at that time they retain internal reserves of skilled workers. Large firms can easily recruit unskilled-workers instead of skilled workers, allocate the newly recruited workers to low-skill jobs and internally reallocate the skilled workers that are working in these low-skill jobs to high-skill jobs.

Chapter 6 concludes and summarises the main findings of this study.

\subsection{Related discussions}

The analyses performed in this study are related to several discussions in the field of labour economics. It relates to the literature on labour demand, the literature on wage inequality across countries and over time, the literature on the

\footnotetext{
${ }^{10}$ See De La Fontaine (1668).
} 


\subsection{RELATED DISCUSSIONS}

'overeducation' of the workforce, the literature on firms' heterogeneity in output, productivity and input mix and the debate on the relevance of general versus specific education and the educational structure.

\subsubsection{Labour demand}

In the standard model of labour demand, labour is homogeneous and knowledge of the shape of the labour-demand function enables to infer how exogenous changes in labour supply affect the wage rate or its dual that is how exogenous changes in the wage rate affect the demand for labour (see Hamermesh (1992)). Studies by Dhrymes (1969), Hamermesh (1983) and Levy (1990) for instance emphasise the degree of price complementarity between capital and labour ${ }^{11}$ and Berndt and Wood (1975), Diewert and. Wales (1987) and Morrison (1988) highlight the downward sloping property of the aggregate demand curve, i.e. the negative own-price elasticity of labour. ${ }^{12}$

The theory of demand for heterogeneous labour enables us to infer on how changes in the wage rate of one group of workers affect the demand for labour in other groups. Hence, changing market conditions lead to changes in the demand for labour as well as changes in the composition of labour. A well-studied example is the capital-skill complementarity in production (see Rosen (1968), Griliches (1969), Grant and Hamersmesh (1979) and Hamermesh (1993)). ${ }^{13}$ When the price of capital decreases, firms substitute capital for labour which results in a decrease in the demand for labour. Since skilled labour and capital are complementary, that is when the price of one of the two decreases firms use more of both, the denand for labour shifts out in favour of skilled labour altering the skill composition of labour. ${ }^{14}$ Grant (1979) and Bresson et al. (1992) show that the demand for the least-skilled group of workers is most elastic.

\footnotetext{
${ }^{11}$ See also Lever (1996), Al-Shansi (2001), Ramcharran (2001a and 2001b) for recent estimates.

${ }^{12}$ See also Mairesse and Dormont (1985), Allen (1986), Card (1986) and Blanchflower et al. (1991).

${ }^{13}$ See also Johnson (1970), Welch (1970), Dougherty (1972), Berndt and Christensen (1974), Timbergen (1973, 1974 and. 1975), Brogan and Erickson (1975), Fallon and Layard (1975), Hamermesh and Grant (1979), Chen and Tang (1987), Gyapong and Gyimah-Brempong (1988) and Levy (1996).

${ }^{14}$ Skill is understand in a broad sense here. Griliches (1969), Johnson (1970), Welch (1970), Tinbergen (1973, 1974 and 1975) and. Grant (1979) differentiate labour by education whereas the other authors differentiate between production and nonproduction workers.
} 
In our allocation model, the adjustments in the demand for heterogeneous labour do not occur homogeneousily across occupations. This model of the allocation of workers with different educational backgrounds to the various occupations acknowledges the interdependence of the labour markets for different educational groups. A downward shift in supply of a particular group of workers increases the associated wage rate and induces substitution between types of labour within and between occupations. In other words, the allocation model infers on the elasticity of substitution between educational groups of workers within occupation as well as between different occupations. Allocation models therefore require to differentiate labour with respect to both education and occupation. Literature in this field is, to the extent of our knowledge, limited to Dougherty and Selowsky (1973), Tinbergen (1973) and Bound and Johnson (1992). Dougherty and Selowsky (1973) and Bound and Johnson (1992) consider the allocation of workers with different educational levels to the various industries while Tinbergen (1973) emphasises the allocation of workers with different educational levels to various occupational levels. These models provide the basis for the framework on which we rely throughout this study. The model developed in this study nests those of Dougherty and Selowsky (1973), Tinbergen (1973) and Bound and Johnson (1992).

\subsubsection{Wage inequality}

The question whether the allocation structure influences the substitution process that takes place in the labour market, and thereby the wage structure and labour productivity, relates to the literature on international differences in the wage inequality between skill groups led by Blau and Kahn (1996), Leuven et al. (2004), Freeman and Schettkat (2001) and Acemoglu (2003) and to the literature on changes in the structure of wages between skill-groups of workers, e.g. Katz and Revenga (1989), Bound and Johnson (1992), Katz and Murphy (1992), Murphy and Welch (1992), Card and Lemieux (1996), Johnson (1997), Card et al. (1999) and Acemogln (2002). ${ }^{15}$ In this literature, the structure of wages is confronted with a (neo-) classical supply and demand framework. Through time, shifts in the relative supply of certain types of labour induce substitution between the various types of labour resulting in changes in relative wages, whereas across countries,

\footnotetext{
${ }^{15}$ See also Berman et al. (1994), Berman et al. (1998) and Krusell et al. (2000).
} 


\subsection{RELATED DISCUSSIONS}

differences in the relative supply of labour should coincide with wage differentials if the substitution process between the various types of labour occurs freely in each country. Time-series analyses, e.g. Katz and Murphy (1992), indicate that changes in the wage structure are consistently explained by the substitution effect (supply and demand) once acknowledged for continuous shifts in the relative demand for skilled workers, either due to skill-biased technological change or capital-skill complementarity. However, some authors, e.g. Blau and Kahn (1996), reject the supply and demand explanation of wage differentials across countries because the magnitude of the substitution effect necessary to match supply and demand differentials with wage differentials is not plausible. Several authors, e.g. Leuven et al. (2004) and Freeman and Schettkat (2001), argue that the skill content of educational groups varies a great deal across countries which makes educational comparisons difficult. Our contribution is to decompose the substitution effect into an effect due to differences in the allocation structure induced by differences in the skill content of educational segments and the true substitution effect resulting from supply shifts only. The use of the allocation model developed in this study enables to detect differences in the allocation that are not caused by supply and demand factors but caused by differences in the skill content across countries. The remaining supply and demand differential can be compared with wage differentials to measure the real substitution effect. The model can be used to draw conclusions on the extent to which differences in the wage structure across countries fit with a supply and demand explanation and how changes in the allocation structure can be linked to changes in the wage structure.

\subsubsection{Effect of overeducation on productivity and wages}

The second question we address is whether some allocation structures can lead to a substitution process that is relatively more advantageous in terms of market outcomes (higher labour productivity and lower labour market instability). This question is related to the literature investigating the relationship between allocation, wages and productivity. Empirical evidence acknowledges the interaction between the supply of workers with different educational backgrounds and the demand for workers in the various occupations. This interaction results in the presence of workers with different educational backgrounds in the same occupation whereas workers with the same education are employed in different occupations. 
Since Freeman (1976), several authors have studied allocation from a supply perspective and shed some light on the impact of 'overeducation' on workers' productivity and earnings. ${ }^{16}$ Tinbergen (1973, 1975, 1982 and 1984), Hartog (1980, 1985 and 1992), Duncan and Hoffman (1981), Hartog and Tsang (1987), Hartog and Oosterbeek (1988), Verdugo and Verdugo (1989), Alba-Ramirez (1993), Cohn and Kahn (1995) and Dolton and Vignoles (2000) demonstrate that the returns to years of 'overschooling' are significantly less than the returns to years of adequate schooling such that investments in education have not been optimal for the 'overeducated' workers as well as society. ${ }^{17} \mathrm{~A}$ few authors observe wage differentials between workers with different fields of education when working in the same occupation (see James et al. (1989) and Dolton and Makepeace (1990) for instance). Murphy et al. (1991) recognise that the US productivity growth slowdown may also be due to an improper distribution of 'talented people' among the different fields of study. They argue that a student's educational choice is guided by the perspective of sharing rents with employers which alters the supply of 'talented people' in the various fields of study and lowers productivity. Tsang (1987) shows that the drop in firms' output due to the 'crowding out' of less skilled workers from their traditional occupational domains by more skilled workers can be as large as $8 \%$ to an one-year increase in 'overeducation'. ${ }^{18}$ In his view, workers with more education than their jobs require are more dissatisfied with their jobs ${ }^{19}$ and exhibit higher rates of turnover ${ }^{20}$ such that 'overeducation' decreases workers' productivity. The allocation model developed in this study enables to evaluate the impact of various allocation structures on labour productivity and wage dispersion. Looking at workers with different fields of study, the model emphasises first the relevance to distinguish between different allocation structures. We expect that a shift in the supply of workers between two specific educational fields leads to a reciprocal change in the wage rate of these two types of workers but leaves the wage of workers with general education unchanged be-

\footnotetext{
${ }^{16}$ See Green et al. (1999), Borghans and De Grip (2000) and Büchel et al. (2003) for an overview of the literature.

${ }^{17}$ See also Groot (1996), Kiker et al. (1997), Battu et al. (1999), Sloane et al. (1999), Groot and Maasen Van Den Brink (2000), De Oliveira et al. (2000), Vahey (2000) and Ng (2001).

${ }^{18}$ See also Tsang and Levy (1985 and 1989) and De Grip (1989) for a discussion on the impact of 'overeducation' on productivity.

${ }^{19}$ See Berg (1970). Note that Buchel (2002) finds no evidence for higher job dissatisfaction among 'overeducated' workers in Germany.

${ }^{20}$ See among others Vroom (1964) and Sicherman (1991).
} 
cause workers with general education can perform a rather large range of tasks in every occupation and therefore can easily switch occupations. We show that there is a family of allocation structures that satisfy this condition. This family of allocation structures is characterised by three productivity parameters: the productivity parameter of workers with general education outside their own occupation, the productivity parameter of both workers with technical and social services vocational specialisations in each other's occupation and the productivity parameter of both workers with technical and social services specialisations in the general occupation. We show that both the labour productivity and wage dispersion are sensitive to the relative magnitude of these three productivity parameters.

\subsubsection{Firms' heterogeneity}

In Chapter 5 we investigate whether the production functions and thereby the substitution possibilities differ between firms in the same industry and whether these differences are related to the differences in the allocation of workers and productivity between firms. This question relates to the growing literature on firms' heterogeneity in output, productivity and input mix..$^{21}$ Among others, Bayard and Troske (1999), Haltiwanger et al. (1999) and Idson and Oi (1999) suggest a conjecture that different firms choose different modes of production requiring a different input mix. This study adds to this literature a theoretical and empirical analysis of the shape of the production function of heterogeneous firms. We prove that i) ceteris paribus, the higher the elasticity of substitution between skilled and unskilled labour, the higher the labour productivity and ii) that given skill-biased technological change, the larger the elasticity of substitution between skilled and unskilled labour the larger the skill intensity. Using matched employer-employee data for Denmark, we evaluate the extent to which the elasticities of substitution between capital and labour and between skill-groups differ between large and small firms and whether these differences explain the firm-size effects on labour productivity, capital intensity and the skill composition of the workforce. Our main findings are that large firms indeed have higher elasticities of substitution between skilled workers in skilled jobs and all other inputs than small firms. These differences in elasticities of substitution are of the magnitude to explain

${ }^{21}$ See Baily et al. (1992), Olley and Pakes (1996) and Abowd et al. (1999)). 
the higher labour productivity, capital intensity and skill intensity observed in large firms. As the skill segregation hypothesis suggests, we find that large firms employ more overeducated workers than small firms. We relate the tendency of large firms to employ a relatively overeducated workforce to an 'ant versus cicada' behaviour. The larger productivity enables large firms to build in a reserve capacity of skilled workers in periods of low wages for skilled people in order to anticipate demand or supply shocks in the labour market for skilled workers. If the wage of skilled workers increases, large firms are affected less since at that time they retain internal reserves of skilledl workers.

\subsubsection{General versus specific education and the educa- tional structure}

The relevance of vocational specialisation in initial education has long been the subject of a divergence of opinion. Some authors, e.g. Kang and Bishop (1989) and Bishop (1995), argue that generic skills are mere tools for developing specific skills but have no direct market value. Others, e.g. Comay et al. (1973) and Dothan and Williams (1981), argue that general education offers individuals the option of choosing among different occupations or careers. This option value hypothesis would imply that workers with general educational field can perform. a rather large range of tasks in the various occupations. The argument reads as follows. Since generic skills can be used to perform some of the tasks in specific occupations, individuals that possess generic skills can perform some of the tasks in specific occupations.

In this study, we argue that the option value offered by generic skills does not increase linearly with the amount of generic skills of individuals but rather that the range of tasks that workers with generic skills can perform in specific occupations levels off at a certain amount of generic skills. For instance, if a person with math skills would work as a pharmacist he conld calculate the doses of a prescription but his ability to solve differential equations will not increase the range of tasks he can perform as a pharmacist.

Moreover, we argue that workers with vocational specialisations also have an option value. We do expect workers with specific skills to perform a rather restricted range of tasks in other specific occupations but acknowledge that if generic skills are tools for developing specific skills, workers with specific skills have a fair amount of general skills which enables them to perform a quite large 
range of tasks in the general occupation. This option value is confirmed by our empirical result showing that workers with vocational specialisations can perform a large range of tasks in the general occupation. 


\section{Chapter 2}

\section{Assignment models and substitution}

\subsection{Introduction}

The aim of this study is to understand the substitution process taking place in the labour market. Looking at the assignment of heterogeneous workers to heterogeneous tasks will help to explain the substitution process and to analyse the degree of substitution between different skill types of workers. In this chapter we will develop an allocation model that enables us to understand how the allocation structure of heterogeneous workers to heterogeneous jobs affects the substitution between educational groups of workers.

The model we will develop builds on the various existing models in the assignment literature. Assignment theory ${ }^{1}$ focuses on the relationship between the distribution of workers' skills, the distribution of the skills required to perform the various jobs and the resulting income distribution. In the assignment literature, three general models can be distinguished. These models differ from each other with respect to the origin of heterogeneity in the labour market, workers and/or

\footnotetext{
${ }^{1}$ The assignment literature diverges from the matching theory, see Mortensen (1986) for instance, and search theory, (see Jovanovic (1979), Diamond (1981) and Pissarides (1984)) by assuming that workers have full knowledge of all employers' wage offers and that employers have full knowledge of all workers' abilities. In assignment models, it is assumed that free choice and competitive markets assign tasks to workers efficiently. Perfect competition ensures that workers in each group are rewarded according to the productivity of the marginal worker in the associated group. Free choice ensures that workers select their education according to their comparative advantage and tasks are assigned according to the structure of comparative advantage.
} 
jobs. The self-selection model proposed by Roy (1950 and 1951) puts the emphasis on the supply side of the labour market by focusing on the heterogeneity of individuals. Individuals are endowed with different capacities and choose a sector among a small number of sectors. The demand for workers and wage rates by sectors are exogenous to the model. An interesting feature of Roy's model is that it can be used to model individuals' educational choice. Individuals choose their educational profile based on their initial capacities and the exogenous market wages associated with each educational background. Although. Roy's model can be used to model individuals' selection of education or occupation, it does not enable us to analyse the allocation of workers with various educational backgrounds to various occupations.

In contrast to Roy's model, Rosen's tasks assignment model (Rosen (1978)) puts the emphasis on the demand side of the labour market by focusing on the heterogeneity of tasks. Tasks differ from one another by the levels of the various types of skills they require. Workers are grouped in a small number of homogeneous skill groups (educational categories) and the supply of workers and wage rates by skill groups is assumed to be exogenous. The principal advantage of this model is that it offers a very convenient framework to analyse substitution between skill groups of workers. Rosen considers the demand for labour by modeling firms' indirect production function resulting from the assignment of tasks to workers that maximises output, given exogenous wages. However, in the model proposed by Rosen tasks are ranked on a single continuum such that there is implicitly only one occupation considered.

The allocation model proposed by Tinbergen (1956) is situated at the junction between Roy's (1950) and Rosen's (1978) models as both the beterogeneity of individuals and tasks are considered. In the allocation model, workers as well as tasks are defined along a finite number of types of skills and the quantity of each type of skill workers have and tasks require are continuously distributed. Since in practice the supply and demand distribution do not coincide, the supply distribution has to be deformed so as to coincide with the demand distribution otherwise there will not be an equilibrium. The endogenous income scale serves to equilibrate the demand and supply distributions. Tinbergen's model is very general as it incorporates both sources of heterogeneity, but education and oceupation are absent from the model. Though in practice it is possible to incorporate these two concepts into Tinbergen's model, as we will show in this chapter, the derivation of substitution possibilities between the various labour types is very 
complicated as the type of the implicit function of production is undefined.

Rosen's approach is more appealing for our purpose as it allows to infer on labour demand, productivity and factor substitution between educational groups of workers, while taking into account the heterogeneity of tasks and the assignment of tasks to workers. However, in Rosen's tasks assignment model, jobs are implicitly assumed to be consistently defined by a single continuum of tasks. Occupational levels and fields are ranked on a single scale and it becomes impossible to analyse the allocation of workers with different educational backgrounds to various occupational levels and fields. Therefore, we will develop in this study an allocation model that builds on Rosen's tasks assignment model but incorporates more than one occupation. We will consider a tasks assignment model with several educational types of workers and several occupations where each occupation is characterised by a different continuum of tasks. In this model, workers with the same educational background are assumed to be homogeneous. In practice, workers heterogeneity can be accounted for if we assume that workers have perfect foresight, as in Willis and Rosen's (1979) application of Roy's model on educational choice. We will show how to extend our model in order to simultaneously take into account the heterogeneity of both workers and jobs as in Tinbergen's model. However, we will show that the structure of factor substitution is similar in both the generalised and restricted models. Since taking into account workers' heterogeneity within education do not quantitatively change the structure of factor substitution and allowing for fluctuations in the supply of labour by education is more realistic for empirical work, the model of section 2.6.1 will be preferred in this study.

The chapter is organised as follows. In Section 2.2 we provide insight in the way in which the heterogeneity of workers and jobs is related to the substitution process in the labour market. In Section 2.3 we present Roy's self-selection model. In Section 2.4 we discuss Rosen's tasks assignment model. In Section 2.5 we present Tinbergen's allocation model. In Section 2.6, we discuss the model developed in this study (Section 2.6.1) and a possible extension by considering both the heterogeneity of workers and jobs (Section 2.6.2). We will summarise and conclude in Section 2.7. 


\subsection{Heterogeneity of workers and jobs and the substitution process}

Before we discuss the assignment models in details, let us first show, with an example, how the shape of the production function and thereby the substitution process both between and within occupations depends on the assignment of jobs to workers and the extent to which workers and tasks are heterogeneous.

Consider a decrease in the relative wage rate of college to high-school graduates. Since college graduates become relatively cheaper, some of them will be used to replace high-school graduates such that substitution between college and high-school graduates takes place. The substitution occurs as in the following line of thought. The first college graduate is assigned to the most difficult task high-school graduates performed before the wage shift, and the remaining tasks are reassigned to the remaining high-school graduates. This process is repeated when the second extra college graduate has been assigned to the most difficult task high-school graduates performed until then and the remaining tasks are reassigned to the remaining high-school graduates. In the extreme case where the productivity of all college graduates relative to the productivity of all high-school graduates is constant in all tasks of each occupation, this process lasts until all high-school graduates would be replaced by college graduates, i.e. perfect substitution between college and high-school graduates. However, in general, at some point in the substitution process the relative productivity of high-school graduates compared to college graduates in the marginal task, i.e. the task to which. the next college graduate should be assigned, compensates for the relative wage differential. The substitution between college graduates and high-school graduates is limited to the extent of the marginal task. There is imperfect substitution between workers of different skill types. In the extreme case where the relative productivity of high-school graduates compared to the first college graduate in the marginal task already compensates for the relative wage differential, there is no substitution possibility between college and high-school graduates and the production function is accurately depicted by a Leontief production function.

In assignment models, workers are heterogeneous with respect to their skills and jobs are heterogeneous with respect to the skills they require. These models generally differ from one another depending on whether workers' skills and the skills required in the jobs are continuous or discrete, i.e. educational and occu- 
pational categories are discrete variables describing workers' skills and the skills required in jobs. However, in all models, there need not be a one-to-one relation * ship between the type of skills workers have and the type of jobs or occupation. To achieve a one-to-one relationship between workers' skill types and occupations, workers of different types of skills have to be perfect substitutes within occupations. This requires that the relative productivity of workers of different types of skills is constant in all tasks within occupations. In that case the output of an occupation could be produced with either types of workers and as soon as the relative wage premium of workers with a particular type of skill increases, all workers with this type of skill are immediately replaced by workers of a cheaper skill type. As a consequence, in each occupation, we will then observe one type of worker only. This type of production technology within an occupation is known as a linear production function.

However, because we generally do not observe a one-to-one relationship between education and occupation, it is reasonable to assume that workers of different skill types are less than perfectly substitutable within occupations. Moreover, because we observe shifts in the allocation of workers with different educational backgrounds to the various occupations through time, it is reasonable to assume that workers of different skill types are substitutable within an occupation though less than perfectly. When the wage rate of workers with a particular type of skill increases, some of these workers will be replaced by workers of a relatively cheaper skill type within occupations. Therefore, in each occupation, there will be workers employed with different skill types.

Moreover, the substitution process may occur between occupations as well. Indeed, although a decrease in the wage rate of for instance economics graduates will reduce total labour costs, the cost of producing economic papers will probably reduce more than the costs of producing sciences papers (Marshall's importance of being unimportant law). This cost differential will in turn induce substitution between occupations. This substitution process goes on until the respective marginal jobs of all occupations for which a relatively higher costs of production is observed are replaced by jobs in occupations for which lower costs of production are observed.

Two extreme cases are noteworthy. First, if all tasks are identical within each occupation, i.e. the case of perfect substitution between the occupational products, all jobs in occupations with relatively higher costs are immediately replaced by jobs in occupations with relatively lower costs. In the case of perfect substi- 
tution between occupational products, we would only observe workers in some occupations, whereas no one is employed in the other occupations. The second extreme case is met when substitution between occupational products is not possible. In this case, though the skill composition of workers within occupations may change in response to wage changes, the output of each occupation is a fixed proportion of the output in other occupations. Depending on how substitutable workers of different types are, at least one type of workers would be observed in each occupation.

\subsection{Roy's self-selectivity model: A supply ap- proach with workers' heterogeneity}

The self-selection model developed by Roy (1950 and 1951) focuses on the supply side of the labour supply by looking at the heterogeneity between individuals. Roy's perspective is to assume that the demand for labour is exogenous, perfectly elastic to wages and does not affect the distribution of comparative advantages among workers. Though Roy's self-selection model is governed by the principle of comparative advantage, the theory of comparative advantage in labour markets was formally developed by Sattinger (1975). ${ }^{2}$ The presence of comparative advantage was later demonstrated empirically in Sattinger (1978 and 1980). ${ }^{3}$ Changes in labour demand correspond to changes in relative wages. Extensions of Roy's model to more than two sectors are provided in Heckman and Sedlacek (1985 and 1990) and Gould (2002).

In this model, the economy is characterised by several educational segments. ${ }^{4}$ Individuals, prior to their educational choice, are heterogeneous with respect to their endowed initial capacities. Individuals choose their education according to their endowed capacities (vector $x$ ). If an individual choose education $j$, the educational system transforms this individual's capacities into skills by the function

\footnotetext{
${ }^{2}$ See also Sattinger (1993) for a survey of assignment models and comparative advantage.

${ }^{3}$ MacDonald (1982) extends the comparative advantage model to labour markets with incomplete information.

'In Roy's (1951) original work, workers can choose between two sectors. Willis and Rosen (1979) and Willis (1986) show that Roy's model expresses the self-selection of people into educational groups assuming that there is a one-to-one relationship between education and occupation. Therefore, throughout this section, we will use the term education although we could use the term occupation.
} 
$t_{j}(x)$. For example, $t_{j}(x)$ takes an individual's strength, intelligence and so forth and transforms these endowments into that individual's skills. For the sake of notational simplicity, the skills of workers $t_{j}(x)$ are better understood as measured in ( $\log$ ) output units per hour. ${ }^{5}$ An individual endowed with capacities $x$ that chooses education $j$ will have skills level $t_{j}(x)$ and will produce $t_{j}(x)(\log )$ units of output per hour. Note that since individuals are heterogeneous with respect to their ex ante capacities, they are also heterogeneous with respect to their skills, ex post, even when they have the same education.

For the sake of convenience, let's consider the original two-sector model. The population distributions of skills in the two educational segments are characterised by their means, variances and covariance across educational groups. If workers were randomly distributed over the educational segments, the observed skill distributions would match the population distributions in the two educational segments. However, as workers will maximise their utility by pursuing their comparative advantage, the skill distribution in each educational group will differ from the population distribution of skills.

In order to illustrate Roy's findings, we assume that workers choose between two educational segments and that utility maximisation is equivalent to wage maximisation. Since individuals choose their education once for good, this means that individuals perfectly foresee what their earnings will be in the future at the time the educational choice is made. Therefore, we assume that individuals have perfect foresight.

Suppose workers are endowed with certain capacities, $x$, which are transformed through education in segment $j$ into skills by the function $t_{j}(x)$. An individual with initial capacities $x$ will have skills $t_{1}(x)$ if he chooses education 3. and skills $t_{2}(x)$ if he chooses education 2. Let $w_{j}$ be the piece rate pay per unit of output for workers with education $j$ determined in a competitive market. The $\log$ earnings, denoted by $y(x)$, of an individual with capacities $x$ choosing education $j$ is given by:

\footnotetext{
${ }^{5} \mathrm{Hartog}(2001)$ describes in a basic structure the transformation of individuals' initial endowments (abilities) into earnings. In the first step, individuals' initial endowments are transformed into skills through an educational production function, the function $l_{j}(x)$. These skills are then transformed into an individual's output by a production matrix, the function $p\left(l_{j}\right)$ with $p$ increasing in $l_{j}$. To simplify the notation and without loss of generality, we assume that the function $t_{j}$ actually encompasses both the educational production matrix and the productivity matrix, i.e. $t_{j}(x)=p \circ l_{j}(x)$. In the final step, with piece rate output prices, productivities determine standard earnings, $y$.
} 


$$
y(x)=\ln w_{j}+t_{j}(x)
$$

An individual chooses education 1 over education 2 if:

$$
\ln w_{1}+t_{1}(x) \geq \ln w_{2}+t_{2}(x)
$$

Roy assumes ${ }^{6}$ that the distributions of skills are log-normal.

Let the joint distribution be given by:

$$
\begin{aligned}
n\left(t_{1}, t_{2}\right) & \sim N(\bar{t}, \Sigma) \text { with } \bar{t}=\left\langle\bar{t}_{1}, \bar{t}_{2}\right\rangle \\
\text { and } \Sigma & =\left(\begin{array}{cc}
\sigma_{1} & \sigma_{12} \\
\sigma_{12} & \sigma_{2}
\end{array}\right)
\end{aligned}
$$

The correlation between an individual's skills of type 1 and 2 is given by $c_{t}=\sigma_{12} / \sigma_{1} \sigma_{2}$. The correlation and variances of the skill distribution play a crucial role for determining comparative advantages and therefore for determining the earnings distribution and self-selection. Clearly, someone's choice for one or the other educational segment depends also on the wage rate in each education. The larger the relative wage rate in a particular education, the more people will find it profitable to choose this education. The decision rule can be formalised by an index $I$ such that a person with potential skills $\left\langle t_{1}(x), t_{2}(x)\right\rangle$ will choose education 2 if $t_{2}-t_{1}>\ln w_{1}-\ln w_{2}$. The index function $I$ reads therefore as: $t_{2}^{*}=$ $\ln w_{1}-\ln w_{2}+t_{1}$ where $t_{2}^{*}$ can be interpreted as a person's minimum level of skill of type 2 necessary to have a comparative advantage in education 2 conditional on a person's level of type 1 skill and the wage rates in both educational segments.

Three cases are usually distinguished. The first case, usually referred to as equality of comparative advantage, is given by skills that are equally concentrated and perfectly correlated, i.e. $\sigma_{1}=\sigma_{2}$ and $c_{t}=1$. In this case there is no selection

\footnotetext{
${ }^{6}$ This is a strong assumption in Roy's model. Heckman and Honore (1990) show that few of the implications of Roy's model survive if the skills are drawn from more general distributions.
} 
and individuals appear as if they were sorted into the educational segments at random. Even though we could separate skill types, the skills of individuals could be considered as a one-dimensional factor.

The second case corresponds to hierarchical sorting. This case arises when the skill distribution satisfies one of the following conditions.
A)
$\sigma_{1} / \sigma_{2}>c_{t}>\sigma_{2} / \sigma_{1}$
or
B) $\quad \sigma_{1} / \sigma_{2}<c_{\ell}<\sigma_{2} / \sigma_{1}$

These two conditions imply a sufficiently high positive correlation between both types of skills. It is called hierarchical sorting because e.g. under condition $A$, individuals with education 1 are drawn from the right tail of the distribution of type 1 skill, whereas people with education 2 are drawn from the lower tail of the distribution of type 2 .

The extreme case of hierarchical sorting, with perfect correlation between skills, is illustrated in Figure 2.1. The axes correspond to both types of skills, type 1. (horizontal) and 2 (vertical). The population distributions of both skills are represented on the associated axes. The index line $I$ is the 'decision' line. Given market wage rates, line $I$ intersects the bivariate skill distribution in such a way that people with skills that lie above $I$ choose education 2 and people with skills that lie below $I$ choose education 1 . The joint distribution of skills corresponds to the degenerate bivariate normal whose density lies along line $n$. The index line $I$ and skill distribution line $n$ intersect in point $e$. Skill points defined by $\left\langle t_{1}(x), t_{2}(x)\right\rangle$ lie on $n .^{7}$ Any individual whose skill point is situated to the right of point $e$ chooses education for which the distribution of the associated skill type is most spread among individuals (education 1 in Figure 2.1), while all persons whose skill points are situated to the left of $e$ choose education for which the skills of people are most concentrated (education 2).

The third case is the case of no hierarchical sorting. This occurs when the correlation between both types of skill is sufficiently small or if the scope for skills of type 1 and 2 is about the same and there is a less than perfect correlation.

\footnotetext{
${ }^{7}$ The distribution line $n$ passes through point $\left(\overline{t_{1}}, \overline{t_{2}}\right)$ by definition.
} 


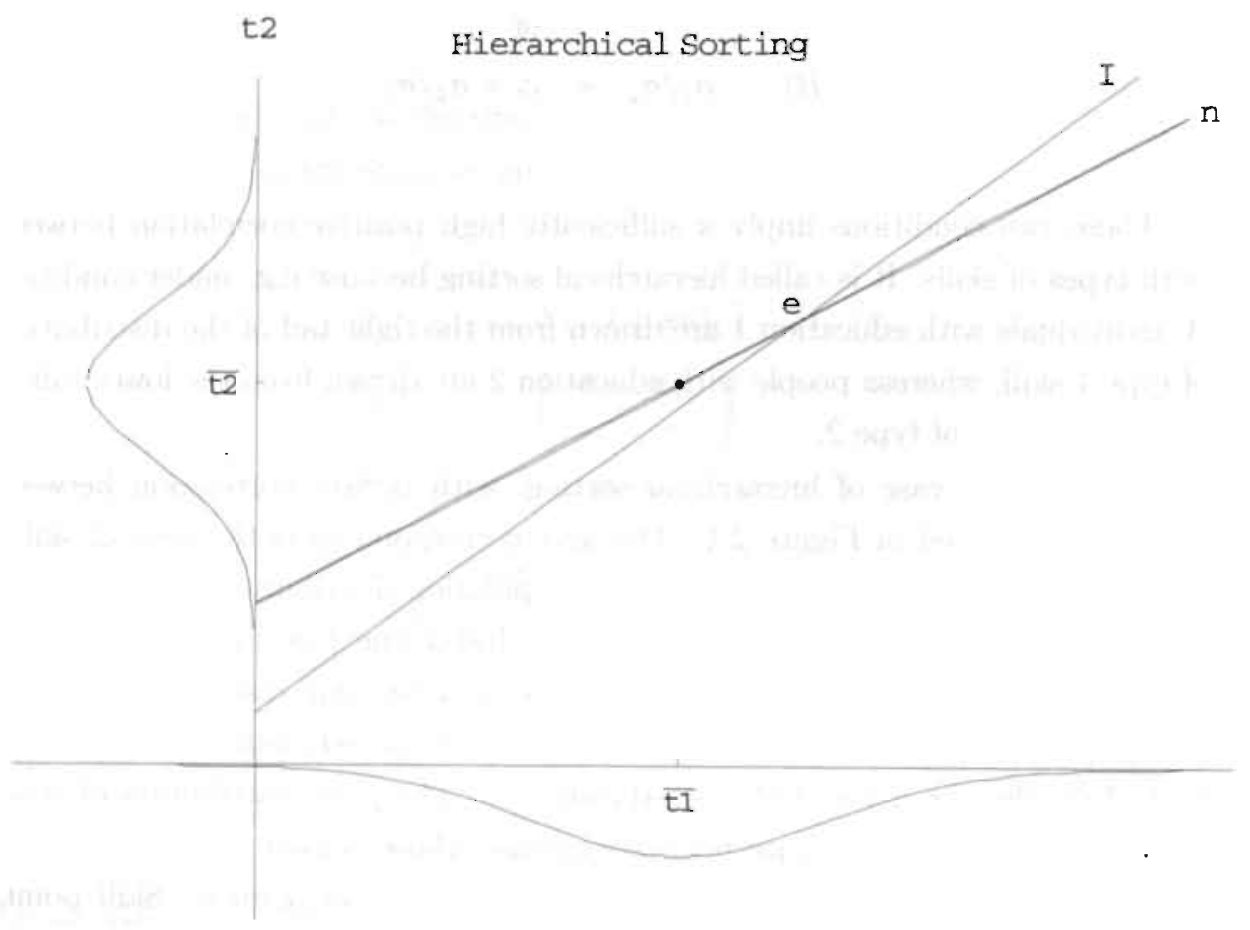

Figure 2.1: Educational choice under hierarchical sorting. 
This condition reads as:

$$
\begin{aligned}
c_{t}< & \sigma_{1} / \sigma_{2}<\sigma_{2} / \sigma_{1} \\
& \text { or } \\
c_{\ell}< & \sigma_{2} / \sigma_{1}<\sigma_{1} / \sigma_{2}
\end{aligned}
$$

In this case, workers with the highest skills of type $;$ tend to choose education $j$. Figure 2.2 illustrates the particular situation where both types of skill are not correlated $\left(c_{t}=0\right)$. The joint distribution of skills is represented by an elliptical set of iso-probability contours ${ }^{8}$ whose major axis is either horizontal or vertical $\left(\sigma_{1} / \sigma_{2}>1\right.$ and $\sigma_{1} / \sigma_{2}<1$ respectively). ${ }^{9}$ The index line $I$ partitions the bivariate distribution on a slant in such a way that the probability that a person has a comparative advantage in education 1 , respectively 2 , is an increasing function of $t_{1}$, respectively $t_{2}$. As depicted in Figure 2.2, the average level of type 1 skill of workers choosing education 1 is larger than the average level of type 1 skill of workers who choose education 2. Respectively, the average level of type 2 skill of workers choosing education 2 is larger than the average level of type 2 skill of workers who choose education 1.

In Roy's model, individual's skills and the distribution of these skills in each education determine the comparative advantage of workers in the two educational groups. As Willis and Rosen (1979) and Willis (1986) show, it is possible to express the self-selection of people into both education and occupation in two steps by assuming an exclusive relationship between education and occupation. Suppose that education $j$ is a necessary and sufficient ${ }^{10}$ condition to work in occupation $j$. Then, Roy 's model depicts individuals' self-selection in a particular education and the related occupation. Given the wage rates in both educationoccupation sectors, people select themselves into education according to their

\footnotetext{
${ }^{8}$ In Figure 2.2, we plot the $95 \%$ contour. This means that $95 \%$ of all individuals are contained in the ellipse $n$.

${ }^{9}$ Note that if the scope for both skills is the same, i.e. the same dispersion of skills in both educational segments, the joint distribution is represented by a circle set of iso-probability. (see Salop (1979))

${ }^{10}$ Herewith, one should use the term 'imposed' instead of 'required' education for a job since both Willis and Rosen (1979) and Willis's (1986) extensions consider a one-to-one relation between education and occupation. The people who are going to work in occupation 1 have studied education 1 whereas those who work in occupation 2 have always studied education 2 .
} 


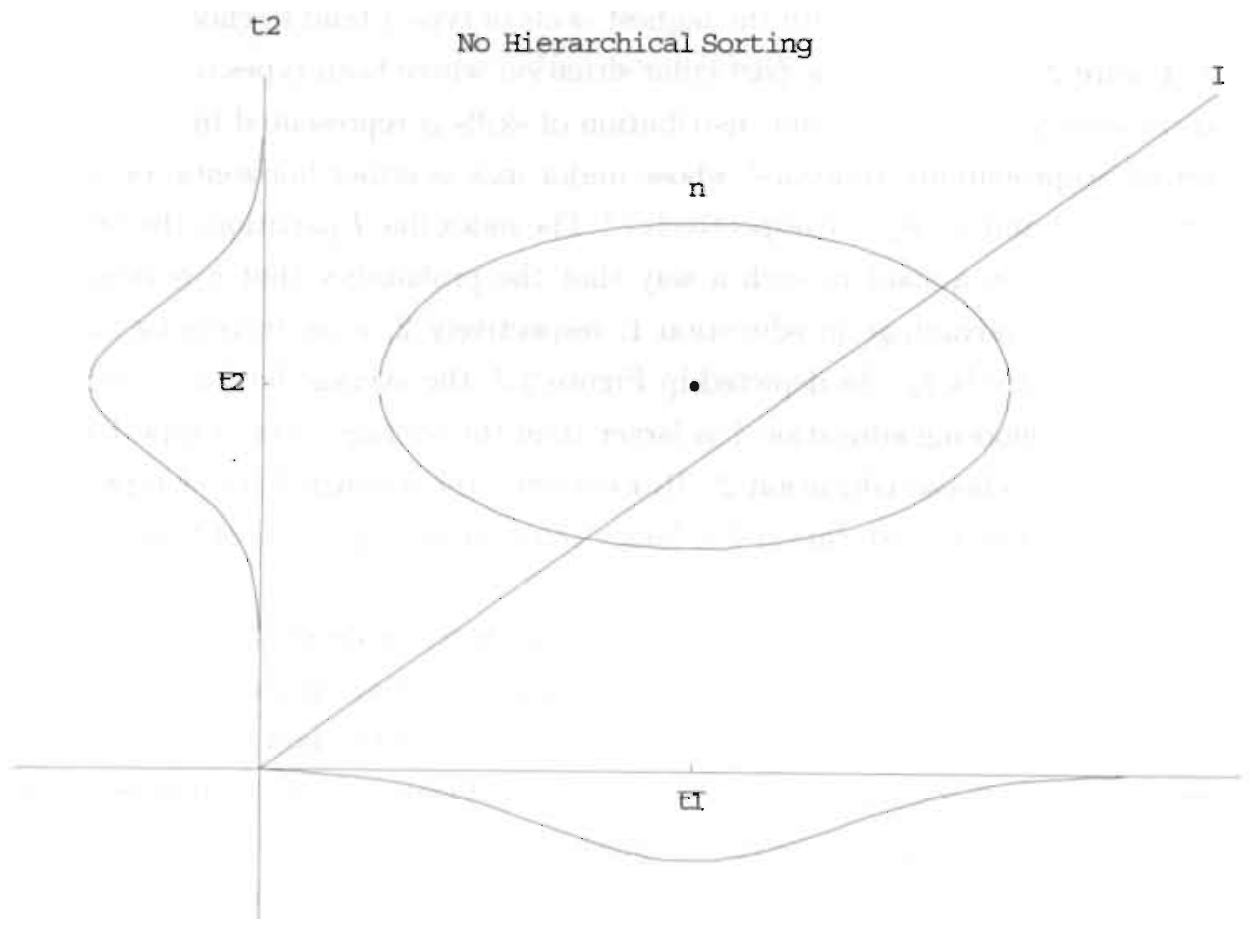

Figure 2.2: Educational choice under non-hierarchical sorting. 
comparative advantage, and find work in the related occupation.

\subsection{Rosen's tasks assignment model}

The assignment model developed by Rosen (1978) focuses on the demand side of the labour market by considering heterogeneity of tasks. In the theoretical framework, there is a rather small number of types of workers. The type of workers refers to a worker's education ${ }^{11}$ and workers with the same education are homogeneous with respect to their skills. Jobs refer to certain tasks and there is a very large set of tasks to be performed in order to produce output. The supply of labour is assumed to be exogenous, perfectly elastic to wages and does not affect the distribution of comparative advantage among educational types of workers. In that sense, the model essentially focuses on the demand for labour. The model focuses on the problem that consists of finding an assignment of the various tasks to types of workers in order to maximise output. Opposite to Roy's model, workers do not select an education given their potential skills but rather are assigned to a task depending on the skills this task requires and the wage rates associated with each type of workers.

We define a task $i$ by the productivity of each type of workers in this task. For instance, if $s_{i j}$ is the productivity, measured in $(\log )$ output per hour, of a worker with education $j$ in task $i$ then task $i$ is defined by a vector $s_{i}=\left\langle s_{i 1}, \ldots, s_{i n}\right\rangle$ containing the productivity of the various types of workers in this task. The skills required in task $i$ are the skills possessed by those workers with the largest productivity in this task, i.e. if $\max _{j} s_{i j}=s_{i k}$ then the required education in task $i$ is education $k$. In order to produce output, firms define the tasks to be performed. The firms' demand for labour forms the multivariate frequency distribution of tasks, say $m\left(s_{1}, \ldots, s_{n}\right)$, in terms of workers' productivity.

Similar to Roy's model, great graphical simplification is achieved when there are two types of workers: workers with education 1 and workers with education 2 . Within each educational group, workers are assumed to be homogeneous in terms of their skills. Therefore, workers belonging to the same educational group are equally productive. However, between educational groups, productivity is neither equal nor constant over tasks. Assume that this joint distribution of productivity

\footnotetext{
${ }^{11}$ Similar to Roy's model, there is a one-to-one relationship between education and occupation.
} 
follows a bivariate normal distribution:

$$
\begin{aligned}
m\left(s_{1}, s_{2}\right) & \sim N(\bar{s}, \Xi) \text { with } \bar{s}=\left\langle\vec{s}_{1}, \bar{s}_{2}\right\rangle \\
\text { and } \Xi & =\left(\begin{array}{cc}
\tau_{1} & \tau_{12} \\
\tau_{12} & \tau_{2}
\end{array}\right)
\end{aligned}
$$

The correlation between the productivity of workers of both types in the various tasks is given by $c_{s}=\tau_{12} / \tau_{1} \tau_{2}$. For instance, if $c_{s}$ is close to 1 , the tasks in which workers with education 1 are the most productive are also the task in which workers with education 2 are the most productive.

Let $\ln w_{j}$ be the log wage rate of workers of type $j$. Moreover, a worker of type $j$ assigned to task $i$ produces $s_{i j}(\log )$ units of output.

The problem is to assign the tasks to both types of workers in such a way that output, denoted by $H$, is maximised. The assignment depends on the wage rates and the joint distribution of workers' productivity associated to the tasks. Similarly to Roy's self-selection model, the assignment of tasks is random, hierarchical sorting or non-hierarchical sorting depending on the magnitude of the variances and covariance of the distribution of the productivity of both types of workers in the various tasks.

In order to illustrate the assignment problem, we graph in Figure 2.3 the demand surface that results if we assume that there is no correlation between the productivity of workers of both types and hence no hierarchical sorting. Therefore, demand is determined by an elliptic set of iso-probability contours ${ }^{i 2}$ whose axes have arbitrary positions depending on the correlation parameter $\varepsilon_{s}$. The assignment rule can be formalised by an index $I_{s}$ in such a way that a task $i$ with productivity point $\left\langle s_{i 1}, s_{i 2}\right\rangle$ will be assigned to a worker of educational type 2 if $s_{i 2}-s_{i 1}>\ln w_{2}-\ln w_{1}$. The index function reads as: $s_{2}^{*}=\ln w_{2}-\ln w_{1}+s_{\curlywedge}$ where $s_{2}^{*}$ is the minimum productivity a worker of type 2 in a given task so that this task is most efficiently assigned to a worker of type 2 depending on the productivity of workers of type 1 in this task and the relative wage rate. In Figure 2.3, the index line $I_{s}$ partitions the demand ellipse $m$ on a slant so that any task $i$ with productivity point $\left\langle s_{i 1}, s_{i 2}\right\rangle$ lying above $I_{s}$, is assigned to a worker of type 2 . The

\footnotetext{
${ }^{12}$ In Figure 2.3, we plot the $95 \%$ contour. This means that $95 \%$ of all tasks are contained in the ellipse $m$.
} 
CHAPTER 2-ASSIGNMENT MODELS AND SUBSTITUTION

follows a bivariate normal distribution:

$$
\begin{aligned}
m\left(s_{1}, s_{2}\right) & \sim N(\bar{s}, \Xi) \text { with } \bar{s}=\left\langle\bar{s}_{1}, \bar{s}_{2}\right\rangle \\
\text { and } \Xi & =\left(\begin{array}{cc}
\tau_{1} & \tau_{12} \\
\tau_{12} & \tau_{2}
\end{array}\right)
\end{aligned}
$$

The correlation between the productivity of workers of both types in the various tasks is given by $c_{\mathrm{a}}=\tau_{12} / \tau_{1} \tau_{2}$. For instance, if $c_{\mathrm{s}}$ is close to 1 , the tasks in which workers with education 1 are the most productive are also the task in which workers with education 2 are the most productive.

Let $\ln w_{j}$ be the log wage rate of workers of type $j$. Moreover, a worker of type $j$ assigned to task $i$ produces $s_{i j}(\log )$ units of output.

The problem is to assign the tasks to both types of workers in such a way that output, denoted by $H$, is maximised. The assignment depends on the wage rates and the joint distribution of workers' productivity associated to the tasks. Similarly to Roy's self-selection model, the assignment of tasks is random, hierarchical sorting or non-hierarchical sorting depending on the magnitude of the variances and covariance of the distribution of the productivity of both types of workers in the various tasks.

In order to illustrate the assignment problem, we graph in Figure 2.3 the demand surface that results if we assume that there is no correlation between the productivity of workers of both types and hence no hierarchical sorting. There fore, demand is determined by an elliptic set of iso-probability contours ${ }^{12}$ whose axes have arbitrary positions depending on the correlation parameter $c_{s}$. The assignment rule can be formalised by an index $I_{s}$ in such a way that a task $i$ with productivity point $\left\langle s_{i 1}, s_{i 2}\right\rangle$ will be assigned to a worker of educational type 2 if $s_{i 2}-s_{i 1}>\ln w_{2}-\ln w_{1}$. The index function reads as: $s_{2}^{*}=\ln w_{2}-\ln w_{1}+s_{1}$ where $s_{2}^{*}$ is the minimum productivity a worker of type 2 in a given task so that this task is most efficiently assigned to a worker of type 2 depending on the productivity of workers of type 1 in this task and the relative wage rate. In Figure 2.3, the index line $I_{s}$ partitions the demand ellipse $m$ on a slant so that any task $i$ with productivity point $\left\langle s_{i 1}, s_{i 2}\right\rangle$ lying above $I_{s}$, is assigned to a worker of type 2 . The

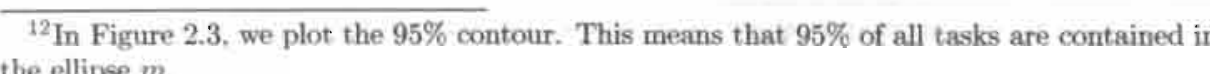

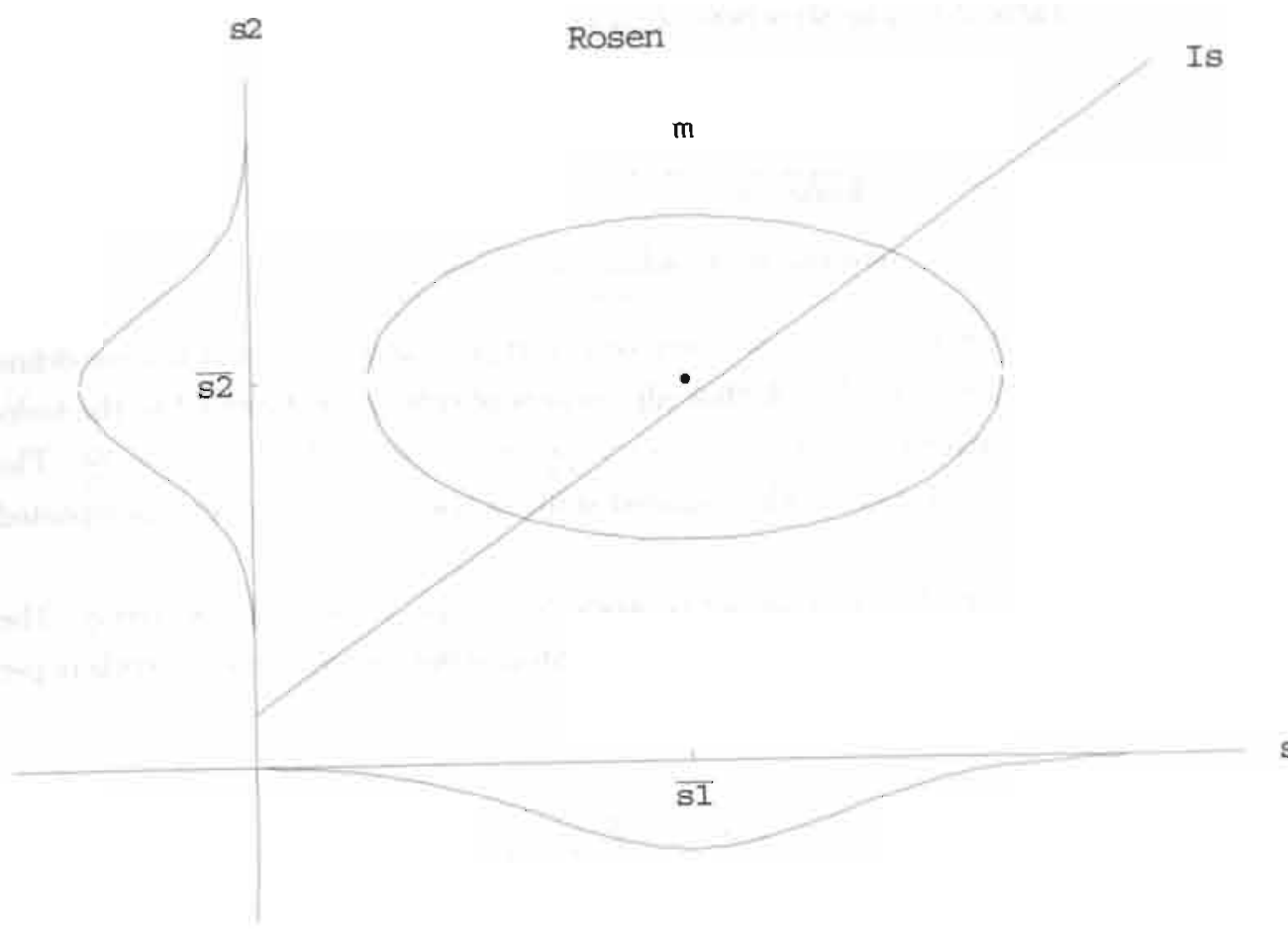

Figure 2.3: Assignment of workers to jobs increases. This results in a lower demand for workers of type 1.

The analytic model of Rosen (1978) presents some interesting features. In the model, tasks are ranked by workers' comparative advantage. To do so, Rosen defines the contimuous index $v=g\left(s_{1}, s_{2}\right)$ on $(0,1)$ with partial derivatives $g_{s_{1}}<0$, $g_{x_{2}}>0$ and $g_{0}<g_{1} \times g_{n}$. This means that a task $i$ is ranked closer to 0 than $g_{s_{2}}>0$ and $g_{s_{1} s_{2}}<g_{s_{1}} \times g_{2}$. This a task $l$ if. $s_{i 1}-s_{i 2}>s_{l 1}-s_{l 2}$. Workers of type 1 have a comparative advantage in tasks close to 0 and workers of type 2 have a comparative advantage in task close to 1 . The continuum partitions the spectrum of tasks in the following way Let $1 / \pi_{j}(v)$ measure the productivity in 'efficiency units' of a worker of type at task $v .^{13}$ The productivity of workers of type 1 relative to workers of type 2 defined by the function $q(v)=\pi_{2}(v) / \pi_{1}(v)$ is therefore increasing in $v$ (i.e.

${ }^{13}$ Note that for task $v$ such that $v=g\left(s_{i 1}, g_{i 2}\right)$, we have $\ln \frac{1}{\pi,(v)}=s_{i j}$, for $j=1,2$. 
Table 2.1: The structure of assignment and the marginal task.

\begin{tabular}{lc|cc}
\hline \hline & & Education & \\
& & 1 & 2 \\
\hline Tasks & $v<\varepsilon$ & $*$ & \\
& $v \geq \varepsilon$ & & $*$ \\
\hline \hline
\end{tabular}

$\left.q^{\prime}>0\right)$. Given the wage rates of workers of type 1 and $2, w_{1}$ and $w_{2}$, we define the task $\varepsilon$ with $\varepsilon \in(0,1)$ such that all workers of type $j$ are assigned to the tasks whose value $v$ exceeds $\varepsilon$, i.e. $q(v<\varepsilon)>\frac{w_{1}}{w_{2}}, q(\varepsilon)=\frac{w_{1}}{w_{2}}$ and $q(v>\varepsilon)<\frac{w_{1}}{w_{2}}$. The assignment structure given the required skills of the marginal tasks $\varepsilon$ is reported in Table 2.1.

Let $L_{1}$ and $L_{2}$ be the number of workers of type 1 and 2, respectively. The unit isoquant is defined parametrically by integrating the demand for workers per unit of output over the spectrum $v$ :

$$
\begin{aligned}
& \frac{L_{1}}{H}=\int_{0}^{\varepsilon} \pi_{1}(v) \cdot d v \\
& \frac{L_{2}}{H}=\int_{\varepsilon}^{1} \pi_{2}(v) \cdot d v
\end{aligned}
$$

where $H$ is the output level.

The elasticity of substitution between both educational types of workers evaluated at the marginal task $\varepsilon$ is therefore given by:

$$
\sigma(\varepsilon) \equiv \frac{d \ln \left(L_{1} / L_{2}\right)}{d \ln q}=\left(\frac{\pi_{1}}{L_{1}}+\frac{\pi_{2}}{L_{2}}\right) /\left(\frac{\pi_{1}^{\prime}}{\pi_{1}}+\frac{\pi_{2}^{\prime}}{\pi_{2}}\right)
$$

where all arguments, i.e. $\pi_{1}, \pi_{2}, \pi_{1}^{\prime}, \pi_{2}^{\prime}$ and $q$, are evaluated at $\varepsilon$.

Equation 2.2 shows that the more similar workers' skills are in the neighbourhood of the marginal task, the larger the elasticity of substitution in the marginal task.

Assume that the functional form of the demand for workers per unit of output is as follows: ${ }^{14}$

\footnotetext{
${ }^{14}$ Given the demand for workers per unit of output as described in equation 2.3 , for $q(v)$ to
} 


$$
\begin{aligned}
& \pi_{1}(v)=\frac{1}{\beta} a_{1}^{-1 / \beta} v^{1 / \beta-1} \\
& \pi_{2}(v)=\frac{1}{\beta} a_{2}^{-1 / \beta}(1-v)^{1 / \beta-1}
\end{aligned}
$$

where $a_{1}$ and $a_{2}$ are positive constants and $\beta \in(0,1)$.

Then, the unit isoquant in equation 2.1 can be rewritten to yield:

$$
\begin{aligned}
& \frac{L_{1}}{H}=a_{1}^{-1 / \beta} \varepsilon^{1 / \beta} \\
& \frac{L_{2}}{H}=a_{2}^{-1 / \beta}(1-\varepsilon)^{1 / \beta}
\end{aligned}
$$

Solving the system for $\varepsilon$ we have:

$$
H=\left[a_{1} L_{1}^{\beta}+a_{2} L_{2}^{\beta}\right]^{1 / \beta}
$$

Equation 2.4 reads as a CES production function. ${ }^{15}$ Rosen's (1978) indirect production function indicates that comparative advantages of workers imply imperfect substitution between the various types of workers. The elasticity of substitution between the two educational types of workers at the marginal task is given by $\sigma=\frac{1}{1-\beta}$ and is constant for all marginal tasks.

Furthermore, given perfect competition in both labour and product markets, $\partial H / \partial L_{i}=w_{i}$, we can solve $\varepsilon$ for the parameters and the relative wage rates $w_{i}$ as follows:

$$
z\left(w_{2} / w_{1}\right) \equiv \varepsilon=a_{1}^{\sigma}\left(a_{1}^{\sigma}+a_{2}^{\sigma}\left(\frac{w_{2}}{w_{1}}\right)^{1-\sigma}\right)^{-1}
$$

increase with $v, q^{\prime}>0$, we need $\overline{\beta \in}(0,1)$.

${ }^{16}$ In general, solving the system for $1>\beta>0$ yields Rosen's indirect production function. Imposing the worker demand per unit of output as in equation $2: 3$ yields the CES form. 
From equation 2.5, changes in the assignment of the marginal task can be inferred from exogenous changes in the wage rate of workers with education 2 relative to the wage rate of workers with education 1 . Since $\sigma>1$, an increase in the relative wage rate of workers with education 2 compared to workers with education 1 will shift the marginal task $\varepsilon$ towards $1\left(z^{\prime}>0\right)$. Since workers with education 2 become relatively more expensive after the shock, workers with education 2 will be assigned to tasks in which they are relatively more productive. As a result, workers with education 1 will perform a wider range of tasks whereas workers with education 2 will perform a narrower range of tasks.

\subsection{Tinbergen's allocation model: A supply ap- proach with heterogeneity of workers and jobs}

The allocation model proposed by Tinbergen (see Tinbergen (1956, 1975 and 1977) and Van Batenburg and Tinbergen (1984)) considers heterogeneity of workers and jobs and income depending on both supply and demand factors. The labour market consists of a (large) number of categories $^{16}$ of labour, and demand, supply and the equilibrating wage rates have to be distinguished for each of these categories though a certain degree of interdependence may exist. Tinbergen models labour supply by maximising individuals' utility. The demand for the various categories of labour is assurned to be inelastic. ${ }^{17}$ Suppose an index is introduced for each category, say $j$. The variables used to characterise the various categories are the degree to which certain types of skill are required or present in that category.

In the model, workers are endowed with a bundle of skills. The level of type $j$ skills a worker possesses is given by $t_{j}$. The worker's skills are therefore defined by the vector $t=\left\langle t_{1}, \ldots t_{j} \ldots, t_{n}\right\rangle$ where for instance $t_{1}$ indicates an individual's mathe-

\footnotetext{
${ }^{16}$ Tinbergen actually refers to compartments.

${ }^{17}$ Tinbergen (1956) shows it is possible to remove the assumption that demand is inelastic (see section VIII). However, Tinbergen derives a solution if only the mean of the distribution of required skills (and not the variance and covariance) changes as the wage rates change. Furthermore, even in this simple case, the derivation of substitution possibilities between the various labour types is very complicated as the type of the implicit function of production remains obscure.
} 
matics skills, $t_{2}$ indicates his or her communication skills, et cetera. ${ }^{18}$ All workers collectively form the supply of labour that is characterised by the multivariate frequency distribution of workers' skills, say $n\left(t_{1}, \ldots t_{j} \ldots, t_{n}\right)$. Next, Tinbergen defines a task $i$ by the level of each type of skill this task requires to be adequately performed. The level of type $j$ skills required to do task $i$ is denoted by $s_{i j}$. Collecting these levels of required skills, Tinbergen defines a task $i$ by the vector. $s_{i}=\left\langle s_{i 1}, \ldots s_{i j} \ldots, s_{i n}\right\rangle$, where $s_{1}$ is the mathematics skills required, $s_{2}$ the communication skills required, et cetera, in task $i^{19}$ In order to maximise output, firms define the tasks to be performed. These tasks differ in the levels of each type of skill they require. Therefore, firms together form the multivariate frequency distribution of tasks, say $m\left(s_{1}, \ldots s_{j} \ldots, s_{n}\right)$, in terms of the required skills.

In practice, the frequency distribution of demand $m$ need not coincide with the frequency distribution of supply $n$. This introduces tensions between the skills demanded and the skills supplied. Therefore, by offering adequate remunerations, employers are able to attract workers for the jobs for which supply is insufficient and repel them from supplying in jobs with excess supply.

In the simplified case of two types of skills, labour supply is determined by the joint distribution $n\left(t_{1}, t_{2}\right)$ and the demand by the joint distribution $m\left(s_{1}, s_{2}\right)$. The allocation problem at hand can be graphically illustrated as in Figure 2.4. The supply of actual skills and the demand for required skills are assumed to be normally distributed with respective distributions:

$$
\begin{aligned}
n\left(t_{1}, t_{2}\right) & \sim N(\bar{t}, \Sigma) \text { with } \bar{t}=\left\langle\bar{t}_{1}, \bar{t}_{2}\right\rangle \\
\text { and } \Sigma & =\left(\begin{array}{cc}
\sigma_{1} & \sigma_{12} \\
\sigma_{12} & \sigma_{2}
\end{array}\right)
\end{aligned}
$$

\footnotetext{
${ }^{18}$ Mind the difference between the definition of $t$ in Tinbergen and the definition of $t$ in the application of Roy's model presented in Section 2.3. In Section 2.3, individuals are endowed with a vector of initial capacities $x$ that is transformed into a productivity scalar $t_{j}(x)$ by the educational choice. In Tinbergen, inidviduals are endowed with a vector of skills $t=<$ $t_{1}, \ldots, t_{n}>$.

${ }^{19}$ Mind the difference between Rosen's and Tinbergen's definitions of tasks. In Rosen's model, tasks are defined. by a vector $s=\left\langle s_{1}, \ldots, s_{n}\right\rangle$ containing the productivity of the various types of workers in this task. In Tinbergen, tasks are defined by a vector $s=\left\langle s_{1}, \ldots, s_{n}\right\rangle$ containing the level of each type of skills required to do task $i$.
} 


$$
\begin{aligned}
m\left(s_{1}, s_{2}\right) & \sim N(\bar{s}, \Xi) \text { with } \bar{s}=\left\langle\bar{s}_{1}, \bar{s}_{2}\right\rangle \\
\text { and } \Xi & =\left(\begin{array}{cc}
\tau_{1} & \tau_{12} \\
\tau_{12} & \tau_{2}
\end{array}\right)
\end{aligned}
$$

The demand and supply surfaces drawn in the figure result from imposing no correlation between the two types of skills workers possess $\left(c_{t}=\frac{\sigma_{12}}{\sigma_{1} \sigma_{2}}=0\right)$ and a positive correlation between the required skills $\left(1>c_{s}=\frac{\tau_{12}}{\tau_{1} \tau_{2}}>0\right)$. Therefore, supply is characterised by an elliptic set of iso-probability contours ${ }^{20}$ whose axes are arbitrarily chosen parallel to the coordinate axes (since $c_{t}=0$, the major axis is parallel to the horizontal axis when $\sigma_{1}>\sigma_{2}$ ) and demand is determined by an elliptic set of iso-probability contours whose axes have arbitrary positions depending on the correlation parameter $c_{s}{ }^{21}$ For the sake of simplicity and without loss of generality, we transformed the space $\left\langle s_{1}, s_{2}\right\rangle$ such that $\left\langle\bar{s}_{1}, \bar{s}_{2}\right\rangle=\left\langle\bar{t}_{1}, \bar{t}_{2}\right\rangle$. Tinbergen derives solutions for the income distribution so that 'tensions' between the skills required in a task and the actual skills of the individual performing this task, i.e. $s_{1}-t_{1}$ and $s_{2}-t_{2}$, are being compensated for by higher remunerations. In the simplified version of Tinbergen's model, the income scale influences the distribution of skills supplied but not the demand distribution:

The t-surface has to be 'deformed' so as to coincide with the ssurface. (Tinbergen (1956), p.162)

Although not explicitly considered in Tinbergen's original work, individuals' educational choice 'deforms' the t-surface. Introducing educational choice to the model provide some insight in why workers with various educational backgrounds find jobs in the same occupation and why workers with the same educational background find jobs in different occupations. Rather than assuming that individuals are directly endowed with skills, we consider that the supply distribution of skills is the result of a self-selection of heterogeneous individuals in education. ${ }^{22}$

\footnotetext{
${ }^{20}$ In Figure 2.4, we plot the $95 \%$ contours. This means that $95 \%$ of all individuals are contained in the ellipse $n$ and $95 \%$ of all jobs are contained in the ellipse $m$

${ }^{21}$ Herewith, we have chosen $c_{s}>0$.

${ }^{22}$ Note that in Tinbergen's view (see Tinbergen (1956)) education...
} ...stands not only for that concept itself but also for all determinants of earn- 
Suppose that workers are endowed with a vector of initial capacities and may choose between two educational categories, namely 1 and 2 . The educational system transforms initial capacities $t^{o}$ into skills $t^{e}$ such that a worker with initial capacities $\left\langle t_{1}^{o}, t_{2}^{o}\right\rangle$ will have skills $\left\langle t_{1}^{e}, t_{2}^{o}\right\rangle$ if he chooses education 1 and skills $\left\langle t_{1}^{o}, t_{2}^{e}\right\rangle$ if he chooses education 2. The distribution of initial capacities is exogenous to the model but the distribution of skills is endogenous, like the distribution of skills supplied in Tinbergen, since it results from the self-selection of individuals in education. Hence, individuals that choose education 1 will tend to have high $t_{1}$ skills and low $t_{2}$ skills while individuals that choose education 2 will tend to have high $t_{2}$ skills and low $t_{1}$ skills. For the sake of simplicity, consider that the index line $I_{t}$ partitions the supply ellipse $n$ on a slant such that workers with skills $\left\langle t_{1}, t_{2}\right\rangle$ that lie below $I_{t}$ have education 1 and workers with skill point that lie above $I_{t}$ have education 2. Note that, as in Tinbergen, the income scale equilibrates the supply and demand such that, given an exogenous shock that results into higher expected returns to education 1 , the distribution of skills will be deformed as more individuals will find it profitable to choose education 1 instead of education 2. Individuals that shift from education 2 to education 1 will increase their $t_{1}$ skills and decrease their $t_{2}$ skills such that the average of type 1 skills, $\bar{t}_{1}$, will increase and the average of type 2 skills, $\bar{t}_{2}$, will decrease. ${ }^{23}$

The demand distribution corresponds to the skills required by firms. As in Tinbergen, we assume that the demand frequency distribution is inelastic such that changes in the income scale do not affect the demand distribution of required skills. Suppose that all tasks that require skills $\left\langle s_{1}, s_{2}\right\rangle$ such that $\frac{s_{2}}{s_{1}}>\lambda$ define a job in occupation 2 and all tasks that require skills such that $\frac{s_{2}}{s_{1}} \leq \lambda$ define a job in occupation 1 . The index line $I_{s}$, i.e. $s_{2}=\lambda s_{1}$, partitions the demand ellipse $m$ on a slant such that a task $i$, whose required skills point $\left\langle s_{i 1}, s_{i 2}\right\rangle$ lies above $I_{s}$, defines a job in occupation 2 and vice versa.

From Figure 2.4, we can see that the relationship between education and

ings that are related with it. Thus education may partly reflect some of the causes that enable some people more than others to complete a certain level of schooling, such as innate intelligence, perseverance and the environment in which an individual has grown up. Education also reflects whatever financial accommodation is made available by the community of the availability of schools of the type needed sufficiently close to a given individual.

\footnotetext{
${ }^{23}$ Note that the variances and covariance of the distribution, may change too. Since this depends on the before-shock distribution it will not be treated here.
} 


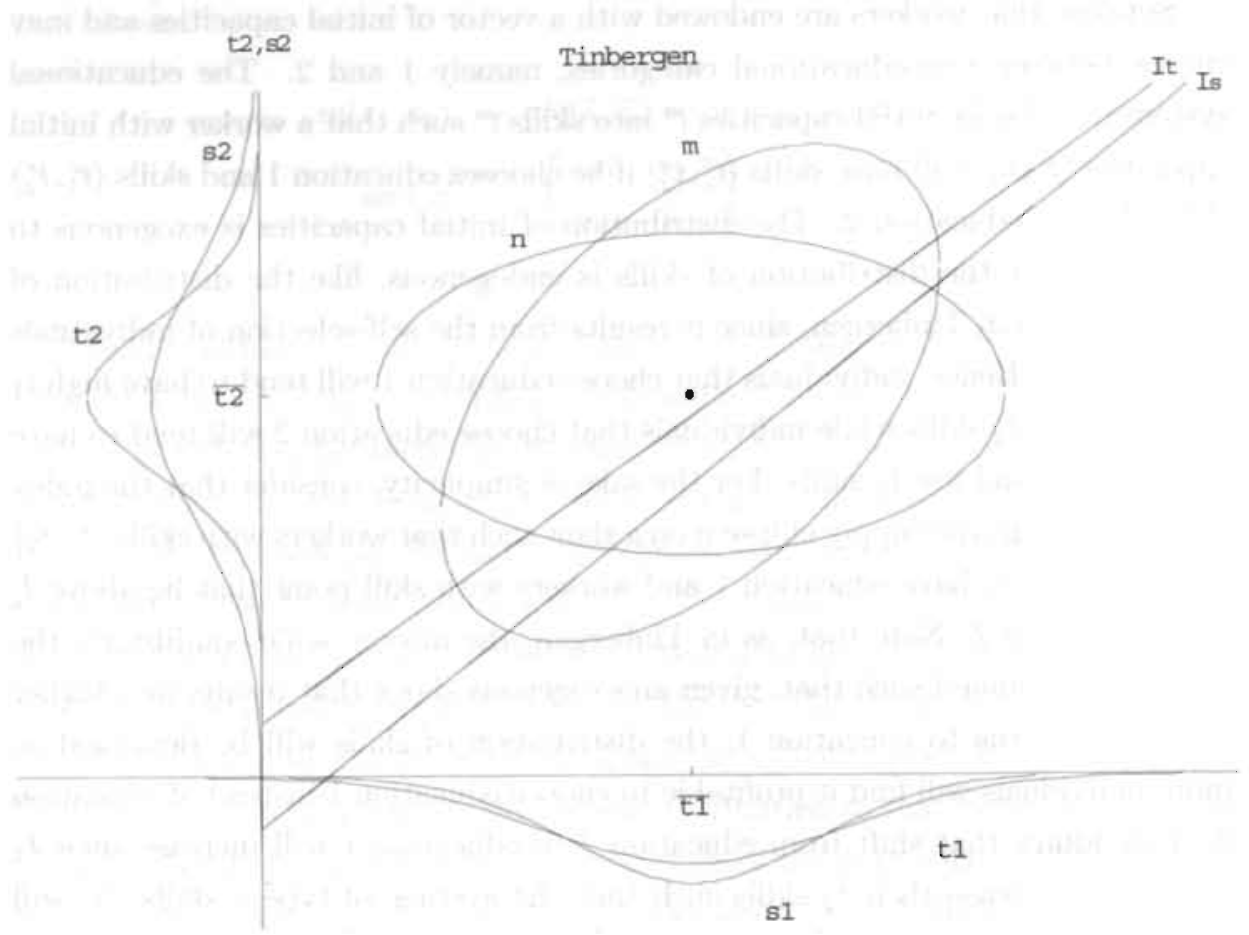

Figure 2.4: The allocation problem and the mapping of abilities required and. actual abilities.

occupation is no longer exclusive but overlaps. This arises since the demand distribution of required skills in occupation 1. and 2 does in general differ from the supply distribution of actual skills in education 1 and 2 that results from selfselection on the supply side. The allocation model is characterised by workers with education 1 finding work in both occupations, whereas the jobs in occupation 1 are held by workers with different educational backgrounds. There is an allocation problem inherent in the labour market that depends on both the selfselection of individuals in education according to their comparative advantage and the mapping of skill requirements and the skills of workers.

The demand for workers in each occupation and the supply of workers by education are balanced through the allocation process which yields equilibrium wage rates by education. In principle, there does not need to be an identity relationship between a worker's actual education and required education. Since 
each individual will try to get the best job and, inversely, each firm offering a job will try to recruit the best person for the job concerned, it seems natural that the allocation process will result in the mapping of supply and demand.

\subsection{Allocation model: A demand approach with heterogeneity of workers and jobs}

\subsubsection{Tasks assignment model with several types of work- ers and occupations}

To improve our understanding of the substitution process, we develop an allocation model that builds on Rosen's tasks assignment model (Rosen (1978)). In our model, jobs belong to a small number of occupational types and each job refers to a certain task. However, in contrast to Rosen's one-occupation model with a single continuum of tasks, we consider several occupations. This enables us to analyse the allocation of workers with various educational backgrounds to various occupations. Each occupation is also characterised by a different continuum of tasks. Moreover, there is a discrete number of educational types of workers and workers of the same type have homogeneous skills. The type of a worker refers to his or her education. The supply of labour is assumed to be exogenous, perfectly elastic to wages and does not affect the distribution of comparative advantage among educational types of workers. In that sense, the model focuses essentially on the demand for labour. The problem is to find an assignment of the various tasks of each occupation to educational types of workers in order to maximise output.

For the sake of simplicity, we consider two occupations, namely occupations 1 and 2 , and two types of workers, workers with education 1 and workers with education 2. Suppose that the productivity of a worker with education $j$ at task $r$ of occupation $i$ is given by $s_{r, i j}$. We rank the tasks of occupations 1 and 2 by workers' comparative advantage. We define two continuous indices $v_{1}=$ $g\left(s_{11}, s_{12}\right)$ and $v_{2}=h\left(s_{21}, s_{22}\right)$ on $(0,1)$ with partial derivatives $g_{s_{11}}<0, g_{s_{12}}>0$ and $g_{s_{11} s_{12}}<g_{s_{11}} \times g_{s_{12}}$ and $h_{s_{21}}<0, h_{s_{22}}>0$ and $h_{s_{21} s_{22}}<h_{s_{21}} \times h_{s_{22}}$. These continuums indicate that workers with education 1 have a comparative advantage in tasks close to 0 of both occupation 1 and 2 and workers with education 2 have a comparative advantage in tasks close to 1 of both occupations. The continuum 
Table 2.2: The structure of assignment and the marginal tasks.

\begin{tabular}{lc|cc}
\hline \hline & & Education & \\
& Tasks & 1 & 2 \\
\hline Occupation 1 & $v<\varepsilon_{1}$ & $*$ & \\
& $v \geq \varepsilon_{1}$ & & $*$ \\
\hline Occupation 2 & $v<\varepsilon_{2}$ & $*$ & \\
& $v \geq \varepsilon_{2}$ & & $*$ \\
\hline \hline
\end{tabular}

$v_{i}$ partitions the spectrum of the tasks of occupation $i$ in the following way. Let $1 / \pi_{i j}\left(v_{i}\right)$ measure the productivity in 'efficiency units' of a worker of type $j$ at task $v_{i}$ of occupation $i^{24}$ The productivity of workers with education 1 relative to workers with education 2, defined by the function $q\left(v_{i}\right)=\pi_{i 2}\left(v_{i}\right) / \pi_{i 1}\left(v_{i}\right)$, is therefore increasing in $v_{i}$ (i.e. $q^{\prime}>0$ ). Given the wage rates of the two types of workers, $w_{1}$ and $w_{2}$, we define the task $\varepsilon_{i}$ with $\varepsilon_{i} \in(0,1)$ such that the tasks $v_{i}<\varepsilon_{i}$ of occupation $i$ are assigned to workers with education $i$, i.e. $q\left(v_{i}<\varepsilon_{i}\right)<\frac{w_{1}}{w_{2}}, q\left(\varepsilon_{i}\right)=\frac{w_{1}}{w_{2}}$ and $q\left(v_{i}>\varepsilon_{i}\right)>\frac{w_{1}}{w_{2}}$.

The structure of assignment given the relative productivity of both types of workers in the marginal tasks in occupation 1, i.e. $\varepsilon_{1}$, and occupation 2, i.e. $\varepsilon_{2}$, is reported in Table 2.2. In occupation 1, workers with education 1 perform tasks $v_{1}<\varepsilon_{1}$ and workers with education 2 perform tasks $v_{1} \geq \varepsilon_{1}$. In occupation 2, workers with education 1 perform tasks $v_{2}<\varepsilon_{2}$ and workers with education. 2 perform tasks $v_{2} \geq \varepsilon_{2}$.

The unit isoquant is defined by integrating the demand for workers per unit of output over the spectrum $v$.

\footnotetext{
${ }^{24}$ Note that for a task $r$ of occupation 1 such that $v_{1}=g\left(s_{r, 11}, s_{r, 12}\right)$ we have $\ln \frac{1}{\pi_{1 j}\left(v_{1}\right)}=s_{r, 1 j}$ for $j=1$ 2. Idem a task $r$ of occupation 2 such that $v_{2}=h\left(s_{r, 21}, s_{r, 22}\right)$ yields $\ln \frac{1}{\pi_{2 j}\left(v_{2}\right)}=s_{r, 2 j}$ for $j=1,2$.
} 


$$
\begin{aligned}
\frac{L_{11}}{H} & =\int_{0}^{\varepsilon_{1}} \pi_{11}\left(v_{1}\right) \cdot d v_{1} \\
\frac{L_{12}}{H} & =\int_{\varepsilon_{1}}^{1} \pi_{12}\left(v_{1}\right) \cdot d v_{1} \\
\frac{L_{21}}{H} & =\int_{0}^{\varepsilon_{2}} \pi_{21}\left(v_{2}\right) \cdot d v_{2} \\
\frac{L_{22}}{H} & =\int_{\varepsilon_{2}}^{1} \pi_{22}\left(v_{2}\right) \cdot d v_{2}
\end{aligned}
$$

where $H$ is the output level, and $L_{i j}$ is the number of workers with education $j$ in occupation $i$.

Knowing the functional form of the demand per unit of output allows us to infer the form. of the indirect production function nested in the unit isoquant defined above. In order to infer further on the assignment of tasks to workers, the following demand for workers per unit of output is adopted: ${ }^{25}$

$$
\begin{aligned}
& \pi_{11}\left(v_{1}\right)=\frac{1}{\beta_{e}}\left(\frac{\lambda}{b_{1}}\right)^{1 / \beta_{o}} a_{11}^{-1 / \beta_{e}} v_{1}^{1 / \beta_{e}-1} \\
& \pi_{1.2}\left(v_{1}\right)=\frac{1}{\beta_{e}}\left(\frac{\lambda}{b_{1}}\right)^{1 / \beta_{o}} a_{12}^{-1 / \beta_{e}}\left(1-v_{1}\right)^{1 / \beta_{e}-1} \\
& \pi_{21}\left(v_{2}\right)=\frac{1}{\beta_{e}}\left(\frac{1-\lambda}{b_{2}}\right)^{1 / \beta_{o}} a_{21}^{-1 / \beta_{e}} v_{2}^{1 / \beta_{e}-1} \\
& \pi_{22}\left(v_{2}\right)=\frac{1}{\beta_{e}}\left(\frac{1-\lambda}{b_{2}}\right)^{1 / \beta_{o}} a_{22}^{-1 / \beta_{e}}\left(1-v_{2}\right)^{1 / \beta_{e}-1}
\end{aligned}
$$

where $\frac{b_{1}}{\lambda}$ and $\frac{b_{2}}{1-\lambda}$ measure occupation-specific efficiency units, ${ }^{26} b_{i}$ are constant and $\beta_{e} \in(0,1)$ and $\beta_{o} \in(-\infty, 1)$. The parameters $a_{i j}$ are productivity parameters reflecting the range of tasks that workers with education $j$ can perform in occupation $i$.

\footnotetext{
${ }^{25}$ Our model reduces to Rosen (1978)'s model when: $\varepsilon_{1}=\varepsilon_{2}=\varepsilon$ and $\frac{\lambda}{b_{1}}=\frac{1-\lambda}{b}, a_{11}=$ const $_{1} \times a_{21}$ and $a_{12}=$ const $_{2} \times a_{22}$ and $\beta_{o}=1$. This means that although we differentiate between the tasks in occupations 1 and 2 , they are actually identical at a constant proxy.

${ }^{26}$ The closer $\lambda$ is to 0 , the larger the efficiency units in occupation 1 . The closer $\lambda$ is to 1 , the larger the efficiency units in occupation 2. Hence, $\lambda$ indicates the relative efficiency units in occupation 2.
} 
Given the specification of demand per unit of output defined in equation 2.6, the unit isoquant reads as:

$$
\begin{aligned}
\frac{L_{11}}{H} & =\left(\frac{\lambda}{b_{1}}\right)^{1 / \beta_{o}} a_{11}^{-1 / \beta_{e}} \varepsilon_{1}^{1 / \beta_{e}} \\
\frac{L_{12}}{H} & =\left(\frac{\lambda}{b_{1}}\right)^{1 / \beta_{o}} a_{12}^{-1 / \beta_{e} e}\left(1-\varepsilon_{1}\right)^{1 / \beta_{e}} \\
\frac{L_{21}}{H} & =\left(\frac{1-\lambda}{b_{2}}\right)^{1 / \beta_{o}} a_{21}^{-1 / \beta_{e}} \varepsilon_{2}^{1 / \beta_{e}} \\
\frac{L_{22}}{H} & =\left(\frac{1-\lambda}{b_{2}}\right)^{1 / \beta_{o}} a_{22}^{-1 / \beta_{e}}\left(1-\varepsilon_{2}\right)^{1 / \beta_{e}}
\end{aligned}
$$

Solving the system for $\varepsilon_{1}, \varepsilon_{2}$ and $\lambda$ and simplifying we have:

$$
H=\left[b_{1}\left[a_{11} L_{11}^{\beta_{e}}+a_{12} L_{12}^{\beta_{e}}\right]^{\beta_{e} / \beta_{e}}+b_{2}\left[a_{21} L_{21}^{\beta_{e}}+a_{22} L_{22}^{\beta_{e}}\right]^{\beta_{o} / \beta_{e}}\right]^{1 / \beta_{\sigma}}
$$

Equation (2.7) is a two-level CES production function (see Sato (1967)). A nested CES production function with an allocation problem of workers with educational backgrounds 1 and 2 to occupations 1 and 2. This production function has 6 noteworthy special cases:

i) when $\beta_{0} \rightarrow-\infty$ and $\beta_{e} \rightarrow 0$ we have a Leontief-Cobb-Douglas production function,

ii) when $\beta_{o} \rightarrow-\infty$ and $\beta_{e} \rightarrow 1$ we have a Leontief-Linear production function,

iii) when $\beta_{o} \rightarrow 0$ and $\beta_{e} \rightarrow 0$ we have a, Cobb-Douglas-Cobb-Douglas production function,

iv) when $\beta_{o} \rightarrow 0$ and $\beta_{e} \rightarrow 1$ we have a Cobb-Douglas-Linear production function,

v) when $\beta_{o} \rightarrow 1$ and $\beta_{e} \rightarrow 0$ we have a Linear-Cobb-Douglas production function and

vi) when $\beta_{o} \rightarrow 1$ and $\beta_{e} \rightarrow 1$ we have a Linear-Linear production function. 


\subsection{ALLOCATION MODEL: A DEMAND APPROACH}

Equation 2.7 is a CES production function. ${ }^{27}$ This extension of Rasen's (1978) indirect production function indicates that comparative advantages of workers imply imperfect substitution between the two educational types of workers within each occupation. The elasticity of substitution between the two educational types of workers at the marginal task of each occupation is given by $\sigma=\frac{1}{1-\beta}$ and is constant for all marginal tasks of each occupation.

Furthermore, using the marginal condition of perfect competition in both the labour and product markets, $\partial H / \partial L_{i j}=w_{j}$, we can solve for the marginal task in occupation 1, i.e. $\varepsilon_{1}$ and the marginal task in occupation 2, i.e. $\varepsilon_{2}$ as well as the relative efficiency units between occupations 2 and 1, i.e. $\lambda$ as a function of the parameters and the relative wage rates $w_{j}$ as follows:

$$
\begin{aligned}
& z_{1}\left(w_{2} / w_{1}\right) \equiv \varepsilon_{1}=a_{11}^{\sigma_{e}}\left(a_{11}^{\sigma_{e}}+a_{12}^{\sigma_{e}}\left(\frac{w_{2}}{w_{1}}\right)^{1-\sigma_{e}}\right)^{-1} \\
& z_{2}\left(w_{2} / w_{1}\right) \equiv \varepsilon_{2}=a_{21}^{\sigma_{e}}\left(a_{21}^{\sigma_{e}}+a_{22}^{\sigma_{e}}\left(\frac{w_{2}}{w_{1}}\right)^{1-\sigma_{e}}\right)^{-1}
\end{aligned}
$$

and

$$
\begin{aligned}
z_{3}\left(w_{2} / w_{1}\right) \equiv & \lambda=b_{1}^{\sigma_{\odot}}\left(a_{11}^{\sigma_{e}}+a_{12}^{\sigma_{e}}\left(\frac{w_{2}}{w_{1}}\right)^{1-\sigma_{e}}\right)^{\frac{1-\sigma_{e}}{1-\sigma_{e}}} \\
& \times\left(\begin{array}{c}
b_{1}^{\sigma_{\sigma}}\left(a_{11}^{\sigma_{e}}+a_{12}^{\sigma_{\varepsilon}}\left(\frac{w_{2}}{w_{1}}\right)^{1-\sigma_{e}}\right)^{\frac{1-\sigma_{e}}{1-\sigma_{e}}} \\
\left.+b_{2}^{\sigma_{\sigma}}\left(a_{21}^{\sigma_{e}}+a_{22}^{\sigma_{e}}\left(\frac{w_{2}}{w_{1}}\right)^{1-\sigma_{e}}\right)^{\frac{1-\sigma_{e}}{1-\sigma_{e}}}\right)^{-1}
\end{array}\right.
\end{aligned}
$$

where $\sigma_{e}=\frac{1}{1-\beta_{e}}$ and $\sigma_{o}=\frac{1}{1-\beta_{o}}$

Since $\sigma_{e}>1$, an increase in the wage rate of workers with education 2 relative

\footnotetext{
${ }^{27}$ In general, solving the system yields Rosen's indirect production function. Imposing the worker demand per unit of output as in equation 2.6 yields the CES form.
} 
to the wage rate of workers with education 1 shifts $\varepsilon_{1}$ and $\varepsilon_{2}$ upward. Because workers with education 2 become relatively more expensive, they are assigned only to those tasks in which they excel. Workers with education 1 will perform a wider range of tasks whereas workers with education 2 will perform a narrower range of tasks. This implies that in both occupations, the productivity of workers with education 2 will increase.

Though quite complicated when expressed in terms of wage rates, the ratio of efficiency units between occupations 2 and $1, \lambda$, can be relatively readily expressed in terms of the marginal tasks in occupations 1 and 2. In Appendix $A$ of this chapter we show that the relative efficiency unit, $\lambda$, shifts toward 1 or 0 as a response to a positive shift in the ratio $\varepsilon_{2} / \varepsilon_{1}$, regarding the relative magnitude of the technology parameters of substitution $\sigma_{0}$. Two cases are classified. An increase in the ratio of the marginal task in occupation 2 to the marginal task in occupation 1, i.e. an upward shift in $\varepsilon_{2} / \varepsilon_{1}$, will shift the relative efficiency units toward 0 when the parameter of substitution between occupations is larger than unity whereas it will shift the relative efficiency units toward 1 when the parameter of substitution between occupations is smaller than unity. Therefore, if $\sigma_{o}>1$, a shift in the relative wage rate that results in an increase of the ratio of the marginal task in occupation 2 induces a relative increase of the efficiency units in occupation 1 . Since workers in occupation 1 produce output more efficiently, the demand for workers in occupation 1 decreases at constant output level. Otherwise, the exogenous shock will induce a relative increase of the efficiency units in occupation 2.

The model we developed in this section offers a very convenient way to estimate the degree of substitution between workers in the labour market resulting from the assignment of workers to tasks. This estimation can simply be done by estimating the respective demand for workers by educational group and occupation as derived from a two-level CES production function.

\subsubsection{Tasks assignment and workers' self-selection}

An obvious extention of the model is to combine the heterogeneity of workers and jobs like in Tinbergen's model. In this section we therefore generalise our model by releasing the assumption that within educational groups workers are homogeneous. This requires to assume that workers have perfect foresight, as in Willis and Rosen (1979)'s application of Roy's model to educational choice. In 
this extension of our model, analogous to Tinbergen (1956), both workers and jobs are heterogeneous with respect to both workers' skills and the skills that jobs require. However, in contrast to Tinbergen, we will focus on the demand for labour by solving for the assignment of workers to jobs that maximises firms' production. We further distinguish several categories of education and occupation, and model the allocation of workers with different educational backgrounds to the various occupations. The supply-side determinants are given by the levels of the various types of skill that workers are endowed with whereas the demandside determinants are defined by the levels of the various types of skill that tasks require. As in the model of section 2.6.1, the allocation problem is characterised by a matrix containing the distribution of workers by education to the various occupations. However, each educational group is composed of workers that are heterogeneous in terms of their skills and each occupational group is composed of tasks that are heterogeneous with respect to the skills they require. Therefore, the optimal assignment of the tasks belonging to each occupation to workers in each educational group leads to the presence of workers with different educational backgrounds in a particular occupation and the presence of workers with the same educational background in various occupations. The optimal assignment of tasks changes as the wage rates by educational groups change through the supply and demand adjustment process.

Suppose workers are endowed with initial capacities $t=\left\langle t_{1}, t_{2}\right\rangle$ where for instance $t_{1}$ and $t_{2}$ represent an individual's strength and intelligence, respectively, and define $s=\left\langle s_{1}, s_{2}\right\rangle$ the skills that tasks require. ${ }^{28}$ We define the continuous index $u=f\left(t_{1}, t_{2}\right)$ on $(0,1)$, with partial derivatives $f_{t_{1}}<0, f_{t_{2}}>0$ and $f_{t_{1} t_{2}} \gtrless$ 0 , such that workers are ranked by their educational comparative advantage. ${ }^{29}$ The continuum $u$ indexes a worker's initial endowments $t=\left\langle t_{1}, t_{2}\right\rangle$ such that individuals with a large initial capacity of type 2 compared to type 1 have a comparative advantage in education 2 and individuals with a large type 1 initial capacity compared to their type 2 initial capacity have a comparative advantage in education 1.

Similarly, we define the continuous index $v=g\left(s_{1}, s_{2}\right)$ (with partial derivatives $g_{s_{1}}<0, g_{s_{2}}>0$ and $g_{s_{1} s_{2}} \gtrless 0$ ) such that workers are ranked by their occupational

\footnotetext{
${ }^{28}$ Note that the definitions of $t$ and $s$ correspond with the definitions used in Section 2.5 to describe Tinbergen's model.

${ }^{29}$ For instance, think of $f$ as: $f\left(t_{1}, t_{2}\right)=\frac{t_{2}}{t_{1}+t_{1}}$.
} 
comparative advantage. The continuum $v$ indexes a task of required skills $s=$ $\left\langle s_{1}, s_{2}\right\rangle$ such that workers with education 1 have a comparative advantage in tasks that require relatively more type 1 skills, i.e. $v$ is close to 0 , and workers with education 2 have a comparative advantage in tasks that require relatively more type 2 skills, i.e. $v$ is close to 1 .

The indexes $u$ and $v$ offer a convenient ordering of both workers and tasks by comparative advantage. ${ }^{30}$ Let $1 / \pi_{i j}(u, v)$ measure, in efficiency units, the productivity of a worker with initial endowments $u$ if he chooses education $j$ and is assigned to task $v$ of occupation $i$. Assume that the $\pi_{i j}$ are such that the function $p_{i}(u)=\pi_{i 2}(u) / \pi_{i 1}(u)$ is decreasing in $u$ (i.e. $\left.p_{i}^{\prime}<0\right)$ in both occupations. Then workers with endowed capacities $u$ close to 0 have a comparative advantage in choosing education 1 and workers with endowed capacities close to 1 have a comparative advantage in education 2. Moreover, assume that the function $q_{j}(v)=\pi_{2 j}(v) / \pi_{1 j}(v)$ is decreasing in $v$ (i.e. $q_{j}^{\prime}<0$ ) so that occupation 1 is composed of tasks $v$ close to 0 and occupation 2 is composed of tasks $v$ closed to 1 . Furthermore, assume that workers with education 1 have a comparative advantage in occupation 1 and workers with education 2 have a comparative advantage in occupation $2, q_{1}(v) / q_{2}(v)>1$.

Assuming that free choice and competitive markets assign people efficiently, the relative wages are such that the optimal assignment of workers to tasks is characterised by three variables $\lambda_{1}, \lambda_{2}$ and $\varepsilon$. Variables $\lambda_{1}, \lambda_{2}$ and $\varepsilon$ depend on the relative wages. The structure of assignment given $\lambda_{1}, \lambda_{2}$ and $\varepsilon$ is reported in Table 2.3. Variable $\lambda_{1}$ indicates the lowest ratio of capacities of type 1 to type 2 of a worker with education 2 assigned to occupation 1. Variable $\lambda_{2}$ indicates the lowest ratio of capacities of type 1 to type 2 of a worker with education 2 assigned to occupation 2. Variable $\varepsilon$ indicates the lowest ratio of skills of type 1 to type 2 that a task in occupation 2 requires.

The individuals' self-selection of education is such that individuals with initial capacities $u \leq \min \left(\lambda_{1}, \lambda_{2}\right)$ choose education 1 , individuals with initial capacities $u \geq \max \left(\lambda_{1}, \lambda_{2}\right)$ choose education 2 and some individuals with initial capacities $\min \left(\lambda_{1}, \lambda_{2}\right)<u<\max \left(\lambda_{1}, \lambda_{2}\right)$ choose education 1 whereas the others choose education $2{ }^{31}$ Occupation 1 consists of the tasks of required skills $v<\varepsilon$ and

\footnotetext{
${ }^{30}$ Rosen (1978) and Macdonald (1982) use a single index to order tasks by comparative advantage. Teulings (1995a, 1995b and 2002) uses a joint density function of worker type and job type.

${ }^{31}$ This raises the question why individuals with equal comparative advantage, equal $u$, make
} 
Table 2.3: The structure of assignment, the marginal worker and the marginal task.

\begin{tabular}{|c|c|c|c|c|c|c|}
\hline & \multirow{2}{*}{\multicolumn{2}{|c|}{$\begin{array}{l}\text { Capacities } \\
\text { Required. skills }\end{array}$}} & \multicolumn{4}{|l|}{ Education } \\
\hline & & & $\begin{array}{c}1 \\
u<\lambda_{1}\end{array}$ & $\begin{array}{c}2 \\
u \geq \lambda_{1}\end{array}$ & $\begin{array}{c}1 \\
u<\lambda_{2}\end{array}$ & $\begin{array}{c}2 \\
u \geq \lambda_{2}\end{array}$ \\
\hline Occupation & $\begin{array}{l}1 \\
2\end{array}$ & $\begin{array}{l}v<\varepsilon \\
v \geq \varepsilon\end{array}$ & * & * & * & $*$ \\
\hline
\end{tabular}

occupation 2 consists of the tasks of required skills $v \geq \varepsilon$.

The unit isoquant is defined by integrating the demand for workers per unit of output over the spectrums $u$ and $v$.

$$
\begin{aligned}
\frac{L_{I 1}}{H} & =\int_{0}^{\varepsilon} \int_{0}^{\lambda_{1}} \pi_{11}(u, v) \cdot d u \cdot d v \\
\frac{L_{12}}{H} & =\int_{0}^{\varepsilon} \int_{\lambda_{1}}^{1} \pi_{12}(u, v) \cdot d u \cdot d v \\
\frac{L_{21}}{H} & =\int_{\varepsilon}^{1} \int_{0}^{\lambda_{2}} \pi_{21}(u, v) \cdot d u \cdot d v \\
\frac{L_{22}}{H} & =\int_{\varepsilon}^{1} \int_{\lambda_{2}}^{1} \pi_{22}(u, v) \cdot d u \cdot d v
\end{aligned}
$$

Knowing the functional form of the demand per unit of output allows us to infer the form of the indirect production function nested in the unit isoquant defined above. In order to infer further on the assignment of tasks to workers, the following demand for workers per unit of output is adopted: ${ }^{32}$

different choices. The problem can be solved be recognising that two individuals with the same relative capacities, the same $u$, need not have the same capacities. Indeed, a person that is twice as strong as intelligent need not be as strong as another person twice as strong as intelligent. We assume that if two individuals have the same relative initial capacities $u$, and $\min \left(\lambda_{1}, \lambda_{2}\right)<u<\max \left(\lambda_{1}, \lambda_{2}\right)$, the individual with an absolute advantage in education 1 , that is the individual with the largest capacity of type 1 , will choose education 1 and vice versa.

${ }^{32}$ Given the demand for workers per unit of output as in equation 2.11 , for $p_{i}(u)$ and $q_{j}(v)$ to decrease with $u$ and $v$ respectively, $q_{j}^{\prime}<0, p_{i}^{\prime}<0$, we need $\beta_{o}, \beta_{e} \in(0,1)$. 


$$
\begin{aligned}
\pi_{11}(u, v) & =\frac{1}{\beta_{o}} \frac{1}{\beta_{e}} b_{1}^{-1 / \beta_{o}} a_{11}^{-1 / \beta_{e}} u^{1 / \beta_{e}-1} v^{1 / \beta_{\mathrm{o}}-1} \\
\pi_{12}(u, v) & =\frac{1}{\beta_{o}} \frac{1}{\beta_{e}} b_{1}^{-1 / \beta_{o}} a_{12}^{-1 / \beta_{e}}(1-u)^{1 / \beta_{e}-1} v^{1 / \beta_{\mathrm{o}}-1} \\
\pi_{21}(u, v) & =\frac{1}{\beta_{o}} \frac{1}{\beta_{e}} b_{2}^{-1 / \beta_{o}} a_{21}^{-1 / \beta_{e}} u^{1 / \beta_{e}-1}(1-v)^{1 / \beta_{\mathrm{o}}-1} \\
\pi_{22}(u, v) & =\frac{1}{\beta_{o}} \frac{1}{\beta_{e}} b_{2}^{-1 / \beta_{\mathrm{o}}} a_{22}^{-1 / \beta_{e}}(1-u)^{1 / \beta_{e}-1}(1-v)^{1 / \beta_{\mathrm{o}}-1}
\end{aligned}
$$

Note that Willis and Rosen's extension of Roy's model can be compared with our model by imposing $a_{i j}=0$ for all $i \neq j$. In this case, people choose an educational sector and get a job in the corresponding occupation.

Given the specification of demand per unit of output defined in equation 2.11, the unit isoquant reads as:

$$
\begin{aligned}
& \frac{L_{11}}{H}=b_{1}^{-1 / \beta_{o}} a_{11}^{-1 / \beta_{e}} \lambda_{1}^{1 / \beta_{e}} \varepsilon^{1 / \beta_{o}} \\
& \frac{L_{12}}{H}=b_{1}^{-1 / \beta_{o}} a_{12}^{-1 / \beta_{e}}\left(1-\lambda_{1}\right)^{1 / \beta_{e}} \varepsilon^{1 / \beta_{o}} \\
& \frac{L_{21}}{H}=b_{2}^{-1 / \beta_{o}} a_{21}^{-1 / \beta_{e}} \lambda_{2}^{1 / \beta_{e}}(1-\varepsilon)^{1 / \beta_{o}} \\
& \frac{L_{22}}{H}=b_{2}^{-1 / \beta_{o}} a_{22}^{-1 / \beta_{e}}\left(1-\lambda_{2}\right)^{1 / \beta_{e}}(1-\varepsilon)^{1 / \beta_{o}}
\end{aligned}
$$

where $\beta_{e}, \beta_{o} \in(0,1)$.

Solving the system for $\lambda_{1}, \lambda_{2}$ and $\varepsilon$ and simplifying we have:

$$
H=\left[b_{1}\left[a_{11} L_{11}^{\beta_{e}}+a_{12} L_{12}^{\beta_{e}}\right]^{\beta_{o} / \beta_{e}}+b_{2}\left[a_{21} L_{21}^{\beta_{e}}+a_{22} L_{22}^{\beta_{e}}\right]^{\beta_{o} / \beta_{e}}\right]^{\mathrm{I} / \beta_{o}}
$$

As indicated by equation 2.12, the production function is a two-level CES production function similar to the production function of the allocation model developed in Section 2.6.1. In contrast to the model of section 2.6.1, in the generalised model workers with the same education are heterogeneous with respect to their skills and therefore differ in their productivity and wages at equivalent 
task and occupation. However, the structure of factor substitution is identical in both models.

The marginal condition of perfect competition in both the labour and product markets, $\partial H / \partial L_{i j}=w_{j}$, enables us to solve for the initial capacities of the marginal worker (with education 2) in occupation 1 , i.e. $\lambda_{1}$, and the initial capacities of the marginal worker in occupation 2 , i.e. $\lambda_{2}$, as well as the relative skills required in the marginal task, i.e. $\varepsilon$, as a function of the parameters and the relative wage rates $w_{j}$ as follows:

$$
\begin{aligned}
& z_{1}\left(w_{2} / w_{1}\right) \equiv \lambda_{1}=a_{11}^{\sigma_{e}}\left(a_{11}^{\sigma_{e}}+a_{12}^{\sigma_{e}}\left(\frac{w_{2}}{w_{1}}\right)^{1-\sigma_{e}}\right)^{-1} \\
& z_{2}\left(w_{2} / w_{1}\right) \equiv \lambda_{2}=a_{21}^{\sigma_{e}}\left(a_{21}^{\sigma_{e}}+a_{22}^{\sigma_{e}}\left(\frac{w_{2}}{w_{1}}\right)^{1-\sigma_{e}}\right)^{-1}
\end{aligned}
$$

and

$$
\begin{aligned}
& z_{3}\left(\lambda_{2} / \lambda_{1}\right) \equiv \varepsilon=b_{1}^{\sigma_{\circ}}\left(a_{11}^{\sigma_{e}}+a_{12}^{\sigma_{e}}\left(\frac{w_{2}}{w_{1}}\right)^{1-\sigma_{e}}\right)^{\frac{1-\sigma_{0}}{1-\sigma_{e}}} \\
& \times\left(\begin{array}{c}
b_{1}^{\sigma_{\circ}}\left(a_{11}^{\sigma_{e}}+a_{12}^{\sigma_{e}}\left(\frac{w_{2}}{w_{1}}\right)^{1-\sigma_{\epsilon}}\right)^{\frac{1-\sigma_{\rho}}{1-\sigma_{e}}} \\
+b_{2}^{\sigma_{\circ}}\left(a_{21}^{\sigma_{e}}+a_{22}^{\sigma_{e}}\left(\frac{w_{2}}{w_{1}}\right)^{1-\sigma_{e}}\right)^{\frac{1-\sigma_{\rho}}{1-\sigma_{e}}}
\end{array}\right)^{-1}
\end{aligned}
$$

where $\sigma_{e}=\frac{1}{1-\beta_{e}}$ and $\sigma_{o}=\frac{1}{1-\beta_{o}}$

An increase in the relative wage rate of workers with education 2 compared to workers with education 1 shifts $\lambda_{1}$ and $\lambda_{2}$ upward. The index of initial capacities of a worker $u=f\left(t_{1}, t_{2}\right)$ increases with the initial capacity of type 2 and decreases with the initial capacity of type 1 . This implies that the ratio of capacities of type 2 relative to type 1 of the marginal worker in both occupations tends to increase as the wage rate of workers with education 2 increases. It follows that an increase of the relative wage of workers with education 2 is accompanied with a relative increase in the level of type 2 capacity of individuals selecting education 
2. The demand for workers with education 1 increases as the relative wage rate decreases. ${ }^{33}$

In Appendix B of this chapter we show that an increase in the ratio of the capacities of the marginal worker in occupation 2 compared to that of the marginal. worker in occupation 1, i.e. upward shift in $\lambda_{2} / \lambda_{1}$, will shift the relative skill required in the marginal task toward 0 . Therefore, a shift in the relative wage rate that results in an increase of the ratio of the capacities of the marginal worker in occupation 2 to the capacities of the marginal worker in occupation 1 induces a relative increase of the level of type 2 skill required in occupation 2 .

\subsection{Summary and conclusion}

In this chapter, we discussed the assignment of heterogeneous workers to heterogeneous jobs in relation to the substitution process in the labour market. To analyse the role of the allocation structure in the substitution process and thereby its impact on labour demand, productivity and the wage structure, we developed an allocation model. This model is an extension of Rosen's (1978) tasks assignment model in which several occupations are considered and each occupation has a different continuum of tasks. We have shown that the assignment of workers with various educational backgrounds to heterogeneous tasks of several occupations can be formalised in an allocation model by specifying a two-level constant elasticity of substitution (CES) production function.

The model presented admits two noteworthy special cases. Using a one-level CES production function and differentiating workers according to their education. only (or their occupation only) is comparable to Rosen (1978). Using a two-level Cobb-Douglas-Linear production function leads to the production function used in Timbergen (1973).

The model we developed in Section. 2.6.1. shows for instance that an increase of the relative wage of workers with education 2 is accompanied with an increase in the relative productivity of workers with education 2 . Workers with education 1 will perform a wider range of tasks whereas workers with education 2 will perform a narrower range of tasks. Moreover, a shift in the relative wage rate

\footnotetext{
${ }^{33}$ In Rosen, $\sigma_{o}>1$ such that an increase in relative wage rate $\left(w_{2} / w_{1}\right)$ shifts $\varepsilon$ upward. The relative skill required in the marginal task shifts toward 1 implying that workers of type 1 will perform a wider range of tasks whereas workers of type 2 will perform a narrower range of tasks.
} 
that results in an increase of the ratio of the marginal task in occupation 2 to the marginal task in occupation 1 induces a relative increase of the efficiency units in occupation 1 if the parameter of substitution between occupations is larger than unity. This increase in efficiency units reduces the demand for workers in occupation 1 at constant output level.

In Section 2.6 .2 we generalised this model by releasing the assumption that within educational groups workers are homogeneous. In this model workers and jobs are, similar to Tinbergen (1956), heterogeneous with respect to both workers' skills and the skills that jobs require. The generalised model shows for instance that an increase in the wage of workers with education 2 relative to workers with education 1 is accompanied by a relative increase in the level of type 2 capacity of the individuals that select education 2. In contrast to the model of section 2.6.1, in the generalised model workers with the same education are heterogeneous with respect to their skills and therefore earn different wages at equivalent task and occupation. However, the generalised model does not allow for supply fluctuations because it requires to assume that individuals have perfect foresight. Moreover, the structure of factor substitution underlying the assignment of heterogeneous workers to heterogeneous tasks is similar to the structure of factor substitution in the model of section 2.6.1. Therefore, the model of section 2.6 .1 will be preferred to the generalised model for the empirical analyses of this study. 


\section{Appendix A. Elasticity of substitution and effi- ciency units between occupations}

$$
z_{1}^{\prime}\left(w_{2} / w_{1}\right)=-\left(1-\sigma_{e}\right) \cdot a_{11}^{\sigma_{e}} \cdot a_{12}^{\sigma_{e}} \cdot\left(\frac{w_{2}}{w_{1}}\right)^{-\sigma_{e}}\left(a_{11}^{\sigma_{e}}+a_{12}^{\sigma_{e}}\left(\frac{w_{2}}{w_{1}}\right)^{1-\sigma_{e}}\right)^{-2}
$$

and

$$
z_{2}^{\prime}\left(w_{2} / w_{1}\right)=-\left(1-\sigma_{e}\right) \cdot a_{21}^{\sigma_{e}} \cdot a_{22}^{\sigma_{e}} \cdot\left(\frac{w_{2}}{w_{1}}\right)^{-\sigma_{e}}\left(a_{21}^{\sigma_{e}}+a_{22}^{\sigma_{e}}\left(\frac{w_{2}}{w_{1}}\right)^{1-\sigma_{e}}\right)^{-2}
$$

Since $a_{i j}>0$ for all $\langle i, j\rangle$, and $w_{j}>0$ for all $j$, we have:

$$
\begin{aligned}
& z_{1}^{\prime} \text { and } z_{2}^{\prime}>0 \text { iff } \sigma_{e}>1 \\
& z_{1}^{\prime} \text { and } z_{2}^{\prime}<0 \text { iff } \sigma_{e}<1
\end{aligned}
$$

Noting that $\lambda$ can be expressed as a function of $\varepsilon_{2} / \varepsilon_{1}$ as follows:

$$
\begin{aligned}
\lambda= & z_{3}\left(\varepsilon_{2} / \varepsilon_{1}\right)=b_{1}^{\sigma_{\alpha}} a_{11}^{\sigma_{e}\left(\sigma_{o}-1\right) /\left(1-\sigma_{e}\right)} \\
& \times\left(b_{1}^{\sigma_{o}} a_{11}^{\sigma_{e}\left(\sigma_{o}-1\right) /\left(1-\sigma_{e}\right)}+b_{2}^{\sigma_{\circ}} a_{21}^{\sigma_{e}\left(\sigma_{o}-1\right) /\left(1-\sigma_{e}\right)}\left(\varepsilon_{2} / \varepsilon_{1}\right)^{\frac{1-\alpha_{o}}{1-\sigma_{e}}}\right)^{-1}
\end{aligned}
$$

Table 2.4: The relative efficiency units between occupations and the number of tasks dealt with in each occupation.

\begin{tabular}{l|ll}
\hline \hline$\lambda^{\prime}$ & & $\sigma_{e}$ \\
\hline & & $(1 ; \infty)$ \\
$\sigma_{o}$ & $(0,1)$ & + \\
& $(1 ; \infty)$ & - \\
\hline \hline
\end{tabular}

Then one can derive the $z_{3}^{\prime}$ and finds: 


$$
\begin{aligned}
\lambda^{\prime}= & -\frac{1-\sigma_{o}}{1-\sigma_{e}} \cdot b_{1}^{\sigma_{o}} \cdot a_{11}^{\sigma_{e}\left(\sigma_{o}-1\right) /\left(1-\sigma_{e}\right)} b_{2}^{\sigma_{o}} \cdot a_{21}^{\sigma_{e}\left(\sigma_{o}-1\right) /\left(1-\sigma_{e}\right)} \cdot\left(\varepsilon_{2} / \varepsilon_{1}\right)^{\frac{\sigma_{e}-\sigma_{o}}{1-\sigma_{e}}}(2.19) \\
& \times\left(b_{1}^{\sigma_{o}} a_{11}^{\sigma_{e}\left(\sigma_{o}-1\right) /\left(1-\sigma_{e}\right)}+b_{2}^{\sigma_{o}} a_{21}^{\sigma_{e}\left(\sigma_{o}-1\right) /\left(1-\sigma_{e}\right)}\left(\varepsilon_{2} / \varepsilon_{1}\right)^{\frac{1-\sigma_{o}}{1-\sigma_{e}}}\right)^{-2}
\end{aligned}
$$

Hence, since $\varepsilon_{1}$ and $\varepsilon_{2}$ are both strictly positive, the derivative of $\lambda$ is of the sign of $-\frac{1-\sigma_{a}}{1-\sigma_{e}}$ and can be expressed as a function of the technological elasticity parameter $\sigma_{o}$. 


\section{Appendix B. Elasticity of substitution and the allocation of the marginal task}

$$
z_{1}^{\prime}\left(w_{2} / w_{1}\right)=-\left(1-\sigma_{\epsilon}\right) \cdot a_{11}^{\sigma_{e}} \cdot a_{12}^{\sigma_{e}} \cdot\left(\frac{w_{2}}{w_{1}}\right)^{-\sigma_{\epsilon}}\left(a_{11}^{\sigma_{\epsilon}}+a_{12}^{\sigma_{e}}\left(\frac{w_{2}}{w_{1}}\right)^{1-\sigma_{e}}\right)^{-2}
$$

and

$z_{2}^{\prime}\left(w_{2} / w_{1}\right)=-\left(1-\sigma_{e}\right) \cdot a_{21}^{\sigma_{e}} \cdot a_{22}^{\sigma_{e}} \cdot\left(\frac{w_{2}}{w_{1}}\right)^{-\sigma_{e}}\left(a_{21}^{\sigma_{e}}+a_{22}^{\sigma_{e}}\left(\frac{w_{2}}{w_{1}}\right)^{1-\sigma_{e}}\right)^{-2}$

Since $a_{i j}>0$ for all $\langle i, j\rangle$, and $w_{j}>0$ for all $j$, we have:

$$
\begin{aligned}
& z_{1}^{\prime} \text { and } z_{2}^{\prime}>0 \text { iff } \sigma_{e}>1 \\
& z_{1}^{\prime} \text { and } z_{2}^{\prime}<0 \text { iff } \sigma_{e}<1
\end{aligned}
$$

Noting that $\varepsilon$ can be expressed as a function of $\lambda_{2} / \lambda_{1}$ as follows:

$$
\begin{aligned}
\varepsilon= & z_{3}\left(\lambda_{2} / \lambda_{1}\right)=b_{1}^{\sigma_{o}} a_{11}^{\sigma_{e}\left(\sigma_{o}-1\right) /\left(1-\sigma_{\epsilon}\right)} \\
& \times\left(b_{1}^{\sigma_{o}} a_{11}^{\sigma_{e}\left(\sigma_{o}-1\right) /\left(1-\sigma_{e}\right)}+b_{2}^{\sigma_{o}} a_{21}^{\sigma_{e}\left(\sigma_{\alpha}-1\right) /\left(1-\sigma_{e}\right)}\left(\frac{\lambda_{2}}{\lambda_{1}}\right)^{\frac{1-\sigma_{o}}{1-\sigma_{e}}}\right)^{-1}
\end{aligned}
$$

Then one can derive the $z_{3}^{\prime \prime}$ and finds:

$$
\begin{aligned}
\varepsilon^{\prime}= & -\frac{1-\sigma_{o}}{1-\sigma_{e}} b_{1}^{\sigma_{\circ}} a_{11}^{\sigma_{e}\left(\sigma_{o}-1\right) /\left(1-\sigma_{e}\right)} b_{2}^{\sigma_{o}} a_{21}^{\sigma_{e}\left(\sigma_{o}-1\right) /\left(1-\sigma_{e}\right)}\left(\frac{\lambda_{2}}{\lambda_{1}}\right)^{\frac{\sigma_{e}-\sigma_{e}}{1-\sigma_{e}}} \\
& \times\left(b_{1}^{\sigma_{o}} a_{11}^{\sigma_{e}\left(\sigma_{o}-1\right) /\left(1-\sigma_{e}\right)}+b_{2}^{\sigma_{o}} a_{21}^{\sigma_{e}\left(\sigma_{o}-1\right) /\left(1-\sigma_{e}\right)}\left(\frac{\lambda_{2}}{\lambda_{1}}\right)^{\frac{1-\sigma_{e}}{1-\sigma_{e}}}\right)^{-2}
\end{aligned}
$$

Hence, since $\lambda_{1}$ and $\lambda_{2}$ are both strictly positive, the derivative of $\varepsilon$ is of the 
sign of $-\frac{1-\sigma_{o}}{1-\sigma_{e}}>0$ since $\beta_{e}, \beta_{o} \in(0,1)$.

Table 2.5: The marginal task and the number of tasks dealt with in each occupation.

\begin{tabular}{l|ll}
\hline \hline$\varepsilon^{\prime}$ & & $\sigma_{e}$ \\
\hline & & $(1 ; \infty)$ \\
$\sigma_{o}$ & $(1 ; \infty)$ & - \\
\hline \hline
\end{tabular}


CHAPTER 2. ASSIGNMENT MODELS AND SUBSTITUTION 


\section{Chapter 3}

\section{Testing the assignment model: An international comparison}

\subsection{Introduction}

The allocation model developed in Chapter 2 describes how the assignment of workers to jobs depends on the distribution of skills among workers and the distribution of skills required in the various jobs. The allocation model explains how the assignment of workers to jobs relates to the substitution process that takes place in the labour market. In this chapter we will test for the relevance of our allocation model in explaining the substitution process between types of workers observed in real data. Since comparing employment and wages across countries seems to be a very challenging exercise, we run this test by comparing the allocation of workers with different fields of study in higher education to various occupations and their wages between different countries.

The formal test is in accordance with the following line of thought. If the skill content of the graduates in the same field of study is not the same across countries, e.g. if the skills of economics graduates in France are significantly different of the skills of economics graduates in the UK, the productivity of workers in each field of study will vary across countries and so will wages. This will make it impossible to compare relative employment and wage equilibrium by educational groups of workers across countries even if the substitution process, linking differences in the relative supply of labour by fields of study with educational wage differentials, occurs freely. According to the model we developed in Chapter 2, the differences in the productivity of workers with a particular study across coun- 
tries result in a different assignment of tasks to workers in the various educational groups between countries even at equivalent employment equilibrium situations. Hence, the difficulty to compare the various educational groups between counties would lead to reject the supply and demand explanation of wage differentials across countries because the magnitude of the substitution effect necessary to match supply and demand differentials with wage differentials is not plausible. The allocation model developed in Chapter 2, enables us to decompose the substitution effect into an effect due to differences in the allocation structure induced by differences in the skill content of (particular) fields of study and the 'true' substitution effect resulting from supply shifts only. Indeed, the allocation model enables us to detect differences in the allocation that are not caused by supply and demand factors but caused by differences in the skill content across countries. Hence, the remaining supply and demand differential can be compared with wage differentials to measure the real substitution effect.

The question of whether the allocation structure significantly influences the substitution process relates to the literature on international differences in wage inequality between skill gxoups led by Blau and Kahn (1996), Leuven et al. (2004), Freeman and Schettkat (2001) and Acemoglu (2003), and to the literature on changes in the structure of wages between skill-groups of workers, e.g. Katz and Revenga (1989), Bound and Johnson (1992), Katz and Murphy (1992), Murphy and Welch (1992), Card and Lemieux (1996), Johnson (1997), Card et al. (1999) and Acemoglu (2002). In this literature, the structure of wages is confronted with a (neo-) classical supply and demand framework. Through time, shifts in the relative supply of certain types of labour induce substitution between the various types of labour resulting in changes in relative wages, whereas across countries, differences in the relative supply of labour should coincide with wage differentials if the substitution process between the various types of labour occurs freely in each country.

Time-series analyses, e.g. Katz and Murphy (1992), indicate that changes in the wage structure are consistently explained by the substitution effect (supply and demand) once acknowledged for continuous shifts in the relative demand for skilled workers, either due to skill-biased technological change (see Bound and Johnson (1992), Juhn et al. (1993), Levy and Murnane (1996), Machin and Van Reenen (1998) and Acemoglu (2002)) or capital-skill complementarity, e.g. Berman et al. (1994), Berman et al. (1998), Autor et al. (1998) and Krusell et al (2000). DiNardo et al. (1996), Lee (1999), Card and Lemieux (2001) and Card 
and DiNardo (2002) claim however that changes in wages do not reflect shifts in supply and demand. They argue that changes in the labour market institutions rather than shifts in the relative demand have caused the US increase in. wage inequality during the eighties. Especially the reduction in the real minimum wage is regarded as a main determinant for increased wage inequality.

Also, some authors, e.g. Blau and Kahn (1996), reject the supply and demand explanation of wage differentials across countries because the magnitude of the substitution effect necessary to match supply and demand differentials with wage differentials is not plausible. However, several authors, e.g. Leuven et al. (2004), Devroye and Freeman (2001) and Freeman and Schettkat (2001), argue that the skill content of educational groups varies a great deal across countries which makes educational comparisons difficult. They raise questions about the validity of the skill measure used by Blau and Kahn, which is based on the assumption that each year of education and each year of experience lead to the same amount of skills in each country. International comparative studies in which students or workers in different countries take a similar test, like the Third International Mathematics and Science Study (TIMSS) ${ }^{1}$ or International Adult Literacy Survey (IALS) provide direct evidence on cross-country differences in the composition of skills by educational levels. These international tests focus, however, on a very specific set of skills. Therefore, they may be neglecting other skills that might be relevant for a worker's productivity. Using several techniques, especially based on the results of the IALS, Freeman and Schettkat show that the actual skill level of workers in Germany, especially with respect to the least skilled workers is much higher than was accounted for by Blau and Kahn. ${ }^{2}$ According to Freeman and Schettkat this less dispersed ability distribution of Germans can not explain the distribution of their wages completely, i.e. German workers in the lower segment of the labour market still earn relative more than their US. counterparts with equal ability. Leuven et al. (2004) use the IALS for a comparison of seven countries in which they also take into account the effects of supply and demand on the wage structure. They find, in contrast to Blau and Kahn, that wage structures are consistent with a supply-demand explanation. The findings of Leuven et al. (2004) show that analyses of the relationship between aggregate supply and demand and wages are very sensitive to the way in which skills are

\footnotetext{
${ }^{1}$ See also Nickell and Bell (1996) and OECD (2001).

${ }^{2}$ American workers with less than 12 years of schooling score in average less than their counterparts elsewhere whereas with more than 16 years of schooling the picture is reversed.
} 
classified. Devroye and Freeman (2001) show in this respect that immigrants seem to have low IALS-scores compared to their wages, due to the relative importance of language ability in such tests.

Our contribution with respect to this literature is that we decompose the substitution effect into an effect due to differences in the allocation structure induced by differences in the skill content of educational segments and the true substitution effect resulting from supply shifts only. The allocation model developed in this study enables us to isolate differences in the allocation that are not caused by supply factors but caused by differences in the content of the various studies across countries. By taking advantage of the information contained in the occupational allocation of workers, our model is robust for the way in which skills are classified. The remaining supply and demand differential can be related to wage differentials to measure the real substitution effect. The model enables us to evaluate not only the sign but also the magnitude of the effects of supply and demand on the wage structure.

We will compare types of skills (measured by field of study) to avoid the inherent problems of comparing skill levels between countries. We distinguish between education and occupation and model the allocation of workers with different educational fields to the various occupations. Using data on the labour market position of graduates from higher education in nine countries, we estimate whether differences in the skill wage structure can be explained by differences in supply and demand. We find that once we correct for differences in the allocation structure, the differences in the wage structure are consistent with a supply-demand explanation and show that with an elasticity parameter of 2.14, wage differentials across countries coincide with at least $64 \%$ of employment differentials.

The structure of the chapter is as follows. The next section covers the sources and description of the data. In addition, we present measures of wage inequality for all countries in the data. In a third section, the theoretical model is presented. Therein, we subsequently derive a method to identify the relationship between supply and demand and wages, allowing differences across countries in the allocation structure. The fourth section contains empirical results. Some final remarks and conclusions appear in Section 3.5. 


\subsection{Data}

The data we use for our empirical analysis are taken from the "Careers after Higher Education European Research Survey" (CHEERS). Samples of graduates from higher education in the 1994/1995 academic year have been conducted 3 years after graduation (1998). The nine countries for which all necessary data is available are Italy, Spain, France, Austria, The Netherlands, The United Kingdom, Finland, Germany and Japan. The sample sizes are approximately 3,500 for each country and are representative of the target population defined along field of study, the type of degree/institution, gender and the region.

For each country, we need information on the allocation of workers with different fields of education to the various occupational fields as well as the wage rates associated to each educational field.

\section{The allocation of workers}

We make use of the information on the individuals' educational and occupational fields provided by the International Standard Classification of EDucation (ISCED, 3 digits) and the International Standard Classification of Occupation (ISCO, 3 digits) respectively. These two classifications distinguish categories, with respect to both the levels and the fields of education and occupation. The first digit of the two codes give the educational and job level, respectively, while the two last digits characterize the vocational fields. We re-code the 3 -digits ISCED and ISCO into 7 educational fields and 11 occupational categories according to the classification reported in Table 3.6 of appendix A. Since most of the graduates end up in higher level occupations, and ISCO makes hardly any distinction between very different occupations at the first digit level, we refined the classification for high level jobs and take together lower level jobs. Based on this classification, the number of workers per education and occupation for the nine countries considered are computed.

The average number of workers per education and occupation in the nine countries is reported in Table 3.1. The table shows that even though a large amount of workers is allocated to occupations for which their education is 'required' (largest, frequency in bold figures), in each occupation the educational distribution of workers is fairly spread. The educational group with the largest frequency (Arts-Humanities field) accounts for $23 \%$ of the workers in Other-lower occupations. Health graduates account for up to $82 \%$ of the workers in Health 
Table 3.1: Average number of workers by education and occupation expressed in the nine countries in promile.

\begin{tabular}{|c|c|c|c|c|c|c|c|c|}
\hline \multirow[b]{2}{*}{ Oecapation } & \multicolumn{5}{|c|}{ Education $^{a}$} & \multirow[b]{2}{*}{ Engineer } & \multirow[b]{2}{*}{ Health } & \multirow[b]{2}{*}{ total } \\
\hline & Artw-Hvm & Soci-Scie & Businew: & Las & Natur-acie & & & \\
\hline Arts-Hum & 17 & 6 & 9 & 2 & 2 & 2 & 1 & 39 \\
\hline Soei-Scie & 15 & 24 & 15 & 2 & 1. & 2 & 7 & $66^{\circ}$ \\
\hline Busisers & 14 & 18 & 60 & 11 & 8 & 10 & 2 & 123. \\
\hline Legal & 3 & 2 & 1 & 36 & 1 & 1. & 1 & 45 \\
\hline Sciences: & 6 & 5 & 11 & 2 & 59 & 44 & 7 & 134 \\
\hline Eagineerisg & 3 & 2 & 7 & 1 & 14 & 92 & 1 & 120 \\
\hline Health & 3 & 2 & 1 & 1 & 2 & 5 & 64 & 78 \\
\hline Managers: & 19 & 16 & 39 & 5 & 7 & 17 & 6 & 109 \\
\hline Tenching & 89 & 12 & 10 & 2 & 21 & 11. & 5 & 150 \\
\hline Clerk: & 22 & 17 & 24 & 10 & 3 & 5 & 3 & 84 \\
\hline Other-lower & 12 & 10 & 11 & 4. & 4 & 8 & 3 & 52 \\
\hline total & 203 & 114 & 188 & 76 & 122 & 197 & 100 & 1000 \\
\hline
\end{tabular}

${ }^{2}$ For each occupation, the educational group with the largest frequency is represented in bold.

occupations. Over all occupations, the number of workers having an education that differs from the educational field for which the largest frequency is observed adds up to about $48 \%$. This figure indicates a fair dispersion in the distribution of workers by education within occupations.

Allocation turns out to be different between countries. To show this, we compute the average absolute distances between the allocation of workers with different education to the various occupations of each country and the ninecountry average allocation defined as:

$$
\bar{A}_{c}=\frac{1}{7 \times 11} A_{c}=\frac{1}{7 \times 11} \sum_{i j}\left|L_{i j, c}^{0}-\overline{L_{i j}}\right|
$$

where $\bar{L}_{i j}$ is the nine-country average number of workers with education $j$ in occupation $i$ and $L_{i j, c}^{0}$ is the actual number of workers with education $j$ in occupation $i$ observed in country $c$. Both are expressed in promiles.

The absolute distances, reported in the bottom row of Table 3.7 of Appendix 
B, indicate large differences in allocation matrices across countries. These differences may correspond with (i) cross-country differences in supply and demand situations, (ii) differences in the content of the various fields of study and/or (iii) differences across countries in the classifications of education and occupation. Though institutional factors might affect the level of employment, the relative allocation of workers with different education to the various occupations can reasonably be assumed unaffected by labour market institutional factors. The challenge is to separate (i) the demand and supply explanation from (ii) the classification and the content of the study explanations.

\section{The educational wage rates by country}

In order to derive the wage rates by educational categories in each country, we run hourly earnings regressions independently for each country, including control for the effects of gender, age (quadratic form), job-tenure (quadratic form), hours weekly worked (log term), part-time, interaction of gender with age, job-tenure and part-time. Tenure is measured by means of workers' answers to the question: "In which year did you start your current job?" It therefore refers to an occupation-related-tenure rather than a firm-tenure. We excluded anyone earning less than 5 euro per hour or more than 150 euro per hour. The log wage-premia by educational groups are derived from the OLS estimated parameters.

The following equation is estimated for each worker $p$ in country $c$ :

$$
\ln W_{p, c}=\gamma_{c}+G_{c}^{\prime} X_{p c}+\sum_{j} \alpha_{j, c} E_{j}+e_{p, c}
$$

The variable $\ln W$ is the $\log$ of hourly earnings; $X_{c}$ is a vector of explanatory variables including age and its square, tenure: and its square, a dummy variable for part-time work (less than 36 hours per week), gender and its interaction with age, tenure and part-time, and the log of weekly hours worked. $E_{j}$ are dummies for the fields of education. Reported in Table 3.7 of Appendix B, the estimates $\alpha_{j, c}$ can be regarded as educational wage-premia for each country.

Wage inequality across countries

In several studies, wage inequality is found very different across countries with a larger wage inequality in the US and the UK than in continental Europe and 
Japan, ${ }^{3}$ In order to evaluate the extent to which this stylised fact is reflected in our data on higher educated workers we compute some measures of wage inequality. ${ }^{4}$

First we derive from the estimation of equation 3.2 the total variance and the within and between educational categories variance in log hourly earnings. The total variance as well as the variance within and between educational categories in $\log$ hourly earnings are given by:

$$
\begin{aligned}
\text { Within }_{c} & =\frac{1}{L_{c}} \sum_{j} L_{j, c} \times \sum_{p, E_{j}=1}\left(\ln W_{p, c}-\widehat{\ln W_{p, c}}\right)^{2} \\
\text { Between }_{c} & =\frac{1}{L_{c}} \sum_{j} L_{j, c} \times \sum_{p, E_{j}=1}\left(\widehat{\ln W}_{p, c}-{\widehat{\ln W_{c}}}^{2}\right. \\
\text { Total }_{c} & =\frac{1}{L_{c}} \sum_{p}\left(\ln W_{p, c}-\overline{\ln } \bar{W}_{c}\right)^{2}
\end{aligned}
$$

where $L_{j, c}$ is the number of workers with education $j$ in country $c, L_{c}$ is the number of workers in country $c, \widehat{\ln }_{p, c}$ is the estimated log-earnings for workers $p$ in country $c$ and $\ln \bar{W}_{c}$ is the average log-earnings in country $c$.

We complete the analysis of wage inequality by computing; for each worker in each country, $Y_{p, c}$, the male, 40 hours per week, 30 years old, 2.8 years of tenure, etc. $^{5} \ldots$ equivalent hourly earnings using equation 3.2 as follows:

$$
\begin{aligned}
Y_{p, c} & =\ln W_{p, c}-\gamma_{c}-G_{c}^{\prime}\left(X_{p, c}-\bar{X}\right) \\
& =\sum_{j} \alpha_{j, c} E_{j}+G_{c}^{\prime} \bar{X}+e_{p, c}
\end{aligned}
$$

For each country, the standard-deviation and the 10,50 and 90 percentiles of the corrected hourly earnings distribution are computed. The variance decomposition of the hourly earnings distribution as well as the 50-10, 90-50 and

\footnotetext{
${ }^{3}$ See for instance Blau and Kalin (1996), Leuven et al. (2004), Devroye and Freernan (2001) and Freeman and Schet that (2001).

${ }^{4}$ Notice that our measure of between educational fields wage inequality is part of the within. educational levels wage inequality measured in most empirical analyses.

${ }^{5}$ The world-wide average age and tenure are 30 years of age and 2.8 years of tenure.
} 
Table 3.2: Variance decomposition of hourly earnings for each country.

\begin{tabular}{l|ccccccccc}
\hline \hline & It & Sp & Fr & Au & $\overline{\mathrm{N} l}$ & $\mathrm{UK}$ & $\overline{\mathrm{Fi}}$ & $\mathrm{Ge}$ & $\mathrm{Jp}$ \\
\hline $\ln W_{p, c}$ & & & & & & & & & \\
Variance decomposition & & & & & & & & & \\
Between $_{c}(\times 10)$ & .10 & .07 & .16 & .08 & .03 & .03 & .07 & .05 & .03 \\
Within $_{c}$ & .14 & .16 & .11 & .12 & .05 & .12 & .08 & .10 & .08 \\
Total $_{c}$ & .19 & .19 & .15 & .18 & .09 & .15 & .10 & .15 & .11 \\
\hline$Y_{p, c}$ & & & & & & & & & \\
Wage Inequality $_{50-10}$ & & & & & & & & & \\
$90-50$ & .50 & .59 & .50 & .45 & .27 & .44 & .32 & .42 & .41 \\
$90-10$ & .38 & .49 & .36 & .41 & .28 & .42 & .34 & .33 & .29 \\
Stdv & .88 & 1.08 & .86 & .86 & .55 & .86 & .66 & .75 & .70 \\
\hline \hline
\end{tabular}

The variance of hourly earnings is decomposed into between, within and total variance as obtained from estimation of separate regressions of equation 3.2 for each country.

The standard deviation and the 50-10,90-50 and 90-10 percentile gaps of the distribution of corrected hourly earnings as obtained from equation 3.3 .

90-10 percentiles gaps in the corrected hourly earnings distribution are reported for each country in Table 3.2. Whereas most studies that differentiate workers by their educational level find a significantly higher inequality in the UK, we find no such evidence among workers with the same educational level. The total variance in hourly earnings and the variance within educational groups in the UK is of the same magnitude as that of France, Germany and to some extent Japan. These results are corroborated by those derived from the distribution of the corrected hourly earnings. The standard deviation of the distribution of the corrected hourly earnings for the UK is indeed roughly the same as that for France and Germany. Though, the 90-10 gap in earnings differential in the UK lies above that of Germany, we find no differences between the UK and France and Austria and even a slightly larger 90-10 gap for Italy. This result is consistent with the view that the large wage differentials in the UK reflect a wide distribution of skill levels among the workforce. 


\subsection{Conceptual framework}

\subsubsection{Production function}

The economy of each country is assumed to produce one output-good denoted $H$. The price of this good is used as numeraire. In each occupation $i$ an intermediate good, denoted $H_{i}$ is produced with workers from different fields of study as input.

The production function is of the form depicted in the theoretical model of Chapter 2, i.e. equation 2.7, but with $n_{o}$ occupations and $n_{e}$ educational groups: ${ }^{6}$

$$
H=\min \left(\delta_{i} H_{i}\right)
$$

where $\delta_{i}$ is a technological parameter measuring the optimal proportion of output $i$ in output.

Assuming that the intermediate outputs are inelastic (Leontief production function at the occupational level), substitution on the goods market is impossible and all adjustments come from educational substitution within the various occupational groups. Note that allowing for substitution on the goods market is just a matter of decomposing the adjustments in the demand for workers into occupational and educational substitution. It would not affect substantially the magnitude of the adjusments in labour demand. ${ }^{7}$ Within each occupation, educational groups of workers are imperfect substitutes and occupational technology is defined by:

$$
H_{i}=\left(\sum_{j} a_{i j} L_{i j}^{\beta}\right)^{1 / \beta}
$$

where $a_{i j}$ is the productivity parameter of workers with education $j$ in occupation $i$ and satisfies $a_{i j}>0 \forall i, j$ and $\sum_{j} a_{i j}=1 . \beta$ is a production technology parameter and $\beta \leq 1, L_{i j}$ denotes the employment of workers with education $j$ in occupation $i$.

\footnotetext{
${ }^{6}$ For the sake of simplicity, we skip the country index, i.e. $c$ on both the parameters and the variables of the model.

${ }^{7}$ We reproduced the analysis with the general 2-level CES production function specification and found similar results as those presented in this chapter.
} 
The allocation is characterised by the distribution of workers by educational fields to the various occupational fields. As argued in Chapter 2, several educational fields may be fairly represented, within an occupation. There is an inherent dispersion due to the heterogeneous character of occupations and its impact. on the assignment of tasks to educational groups of workers. Workers who find employment in the same occupation need not to perform exactly the same tasks. Since educational fields differ in their skill content, workers with different educational backgrounds differ in their ability to perform the various tasks. Therefore, the optimal assignment of tasks to educational groups of workers leads to the presence of workers with different education in some (if not all) occupations. The optimal assignment of tasks changes as the wage rates by educational groups change through the supply and demand adjustment process. When comparing allocation across countries, differences in supply and demand should correspond to differences in wage rates between countries if the skill contents of each study is comparable across countries. However, when differences in the contents of a study are observed, the optimal assignment of tasks to groups of workers would differ across countries generating differences in the allocation even at equivalent wage rates and supply and demand situations. Furthermore, differences in the classification of education might cause observed differences in the allocation of workers. The difficulty to compare educational systems between countries makes it necessary to take into account such differences.

The parameter of educational substitution elasticity within a single occupation equals $\sigma=\frac{1}{1-\beta}$. However, since fields of study compete in more than one occupation, the Allen partial Elasticities of Substitution (AES, see Allen 1938) between educational groups of workers need not to be equal to $\sigma$ nor to be constant between all pairs of educational groups of workers, $\sigma$ measures the partial elasticity of substitution between two educational groups of workers within an occupation. The AES between two educational groups of workers equal:

$$
\begin{aligned}
A E S_{j k} & =\frac{\eta_{j k}}{s_{s}} \\
\eta_{j k} & \equiv \frac{\partial \ln L_{j j}}{\partial \ln w_{k}}=\sigma \sum_{i} s_{k, i} \frac{L_{i j}}{L_{j}}
\end{aligned}
$$

where $\eta_{j k}$ is the corresponding cross-wage elasticity, $s_{k}$ the cost-share of educational group $k$ in total costs, $s_{k, i}=\frac{a_{i k}^{\sigma} w_{k}^{1-\sigma}}{\sum_{t} a_{i l}^{\sigma} w_{l}^{1-\sigma}}=\frac{w_{k} L_{i k}}{\sum_{l} w_{l} L_{i l}}$ the cost-share of workers 
with education $k$ in occupation $i$ and $L_{. j}=\sum_{i} L_{i j}$ the demand for workers with education $j$.

Assuming that both the labour and commodity markets are perfectly competitive, the demand for workers with different fields of study in the various occupations is derived by equating marginal products to the respective wage rates. The demand for workers with education $j$ in occupation $i$, expressed in logarithmic terms, reads as:

$$
\begin{aligned}
\ln L_{i j}= & \ln H-\ln \delta_{i}+\sigma \ln a_{i j}-\sigma \ln w_{j}+\sigma \ln P C_{i} \\
& \text { with } \\
P C_{i}= & \left(\sum_{k} a_{i j}^{\sigma} w_{j}^{1-\sigma}\right)^{\frac{1}{1-\sigma}}
\end{aligned}
$$

where $w_{j}$ stands for the wage of workers with education $j$. The function $P C_{i}$ represents the shadow price of producing one extra unit of intermediate output in occupation $i$ (the unit cost function).

From equation 3.7 we can derive changes in the demand for workers with education $j$ in occupation $i$ as a function of changes in wages, output and productivity parameters, i.e. $a_{i j}$. The demand equation in infinitesimal form equals:

$$
\mathrm{d} \ln \frac{L_{i j}}{H}=\sum_{k} \frac{\partial \ln L_{i j}}{\partial \ln w_{k}} \times d \ln w_{k}+\sum_{k} \frac{\partial \ln L_{i j}}{\partial \ln a_{i k}} \times d \ln a_{i k}
$$

Using workers with education $l$ in occupation $g$ as reference group, changes in the relative allocation of workers with different educational backgrounds and occupations read as:

$$
\mathrm{d} \ln \frac{L_{i j}}{L_{g l}}=\sum_{k} \frac{\partial \ln L_{i j} / L_{g l}}{\partial \ln w_{k} / w_{l}} \times \mathrm{d} \ln \frac{w_{k}}{w_{l}}+\sum_{k} \frac{\partial \ln L_{i j} / L_{g l}}{\partial \ln a_{i k} / a_{g l}} \times \mathrm{d} \ln \frac{a_{i k}}{a_{g l}}
$$

The change in the allocation of workers with education $j$ in occupation $i$ is decomposed into a supply and demand effect (denoted SD), initiated by changes 
in the relative wages of the various educational fields, and an allocation structure effect (denoted AS) characterised by differences in the production function parameters $a_{i j}$.

The supply and demand effect equals:

$$
\begin{aligned}
S D & =\sum_{k} \frac{\partial \ln L_{i j} / L_{g l}}{\partial \ln w_{k} / w_{l}} \times \mathrm{d} \ln \frac{w_{k}}{w l} \\
& =-\sigma \times \mathrm{d} \ln \frac{w_{j}}{w_{l}}+\sigma \sum_{k}\left(s_{k, i}-s_{k, g}\right) \times \mathrm{d} \ln \frac{w_{k}}{w_{l}}
\end{aligned}
$$

and the allocation structure effect:

$$
\begin{aligned}
A S & =\sum_{k} \frac{\partial \ln L_{i j} / L_{g l}}{\partial \ln a_{i k} / a_{g l}} \times \mathrm{d} \ln \frac{a_{i k}}{a_{g l}} \\
& =\sigma \times \mathrm{d} \ln \frac{a_{i j}}{a_{g l}}+\frac{\sigma^{2}}{1-\sigma} \sum_{k}\left(s_{k, i}-s_{k, g}\right) \times \mathrm{d} \ln \frac{a_{i k}}{a_{g l}}
\end{aligned}
$$

Changes in the demand for workers with the various educational backgrounds in the various occupations can be linked to exogenous changes in wages, due to shifts in the composition of supply and exogenous changes in the productivity parameters of the various types of workers.

In the context of cross-country analysis, exogenous changes in wage rates correspond to the distance between the relative wages observed in each country, and arbitrarily chosen new relative wages common to all countries. However, if the skill content of the graduates in the same field of study is not the same across countries, the relative productivity of workers in each field of study will vary across countries and so will wages. This will make it impossible to compare relative employment and wage equilibrium by educational groups of workers across countries even if the substitution process, linking differences in the relative supply of labour by fields of study with educational wage differentials, occurs freely. To illustrate the operation of the model we consider the differences in the relative wage of engineering graduates to business graduates in France and the UK. Great graphical simplification is achieved with only one occupation. Therefore in the following example we consider only workers in the managerial occupation. 


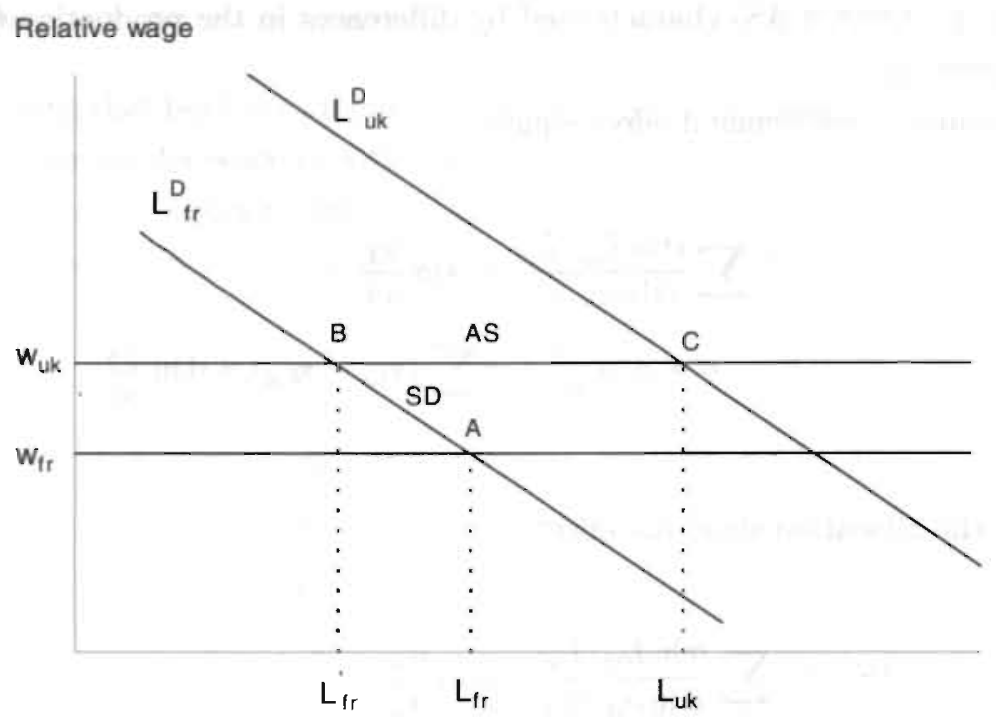

Figure 3.1: Decomposition of wage differentials across countries.

Figure 3.1 shows the relative demand for and relative supply of graduates in that occupation. In France, the relative wage observed is -0.1 and is accompanied by a relative supply of -2.97 . Intuitively, an increase in the relative wage rate from -0.1 to $0.08\left(w_{u k}\right.$, relative wage in the UK, is 0.08$)$ induces substitution between both engineering and business workers and reduces the relative demand from $L_{f r}$ to $L_{f,}^{\prime}$ through the operation $S D$ in equation 3.9 (movement from A to $\mathrm{B}$ on the French demand curve). The fact that the new equilibrium point in France, i.e. point $B$ in Figure 3.1, does not correspond with the equilibrium point in the UK $\left(L_{f r}^{\prime}<-2.97<-1.03=L_{u k}\right)$, i.e. point $C$, implies differences in the productivity parameters between both countries. To match the UK equilibrium, the relative demand function in. France has to shift from $L_{f r}^{D}$ to $L_{u k}^{D}$ through the operation of $A S$ in equation 3.9 . 


\subsubsection{Isolating supply and demand from allocation struc- ture effects}

Since institutions in some countries may choose to compress wages for social cohesion purposes, relative wages observed may, in those countries, not correspond to competitive wage rates. We therefore choose to correct for supply and demand differences across countries independently from observed wage rates. We do so by equalising labour supply and demand by educational group and occupation in the various countries. In other words, for each country, we set the total supply of workers in each educational segment and the total demand for workers in each occupation to the nine-country average. After controlling for demand and supply differences between countries, the allocation of workers with different education to the various occupations in each country $c$, say $L_{i j, c}^{t}$, satisfies thereby the following conditions:

$$
\left\{\begin{array}{l}
\sum_{i=1}^{n_{o}} L_{i j, c}^{t}=\overline{L_{, j}} \\
\sum_{j=1}^{n_{e_{e}}} L_{i j, c}^{t}=\overline{L_{, i}}
\end{array} \forall c\right.
$$

Equation 3.7 shows that changes in the allocation of workers as derived from the production function are bi-proportional and break down into an occupation specific $R_{i}$ and an education specific $S_{j}$ effect.

$$
\begin{aligned}
\ln L_{i j}^{t} & =\ln H^{t}-\ln \delta_{i}+\sigma \ln a_{i j}-\sigma \ln w_{j}^{t}+\sigma \ln P C_{i}\left(w^{t}\right) \\
\ln \frac{L_{i j}^{t}}{L_{g k}^{t}} & =-\ln \frac{\delta_{i}}{\delta_{g}}+\sigma \ln \frac{a_{i j}}{a_{g k}}-\sigma \ln \frac{w_{j}^{t}}{w_{k}^{t}}+\sigma \ln \frac{P C_{i}\left(w^{t}\right)}{P C_{g}\left(w^{t}\right)} \\
\ln \frac{L_{i j}^{t}}{L_{g k}^{t}}-\ln \frac{L_{i j}^{0}}{L_{g k}^{0}} & =-\sigma\left(\ln \frac{w_{j}^{t}}{w_{k}^{t}}-\ln \frac{w_{j}^{0}}{w_{k}^{0}}\right)+\sigma\left(\ln \frac{P C_{i}\left(w^{t}\right)}{P C_{g}\left(w^{t}\right)}-\ln \frac{P C_{i}\left(w^{0}\right)}{P C_{g}\left(w^{0}\right)}\right) \\
\ln \frac{L_{i j}^{t}}{L_{g k}^{t}} & \Leftrightarrow \ln R_{i}+\ln S_{j}+\ln \frac{L_{i j}^{0}}{L_{g k}^{0}}
\end{aligned}
$$

Therefore, the new allocation of workers with education $j$ in occupation $i$ in 
each country, $L_{i j, c}^{t}$, can be derived by finding vectors $R$, and $S$. that satisfy the border conditions (same supply and demand vectors across countries) given the structure of allocation in country $c$, i.e. given the $a_{i j, c}$ of country $c$.

Equation 3.13 is equivalent to the RAS method. ${ }^{8}$ Using an iterative procedure in order to avoid approximation problems involved when inverting large matrices, ${ }^{9}$ we derive the demand and supply vectors $R_{i, c}$ and $S_{j, c}$ for each country such that the border conditions (equation 3.12) are satisfied, given the allocation observed in each country, $L_{i j, c^{\prime}}^{0}$

This approach to derive changes in the allocation without taking wages explicitly into account is conceptually comparable to Tinbergen (1984). Tinbergen presents two structures related. to our approach. The so-called Northwest-corner rule, $t$-method, that minimizes the total tension (in the case of diagonal matrix, when the demand vector equals the supply vector, i.e. 'educational equilibrium', only the main diagonal is non-empty) and, the independency solution met when the supply and demand probability distributions are independent. ${ }^{10}$

\subsubsection{Allocation structure}

Since the border conditions are equal for all countries, if all countries would have the same production function, i.e. the same $a_{i j}$, the allocation after correction for supply and demand differences should be equal for all nine countries. Hence, the differences between the nine-country average allocation and these constructed allocation matrices provides information about the differences in the production functions across countries. We use the distance between the logarithm of the

\footnotetext{
${ }^{8}$ See Stone and Brown (1964), Evans and Lindley (1973), Kadas and Klafzky (1976) and Van Eijs and Borghans (1996).

${ }^{9}$ For more details see Evans and Lindley (1973) and van Eijs and Borghans (1996).

${ }^{10}$ Tinbergen notices that since the first solution concentrates all observations whereas the second solution spreads them evenly over the matrix, the actual allocation matrix may be somewhere in between. Our method minimises the relative entropy, $E_{L^{\circ}}\left(L^{t}\right)=\sum_{i j} L_{i j, c}^{t} \ln \left(\frac{L_{i j, c}^{t}}{L_{i, j, c}^{0}}\right)$, such that the new matrix $\left\{L_{i j, c}^{t}\right\}$ satisfies the border conditions conditional on the reference matrix $L^{0}$. The relative entropy reaches a global minimum, i.e. 0 , when the allocation $L_{i j, c}^{t}$ is equal to the allocation $L_{i j, c}^{0}$. Therefore, this method can be seen as a minimisation of tension given relative scarcity of certain workers' characteristics (border vectors) and initial allocation. It is comparable to Tinbergen's $t$-method. However, in contrast with Tinbergen, our method uses a production function as underlying structure. Furthermore, when educational equilibrium is reached (supply vector equals demand vector) the resulting allocation would not necessarily lead to unimodal distribution of workers by education within each occupation and the new allocation satisfies the properties of equation 3.7 .
} 
relative average allocation and the logarithm of the new relative allocation to proxy the differences in the production function parameters across countries:

$$
\ln \frac{\overline{L_{i j}}}{\overline{L_{g k}}}-\ln \frac{L_{i j, c}^{t}}{L_{g k, c}^{t}}=\widehat{A S_{i j, c}}
$$

Obviously, if we would have observed one occupation only, then $\widehat{A S}$ would equal zero for all educational groups $j$ and all countries even if the true production functions ${ }^{11}$ are different across countries. In order to disentangle allocation structure differences across countries, at least two occupations are necessary. Intuitively, if one only knows that the relative employment of engineering graduates in France is twice the relative employment in the UK, one cannot conclude on whether the relative supply of France engineering graduates is twice that of the UK or whether the engineering graduates in France are more productive in each occupation, compared to their UK counterparts. Our proxy therefore only picks up differences in occupation specific productivity assuming the relative average productivity between educational groups to be about the same in each country.

\subsubsection{Supply and demand}

Bearing in mind the passible differences in production function parameters between countries, we confront observed relative wage rates to supply and demand across countries using the structural equation of the model, equation 3.9. The equation relates the allocation of workers to on the one hand supply and demand, and on the other hand the structure of allocation. If wages reflect supply and demand they should explain allocation consistently after controlling for differences in production function. Comparing both the allocation structure and wages with the nine-country averages, we get:

\footnotetext{
${ }^{11}$ With one occupation, say $i$, even if the $a_{i j}$ parameters are different in the yarious countries, imposing the border conditions, $L_{i j c}^{t} \equiv L_{j, c}^{t}=\overline{L_{\cdot j}} \equiv \overline{L_{i j}}$ implies $\widehat{A S_{i j, c}}=\ln \frac{\overline{L_{i j}}}{L_{i k}}-\ln \frac{L_{i k}^{t}}{L_{i k, c}^{i}}=0$.
} 


$$
\begin{aligned}
\ln \frac{\overline{L_{i j}}}{\overline{L_{g l}}}-\ln \frac{L_{i j, c}^{0}}{L_{g l, c}^{0}=} & -\sigma\left(\ln \frac{w_{j}^{t}}{w_{l}^{t}}-\ln \frac{w_{j, c}^{0}}{w_{l, c}^{0}}\right)+ \\
& \sigma \sum_{k}\left(s_{k, i, c}-s_{k, g, c}\right)\left(\ln \frac{w_{j}^{\ell}}{w_{l}^{t}}-\ln \frac{w_{j, c}^{0}}{w_{l, c}^{0}}\right)+ \\
& \widehat{A S}_{i j, c} \\
= & S D+\widehat{A S}
\end{aligned}
$$

\subsubsection{A supply and demand explanation of wage differen- tials across countries}

The remaining question is how much of the observed differences in allocation across countries is due to observed differences in wage rates, allocation structures and other unobserved differences that might reflect labour market institutions. To answer this question we decompose the allocation differences between countries into three factors. To that aim. we introduce three quantities.

Quantity $A_{c}$ measures the distance between observed allocation and ninecountry average allocation.

$$
A_{c}=\sum_{i j}\left|L_{i j, c}^{0}-\overline{L_{i j}}\right|
$$

Quantity $B_{c}$ measures the distance between country-specific allocation at equalised wage rates by education and nine-country average allocation.

$$
B_{c}=\sum_{i j}\left|L_{i j, c}^{1}-\overline{L_{i j}}\right|
$$

in which $L_{i j, c}^{1}$ represents the allocation associated with equal wages for all educational fields for each country: 


$$
\begin{aligned}
\ln \frac{\overline{L_{i j}}}{\overline{L_{g l}}}-\ln \frac{L_{i j, c}^{1}}{L_{g l, c}^{1}}= & -\widehat{\sigma}\left(\ln 1-\ln \frac{w_{j}^{0}}{w_{l}^{0}}, c\right)+ \\
& \widehat{\sigma} \sum_{k}\left(s_{k, i, c}-s_{k, g, c}\right)\left(\ln 1-\ln \frac{w_{j}^{0}}{w_{l}^{0}}, c\right)+ \\
& \widehat{A S}_{i j, c}
\end{aligned}
$$

Rearranged and taking the exponential:

$$
\begin{aligned}
\frac{L_{i j, c}^{1}}{L_{g l, c}^{1}}= & \operatorname{Exp}\left[\begin{array}{c}
\ln \frac{\overline{L_{i j}}}{\bar{L}_{g l} l}-\widehat{A S}_{i j, c}- \\
\widehat{\sigma}\left(\ln \frac{w_{j, c}^{0}}{w_{l, c}^{0}}-\ln 1\right)+ \\
\hat{\sigma} \sum_{k}\left(s_{k, i, c}-s_{k, g, c}\right) \times\left(\ln \frac{w_{j, c}^{0}}{w_{i, c}^{0}}-\ln 1\right)
\end{array}\right] \\
& \text { with. } \\
L_{c}^{1}= & \sum_{i j} L_{i j, c}^{1}=1000
\end{aligned}
$$

$\ln 1$ indicates that the new allocation matrix $L_{i j, c}^{1}$ is associated to equal wage: rates between educational groups of workers.

This measure of the distance between the allocation in different countries is corrected for country-specific wage-premia, that is those wages equilibrating: country-specific supply and demand vectors ${ }^{12}$ but includes country-specific allocation structure and unobserved country-specific effects.

Quantity $C_{c}$ measures the distance between country-specific allocation given same supply and demand vectors across countries and nine-country average allocation matrix:

$$
C_{c}=\sum_{i j}\left|\widehat{A S_{i j}}\right|
$$

Therefore quantity $C_{c}$ measures the distance between the allocation structure of each country with an average structure/yardstick structure.

\footnotetext{
${ }^{12}$ This would imply equalised supply and demand vectors across countries if and only if the allocation structures were equal across countries.
} 


\subsection{Empirical results}

\subsubsection{Estimation of the substitution elasticity parameter and relative equilibrium wages}

From the theoretical model we derive four nested specifications.

First, assuming that all countries have the same allocation structure, i.e. there are no differences in the production functions, the model reduces to specification (I).

$$
\begin{aligned}
\ln \frac{\overline{L_{i j}}}{\overline{L_{g l}}}-\ln \frac{L_{i j, c}^{0}}{L_{g l, c}^{0}}= & -\sigma\left(\ln \frac{w_{j}^{t}}{w_{l}^{t}}-\ln \frac{w_{j}^{0}}{w_{l}^{0}}, c\right)+ \\
& \sigma \sum_{k}\left(s_{k, i, c}-s_{k, g, c}\right)\left(\ln \frac{w_{j}^{t}}{w_{l}^{t}}-\ln \frac{w_{j}^{0}}{w_{l}^{0}}, c\right)+\varepsilon_{i j, c} \\
= & S D
\end{aligned}
$$

In specification (II), we model the allocation changes against differences in the allocation structure only.

$$
\ln \frac{\overline{L_{i j}}}{\overline{L_{g l}}}-\ln \frac{L_{i j, c}^{0}}{L_{g l, c}^{0}}=\gamma \widehat{A S}_{i j, c}+\varepsilon_{i j, c}
$$

In the third and fourth specifications, both changes in wages and differences in the allocation structure are nested. Specification (III) corresponds to equation 3.15 where we replace the true allocation structure effect by its proxy $\widehat{A S}$.

$$
\begin{aligned}
\ln \frac{\overline{L_{i j}}}{\overline{L_{g l}}}-\ln \frac{L_{i j, c}^{0}}{L_{g l, c}^{0}}= & -\sigma\left(\ln \frac{w_{j}^{t}}{w_{l}^{t}}-\ln \frac{w_{j}^{0}}{w_{l}^{0}}, c\right)+ \\
& \sigma \sum_{k}\left(s_{k, i, c}-s_{k, g, c}\right)\left(\ln \frac{w_{j}^{t}}{w_{l}^{t}}-\ln \frac{w_{j}^{0}}{w_{l}^{0}, c}\right)+ \\
& \widehat{A S}_{i j, c}^{t}+\varepsilon_{i j, c}
\end{aligned}
$$

To check the robustriess of the $A S$-proxy in specification (IV) we actually 
estimate the coefficient of the allocation structure effect rather than assuming unity. Comparing the results of both specifications enables us to evaluate the impact of using the proxy $\widehat{A S}$ for the real allocation structure effect.

$$
\begin{aligned}
\ln \frac{\overline{L_{i j}}}{\overline{L_{g l}}}-\ln \frac{L_{i j, c}^{0}}{L_{g l, c}^{0}=} & -\sigma\left(\ln \frac{w_{j}^{t}}{w_{l}^{t}}-\ln \frac{w_{j}^{0}}{w_{l}^{0}}, c\right)+ \\
& \sigma \sum_{k}\left(s_{k, i, c}-s_{k, g, c}\right)\left(\ln \frac{w_{j}^{t}}{w_{l}^{t}}-\ln \frac{w_{j}^{0}}{w_{l}^{0}}, c\right)+ \\
& \gamma \widehat{A S_{i j, c}}+\varepsilon_{i j, c}
\end{aligned}
$$

We estimate specifications (I), (III) and (IV) by nonlinear least squares method and specification (II) by ordinary least squares. The results of the estimations are reported in Table 3.3. When no controls for differences in the allocation structure are included, changes in wages across countries, through a production function specification, explain little of the changes in allocation as indicated by the very low adjusted $R^{2}$ of specification (I). Though of a realistic magnitude, ${ }^{13}$ the estimate of the substitution elasticity parameter obtained via specification (I) is found insignificant.

The results derived by estimating the model with specification (II) indicate that differences in allocation across countries are to a large extent due to differences in allocation structure. The adjusted $R^{2}$ increases drastically compared to that of specification (I) indicating a large explicative power of allocation structure differences on differences in allocation observed across countries.

Therefore in specification (III) and (IV) we account for the allocation structure differences when estimating the production function. The results show that once control for allocation structure differences is included to specification (I), not only the explanatory power of changes in wages on changes in allocation is significantly increased, ${ }^{1.4}$ but the elasticity of substitution parameter becomes significant (at $1 \%)$.

\footnotetext{
${ }^{13}$ See Hamermesh (1992 and 1993) for an exhaustive survey of empirical estimates of labourlabour substitution elasticities. 'Hamermesh 's law,' based on empirical regularities, indicates that labour-labour substitution elasticities lie around 1.4.

${ }^{14} \mathrm{An}$ F-test reveals that specification (IV) also fits the data significantly better than specification (II), at the $1 \%$ level.
} 
Table 3.3: The relationship between allocation, wages and the allocation structure.

\begin{tabular}{|c|c|c|c|c|c|c|c|c|}
\hline Specification & (I) & & (II) & & (III) & & (IV) & \\
\hline \multicolumn{9}{|l|}{ Education } \\
\hline Arts-Humanities & & - & & & & - & & - \\
\hline Social-Sciences & .070 & $(.221)$ & & & .015 & $(.090)$ & .013 & $(.090)$ \\
\hline Business & -.177 & $(.312)$ & & & .064 & $(.091)$ & .069 & $(.091)$ \\
\hline Law & -.526 & $(.470)$ & & & -.053 & $(.094)$ & -.042 & $(.094)$ \\
\hline Natural-Sciences & -.105 & $(.271)$ & & & .102 & $(.089)$ & .107 & $(.090)$ \\
\hline Engineer & -.229 & $(.343)$ & & & .151 & $(.089)$ & .160 & (.090) \\
\hline Health & -.962 & $(.765)$ & & & -.109 & $(.102)$ & -.089 & $(.100)$ \\
\hline Constant: & .252 & $(.389)$ & .077 & $(.053)$ & .002 & $(.146)$ & .007 & $(.146)$ \\
\hline$\sigma$ & 2.362 & $(1.695)$ & & & 2.143 & $(.623)^{* *}$ & 2.138 & $(.623)^{* *}$ \\
\hline Control $\widehat{A S}$ & No & & Yes & & Yes & & Yes & \\
\hline$\gamma$ & - & & 1.026 & $(.015)^{* *}$ & - & & 1.020 & $(.016)^{* *}$ \\
\hline$T$ & 684 & & 684 & & 684 & & & 684 \\
\hline $\mathrm{df}$ & 8 & & 2 & & 8 & & & 9 \\
\hline$R_{a d j}^{2}$ & 0.097 & & 0.876 & & 0.878 & & & 0.878 \\
\hline
\end{tabular}


Table 3.4: Own-wage elasticities and Allen partial elasticities of substitution. evaluated for the world-wide allocation and equal wages across educational fields.

\begin{tabular}{|c|c|c|c|c|c|c|c|}
\hline \multicolumn{3}{|c|}{ Educational Fields } & \multicolumn{3}{|c|}{ Quantity of: } & \multirow[b]{2}{*}{ Engin } & \multirow[b]{2}{*}{ Health } \\
\hline $\begin{array}{l}\text { With respect } \\
\text { to wage of: }\end{array}$ & $\begin{array}{l}\text { Arts- } \\
\text { Huma }\end{array}$ & $\begin{array}{l}\text { Social } \\
\text { Siences }\end{array}$ & Busin & Law & $\begin{array}{l}\text { Natur- } \\
\text { Scienc }\end{array}$ & & \\
\hline Arts-Humanities & -1.32 & 2.53 & 2.05 & 1.49 & 1.78 & 1.05 & 1.12 \\
\hline Social-Sciences & & -1.74 & 2.97 & 1.99 & 1.30 & 1.12 & 1.39 \\
\hline Business & & & -1.46 & 1.94 & 1.49 & 1.43 & 0.94 \\
\hline Law & & & & -1.25 & 0.91 & 0.78 & 0.88 \\
\hline Natural-Sciences & & & & & -1.58 & 3.07 & 1.15 \\
\hline Engineer & & & & & & -1.15 & 1.04 \\
\hline Health & & & & & & & -0.98 \\
\hline Shares & .203 & 114 & .188 & .076 & .122 & .197 & .100 \\
\hline
\end{tabular}

The estimated substitution elasticity within occupations equals 2.14. Table 3.4 reports the Allen elasticities of substitution between all pairs of educational groups to illustrate the substitution possibilities between educational groups. The elasticities have been evaluated for the nine-country average allocation and equal wage rates between educational groups. The own-wage elasticities indicate that countries usually have more difficulties to adjust changes in relative wages of Health graduates $(-0.98)$ while they can more easily adjust changes in the wage rate of Social sciences graduates $(-1.74)$. All elasticities lie in the range of empirical regularities observed in Hamermesh and Grant (1979), Hamermesh (1992) and (1993). Though obtained in a context of cross-country analysis of wage differentials, the magnitude of our elasticities is comparable to the magnitude of elasticities obtained from time-series analyses. Bound and Johnson (1992) find a parameter of substitution elasticity of 1.75 between skill-groups within sectors once accounting for skilled-biased technological change, Katz and Murphy's (1992) estimate implies an elasticity of substitution between college and high school labour of 1.41. In our data, the largest elasticity of substitution is found between Engineering graduates and graduates in Natural Sciences which equals. 3.07 while the lowest elasticity of substitution is found between Engineering graduates and graduates from Law school (0.78). 
Table 3.5: Decomposition of international differences in allocation into supply and demand effects and allocation structure effects.

\begin{tabular}{l|ccccccccc|c}
\hline \hline $\begin{array}{l}\text { Countries } \\
\text { Allocation Gap: }\end{array}$ & It & Sp & Fr & Au & NI & UK & Fi & Jp & Ge & Tot \\
\hline $\begin{array}{l}\text { Observed } \\
\mathrm{A}_{c} \\
\begin{array}{l}\text { After control } \\
\text { for } S D\end{array}\end{array}$ & 55.1 & 55.5 & 63.3 & 65.8 & 64.3 & 50.0 & 52.5 & 81.4 & 49.8 & 59.7 \\
$\mathrm{~B}_{c}$ & & & & & & & & & & \\
$\begin{array}{l}\text { Structure } \\
\mathrm{C}_{c}\end{array}$ & 41.6 & 40.6 & 43.7 & 47.0 & 46.5 & 34.5 & 37.5 & 39.6 & 37.0 & 40.9 \\
& 29.9 & 31.4 & 32.7 & 38.0 & 39.1 & 22.0 & 26.2 & 27.7 & 25.1 & 30.2 \\
\hline $\begin{array}{l}\text { After control } \\
\text { for } \text { AS }\end{array}$ & & & & & & & & & & \\
$\mathrm{A}_{c}^{\prime}=\mathrm{A}_{c}-\mathrm{C}_{c}$ & 25.2 & 24.1 & 30.6 & 27.8 & 25.2 & 28.0 & 26.3 & 53.7 & 24.7 & 29.5 \\
$\begin{array}{l}\text { After control } \\
\text { for } S D \text { and } A S\end{array}$ & & & & & & & & & & \\
$\mathrm{~B}_{c}^{\prime}=\mathrm{B}_{c}-\mathrm{C}_{c}$ & 11.7 & 9.2 & 11.0 & 9.0 & 7.4 & 12.5 & 11.3 & 11.9 & 11.9 & 10.7 \\
\hline $\begin{array}{l}\% \text { Change in } \\
\text { Allocation }\end{array}$ & & & & & & & & & & \\
$\begin{array}{l}\text { No control for } A S \\
\text { Control for } A S\end{array}$ & 24.4 & 26.8 & 31.0 & 28.6 & 27.8 & 31.0 & 28.6 & 51.3 & 25.7 & 31.6 \\
\hline \hline
\end{tabular}

\subsubsection{A supply and demand explanation of wage differen- tials across countries}

The question is how much of the observed differences in allocation across countries is clue to observed differences in wage rates, allocation structures and other unobserved differences that might reflect labour market institutions. To answer this question we decompose the allocation differences between countries into quantity $A_{c}$ which measures the distance between observed allocation and the ninecountry average allocation, quantity $B_{c}$ which measures the distance between country-specific allocation at equalised wage rates by educational fields and the nine-country average allocation and quantity $C_{c}$ which measures the distance between country-specific allocation given the same supply and demand vectors across countries and the nine-country average allocation matrix.

Table 3.5 reports the results. First, the total actual differences in allocation 
reduces from 59.7 to 40.9 when wage differentials across countries are eliminated. This result implies that differences in supply and demand in the nine countries as measured by the between-educational-group wage differentials across countries account for $31.6 \%$ of the observed aliocation differences as indicated in the last row but one of Table 3.5. However, the differences in allocation structure already account for roughly $51 \%(30.2 / 59.7=.506)$ of the differences in observed allocation across countries. This shows that differences in the contents of the study are important across countries. The last row of the Table indicates that, once we control for the allocation structure differences across countries, the betweeneducational-group wage differentials across countries account for $63.9 \%$ of the observed allocation differences. This implies that after correcting for differences in the production function between countries roughly $2 / 3$ of the differences in allocation can be explained by wage differentials while the remaining $1 / 3$ can be imputed to unobserved factors, that may be related to labour market institutional factors like wage-setting, pay norms and minimum wage.

\subsection{Summary and conclusion}

The analysis pursued in this chapter and the ensuing empirical results highlighted the relevance of our allocation model in explaining the substitution process that take place in the labour market between different types of workers. We compared the allocation of workers with different educational fields to various occupations and wages across countries. Differences in the relative supply of labour across countries should coincide with wage differentials if the substitution process between the various types of labour occurs freely in each country. Blau and Kahn (1996), reject the supply and demand explanation of wage differentials across countries because the magnitude of the substitution effect necessary to match supply and demand differentials with wage differentials is not plausible. However, several other authors argue that the skill content of educational groups varies a great deal across countries which makes educational comparisons difficult.

The allocation model developed in Chapter 2, enabled us to detect differences in the allocation that are not caused by supply and demand factors but caused. by differences in the skill content of the various fields of study across countries. Therefore, we decomposed the substitution effect into an effect due to differences in the allocation structure induced by differences in the skill content of educa- 
tional segments and the true substitution effect resulting from supply shifts only. The true substitution effect can be compared with wage differentials.

Our empirical results have shown that cross-country differences in allocation are to a large extent $(50 \%)$ due to differences in allocation structure. Moreover, once these differences in allocation structure are controlled for, we found that wage differentials across countries coincide with at least $64 \%$ of employment differentials. The remaining differences can be related to differences in the labour market institutions of the various countries. 


\section{Appendix A. Cross-classification of workers' ed- ucational backgrounds and the various jobs}

Table 3.6: Classification of educational fields and occupational fields ('required education').

\begin{tabular}{l|l}
\hline \hline Educational fields & ISCED $^{a}$ codes (3 digits) \\
\hline & \\
'Arts-Humanities' & $14,20,21,22$ \\
'Social-Sciences' & $30-32$ \\
'Business' & $34,80-81,84,86$ \\
'Law' & 38 \\
'Natural-Sciences' & $40-48$ \\
'Engineer' & $50-64,85$ \\
'Health' & $72-76$ \\
& \\
\hline Occupations & ISCO ${ }^{b}$ codes (3 digits) \\
\hline & \\
'Managers-Legislators' & $100-131$ \\
'Natural-Sciences' & $200-213,220-221,300-312,314-321$ \\
'Engineering' & 214 \\
'Health' & $222-225,313,322-323$ \\
'Teaching' & $230-235,331-334$ \\
'Business' & $240-241,341-343$ \\
'Legal' & $242,344-345$ \\
'Social-Sciences' & $243-244,346$ \\
'Arts-Humanities' & $245-271,347-349$ \\
'Clerks' & $400-490$ \\
'Other-Lower' & $>499$ \\
\hline
\end{tabular}

${ }^{a}$ Since all individuals have a higher education, only the two last digits are reported. Individuals' ISCED first digits are 5, 6 or 7 .

${ }^{b}$ The first 9 occupational categories correspond to jobs for which a higher education is 'required' while for the last two, i.e. Clerks and Other-lower, a lower educational level is 'required'. 


\section{Appendix B. Wage premium by educational field and country}

Table 3.7: Wage-premium by educational field relative to Arts-Humanities graduates for each country and absolute distances in allocation.

\begin{tabular}{l|rrrrrrrrr}
\hline \hline $\ln w_{j 1, c}^{o b s}=\alpha_{j, c}$ & It & $\mathrm{Sp}$ & $\mathrm{Fr}$ & $\mathrm{Au}$ & $\mathrm{Nl}$ & $\mathrm{UK}$ & $\mathrm{Fi}$ & $\mathrm{Ge}$ & $\mathrm{Jp}$ \\
\hline Arts- & & & & & & & & & \\
Humanities (1) & - & - & - & - & - & - & - & - & - \\
Social- & & & & & & & & & \\
Sciences (2) & .10 & .03 & -.00 & -.01 & .12 & .05 & -.02 & .11 & .01 \\
Business (3) & .26 & -.02 & .23 & .19 & .10 & .09 & .21 & .12 & .00 \\
Law (4) & .17 & -.12 & .06 & -.07 & .19 & .12 & .15 & -.04 & .03 \\
Natural- & & & & & & & & & \\
Sciences (5) & .13 & .09 & .30 & .11 & .13 & .10 & .05 & .04 & .14 \\
Engineering (6) & .28 & .14 & .13 & .08 & .06 & .17 & .16 & .15 & .09 \\
Health (7) & .15 & -.09 & .13 & -.00 & .02 & .14 & .11 & -.05 & .14 \\
\hline $\bar{A}_{c}$ & 7.16 & $\overline{7} .21$ & 8.22 & 8.55 & 8.35 & 6.49 & 6.82 & 6.47 & 10.57 \\
\hline \hline
\end{tabular}

The wage-premia by educational field relative to Arts-Humanities graduates are derived from separate estimations of the earnings regression (equation 3.2) for each counity.

The average absolute distances between the allocation of each country and the nine-country average allocation, are measured as specified in equation 3.1. 


\section{Appendix C. Derived educational changes}

Table 3.8: Education-specific changes in allocation after controlling for demand and supply differences.

\begin{tabular}{l|rrllllllll}
\hline \hline $\ln S_{j 7}$ & It & $\mathrm{Sp}$ & $\mathrm{Fr}$ & $\mathrm{Au}$ & $\mathrm{Nl}$ & $\mathrm{UK}$ & $\mathrm{No}$ & $\mathrm{Fi}$ & $\mathrm{Ge}$ & \multicolumn{1}{c}{$\mathrm{Jp}$} \\
\hline Arts- \\
$\begin{array}{l}\text { Humanities } \\
\text { Social- }\end{array}$ & 0.15 & 0.48 & -2.98 & -1.18 & 0.26 & -1.05 & 2.09 & -0.70 & 0.28 & -0.98 \\
$\begin{array}{l}\text { Sciences } \\
\text { Business }\end{array}$ & 0.24 & -0.20 & -4.03 & -0.69 & 0.73 & -0.89 & 2.32 & -0.36 & 0.86 & -0.72 \\
Law & 0.48 & 0.32 & -4.07 & -1.06 & 0.17 & -0.41 & 3.79 & -0.37 & -0.61 & -0.17 \\
Natural- & 0.18 & 0.10 & -3.87 & -0.96 & 0.79 & 0.35 & 2.60 & 0.32 & 0.91 & -0.65 \\
Sciences & 0.30 & -0.10 & -3.82 & -1.44 & 1.13 & -1.00 & 2.22 & -0.69 & -0.37 & 0.10 \\
Engineering & -0.13 & -0.23 & -2.94 & -1.54 & 0.82 & -0.13 & 1.84 & -0.77 & -0.27 & -0.60 \\
Health & - & - & - & - & - & - & - & - & - & - \\
\hline \hline
\end{tabular}




\section{Appendix D. Derived occupational changes}

Table 3.9: Occupation-specific changes in allocation after controlling for demand and supply differences.

\begin{tabular}{l|rlllllllll}
\hline \hline $\ln R_{1 i}$ & It & Sp & Fr & Au & NI & UK & No & Fi & Ge & \multicolumn{1}{l}{ Jp } \\
\hline Manager & \multicolumn{1}{l}{ - } & - & - & - & - & - & - & - & - & - \\
Sciences & 1.15 & 0.22 & 0.66 & 0.88 & -0.75 & -0.79 & 0.45 & 0.10 & 0.46 & 1.04 \\
Engineer & 0.65 & 0.35 & 0.12 & 1.36 & -0.40 & -0.68 & 0.45 & 0.36 & 1.11 & 0.64 \\
Health & -0.19 & 0.62 & -0.28 & 2.82 & -1.13 & -0.06 & -0.37 & 0.71 & 0.61 & 0.67 \\
Teaching & 0.91 & 0.52 & -0.04 & 1.80 & -1.94 & -1.28 & 0.73 & 1.06 & 1.06 & 0.43 \\
Business & 2.10 & -1.55 & -0.75 & 1.79 & -0.29 & -0.93 & 0.72 & 0.65 & 0.91 & -0.41 \\
Legal & 1.92 & 0.24 & -0.15 & 2.67 & -2.10 & 0.15 & -1.09 & 0.87 & 2.18 & -0.50 \\
Social- & & & & & & & & & & \\
Sciences & 0.47 & -0.29 & -0.35 & 2.93 & -0.67 & -1.71 & -1.22 & 0.62 & 0.98 & -1.16 \\
Arts- & & & & & & & & & & \\
Humanities & 0.17 & -2.15 & -1.01 & 2.17 & -1.59 & -0.93 & 2.39 & 0.62 & 1.36 & -1.33 \\
Clerks & 1.04 & 1.12 & -0.80 & 0.44 & -1.42 & -1.19 & -3.68 & -1.35 & 0.12 & 2.16 \\
Other- & & & & & & & & & & \\
Lower & 0.46 & 0.59 & 0.05 & -0.28 & -1.69 & -0.91 & -1.75 & -0.97 & -0.55 & 2.32 \\
\hline \hline
\end{tabular}




\section{Appendix E. Decomposition of international dif- ferences in allocation: Weighted absolute distances}

Table 3.10: Decomposition of international differences in allocation into supply and demand effects and allocation structure effects, using weighted absolute distances

\begin{tabular}{|c|c|c|c|c|c|c|c|c|c|c|}
\hline $\begin{array}{l}\text { Countries } \\
\text { Allocation gap: }\end{array}$ & $\mathrm{It}$ & $\mathrm{Sp}$ & $\mathrm{Fr}$ & $\mathrm{Au}$ & $\mathrm{N}]$ & UK & $\mathrm{Fi}$ & $\overline{J p}$ & $\mathrm{Ge}$ & Tot \\
\hline $\begin{array}{l}\text { Observed } \\
\mathrm{A}_{C} \\
\text { After control } \\
\text { for } S D\end{array}$ & 52 & 62 & 51 & 83 & 72 & 55 & 50 & 78 & 51 & 554 \\
\hline $\begin{array}{l}\mathrm{B}_{c} \\
\text { Structure }\end{array}$ & 42 & 45 & 44 & 44 & 62 & 36 & 42 & 66 & 43 & 423 \\
\hline $\mathrm{C}_{c}$ & 39 & 50 & 43 & 49 & 58 & 34 & 43 & 59 & 39 & 413 \\
\hline $\begin{array}{l}\text { After control } \\
\text { for } A S \\
\mathrm{~A}_{c}^{\prime}=\mathrm{A}_{c}-\mathrm{C}_{c} \\
\text { After control for } \\
S D \text { and } A S \\
\mathrm{~B}_{c}^{\prime}=\mathrm{B}_{c}-\mathrm{C}_{c}\end{array}$ & 12 & -5 & 1 & -5 & 15 & 21 & -1 & 19 & 12 & 10 \\
\hline $\begin{array}{l}\text { \% Change in } \\
\text { Allocation } \\
\text { No control for } A S \\
\text { Control for } A S\end{array}$ & $\begin{array}{l}18 \\
76 \\
\end{array}$ & $\begin{array}{r}28 \\
141\end{array}$ & $\begin{array}{l}14 \\
93 \\
\end{array}$ & $\begin{array}{r}47 \\
113 \\
\end{array}$ & $\begin{array}{l}14 \\
71\end{array}$ & $\begin{array}{l}35 \\
91\end{array}$ & $\begin{array}{r}16 \\
108\end{array}$ & $\begin{array}{l}16 \\
63 \\
\end{array}$ & $\begin{array}{l}17 \\
74\end{array}$ & $\begin{array}{l}24 \\
93\end{array}$ \\
\hline
\end{tabular}

The distances are weighted by the average number of workers by education and occupation. 
CHAPTER 3. TESTING THE ASSIGNMENT MODEL 


\section{Chapter 4}

\section{Allocation structures, labour productivity and wage dispersion}

\subsection{Introduction}

An important implication of the allocation model developed in Chapter 2 is that the skill content of a study determines the assignment possibilities and therefore the substitution process in the labour market. In this chapter, we address the question whether some allocation structures can lead to a substitution process that is relatively more advantageous in terms of a higher labour productivity and lower labour market instability. ${ }^{1}$

For this reason, we analyse the structure of the allocation of workers with different fields of education to different occupations using the allocation model developed in Chapter 2. In the model, the optimal assignment of workers to tasks depends on productivity parameters indicating the range of tasks that workers with the various educational backgrounds can perform in each occupation. The allocation model enables us to distinguish between different allocation structures. Intuitively, the way in which generic and specific skills are integrated in each education would provide a first guess on how the general allocation structure looks like. Since generic skills provide workers with a wide range of occupational possibilities, we expect that graduates in educational fields that focus on generic skills

\footnotetext{
${ }^{1}$ In Newbery and Siglitz's (1981) terminology, we consider in this chapter only systematic supply variability. In our analysis, labour market instability is brought about by short run vertical shifts in the supply of labour with different educational backgrounds and these shifts manifest themselves in between education wage inequality.
} 
are able to perform a relatively large range of tasks in all specific occupations. However, we do not expect a linear relationship between the amount of generic skills someone has and the range of tasks he can perform in all occupations. We rather argue that the range of tasks that workers with generic skills can perform in specific occupations levels off after a certain amount of generic skills. For instance, if a person with some math skills would work as a pharmacist, he could calculate the doses of a prescription but his ability to solve differential equations will not increase the range of tasks he can perform as a pharmacist.

In contrast, we expect that graduates in educational fields that focus on specific skills are only able to perform a restricted range of the tasks in occupations outside their own occupational field. However, we expect that these workers are more productive in more general occupations than in another specific occupational field. Since generic skills are often needed to acquire more specific skills, workers with specific skills also have a fair amount of general skills which enables these workers to perform quite some tasks in the general occupation.

The question arises what happens when the relative supply of labour shifts given the allocation structure. Since workers with general education can perform a rather large range of tasks in every occupation, they can easily switch occupations without any effect on their wage level. We would therefore expect that a shift in the supply of workers between two specific educational fields leads to a change in the wage rates of these two types of workers and leaves the wage of workers with general education unchanged.

In a theoretical section we therefore analyse under what conditions one of the educational fields takes this role in the labour market. We derive a sufficient condition for the allocation structure to satisfy this type of reciprocal supply shifts in a three educational fields-three occupations case. We show that there is a family of allocation structures that satisfy the sufficient condition. These allocation structures are characterised by three productivity parameters. The first productivity parameter indicates the range of tasks that workers with the two educational backgrounds for which a supply shift is observed can perform in each other's occupation. The second parameter indicates the range of tasks that workers with the two educational backgrounds for which a supply shift is observed can perform in the occupational field of workers with the educational background for which the supply does not shift. The third parameter indicates the range of tasks that workers with the educational background for which there is no supply shift can perform in the occupational fields of workers for which a 
supply shift is observed. Simulations show that both the labour productivity and wage dispersion are sensitive to the relative magnitude of these three parameters. As expected, the model shows that the more specific the skills of workers the larger labour productivity, i.e. increasing the range of tasks that workers can perform in occupations for which they are not directly trained decreases labour productivity. This result emphasises the relative importance of specific skills for productivity. However, the larger the range of tasks that workers can perform outside their own occupation the smaller the sensitivity of labour productivity to shifts in the supply of labour, and the smaller the increase in wage dispersion in case of unexpected supply shifts. This result emphasises the relative importance of generic skills for labour market stability.

To illustrate the findings of our theoretical model, we use data on the Dutch labour market and estimate the elasticity of substitution parameters together with the allocation structure of workers with general, technical and social services educational fields working in three more or less related occupations at the intermediate level. The estimation results show that the demand for workers with a general educational background is less elastic than the demand for workers with technical and social services vocational specialisation. This result corroborates empirical findings showing that the more general the human capital, the more inelastic the demand for that group of workers (e.g. Hamermesh (1992)). This suggests that a relative decrease in the supply of graduates with general education can only be absorbed by a relatively large increase in the relative wage of these graduates.

Moreover, the estimated allocation structure indicates that as expected 1) workers with general education can perform a large range of tasks in technical and social services occupations, 2) the range of tasks that workers with technical and social services educational fields can perform in each other's occupation is rather similar and relatively small and 3 ) the range of tasks that workers with technical education can perform in the general occupation is relatively large and roughly equal to the range of tasks that workers with social services can perform in this occupation. The role of the general educational field at the intermediate educational level in the Netherlands is very similar to our theoretical definition of general education and technical and social services educational fields correspond to our theoretical definition of more specific vocational education.

We show that increasing the amount of specific skills that enables graduates of general education to be more productive in the general occupational field at 
the expense of their generic skills, will increase labour productivity but will also increase the sensitivity of labour productivity to shifts in the supply of workers with technical and social services education. Moreover, wage dispersion would increase when the supply of workers with general education shifts. Decreasing the range of tasks that technical and social services graduates can perform in general occupation, by decreasing the amount of generic skills of these graduates, will increase labour productivity but make labour productivity more sensitive to shifts in the supply of labour with general education. Moreover, when the supply of workers with general education shifts, wage inequality will increase. Finally, increasing the range of tasks that workers with technical and social services education can perform in each other's occupations by increasing their amount of generic skills, would decrease both labour productivity and wage dispersion.

Although the specialisation of labour is an important feature of the labour market, as it enhances workers' productivity in their related occupational field, our results suggest that the flexibility of the labour market, measured by the ease to substitute between occupations and between workers with different educational backgrounds, should be accounted for when defining the skill content of the various educational fields. Our results show that the larger the ease to substitute between occupational outputs compared to the ease to substitute between workers, the larger the change in labour productivity associated to a $x \%$ decrease in the range of tasks that workers with general education can perform outside the general occupation. However, the smaller the ease to substitute between occupations compared to the ease of substitution between workers, the larger the change in labour productivity associated to a $x \%$ decrease in the range of tasks that workers with technical and social services can perform in the general occupation.

The question whether the allocation structure in the labour market affects the labour market outcomes is related to the literature on the relevance of vocational specialisation in initial education. The relevance of vocational specialisation in initial education has long been the subject of divergence of opinion. Some authors, e.g. Kang and Bishop (1989) and Bishop (1995), argue that generic skills are mere tools for developing specific skills but have no direct market value. Others, e.g. Comay et al. (1973) and Dothan and Williams (1981), argue that general education ${ }^{2}$ offers the individuals the option of choosing among additional

\footnotetext{
${ }^{2}$ Note that we use the terminology 'general education' for the educational fields that em-
} 
occupations or careers. This option value hypothesis would imply that workers with general educational field can perform a rather large range of tasks in the various occupations. We contribute to this discussion in two ways. First, our model enables us to account for the option value of generic skills but without imposing that the option value increases linearly with the amount of generic skills. We rather expect the option value to level off at a certain level of generic skills. Second, we argue that workers with vocational specialisations also have an option value. Though workers with specific skills can perform a rather restricted range of tasks in other specific occupations, if generic skills are tools for developing specific skills, we would expect that workers with specific skills have a fair amount of general skills which enables them to perform a quite large range of tasks in the general occupation. This option value is confirmed by our empirical result showing that workers with vocational specialisations can perform a large range of tasks in the general occupation.

The structure of the chapter is as follows. In the next section, we adapt the allocation model developed in Chapter 2 to a three educational fields-three occupations case. In Section 4.3 we isolate allocation structures such that a shift in the supply of labour in two educational segments leads to a reciprocal change in wage rates in these two segments and leaves the wage rate in the other segment unchanged. We then evaluate how these different structures affect labour productivity and wage inequality between the various educational groups of workers. Section 4.4 discusses the data we use for our empirical analysis. In Section 4.5, we estimate the allocation structure in the Dutch labour market and discuss some implications of the results we find. Section 4.6 summarises and concludes.

\subsection{The theoretical model}

Assume the economy to produce a physical output in time period $t$, denoted $H_{t}$. Its price is used as a common denominator to all input prices. There are $m$

\footnotetext{
phasise on generic skills, e.g. skills that can be used in several occupations, like reading: mathematies, etc and not to indicate the breadth of the curriculum (see Dolton and Vignoles (2002) for instance). In both cases, workers can perform a quite large range of tasks in occupations outside their own occupation. But in the first case, because they have generic skills that are overall usefull, whereas in the curriculum case, workers have learnt a broad range of specific skills.
} 
distinct occupations and $n$ educational groups of workers. In each occupation, the various labour groups are combined in certain proportions to produce intermediate output, denoted $H_{i t}$. These occupational outputs are all intermediates which serve only to contribute to the production of the physical output. Both the labour and commodity markets are assumed to be perfectly competitive.

The production function is of the form depicted in the theoretical model of Chapter 2, i.e. equation 2.7 , but with $m$ occupations and $n$ educational groups, and looks like: ${ }^{3}$

$$
H_{t}=\left(\sum_{i}\left(\sum_{j} a_{i j} L_{i j t}^{\beta_{e}}\right)^{\beta_{\mathrm{o}} / \beta_{e}}\right)^{1 / \beta_{o}}
$$

where $\beta_{o}$ is a production technology parameter determining the ease to substitute between occupational outputs $\left(H_{i t}=\left(\sum_{j} a_{i j} L_{i j t}^{\beta_{e}}\right)^{1 / \beta_{e}}\right.$ is the output in occupation $i$ at time $t), a_{i j}$ is the productivity parameter of workers with education $j$ in occupation $i$ and satisfies $a_{i j}>0 \forall i, j$ and $\sum_{j} a_{i j}=1$. $\beta_{e}$ is a production technology parameter determining the ease to substitute between educational categories within occupations. By definition of the CES production function $\beta_{o}, \beta_{e} \in(-\infty, 0) \cup(0,1) . L_{i j t}$ denotes the employment of workers with education $j$ in occupation $i$ at time $t$.

The allocation structure is characterised by the parameters $a_{i j}$ reflecting the range of tasks in occupation $i$ that workers with education $j$ can perform. Since occupations are measured in the same dimension as education: 'required' education and education attained respectively, in each occupation, we expect that the workers whose attained education is in the required field are able to perform all tasks in that occupation, i.e. $a_{i i} \geq a_{i j} \forall j \neq i$.

Assume workers' wage with educational background $j$ is uniformly distributed over occupations. This implies that wherever these workers find employment they

\footnotetext{
${ }^{3}$ This CES specification is similar to the specification used in Bound and Johuson (1992) and is the discrete form of Teulings (1995a, 1995b and 2002). However, we do not restrict the elasticity of substitution between the various groups of workers to be greater than 1 , as in both Bound and Johnson (1992) and Teulings (1995a and 1995b). This refers to Hamermesh's law (see Hamermesh (1986)). It reflects apparent regularities in empirical results.
} 
are offered a standard wage corresponding to their education. ${ }^{4}$ The demand for workers with education $j$ in occupation $i$ is derived by equating marginal products and to competitive wages $\frac{\partial H}{\partial L_{i j}}=w_{j}$ :

$$
L_{i j t}=H_{t} \times U C^{\sigma_{o}}\left(w_{t}\right) \times U C_{i}^{\sigma_{e}-\sigma_{o}}\left(w_{t}\right) \times\left(\frac{a_{i j}}{w_{j t}}\right)^{\sigma_{e}} \forall i, j
$$

with

$$
\begin{aligned}
U C\left(w_{t}\right) & =\left(\sum_{i} U C_{i}^{1-\sigma_{o}}\left(w_{t}\right)\right)^{1 /\left(1-\sigma_{o}\right)} \\
U C_{i}\left(w_{t}\right) & =\left(\sum_{j} a_{i j}^{\sigma_{e}} \times w_{j t}^{1-\sigma_{e}}\right)^{1 /\left(1-\sigma_{e}\right)}
\end{aligned}
$$

where $w_{j t}$ stands for the nominal wage of workers with education $j$ and $w_{t}=$ $\left\langle w_{1 t}, \ldots, w_{n t}\right\rangle . U C$ stands for Unit Cost. The function $U C_{i}$ can be viewed as the shadow price of producing an extra unit of intermediate output $H_{i t}$. The ratio between two occupations is exactly defined as minus the marginal rate of technical substitution between the intermediate outputs of these two occupations. $U C$ can be viewed as the shadow price of producing an extra unit of output $H_{t}$.

Aggregating equation 4.2 on $i$ gives the labour demand for workers with education $j$ that minimises costs.

$$
L_{j t}=\sum_{i} L_{i j t}=H_{t} \times U C^{\sigma_{o}}\left(w_{t}\right) \times w_{j t}^{-\sigma_{e}} \times \sum_{i} U C_{i}^{\sigma_{e}-\sigma_{o}}\left(w_{t}\right) \times a_{i j}^{\sigma_{e}}
$$

\footnotetext{
"The analysis assumes that workers are rewarded according to their vocational specialisation as stated by the human capital theory. Therefore, the optimal allocation path is characterised by a constant ratio of the relative allocation of workers with one education, say $j$, in two different occupations versus the relative allocation of workers with another education, say $k$, in these two occupations. The presence of workers outside their specific occupational field is conditioned to some extent by the production technology that firms use rather than by wage differentials (as stated by the comparative advantage theory). We tested the human capital earnings function specification against competing hypothesis of assignment for the Dutch labour market and did not find support for the assignment earnings specification. The job competition and human capital hypotheses where statistically equivalent.
} 
When the supply of labour with education $j$ is inelastic to the market, i.e. $\bar{L}_{j t}$, equation 4.5 can be used to derived equilibrium wage rates by solving, for all educational groups, the system $L_{j t}\left(w_{j}\right)=\bar{L}_{j t}$.

Aggregating equation 4.5 on $j$ gives the total labour demand that minimises costs given full employment $L_{t}=\bar{L}_{t}=\sum \bar{L}_{. j t}$ at $t$.

$$
\bar{L}_{t} \equiv L_{t}=\sum_{i} \sum_{j} L_{i j t}=H_{t} \times U C^{\sigma_{o}}\left(w_{t}\right) \times \sum_{i} U C_{i}^{\sigma_{e}-\sigma_{o}}\left(w_{t}\right) \times \sum_{j} a_{i j}^{\sigma_{e}} \times w_{j t}^{-\sigma_{\epsilon}}
$$

The minimum costs, given the labour supply constraint, are therefore:

$$
\sum_{i} \sum_{j} w_{j t} L_{i j t}=H_{t} \times U C\left(w_{t}\right)
$$

and hence, the output price is given by the unit cost function $U C$ :

$$
p_{t}=U C\left(w_{t}\right)
$$

The relative educational demand equations in each occupation can be directly derived from equation 4.2 :

$$
\frac{L_{i j t}}{L_{i k t}}=\left(\frac{a_{i j}}{a_{i k}} \frac{w_{k t}}{w_{j t}}\right)^{\sigma_{e}} \forall i, j, k
$$

Equation 4.9 tells that in a given occupation, $i$, the relative allocation of workers with two different types of education is proportional to the relative range of tasks these workers can perform in occupation $i$ raised to the power of the elasticity of substitution $\sigma_{e}$. 
The relative demand for workers with education $j$ in two different occupations read as:

$$
\begin{gathered}
\frac{L_{i j t}}{L_{g j t}}=\left(\frac{U C_{i}\left(w_{t}\right)}{U C_{g}\left(w_{t}\right)}\right)^{\sigma_{e}-\sigma_{o}} \times\left(\frac{a_{i j}}{a_{g j}}\right)^{\sigma_{e}} \forall i, g, j \\
\frac{L_{i j t}}{L_{g j t}}=\left(-M R T S_{i, g}\right)^{\sigma_{e}-\sigma_{o}} \times\left(\frac{a_{i j}}{a_{g j}}\right)^{\sigma_{e}}
\end{gathered}
$$

where $M R T S_{i, g}$ stands for the marginal rate of technical substitution between the intermediate outputs in occupation $i$ and $g$.

Equation 4.10 is somewhat more complicated to interpret. The larger the range of tasks that workers with education $j$ can perform in occupation $i$ compared to the range of tasks these workers can perform in another occupation, the larger the relative allocation of workers with education $j$ in occupation $i$. Moreover, the larger the costs of producing an extra unit of output in occupation $i$ compared to the costs of producing an extra unit of output in occupation $g$, the larger (smaller) the relative allocation of workers with education $j$ in occupation $i$ when the ease to substitute between educational groups of workers is larger (smaller) than the ease to substitute between workers within occupations. Intuitively, as the costs of producing output in occupation $i$ increase, firms will be willing to substitute production in this occupation for production in other occupations. As long as firms find it technically possible to substitute occupational outputs, i.e. large $\sigma_{o}$, the demand for workers in occupation $i$ will decrease. In contrast, when the ease to substitute between occupational output is small, final output is produced with fixed proportions of occupational outputs. However, it may be technically possible to substitute workers within occupations, i.e. $\sigma_{e}$ is large, such that the demand for workers in occupation $i$ increases.

Combining equations 4.9 and 4.10 results in a general expression of the relative allocation of workers with different educational backgrounds in different occupations. 


$$
\frac{L_{i j t}}{L_{g k t}}=\left(\frac{U C_{i}\left(w_{t}\right)}{U C_{g}\left(w_{t}\right)}\right)^{\sigma_{e}-\sigma_{a}} \times\left(\frac{a_{i j}}{a_{g k}} \frac{w_{k t}}{w_{j t}}\right)^{\sigma_{e}} \forall<i, g>\text { and }<j, k>
$$

\subsection{Allocation structures}

The economy is assumed to produce output, $H_{t}$, at the lowest possible costs given labour supply $\bar{L}_{j t}$. Solving this optimisation problem, the optimal allocation of workers with a particular education to the various occupations, $L_{i j t}$ is derived from equation 4.2 and the optimal employment of workers by education $L_{, j t}$ is obtained by summing equation 4.2 over $i$ and equating to labour supply $\vec{L}_{, j t}$. Suppose at time $t$ the economy is in equilibrium for wages $w_{t}$ and allocation $L_{i j t}$ given labour supply by education $\bar{L}_{. j t}$. Suppose that the supply of labour shifts such that the composition of labour by education, $\bar{L}_{. j t+1}$, differs from $\bar{L}_{. j t}$ for some educational segments. How would this shift affect the allocation of workers with different educational backgrounds to the various occupations, labour productivity and wages? Would the wage of workers whose supply does not shift be affected? The answers to these questions obviously depend on the range of tasks in each occupation workers with the various educational backgrounds can perform, i.e. the structure of the productivity parameters $a_{i j}$.

The allocation model enables us to distinguish between different types of allocation structures. Intuitively, the way in which general and specific skills are integrated in each educational field would provide a first guess on how the general allocation structure looks like. Since general skills are often acknowledged as providing workers with a wide range of occupational possibilities, we expect graduates in educational fields that emphasise on general skills to be able to perform a relatively large range of tasks in all occupations. In contrast, we expect graduates in educational fields emphasising on specific skills to be able to perform a restricted range of the tasks in occupations other than their own occupational field. However, we expect graduates in educational fields focusing on specific skills to be relatively productive in general occupations. Indeed, since general skills are often needed to acquire more specific skills, workers with specific skills have a fair amount of general skills which enables these workers to perform a quite large range of tasks in the general occupation. The question arises what happens when the relative supply of labour shifts given such an allocation structure. Since 
workers with general education can perform a rather large range of tasks in every occupation, they can easily switch occupations. We would therefore expect a shift in the supply of workers between two specific educational fields to lead to a reciprocal change in the wage rate of these two types of workers that leaves the wage of workers with general education unchanged. We first isolate allocation structures that satisfy this condition. We then evaluate how these different structures affect labour productivity and the wage dispersion between the various educational groups of workers as unexpected shifts in labour supply occur.

\subsubsection{Isolating allocation structures}

Answering the question how would shifts in the composition of labour supply affect the allocation of workers with different educational backgrounds to the various occupations requires first to define a benchmark equilibrium situation to which unexpected supply shifts will be measured. We will refer to this benchmark situation as the long run equilibrium situation. An obvious choice for the long run equilibrium is the equilibrium associated with equal wage rates between educational groups of workers, i.e. $w_{j t}=w_{k t}=w_{t} \forall j, k$, as the wage dispersion between groups of workers is 0 for equal wages. In the short run however, unexpected shifts in labour supply may occur. These shifts generate a substitution process which will affect labour productivity and wage dispersion relatively more for some allocation structures than for others.

We consider a labour market with three educational segments, say the educational segments 1,2 and 3, and three occupations more or less related to the educational segments. We focus on reciprocal supply shifts that lead to changes in the educational composition of labour such that the total level of employment remains constant. These shifts are defined as follows:

- Supply of labour with education 1 and 3 shifts $\Delta \bar{L}_{.1}=-\Delta \bar{L}_{.3}$

- Supply of labour with education 2 is unchanged $\left(\Delta \bar{L}_{2}=0\right)$.

The changes in wages resulting from these supply shifts are derived by some back-of-the-envelope calculations. We derive equation 4.2 with respect to $\left\langle w_{j t}\right\rangle_{j=1,2,3}$ and solve the system of supply differentials $\Delta \bar{L}_{. j}$ for $\left\langle\Delta w_{1}, \Delta w_{2}, \Delta w_{3}\right\rangle$ : 


$$
\Delta \bar{L}_{, j}=\sum_{i} \sum_{k} \Delta w_{k} \frac{\partial L_{i j}}{\partial w_{k}}, \forall j
$$

The system defined by equation 4.12 has 2 degrees of freedom for three unknowns. One way to solve the system is to impose the linear restriction $\Delta w_{1}=-\Delta w_{3}$ for instance. This way we simultaneously minimise wage differentials by spreading the wage gap evenly on both the wage for education 1 and 3. (see Appendix $\mathrm{D}$ for a step by step derivation.)

The solution for $\left\langle\Delta w_{1}, \Delta w_{2}, \Delta w_{3}\right\rangle$ reads as:

$$
\begin{aligned}
\Delta w_{1} & =-\frac{1}{2} \frac{\partial L_{2}}{\partial w_{2}} \Gamma \\
\Delta w_{2} & =\left(-\frac{\partial L_{2}}{\partial w_{3}}-\frac{1}{2} \frac{\partial L_{.2}}{\partial w_{2}}\right) \Gamma \\
\Delta w_{3} & =\frac{1}{2} \frac{\partial L_{.2}}{\partial w_{2}} \Gamma
\end{aligned}
$$

where $\Gamma=\frac{\Delta \bar{L}_{3}}{\frac{\partial L_{1}}{\partial w_{2}} \frac{\partial L_{3}}{\partial w_{2}}-\frac{\partial L_{3}}{\partial w_{1}} \frac{\partial L_{2} 2}{\partial w_{2}}}$ and $\frac{\partial L_{j j}}{\partial w_{k}}=\sum_{i} \frac{\partial L_{i j}}{\partial w_{k}}$.

Note that $\Gamma \neq 0$ for all $\Delta \bar{L}_{3} \neq 0$. Indeed, since $\frac{\partial L_{2}}{\partial w_{2}}<0$ and $\frac{\partial L_{2}}{\partial w_{k}}>0$ for $k \neq j$, we have $\frac{\partial L_{1}}{\partial w_{2}} \frac{\partial L_{3}}{\partial w_{2}}-\frac{\partial L_{3}}{\partial w_{1}} \frac{\partial L_{2}}{\partial w_{2}}>0$. Moreover, since $\frac{\partial L_{2}, 2}{\partial w_{2}}$ is strictly negative for all $w_{1}, w_{2}$ and $w_{3}$ we know that $\Delta w_{1}=-\Delta w_{3}$ are different from zero and of the sign of $-\Delta \bar{L}_{3}$. However $\Delta w_{2}$ can be positive, zero or negative depending on the sign of $\left(-\frac{\partial L_{2}}{\partial w_{3}}-\frac{1}{2} \frac{\partial L_{2}}{\partial w_{2}}\right)$.

Hence, the reciprocal shifts in the educational composition of labour supply always lead to changes in the wage rate of workers with education 1 and 3 whereas changes in the wage of workers with education 2 may not be necessary, i.e. $\Delta w_{2}=0$ if $-\frac{\partial L_{2}}{\partial w_{3}}=\frac{1}{2} \frac{\partial L_{2}}{\partial w_{2}}$ for all $\Delta \bar{L}_{3.3}$. This leads us to isolate conditions on the productivity parameters for which supply shifts between two educational fields lead to reciprocal changes in the wage rates of workers in these two educational fields only, i.e. $\Delta w_{2}=0$.

Using the notation $a_{i j}=\pi_{i j} / \sum_{k} \pi_{i k} \forall i, j$ and $\pi_{i i}=1>\pi_{i j} \forall i$, to simplify the expression of the results, it can be shown that $\pi_{21}=\pi_{23}=a, \pi_{31}=\pi_{13}=c$ and 
Table 4.1: Allocation structure: some particularities.

$$
\Delta w_{2}=0
$$

\begin{tabular}{ll|lll}
\multicolumn{2}{c}{$\pi_{i j}$} & \multicolumn{3}{c}{ Edu } \\
& & 1 & 2 & 3 \\
\hline \multirow{3}{*}{ Occ } & 1 & 1 & $\pi_{12}$ & $\pi_{13}$ \\
& 2 & $\pi_{21}$ & 1 & $\pi_{23}$ \\
& 3 & $\pi_{31}$ & $\pi_{32}$ & 1
\end{tabular}

$\Longrightarrow \quad$\begin{tabular}{cc|ccc}
\multicolumn{3}{c}{$\pi_{i j}$} & \multicolumn{3}{c}{ Edu } \\
& & 1 & 2 & 3 \\
\hline & 1 & 1 & $b$ & $c$ \\
Occ & 2 & $a$ & 1 & $a$ \\
& 3 & $c$ & $b$ & 1
\end{tabular}

$\pi_{32}=\pi_{12}=b$ is a sufficient condition ${ }^{5}$ to achieve the reciprocal changes in the educational composition of employment with shifts in the wage rate of workers with education 1 and 3 only. The sufficient condition is visualised in Table 4.1.

The structure of parameters that makes that $\Delta w_{2}=0$ indicates that the range of tasks that workers with education 2 , that is workers whose employment does not change, can perform outside their own occupation has to be evenly distributed. This contrasts with workers with education 1 and 3 . However, this structure indicates that the range of the tasks in occupation 3 that workers with education 1 can perform must be equivalent to the range of tasks in occupation 1 that workers with education 3 can perform. Moreover, workers with education 1 and 3 must be able to perform the same range of tasks in occupation 2 .

Intuitively, we expect studies that emphasise on general skills to satisfy the characteristics of education 2 with $b$ relatively large. Indeed, general skills are often acknowledged as providing workers with a wide range of occupational possibilities. In contrast, we expect educational fields emphasising on specific skills to satisfy the characteristics of education 1 and 3 with a relatively small value of $c$. However, we expect $a$ to be relatively large. Indeed, since general skills are often needed to acquire more specific skills, workers with specific skills have a fair amount of general skills which enables these workers to perform a quite large range of tasks in the general occupation.

\subsubsection{Simulations}

The question arises whether the different allocation structures affect the labour productivity and wage dispersion. In particular, we are interested in answering the three following types of questions: would labour productivity and wage dispersion increase or decrease if 1 ) the range of tasks that workers with education 2

\footnotetext{
${ }^{5}$ See Appendix D for more details on the derivation of the sufficient conditions.
} 
can perform outside their own occupation increases or decreases? 2) the range of tasks that workers with education 1 and 3 can perform in occupation 2 increases or decreases? and 3 ) the range of tasks that workers with education 1 and 3 can perform in each other's occupation increases or decreases? To evaluate the relative impact of parameters $a, b$ and $c$ on labour productivity and the wage dispersion between educational groups we run simulations of labour productivity and wage dispersion as we move on the demand curve of each educational type of labour (supply of each type of labour varies from 0 to $\infty$ ). We then compare labour productivity and wage dispersion for two different values of each parameter.

The relative magnitude of the elasticity of substitution parameters. $\sigma_{s}$ and $\sigma_{e}$ plays an important role in the allocation of workers. Increasing the range of tasks a group of workers can perform in occupation $i$ decreases (respectively increases) the costs of producing an extra unit of output in this occupation if the ease to substitute workers within occupation is larger (smaller) than unity. As can be seen from equation 4.4, increasing $a_{i j}$ increases $U C_{i}$ if and only if $\sigma_{e}<1$. In turn, the demand for workers in occupation $i$ increases (decreases) as the costs of producing output in occupation $i$ increases if the ease to substitute between occupations is smaller (larger) than the ease to substitute workers within occupations. We therefore replicate the comparisons of labour productivity and wage dispersion for two different values of each parameter for $\sigma_{b}>\sigma_{e}$ and $\sigma_{o}<$ $\sigma_{e}$.

Though the mathematical expression of labour productivity in terms of the supply of labour with the various educational fields only does not exist, we can derive numerical solutions. The expression of the labour productivity as a function of the equilibrium wages in the $3 \times 3$ situation is derived from equation 4.6. Denoting labour productivity $h$, we obtain:

$$
\begin{aligned}
h\left(w_{1}, w_{2}, w_{3}\right) & \equiv \frac{H}{\bar{L}}=\left[U C^{\sigma_{o}}(w) \sum_{i=1,2,3} U C_{i}^{\sigma_{e}-\sigma_{o}}(w) \sum_{j=1,2,3} a_{i j}^{\sigma_{e}} w_{j}^{-\sigma_{e}}\right]^{-1} \\
& =\frac{1}{p} \frac{\sum_{j} w_{j} \bar{L}_{. j}}{\bar{L}}=\frac{\bar{w}}{p}
\end{aligned}
$$

The labour productivity is equal to the average real wage of workers $\bar{w} / p$ 
as can be seen from the equations 4.7 and 4.8. Numerical solutions for the labour productivity as a function of labour supply are derived by searching for the equilibrium wages $w=\left\langle w_{1}, w_{2}, w_{3}\right\rangle$ that correspond to the target composition of labour supply. Hence, we search for the vector:

$$
\left\langle w_{1}, w_{2}, w_{3}\right\rangle=\left\langle w_{1}\left(\bar{L}_{.1}, \bar{L}_{.2}, \bar{L}_{.3}\right), w_{2}\left(\bar{L}_{.1}, \bar{L}_{.2}, \bar{L}_{.3}\right), w_{3}\left(\bar{L}_{.1}, \bar{L}_{.2}, \bar{L}_{.3}\right)\right\rangle .
$$

The same procedure is used to derive numerical solutions for the wage dispersion as a function of labour supply only. The variance in real wages between educational groups of workers, denoted $V$, reads as:

$$
\begin{aligned}
V\left(w_{1}, w_{2}, w_{3}\right)= & \frac{1}{p^{2}}\left(\frac{1}{\bar{L}} \sum_{j=1,2,3} \bar{L}_{j} \times w_{j}^{2}-\bar{w}^{2}\right) \\
= & U C^{-2}(w) \frac{\sum_{j} w_{j}^{2-\sigma_{e}} \sum_{i} a_{i j}^{\sigma_{e}} \times U C_{i}^{\sigma_{e}-\sigma_{o}}(w)}{\sum_{j} w_{j}^{-\sigma_{e}} \sum_{i} a_{i j}^{\sigma_{e}} \times U C_{i}^{\sigma_{e}-\sigma_{o}}(w)}- \\
& {\left[U C^{\sigma_{o}}(w) \sum_{i=1,2,3} U C_{i}^{\sigma_{e}-\sigma_{o}}(w) \sum_{j=1,2,3} a_{i j}^{\sigma_{e}} w_{j}^{-\sigma_{e}}\right]^{-2} }
\end{aligned}
$$

To evaluate the relative impact of the parameters $a, b$ and $c$ on labour productivity and wage dispersion between educational fields, we evaluate the labour productivity and wage dispersion given some benchmark allocation structure and compare them with the labour productivity and wage dispersion obtained by changing one parameter at a time. The benchmark allocation structure ${ }^{6}$ is $a=0.5, b=0.5$ and $c=0.1$ such that education 2 can be seen as a general skill, and education 1 and 2 as specific skills with a fair amount of general skills (i.e. a large $a$ ).

To test for the effect of decreasing the amount of general skills taught in vocational education on labour productivity and wage dispersion, we set $a^{\prime}=0.3$. We let $\bar{L}_{.1}$ and $\bar{L}_{.2}$ vary, one at a time and evaluate the inequalities: ${ }^{7}$

\footnotetext{
${ }^{6}$ We ran the comparative statics for other parameters values as well and found similar conclusions regarding the relative impact of allocation structures in terms of labour productivity and wage dispersion.

${ }^{7}$ Note that $h\left(\bar{L}_{11}, \bar{L}_{.2}, \bar{L}_{3}\right)=h\left(\bar{L}_{3}, \bar{L}_{2}, \bar{L}_{11}\right)$ and $V\left(\bar{L}_{11}, \bar{L}_{2 .}, \bar{L}_{3}\right)=V\left(\bar{L}_{3}, \bar{L}_{2 .}, \bar{L}_{1}\right)$ for all $a$, $b$ and $c$ and all $\bar{L}_{j}$. Hence varying $\bar{L}_{1}$ is equivalent to varying $\bar{L}_{3}$ in terms of productivity and wage dispersion.
} 


\section{Labour productivity}

$$
\frac{h\left(\bar{L}_{.1}, \bar{L}_{.2}, \bar{L}_{.3}\right) \mid a^{\prime}}{h\left(\bar{L}_{.1}, \bar{L}_{.2}, \bar{L}_{.3}\right) \mid a} \gtreqless 0
$$

Wage dispersion

$$
V\left(\bar{L}_{.1}, \bar{L}_{.2}, \bar{L}_{.3}\right)\left|a^{\prime}-V\left(\bar{L}_{1 .}, \bar{L}_{.2}, \bar{L}_{.3}\right)\right| a \gtreqless 0
$$

We then set $b^{\prime}=0.3$ such that educational field 2 becomes a rather specific educational field. With $b^{\prime}$ instead of $b$, the allocation structure is characterised by three more or less specific educational fields. This enables us to test for the relevance of general education. We let $\bar{L}_{1 .}$ and $\bar{L}_{.2}$ vary, one at a time and evaluate the inequalities:

Labour productivity

$$
\frac{h\left(\bar{L}_{.1}, \bar{L}_{.2}, \bar{L}_{.3}\right) \mid b^{\prime}}{h\left(\bar{L}_{1}, \bar{L}_{.2}, \bar{L}_{.3}\right) \mid b} \gtreqless 0
$$

Wage dispersion

$$
V\left(\bar{L}_{.1}, \bar{L}_{.2}, \bar{L}_{.3}\right)\left|b^{\prime}-V\left(\bar{L}_{.1}, \bar{L}_{.2}, \bar{L}_{3}\right)\right| b \gtreqless 0
$$

To complete this test, we set $c^{\prime}=0.3$. With $\epsilon^{\prime}$ instead of $c$, the allocation structure is characterised by three more or less general educational fields. This enables us to test for the relevance of technical education. We let $\bar{L}_{.1}$ and $\bar{L}_{.2}$ vary, one at a time and evaluate the inequalities:

Labour productivity

$$
\frac{h\left(\bar{L}_{1,}, \bar{L}_{.2}, \bar{L}_{.3}\right) \mid c^{\prime}}{h\left(\bar{L}_{1.1}, \bar{L}_{2,}, \bar{L}_{.3}\right) \mid c} \gtreqless 0 \text { for all } \bar{L}_{. j}
$$


Wage dispersion

$$
V\left(\bar{L}_{1}, \bar{L}_{2}, \bar{L}_{.3}\right)\left|c^{\prime}-V\left(\bar{L}_{1 .}, \bar{L}_{.2}, \bar{L}_{.3}\right)\right| c \gtreqless 0
$$

Since the relative magnitude of the elasticity parameters is determinant for the evaluation of the inequalities, we run the three sets of inequalities for $\sigma_{o}=$ $0.5<\sigma_{e}=1.5$ and $\sigma_{o}=2.5>\sigma_{e}=1.5$.

\section{Labour demand}

A decrease of the range of tasks that workers with education 1 and 3 can perform in occupation 2, i.e. decreasing $a$, would make the demand for workers with education 2 relatively less elastic and leave the demand for labour with education 1 and 3 unchanged if the elasticity of substitution between occupations is less than the elasticity of substitution between workers within occupations. ${ }^{8}$ (See Figure 4.1) In contrast, when $\sigma_{o}>\sigma_{e}$, the demand for labour with education 2 is unchanged, while the demand for labour with education 1 and 3 becomes less. elastic as indicated in Figure 4.2.

A decrease in the range of tasks that workers with education 2 can perform in occupation 1 and 3 , i.e. decreasing $b$, would make the demand for labour with education 1 and 3 relatively less elastic and leaves the demand for labour with education 1 and 3 unchanged if the elasticity of substitution between occupations is less than the elasticity of substitution between workers within occupations. (See Figure 4.3) However, when occupational outputs are better substitutable than workers, i.e. $\sigma_{o}>\sigma_{e}$, the demand for labour with education 2 becomes more elastic, while the demand for labour with education 1 and 3 remains fairly stable. (See Figure 4.4)

An increase in the range of tasks that workers with education 1 and 3 can perform in each other's occupation would have no effect on the demand for labour with education 2 regardless of the relative ease to substitute between occupational output and between workers within occupations. (See Figure 4.5 and 4.6 )

\footnotetext{
${ }^{8}$ We normalised employment of each type to unity at the long run (benchmark) equilitrium (that is for equal wages) for graphical representation.
} 


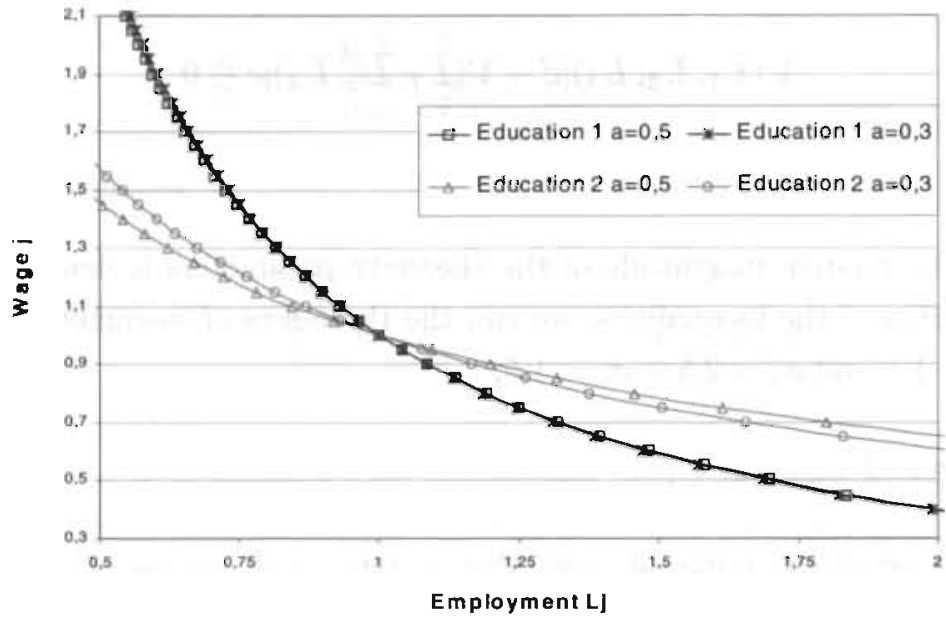

Figure 4.1: Shifts in labour demand associated to a decrease in $a, \sigma_{o}<\sigma_{e}$.

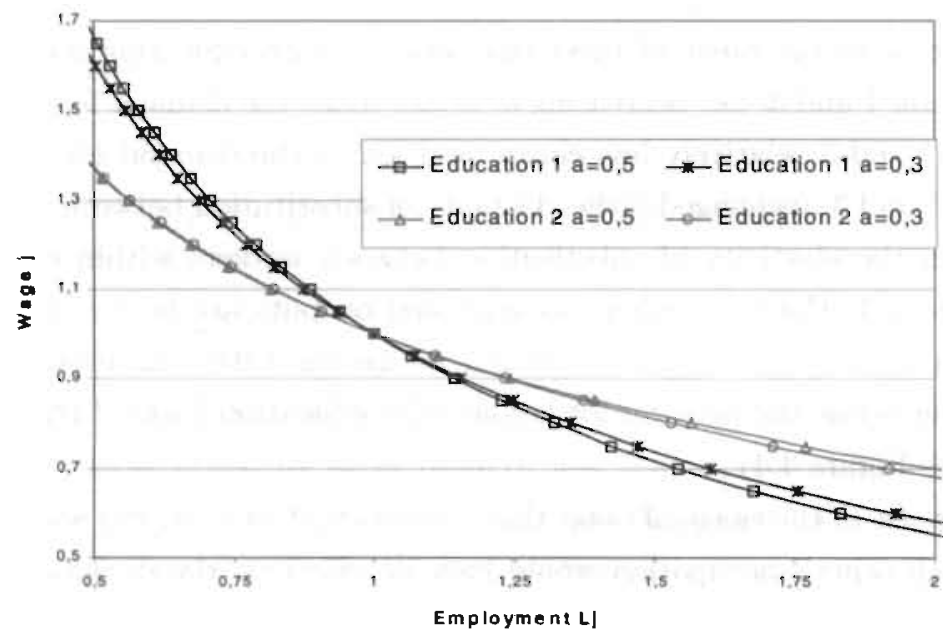

Figure 4.2: Shifts in labour demand associated to a decrease in $a, \sigma_{o}>\sigma_{e}$. 


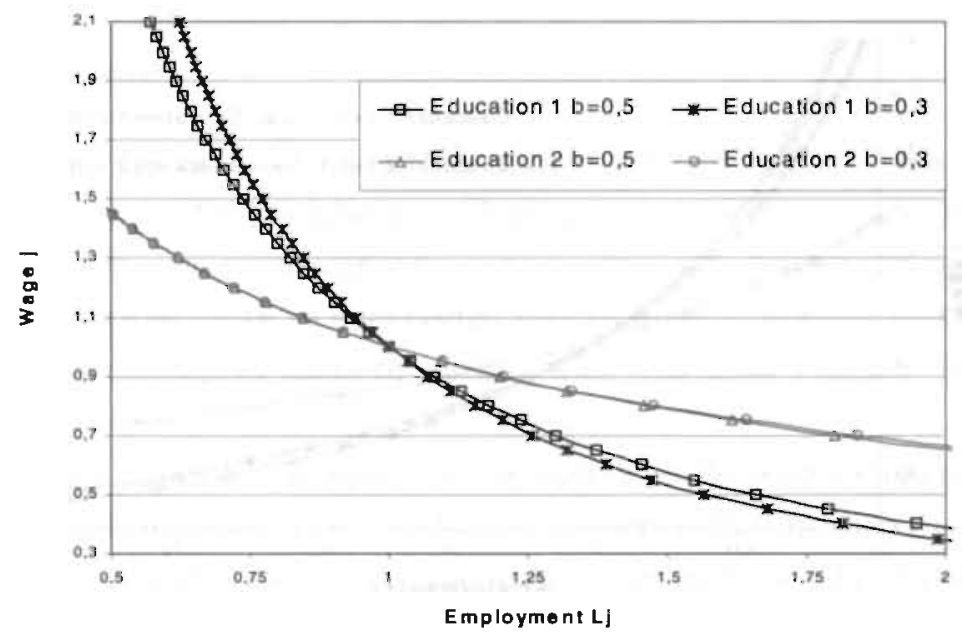

Figure 4.3: Shifts in labour demand associated to a decrease in $b, \sigma_{o}<\sigma_{e}$.

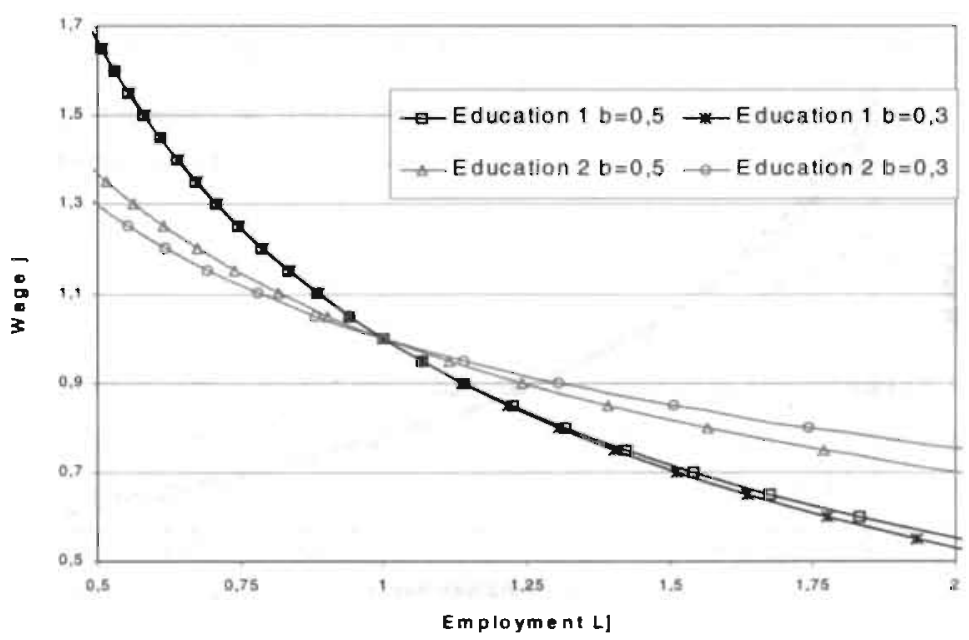

Figure 4.4: Shifts in labour demand associated to a decrease in $b, \sigma_{o}>\sigma_{e}$. 


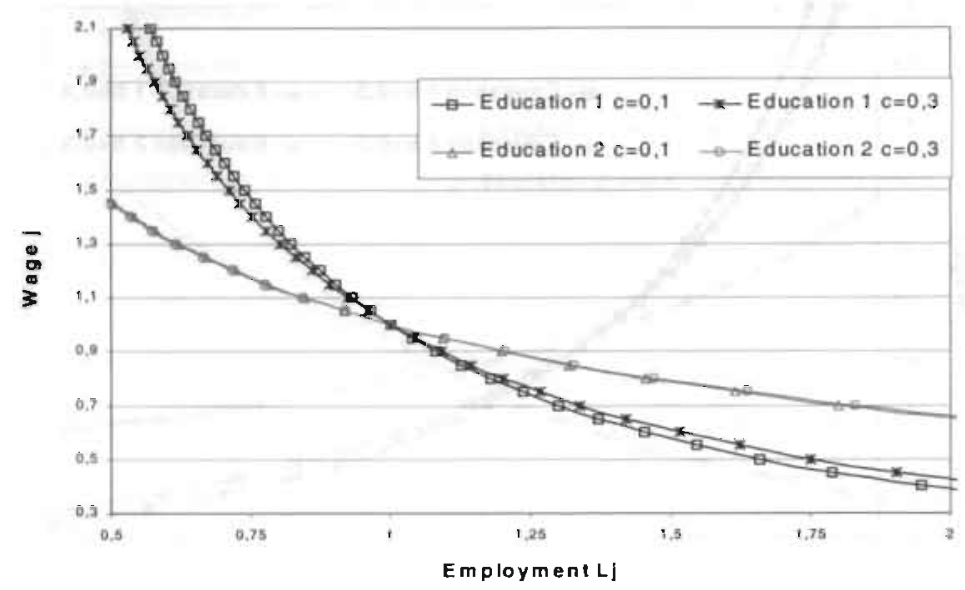

Figure 4.5: Shifts in labour demand associated to an increase in $c, \sigma_{o}<\sigma_{e}$.

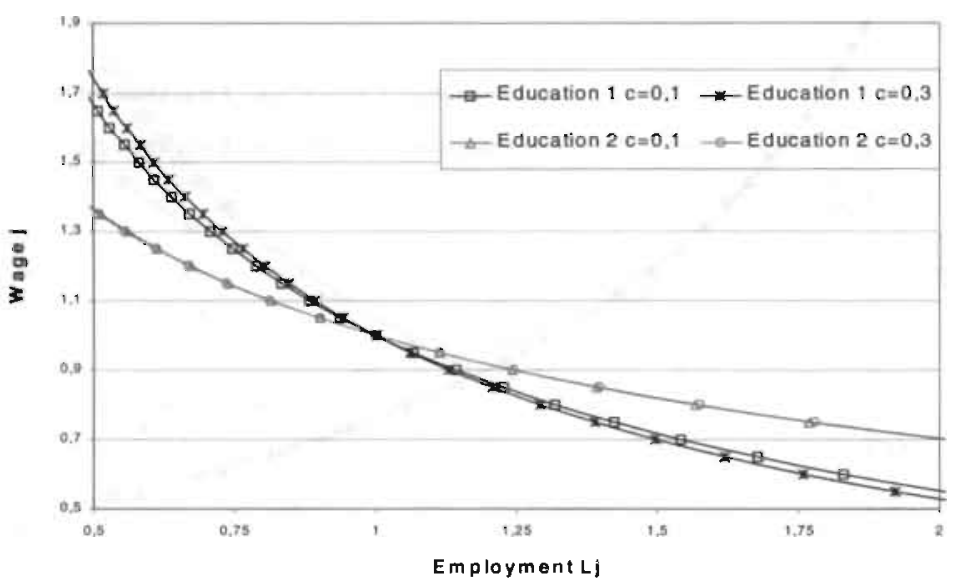

Figure 4.6: Shifts in labour demand associated to an increase in $c, \sigma_{o}>\sigma_{e}$. 


\subsection{ALLOCATION STRUCTURES}

However, the demand for labour with education 1 and 3 becomes more (less) elastic when $\sigma_{o}<\sigma_{e}\left(\sigma_{o}>\sigma_{e}\right)$.

\section{Labour productivity}

Decreasing the range of tasks that workers with education 1 and 3 can perform in occupation 2 shifts labour productivity upward regardless of the relative magnitude of the elasticities of substitution. However, labour productivity becomes also more sensitive to unexpected supply shifts of workers with education 2 than equivalent supply shifts of workers with education 1 and 3. (See Figure 4.7 and 4.8 )

As Figure 4.9 and 4.10 indicate, independently of the relative magnitude of $\sigma_{o}$ and $\sigma_{e}$, a decrease in the range of tasks that workers with education 2 can perform in occupation 1 and 3 , i.e. a decrease in $b$, would increase labour productivity. Although, labour productivity would become more sensitive to shifts in the supply of labour with education 1 and 3 than to equivalent shifts in the supply of labour with education 2 .

Increasing the range of tasks that workers with education 1 and 3 can perform in each other's occupation, increasing $c_{\text {: }}$ would decrease labour productivity regardless of the magnitude of the elasticity of substitution between occupations and between workers within occupations, as indicated in Figure 4.11 and 4.12. Moreover, variation in the magnitude of $c$ appears to have very little effect on. the relative sensitivity of the labour productivity with respect to the respective supply of labour.

\section{Wage dispersion between educational fields}

A decrease in the range of tasks that workers with education 1 and 3 can perform in occupation 2 would increase wage dispersion regardless of the labour supply of workers with education 2, but especially in case of large supply. (See Figure 4.13 and 4.14) However, the wage dispersion will roughly be unchanged, irrespective of the labour supply of workers with education 1 and 3 .

As the range of tasks that workers with education 2 can perform in occupation 1 and 3 decreases, wage dispersion increases regardless the supply of labour with education 1 and 3 , if workers are more substitutable than occupational outputs. 


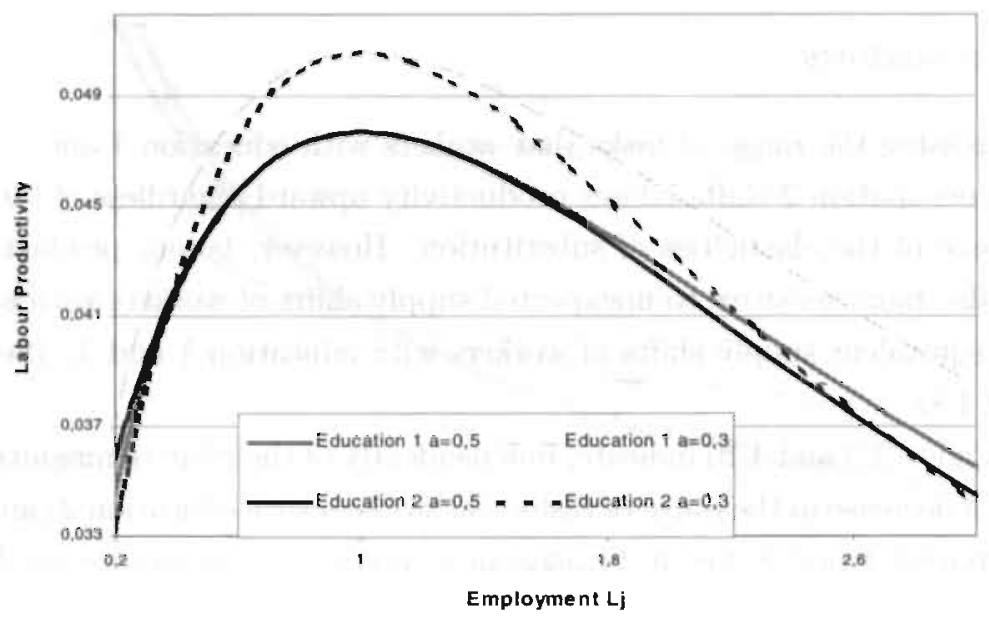

Figure 4.7: Shifts in labour productivity associated to a decrease in $a, \sigma_{o}<\sigma_{e}$.

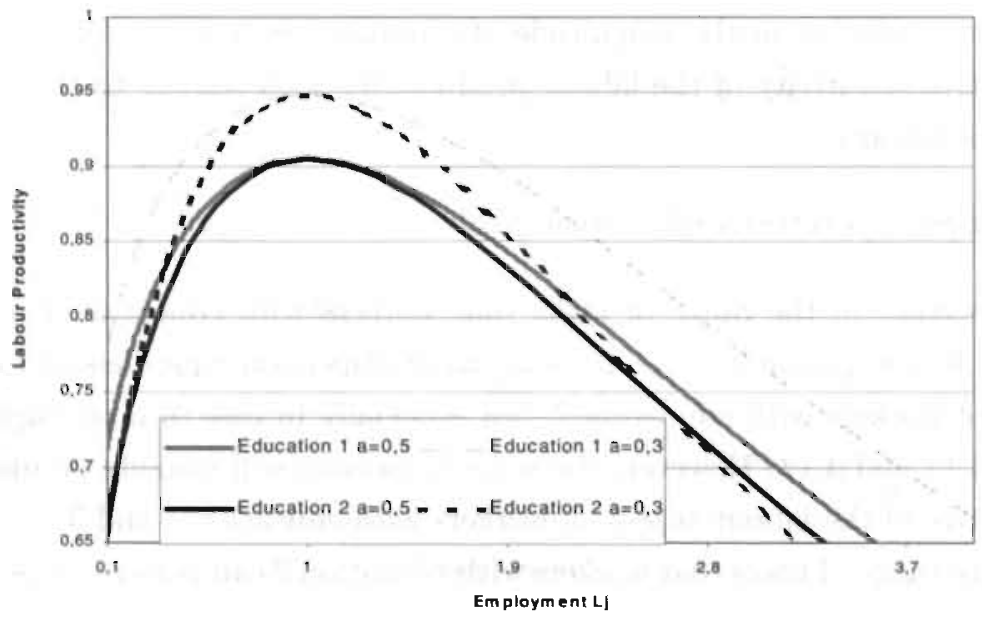

Figure 4.8: Shifts in labour productivity associated to a decrease in $a, \sigma_{n}>\sigma_{e}$. 


\subsection{ALLOCATION STRUCTURES}

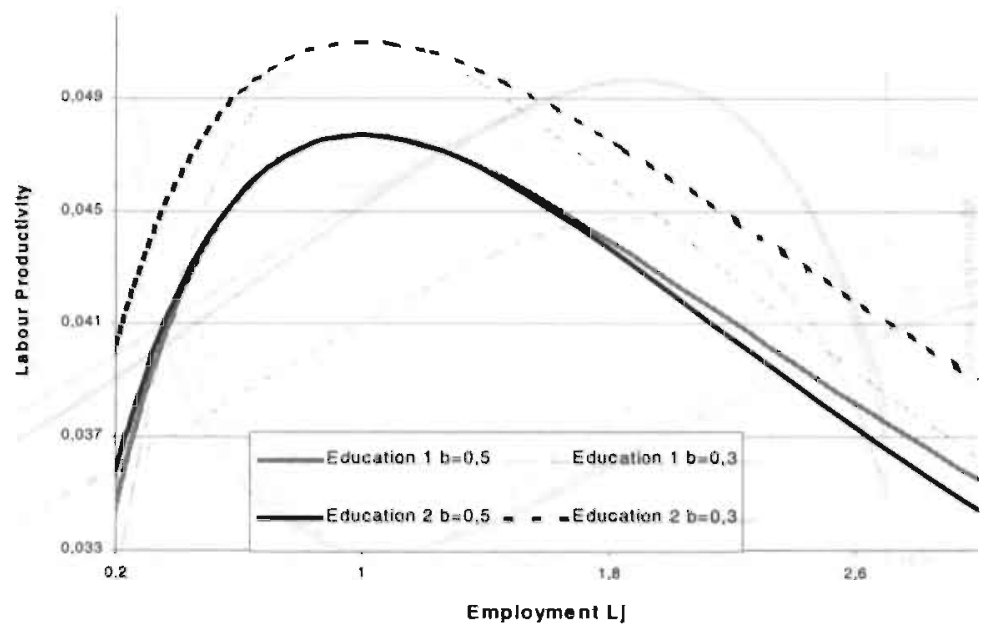

Figure 4.9: Shifts in labour productivity associated to a decrease in $b, \sigma_{o}<\sigma_{e}$.

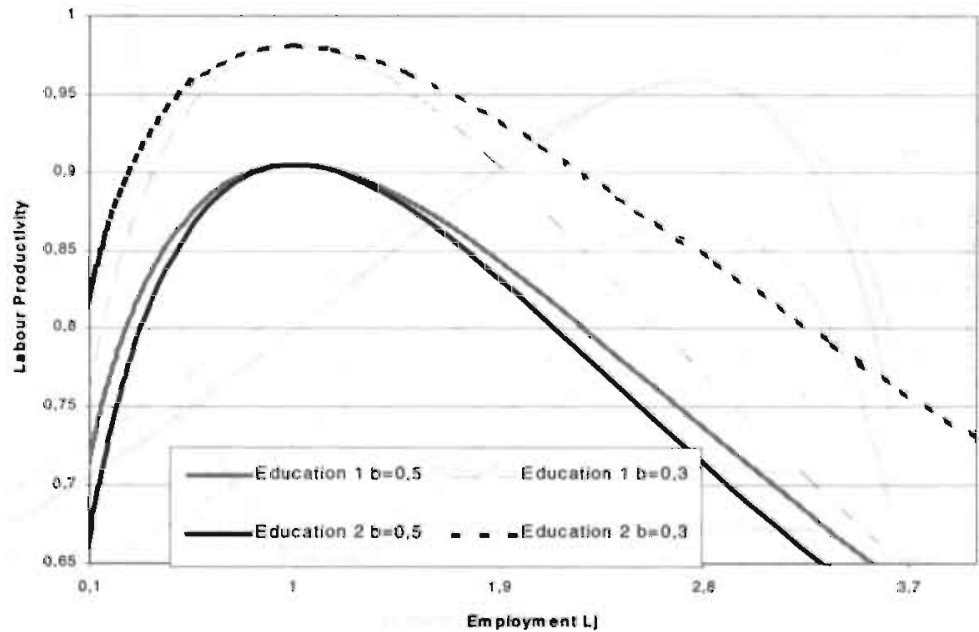

Figure 4.10: Shifts in labour productivity associated to a decrease in $b, \sigma_{o}>\sigma_{e}$. 


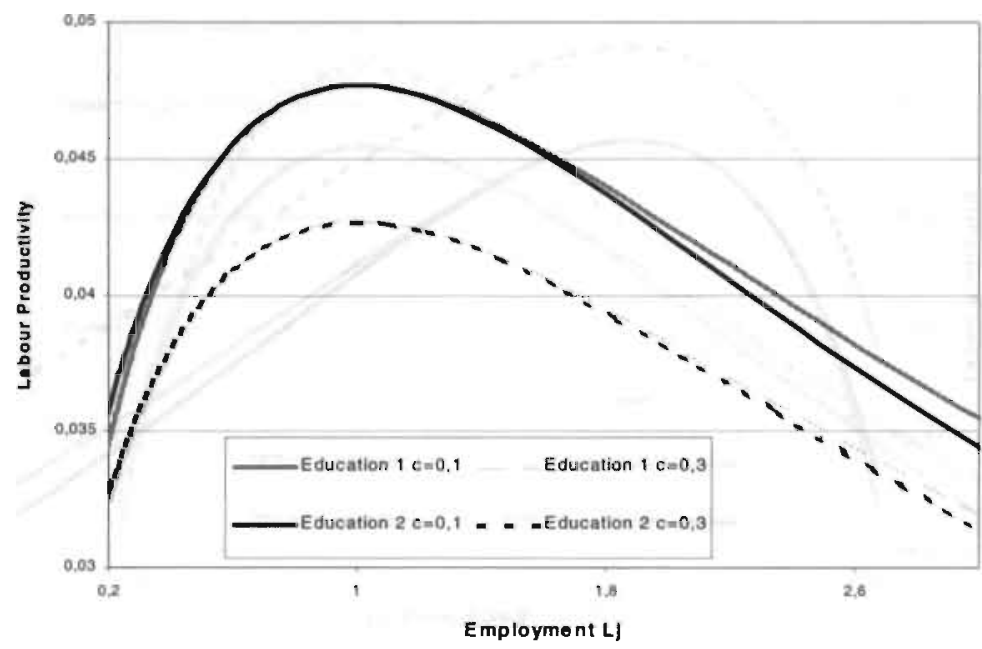

Figure 4.11: Shifts in labour productivity associated to an increase in $c, \sigma_{o}<\sigma_{e}$.

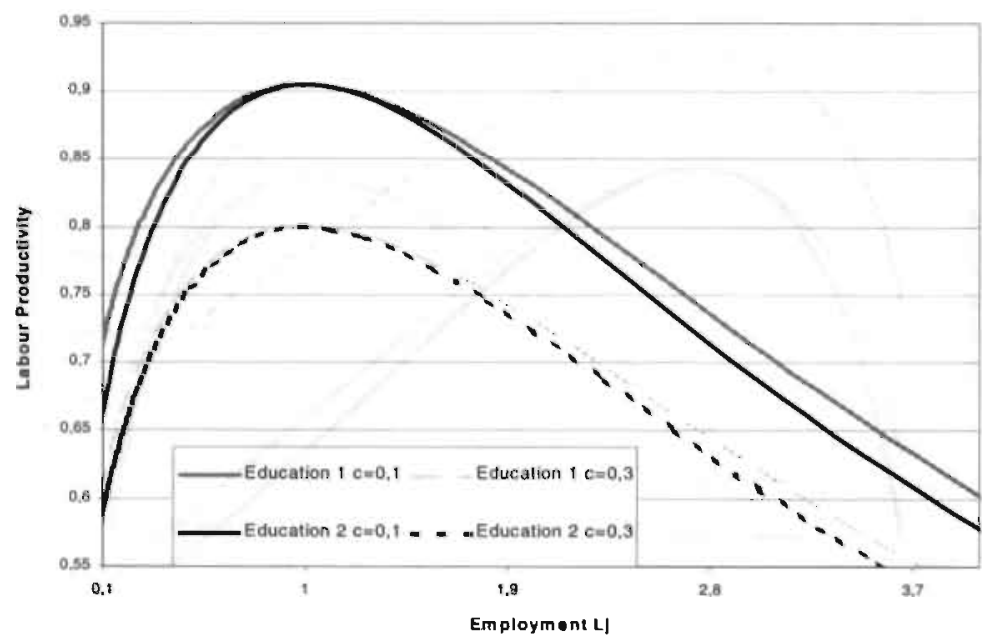

Figure 4.12: Shifts in labour productivity associated to an increase in $c, \sigma_{o}>\sigma_{e}$. 


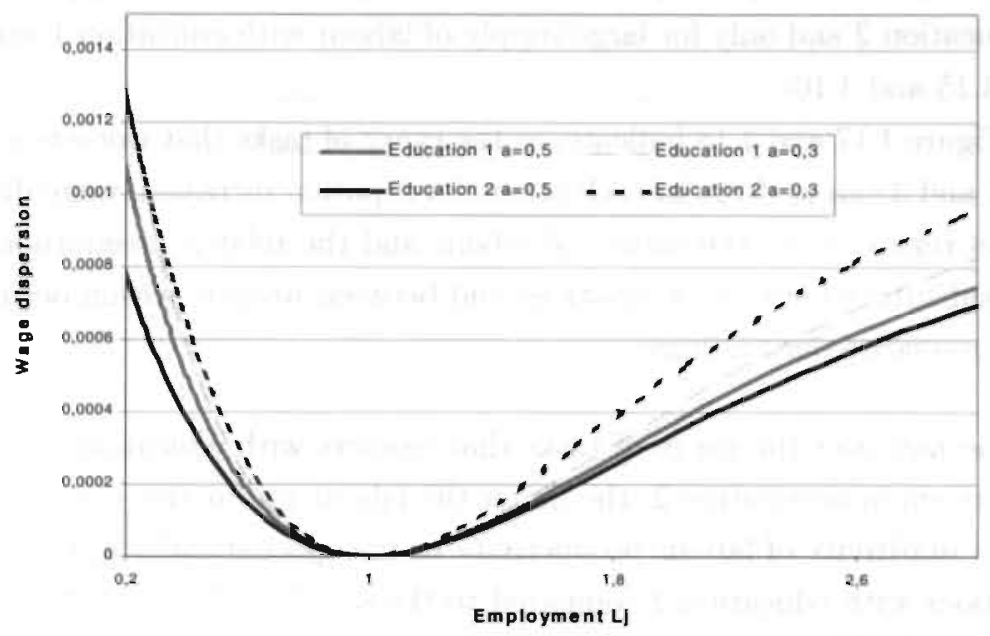

Figure 4.13: Shifts in wage dispersion associated to a decrease in $a, \sigma_{o}<\sigma_{e}$.

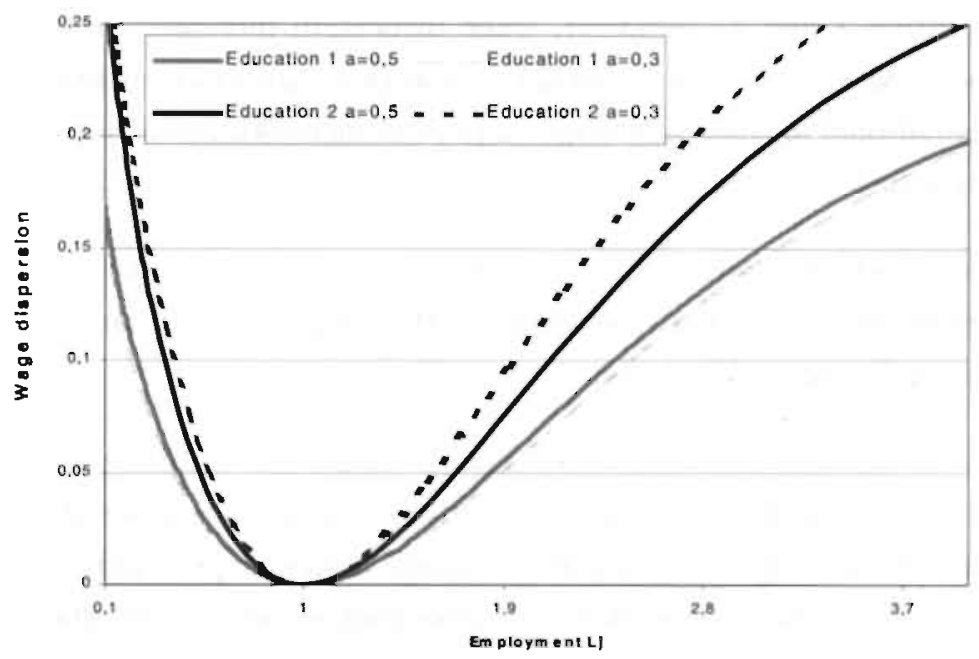

Figure 4.14: Shifts in wage dispersion associated to a decrease in $a, \sigma_{o}>\sigma_{e}$. 
In contrast, when occupational outputs are more substitutable than workers within occupations, wage dispersion increases regardless of the supply of labour with education 2 and only for large supply of labour with education 1 and 3.(See Figure 4.15 and 4.16)

As Figure 4.17 and 4.18 indicate, as the range of tasks that workers with education 1 and 3 can perform in each other's occupation increases, wage dispersion decreases regardless of the supply of labour and the relative magnitudes of the ease to substitute between occupations and between workers within occupations.

To summarise our findings:

- The narrower the range of tasks that workers with education 1 and 3 can perform in occupation 2, the larger the labour productivity and the larger the sensitivity of labour productivity to unexpected shifts in the supply of labour with education 2 compared to the supply of labour with education 1 and 3 . However, wage dispersion increases irrespective of the supply of workers with education 2.

- The narrower the range of tasks that workers with education 2 can perform in occupation 1 and 3, the larger labour productivity and the larger the sensitivity of labour productivity to shifts in the supply of workers with education 1 and 3. However, wage dispersion increases for all supply of labour with education 1 and 3 when workers are more substitutable than occupational outputs and wage dispersion increases for all supply of labour with education 2 when $\sigma_{o}>\sigma_{e}$.

- The larger the range of tasks that workers with education 1 and 3 can perform in each other's occupation, the smaller labour productivity and the smaller wage dispersion.

- Moreover, the simulations show that the larger the elasticity of substitution between occupations compared to the elasticity of substitution between workers, the larger the percentage change in labour productivity associated to a $\mathrm{x} \%$ decrease in the range of tasks that workers with education 2 can perform in occupation 1 and 3. Indeed, decreasing the range of tasks that workers with education 2 can perform in occupation 1 and 3 by $40 \%$ (from 0.5 to 0.3 ) increases long run labour productivity by $8.5 \%$ (see Figure 4.10 ) if the elasticity of substitution between occupations is larger than within 


\subsection{ALLOCATION STRUCTURES}

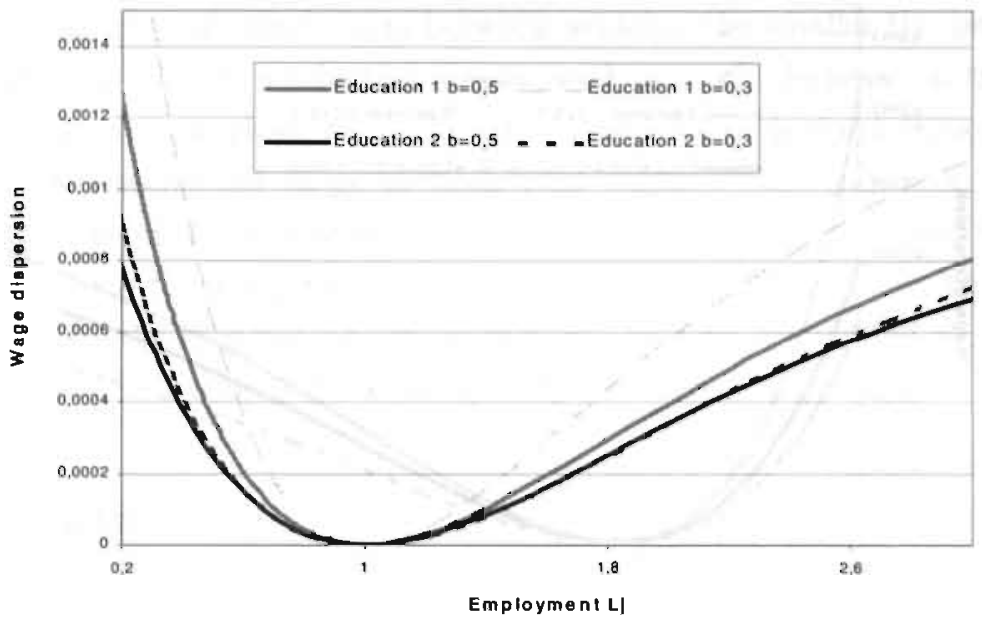

Figure 4.15: Shifts in wage dispersion associated to a decrease in $b, \sigma_{0}<\sigma_{\epsilon}$.

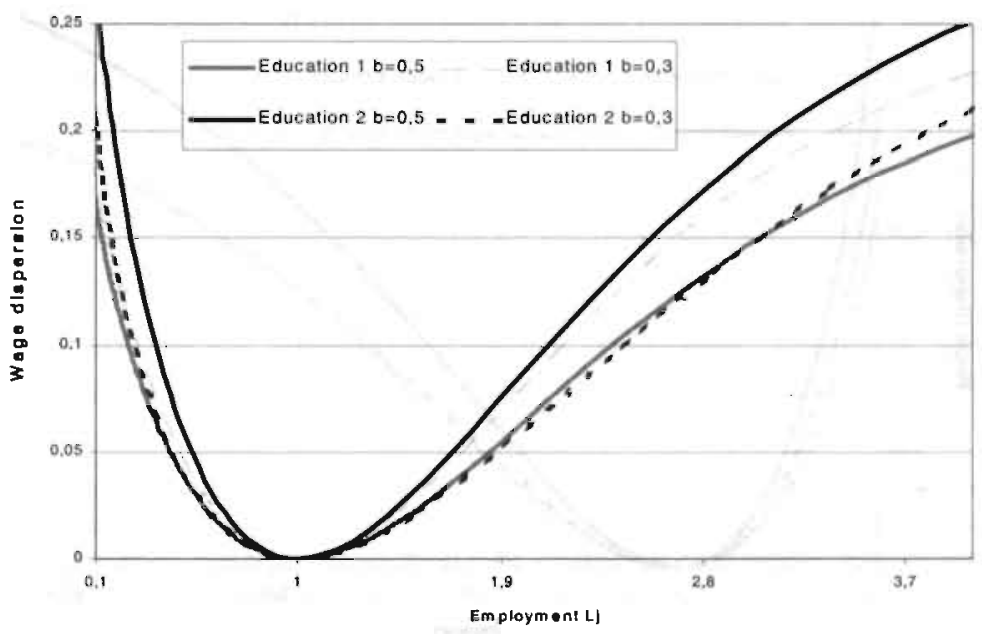

Figure 4.16: Shifts in wage dispersion associated to a decrease in $b, \sigma_{n}>\sigma_{\varepsilon}$. 


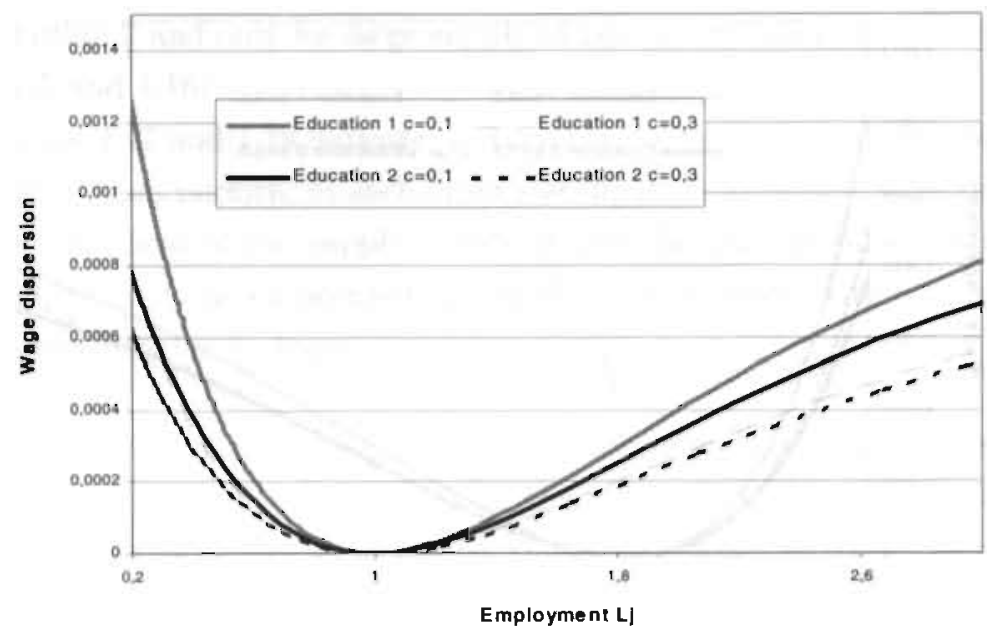

Figure 4.17: Shifts in wage dispersion associated to an increase in $c, \sigma_{o}<\sigma_{e}$.

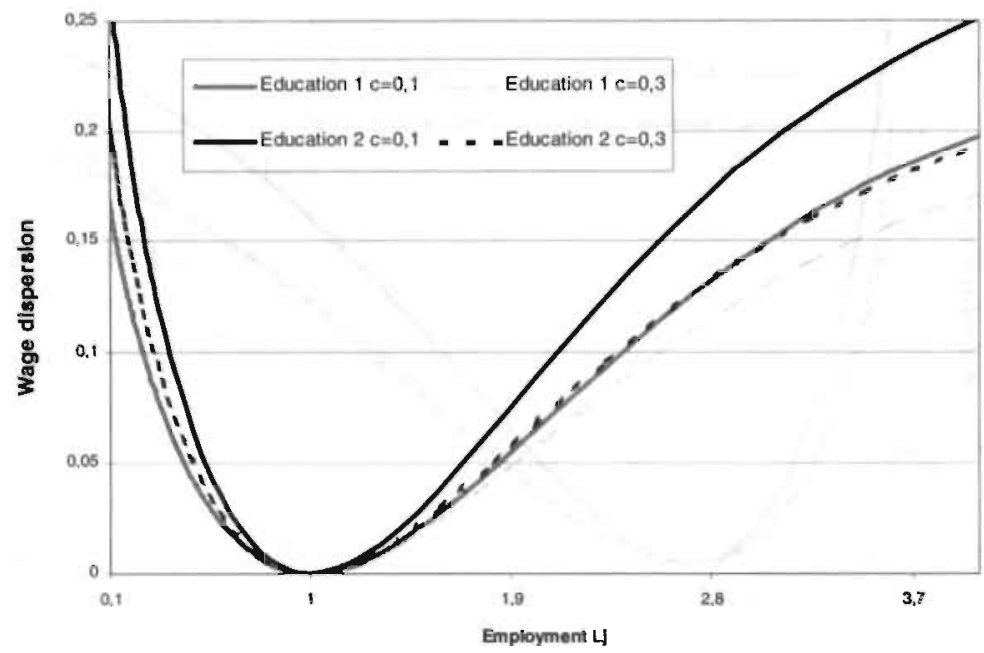

Figure 4.18: Shifts in wage dispersion associated to an increase in $c, \sigma_{o}>\sigma_{e}$. 
occupations and by $7.0 \%$ if the reverse holds (see Figure 4.9). However, the larger the elasticity of substitution between occupations compared to the elasticity of substitution between workers, the smaller the percentage change in labour productivity associated to a $\mathrm{x} \%$ decrease in the range of tasks that workers with education 1 and 3 can perform in occupation 2. Decreasing the range of tasks that workers with education 1 and 3 can perform in occupation 2 by the same percentage (and off the same magnitude to guarantee a fair comparison with the previous test), $40 \%$, increases the long run labour productivity by $4.8 \%$ only, when $\sigma_{o}>\sigma_{e}$ (see Figure 4.8 ) and by $6.2 \%$ when $\sigma_{o}<\sigma_{e}$ (see Figure 4.7 ).

\subsection{Data}

\subsubsection{Data source}

The data we use for an empirical analysis are taken from the 'Socio Economic Panel' (SEP) ${ }^{9}$ of Statistics Netherlands for the years 1994-1996. We have balanced the panel by selecting workers present in the three years of observation. For this study only employees with an intermediate level of education working in the corresponding occupational level are considered.

The panel contains variables observed at the individual level. We have information on gender (dummy for female), age, job tenure, number of hours worked per week and earnings (monthly net income in guilders ${ }^{10}$ ). Job tenure is measured by means of workers' answers to the question: In which year did you start your current job? It therefore refers to an occupation-related-tenure rather than the tenure in the firm where the worker is employed.

We make use of the information on the individuals' educational and occupational fields provided by the $\mathrm{SOI}^{11}$ code ( 3 digits) and the $\mathrm{SBC}^{\prime} 92^{12}$ code (3

\footnotetext{
${ }^{9}$ For our purpose, a pooled panel data set is preferable to pooling time-series of cross-sections, to strictly measure the occupational reallocation of workers in different time periods. In a panel data set the allocation matrix changes from year to year because people have moved vertically (different job level) or horizontally (different occupational field) in the whole allocation matrix (all levels and fields of both education and occupation), not because different individuals are considered in different time periods.

${ }^{10}$ The gross incomes are not available for 1.995 and 1996.

${ }^{11}$ Standaard Opleiding Lndeling, in Dutch. There is a direct link between the SOI and the International Standard Classifictation of Education Diploma (ISCED).

${ }^{12}$ Standaard Beroepen Classificatie, in Dutch. This classification is related to the Interna-
} 
Table 4.2: Classification of educational and occupational fields.

\begin{tabular}{l|l}
\hline \hline Educational fields & SOI codes \\
\hline General & $401,460-469$ \\
Technical & $420-439$ \\
Social services & $450-459,470-499$ \\
\hline Occupational fields & SBC'92 codes \\
\hline General & $420-439,450-459,480-489,510-539,550-559$ \\
Technical & $440-449,460-469$ \\
Social services & $490-499,540-549,560-579$ \\
\hline \hline
\end{tabular}

digits) respectively. These two classifications distinguish categories, with respect to both the levels and the fields of education and occupation. The first digit of the two codes give the educational and job level, respectively, while the two last digits characterise the vocational fields. The individuals selected for an empirical analysis have completed an intermediate vocational education and have a job corresponding to their educational level (i.e. Educational level ISCED 3 and Occupational levels ISCO 3). This generates sample sizes of 535,495 and 506 observations in the three years mentioned above. ${ }^{13}$

At this level of education and occupation, three corresponding educational and occupational fields are distinguished, based on the two last digits of the SOI and $\mathrm{SBC}$ ' 22 codes respectively. The jobs are coded in terms of 'required' educational specialisation. Table 4.2 presents the cross-classification of workers' educational backgrounds and the various jobs.

\subsubsection{The allocation matrix}

Based on the educational and occupational classifications, the number of workers per education and occupation for the three years under investigation are com-

tional Standard Classification of Occupations 1988 (ISCO'88).

${ }^{13}$ The panel of all workers for which information is avadable in the three years is balanced. Therefore, yearly fluctuations in the number of workers with an intermediate educational level in intermediate occupations reflects vertical movements along both educational and occupational scale. 
Table 4.3: Allocation matrix for the pooled sample 1994, 1995 and 1996.

\begin{tabular}{l|rrr|r}
\hline \hline Occupational fields & \multicolumn{3}{|c|}{ Educational fields } & \\
& General & Technical & Social services & Total \\
\hline General & 483 & 102 & 100 & 685 \\
Technical & 53 & 396 & 31 & 480 \\
Social services & 45 & 15 & 311 & 371 \\
\hline Total & 581 & 513 & 442 & 1536 \\
\hline \hline
\end{tabular}

puted. Table 4.3 shows the allocation matrix for the pooled sample. The table indicates that the observations are concentrated on the main diagonal, as one would expect, but with a fair amount of dispersion. Individuals with a given type of educational specialisation find their jobs in different vocational fields and a given occupation is by no means necessarily occupied by individuals with the same educational specialisation.

Digging deeper into these observations, one can confront the two equations 4.9 and 4.10 of the model in section 2 with the actual allocation observed in 1994 , 1995 and 1996. These allocation matrices are presented in Table 4.4.

For example, consider the occupation 'requiring' a general education. The changes in the relative proportion of workers with the required education, i.e. general education, to workers with a technical background can be explained by a change in the relative wages as follows. Since the relative proportion is first constant between 1994 and 1995, i.e. $4.7(30.1 / 6.4)$ in 1994 and $4.7(31.3 / 6.7)$ in 1995 , and increases to $4.8(33.0 / 6.9)$ in 1996 , one would conclude from equation 4.9 , which focuses on one occupation only, that the relative wage of workers with a general educational background first remains constant and decreases in the last period. However, this simplistic explanation is not in accordance with the shifts in the relative proportion of workers with the general educational background compared to workers with a technical education in the other occupations. Indeed, in the second occupation, where a technical education is the 'required' specialisation, one would basically find different results, suggesting that the relative wage first decreased, between 1994 and 1995, and increased in the last year $(2.8 / 26.5=\mathbf{0 . 1 1}$ in $\mathbf{1 9 9 4 ;} \mathbf{0 . 1 5}=4.0 / 25.9$ in $\mathbf{1 9 9 5}$; and $\mathbf{0 . 1 4}=3.6 / 24.9$ in 1996) . This is typical of the contradictory results that equation 4.10 is designed to deal with, as this equation focuses on the allocation of workers in two occupations.

Equation 4.9 measures direct effects of changes in the relative wages between 
Table 4.4: Allocation matrix in percentage of the annual total for 1994, 1995 and 1996.

\begin{tabular}{|c|c|c|c|c|}
\hline \multirow[t]{2}{*}{ Occupational fields } & \multicolumn{3}{|c|}{ Educational fields } & \multirow[b]{2}{*}{$\begin{array}{c}\text { Total } \\
\%\end{array}$} \\
\hline & $\begin{array}{c}\text { General } \\
\%\end{array}$ & $\begin{array}{c}\text { Technical } \\
\%\end{array}$ & $\begin{array}{c}\text { Social services } \\
\%\end{array}$ & \\
\hline 1994 & & & & \\
\hline General & 30.1 & 6.4 & 6.7 & 43.2 \\
\hline Technical & 2.8 & 26.5 & 2.2 & 31.6 \\
\hline Social services & 3.4 & 1.1 & 20.8 & 25.2 \\
\hline Total & 36.3 & 34.0 & 29.7 & 100 \\
\hline 1995 & & & & \\
\hline General & 31.3 & 6.7 & 7.5 & 45.5 \\
\hline Technical & 4.0 & 25.9 & 1.6 & 31.5 \\
\hline Social services & 2.8 & 1.0 & 19.2 & 23.0 \\
\hline Total & 38.2 & 33.5 & 28.3 & 100 \\
\hline 1996 & & & & \\
\hline General & 33.0 & 6.9 & 5.3 & 45.3 \\
\hline Technical & 3.6 & 24.9 & 2.2 & 30.6 \\
\hline Social services & 2.6 & 0.8 & 20.8 & 24.1 \\
\hline Total & 39.1 & 32.6 & 28.3 & 100 \\
\hline
\end{tabular}

the educational groups while equation 4.10 models the indirect effects. Therefore, the picture that emerges on the basis of observed changes in the allocation resulting from 1994 to 1996 is characterised by a chain of reallocations: In a first step, a change in the relative wages of educational groups induces a direct substitution in each occupation via equation 4.9. These direct effects might be unsatisfactory to achieve economic goals (minimum costs) such that in a second step, a rebalancing is carried out via equation 4.10. These indirect effects explain why the relative allocation of people with a general educational background to people with a technical background has opposite signs in accordance with their specific occupational fields. For instance, from 1995 to 1996, the relative allocation of workers with general education to workers with technical education in the general occupation increased from 4.7 to 4.8 , while in the technical occupation, the relative allocation has decreased from 0.15 to 0.14 . 


\subsubsection{Earnings function}

In order to derive wages by education and time period, $w_{j t}$, as needed for the estimation of equations (4.9) and (4.10), an earnings function of the Human Capital type is used, ${ }^{14}$ controlling for other personal characteristics as well. Since the data are observed on a rather short run (time periods), the effects of these personal characteristics can reasonably be assumed to be constant over the three year-period of our analysis (1994 to 1996). ${ }^{15}$ Furthermore, Table 4.4 shows that some cells are poorly filled, so we will estimate the earnings function on the pooled sample of all three years. However, to allow for changes over time in the effect of education on earnings, a full dummy specification for the $3 \times 3-1$ independent combinations of education and time period is included in the regression. Though not reported in Table 4.5, two dummies for the interaction of 1994 and 1995 with general educational field are included in the regression. The model estimated is therefore a model with all coefficients constant over both cross-sectional and timeseries units except for the educational-earnings profiles, which are assumed to vary over time. ${ }^{16}$ Coefficients obtained for these dummy variables $\left(\alpha_{j t}\right)$, educational earnings profiles in each time period, are then saved in $w_{j t}\left(\ln w_{j t}=\alpha_{j t}\right)$ and used in the estimation of the supply parameters in the next section. ${ }^{17}$ Note that in absence of precise observations, the work experience is omitted. However, since all individuals selected have the same level of education and left school at more

\footnotetext{
${ }^{14}$ We have tested this human capital specification against an assignment specification where occupational dummies are entered in the regression model. The Wald-tests did not support rejection of the human capital specification, either for yearly regressions nor for the pooled regression at $5 \%$. Furthermore, the $R_{o d j}^{2}$ associated to on the one hand regression with occupational dummies only and on the other hand educational dummies only are equal. The results are shown in Appendix F.

${ }^{15}$ We make use of the panel aspect of our data. Individuals selected are those being employed in all three years of observation, aged between 16 and 64 . However, since workers can move to an other job level or graduate in an higher educational level in the period of observation, the number of workers with intermediate educational level working in intermediate occupational level is not constant over time.

${ }^{16}$ Estimates obtained by separate regressions for each year are similar to those presented here.

${ }^{17}$ This method of deriving $w_{j t}$ has the advantage over the mean or median of earnings by educational categories and time periods, since it controls for cohort effects. While the technical field of study is dominated almost entirely of males (about $95 \%$ ), females are in a large majority $(65 \%)$ in the field social services. Hence, the gap between the average earnings of workers with technical education and people with social services educational specialisation is partly attributable to the gender gap in earnings. The results should be viewed as average wages by educational groups corrected for composition characteristics rather than returns to education since selectivity bias might be going on.
} 
or less the same age, age is a proxy for work experience.

The following equation is estimated for each worker $p$ :

$$
\ln W_{p t}=\gamma+G^{\prime} X_{p}+\sum_{j, t} \alpha_{j t} E_{j !}+e_{p t}
$$

where $X$ contains the set of explanatory variables like age, tenure etc..., $E_{j t}$ are dummy variables for the interaction of year $t$ with education $j$ and $W_{p t}$ is the earnings of worker $p$ in period $t$.

Table 4.5 shows the results of the OLS estimation. The coefficients indicate that the impact of the field of education is quite substantial. Workers with a technical educational specialisation have a structural earnings disadvantage compared to the others: their wage differential with the two other groups is negative in every period $(-\mathbf{0 . 0 6 2}<-0.030<0$ in $1994,-0.067<0<0.020$ in 1995 and $-0.070<-0.016<0$ in 1996).

The control variables not reported in Table 4.5 show standard results. Males do not earn significantly more than females (see Johnson and Stafford (1974)). However, though there is no significant earnings differential between males and females as such, ${ }^{18}$ the career prospects of men are better than those of women. Indeed, there is an aging effect on earnings differentials between males and females in favour of the former which is estimated at $0.7 \%$ per year ${ }^{19}$. The effects of age (experience proxy) $)^{20}$ are in the familiar quadratic shape, with respective peaks at 48 years old for men and 41 for women (i.e. 31 years of experience for men

\footnotetext{
${ }^{18}$ We ran a regression without allowing for the interaction of age and job tenure with gender and found significant earnings differentials in disfavour of ferrales $(-0.123)$. This suggests that earnings differentials between males and females are due to gender differences in experience and tenure. Verdugo and Schneider (1994) do indeed find that the level of human capital accounts for $60 \%$ of the wage gap between males and fernales.

${ }^{19}$ Johnson and Stafford's (1974) estimate is $2.6 \%$ at the age workers leave school, diminishing (positive coefficient for the quadratic term) to 0 after 15 years of experience.

A possible interpretation of this empirical result is that women are more likely to be employed in part-time jobs than men. Stated otherwise (see Mincer 1993), women are likely to invest less than men in on-the-job training because they 'expect' to spend only part of their adult lives in the labour force. Hence, women accumulate substantially less experience than men in the course of their careers, lowering their human capital compared to men and widening wage-gender differentials (flatter age-experience earnings profiles for women).

${ }^{20}$ Boumahdi and Plassard's (1992) estimate for experience is 0.082. Griffin and Cox-Edwards (1993) find 0.069 and Clark and Leslie (1994) find 0.056.
} 
Table 4.5: Earnings function for pooled sample 1994-1995-1996, the log of net monthiy income being the dependent variable.

\begin{tabular}{|c|c|c|}
\hline & \multicolumn{2}{|l|}{ Coefficient } \\
\hline Educational fields & \\
\hline 1994 & & \\
\hline General & \multicolumn{2}{|l|}{ ref } \\
\hline Technical & -0.062 & $(0.026)^{b}$ \\
\hline Social services & \multirow{2}{*}{\multicolumn{2}{|c|}{-0.030}} \\
\hline 1995 & & \\
\hline General & \multicolumn{2}{|l|}{ ref } \\
\hline Technical & \multicolumn{2}{|l|}{-0.068} \\
\hline Social services & \multirow{2}{*}{\multicolumn{2}{|c|}{0.020}} \\
\hline 1996 & & \\
\hline General & \multicolumn{2}{|l|}{ ref } \\
\hline Technical & \multicolumn{2}{|l|}{-0.070} \\
\hline Social services & \multicolumn{2}{|c|}{$-0.016 \quad(0.028)$} \\
\hline $\bar{R}^{2}$ & \multicolumn{2}{|l|}{0.702} \\
\hline$n$ & \multicolumn{2}{|l|}{1536} \\
\hline$\sigma_{y}^{2}$ & \multicolumn{2}{|l|}{0.062} \\
\hline \multicolumn{3}{|c|}{ Standard deviation (between parentheses) } \\
\hline \multicolumn{3}{|l|}{$a$ significant at $1 \%$} \\
\hline significant at $5 \%$ & & \\
\hline
\end{tabular}

and 24 years of experience for women). Tenure ${ }^{21}$ follows a linear trend with a significantly higher return for women. Furthermore, the elasticity of earnings to the weekly hours worked is significant and estimated at 0.661 (significant at $1 \%$ ). Increasing the number of hours worked per week by $1 \%$ increases net earnings by $0.661 \%$. Part-time variables and their interaction with gender are also included in the model.

\footnotetext{
${ }^{21}$ Our estimate of tenure profile, i.e. 0.005, is actually smaller than that of Teulings and Hartog (1998) for the Netherlands (see table 1.2 p37). However, their estimates refer to firms' tenure profiles while our measure is a job tenure profile.
} 


\subsection{Allocation structure}

In Section 4.3 we derived a sufficient condition on the productivity parameters for which reciprocal supply shifts in two educational fields lead to reciprocal changes in the wages of workers in these two educational fields and leave the wages of workers with other educational fields unaffected. The resulting structure of parameters indicates that the range of tasks that workers with education 2 can perform has to be evenly distributed outside their oun occupation. We argued that this condition characterises educational fields that emphasise on general skills when the range of tasks these workers can perform is relatively large. In contrast, we expect that educational fields emphasising on specific skills satisfy the characteristics of education 1 and 3 with a relatively small value of $c$. However, we expect $a$ to be relatively large. Indeed, since general skills are often needed to acquire more specific skills, workers with specific skills have a fair amount of general skills which enables these workers to perform a quite large range of tasks in the general occupation.

In this section, we will analyse whether the range of tasks that workers with general, technical and social services educational fields can perform in the various occupations corresponds to our ex ante expectations.

\subsubsection{Quantitative methodology}

To estimate the allocation structure parameters we use the first-order conditions of the Lagrangian function summarised in equation 4.11. This requires that we use the demand for labour $\langle g, k\rangle$ as a reference. Hence we lose one degree of freedom, which gives a system of $n \times m-1$ equations. The stochastic specification of the model is basically obtained by adding disturbances to the right-hand sides of each equation in the system. ${ }^{22}$

We estimate equation 4.22 on the data:

\footnotetext{
${ }^{2{ }^{2}}$ In the multifactor case, the direct estimation of $\sigma_{a}$ and $\sigma_{e}$, using the ratio of factor inputs, requires imposing the restrictions that factor demand is homogenous of degree zero in all factor. prices (see Hamermesh (1993), p72). Appendix $C$ shows that equation (4.22) satisfies these restrictions.
} 


$$
\begin{aligned}
\ln \frac{L_{i j t}}{L_{33 t}}= & \left(\sigma_{e}-\sigma_{o}\right) \times\left(\ln U C_{i}\left(w_{t}\right)-\ln U C_{3}\left(w_{t}\right)\right)+ \\
& \sigma_{e} \times\left(\ln a_{i j}-\ln a_{33}+\ln w_{3 t}-\ln w_{j t}\right)+\varepsilon_{i j t}
\end{aligned}
$$

with $i j=\{11,12,13,21,22,23,31,32\}$. Individual components of $\varepsilon_{t}$ relate to equation 4.22 and the allocation of people with a social services educational background working in their specific field is used as a reference, input $L_{33}$.

It is assumed that $\varepsilon$ follows a multivariate Laplace-Gauss distribution which is time-independent. Moreover, attempts to estimate the covariances among the elements of the disturbance vector failed, probably because of collinearity problems and the relatively small number of measurements in time $(T=3)$. More seriously, in the system of equations depicted by equation 4.22 the explanatory variables, i.e. the wages $w_{j t}$, are measured with errors (estimated from an earnings function) since they are unobservable. Judge et al. (1985) propose to formulate such a model as a multiple equation model. The underlying stochastic assumptions are that in each equation the error components are independent of the unobserved variables (explanatory variables) and therefore:

$$
E\left[\varepsilon \varepsilon^{\prime}\right]=\Omega
$$

where $\Omega$ is diagonal.

Consequently, it is also assumed that $\varepsilon$ are distributed with a diagonal covariance matrix. Using the Full Information Maximum Likelihood (FIML) method to simultaneously estimate equations 4.22 , provides consistent and efficient estimates of the parameters of the model (see Judge et al. 1985).

The concentrated $\log$-likelihood function of the system containing $n^{2}-1$ equations, where $n$ is the number of educational and occupational categories considered, is obtained as:

$$
L H F=-\left(\frac{T}{2}\right) \ln \left|\operatorname{diag}\left(T^{-1} \sum_{t=1}^{T} e_{t} e_{t}^{\prime}\right)^{\prime} \otimes I_{n^{2}-1}\right|
$$

where 


$$
e_{t}=\left\langle e_{11 t}, e_{12 t}, e_{13 t}, e_{21 t}, e_{12 t}, e_{22 t}, e_{23 t}, e_{31 t}, e_{32 t}\right\rangle^{\prime}
$$

and

$$
e_{i j t}=\widehat{\varepsilon}_{i j t}
$$

Thus the size of the final estimation problem is $8=n^{2}-1$ equations $\left(L_{33}\right.$ is used as reference) observed in 3 years in order to get estimates of the allocation structure ( 6 allocation structure parameters, since the sum by occupation is restricted to one) and the parameters of elasticity of educational substitution $\sigma_{e}$ and occupational substitution $\sigma_{o}$. We estimate the $\pi_{i j}$ as defined in section 2, with $\pi_{i i}=1 \forall i$ to avoid perfect multicollinearity.

\subsubsection{Empirical results}

Results of the FIML estimation procedure are presented in Table 4.6. The columns refer to the educational specialisation and rows to the occupational field. The last row contains the estimated educational substitution elasticity parameter $\sigma_{e}$, the occupational substitution elasticity parameter $\sigma_{o}$ and the maximum value of the likelihood function LHF.

\begin{tabular}{|c|c|c|c|c|}
\hline \multirow{2}{*}{$\begin{array}{r}\text { Occupational fields } \\
\qquad \pi_{i j}\end{array}$} & \multicolumn{3}{|c|}{ Educational fields } & \multirow[b]{2}{*}{$\sum_{j} \pi_{i j}$} \\
\hline & General & Technical & Social services & \\
\hline General & 1 & $.306(.02)$ & $.320(.04)$ & 1.63 \\
\hline Technical & $.250(.02)$ & 1 & $.169(.02)$ & 1.42 \\
\hline Social services & $.249(.02)$ & $.104(.01)$ & 1 & 1.35 \\
\hline \multirow{2}{*}{$\sum_{i} \pi_{i j}$} & 1.50 & 1.41 & 1.49 & \\
\hline & $\begin{array}{l}\sigma_{e} \\
1.392(.08)\end{array}$ & $\begin{array}{l}\sigma_{o} \\
2.423(.25)\end{array}$ & $\begin{array}{l}L \overline{H F} \\
2.623\end{array}$ & \\
\hline
\end{tabular}

Table 4.6: Allocation structure estimates.

Standard deviations are given (in parentheses).

The estimated allocation structure reported in Table 4.6 indicates that the range of tasks that workers with general education can perform in technical and 
social services occupations is evenly distributed and relatively large. The productivity parameters of workers with general education outside their specific occupational field are equal and relatively high, i.e. 0.25. As expected, general education satisfies the characteristic of education 2. The estimated allocation structure also indicates that the range of tasks that workers with technical and social services educational fields can perform in each other's occupation is relatively small, i.e. 0.17 and 0.10 respectively. Moreover, the range of tasks that workers with technical education field can perform in general occupation is roughly equal to the range of tasks that workers with social services can perform and relatively large (0.31 for technical and 0.32 for social services). This last result indicates the relative importance of general skills in acquiring specific skills.

The parameter of elasticity of substitution between the various educational specialisations is estimated at 1.39 whereas the parameter of occupational substitution elasticity is 2.42. Both parameters are significantly different from 0 and 1 at $1 \%$. A Cobb-Douglas specification would therefore be less accurate than the CES specification we use here. Although workers with different educational specialisations are significantly substitutable, they are far from being perfectly substitutable $(\sigma<<\infty)$ as is implicitly assumed in studies focusing on levels only. ${ }^{23}$ The homogeneity of workers with different educational. specialisations is not supported, especially since the productivity parameters differ significantly overall. $^{24}$

In order to compare our results with empirical estimates in related literature, we derive the Allen partial elasticity of substitution. (see Allen (1938)) between educational groups and the own-price elasticities. The Allen elasticities of substitution $A E S_{j k}$ between workers with education $j$ and $k$ given an increase in the wage rate of the latter are obtained by:

$A E S_{j k}=\frac{\eta_{j k}}{s_{k}}$ with $\eta_{j k}=\frac{\partial \ln L_{j}}{\partial \ln w_{k}}$ the correspondling cross-wage elasticity and $s_{k}$ the share of input $k$ in total costs.

From the model of section 2 we derive the cross and own wage elasticities by educational groups as follows:

\footnotetext{
${ }^{23}$ See Appendix $A$ for details.

${ }^{24}$ When running the model with allocation matrices net of vertical movements (those workers that increase their educational level during the period or change occupational level between 1994 and 1996 are excluded) the coefficients for the supply structure and elasticity of substitution do not change significantly. The results presented here are robust with respect to vertical movements.
} 


$$
\begin{aligned}
& \eta_{j k}=\frac{\partial \ln L_{j}}{\partial \ln w_{k}}=\sigma_{o} \frac{\sum_{i} s_{i k} \times U C_{i}^{1-\sigma_{o}}}{\bar{U} C^{1-\sigma_{o}}}+\left(\sigma_{e}-\sigma_{o}\right) \frac{\sum_{i} s_{i k} L_{i j}}{L_{j}} \\
& \eta_{j j}=\frac{\partial \ln L_{j}}{\partial \ln w_{j}}=\sigma_{o} \frac{\sum_{i} s_{i j} \times U C_{i}^{1-\sigma_{o}}}{U C^{1-\sigma_{o}}}+\left(\sigma_{e}-\sigma_{o}\right) \frac{\sum_{i} s_{i j} L_{i j}}{L_{j}}-\sigma_{e}
\end{aligned}
$$

with $s_{i k}=\frac{w_{k} L_{i k}}{\sum_{j} w_{j} L_{i j}}$

Table 4:7: Own-wage elasticities and Allen partial elasticities of substitution.

\begin{tabular}{l|rrr}
\hline \hline \multicolumn{1}{r}{ Educational fields } & \multicolumn{3}{|c}{ Quantity of: } \\
With respect to wage of: & General & Technical & Social services \\
\hline General & -1.08 & 1.79 & 1.76 \\
Technical & & -1.32 & 2.05 \\
Social services & & & -1.32 \\
\hline Employment Shares & 0.39 & 0.31 & 0.30 \\
\hline \hline
\end{tabular}

The elasticity of substitution between workers with technical and social services is 2 and larger than the elasticity of substitution between workers with general education and the two other groups. The magnitude of the elasticities of substitution between educational fields of study lies in the range of estimates on elasticity of substitution between workers with different levels of education. (See Hamermesh and Grant (1979), Hamermesh (1992) and (1993).) Johnson (1970) estimates the elasticity of substitution between college graduates and high-school graduates at 1.34 and Grant (1979) finds elasticities between different groups of years of schooling of $0.77,0.21$ and 1.16 (for $0-8$ vs. $9-12,0-8$ vs. $13+$ and $9-12$ vs. $13+$ respectively). Bound and Johnson (1992) find a parameter of substitution elasticity of 1.75 between skill groups within sectors once accounting for skilled biased technological change and Katz and Murphy's (1992) estimate implies an elasticity of substitution between college and high-school labour of 1.41 .

\subsubsection{Implications: general versus specific education}

The estimation results show that the demand for workers with a general educational background is less elastic than the demand for workers with technical and social services vocational specialisations. As indicated in Table 4.7, the ownwage elasticity is lower for general studies than for technical and social services 


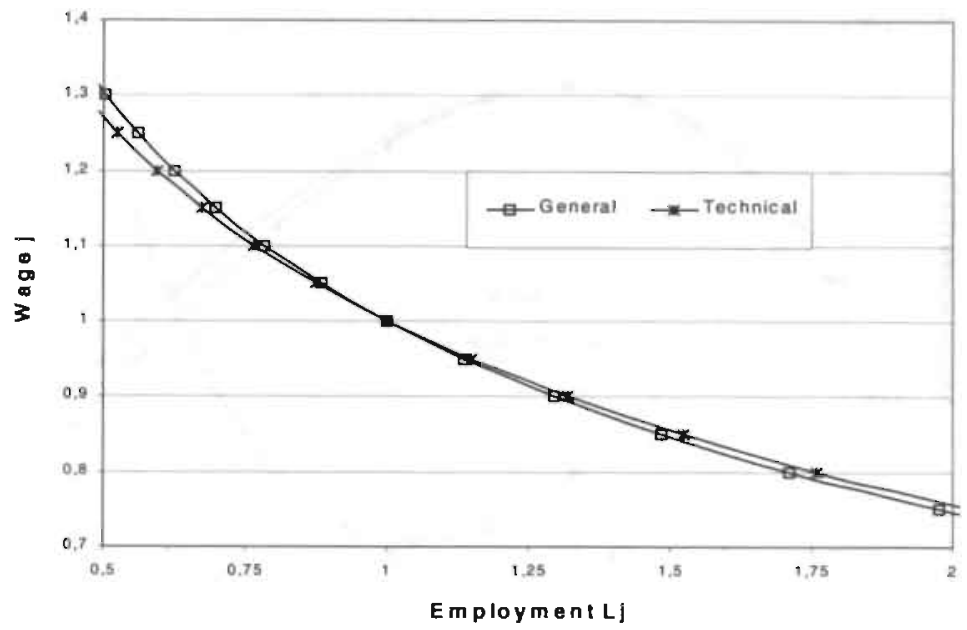

Figure 4.19: The demand for labour with general and technical education.

studies. This empirical result is consistent with other studies that also show that the more general the human capital of workers the more inelastic the demand for that group of workers (see Hamermesh (1986)). To illustrate this result we plot the demand for labour with general and technical education in the Netherlands in Figure 4.19. The steeper slope of the demand curve for workers with general education indicates that the demand for technical labour is more elastic than the demand for general labour.

To illustrate the implication of this result in terms of labour productivity and wage dispersion, we also plot the labour productivity, Figure 4.20 and wage dispersion, Figure 4.21 as a function of the supply of general and technical labour, respectively. The results suggest that labour productivity is relatively more sensitive to unexpected shifts in the supply of technical graduates than to shifts in the supply of workers with general education, whereas wage dispersion is relatively more sensitive to downward shifts in the supply of general graduates than equivalent downward shifts in the supply of technical graduates.

Hence, a relative decrease in the supply of graduates in general educational fields can only be absorbed by a relatively large increase in the wage rate of workers with general education resulting in a relatively large increase in wage 


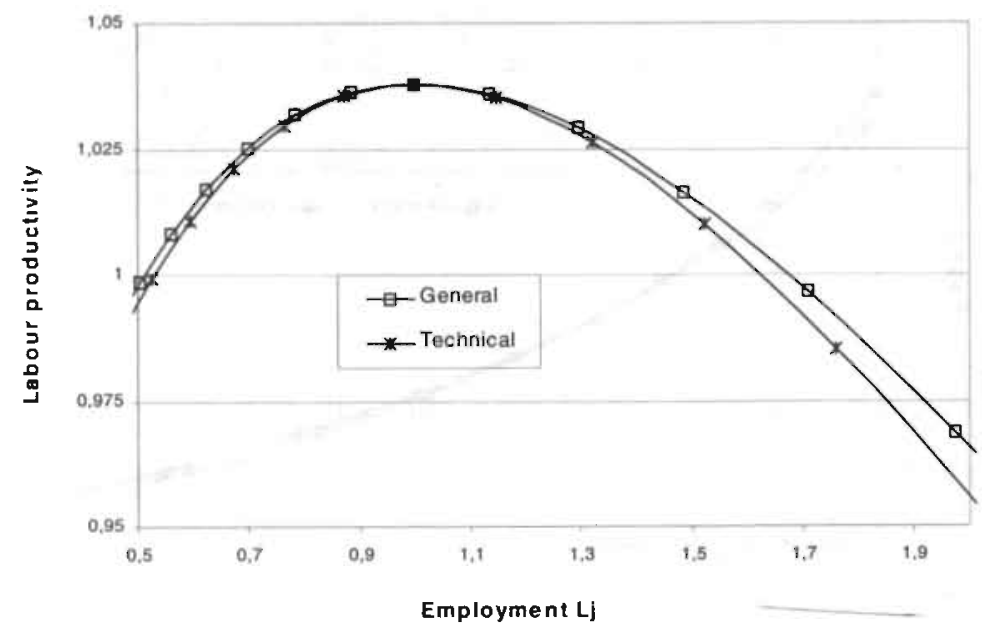

Figure 4.20: Labour productivity.

dispersion and a small decrease in labour productivity.

Since the allocation structure for the Netherlands roughily satisfies the three conditions derived in Section 4.3 and the parameter of the elasticity of substitution between occupations is larger than the parameter of substitution between the different fields of education within occupations, the effects of changing the range of tasks that workers with general, technical and social services can perform in the various occupations on labour productivity and wage inequality in the Netherlands are similar to those simulated in Section 4.3 .2 for an elasticity of substitution between occupational outputs larger than the elasticity of substitution between workers, i.e. for $\sigma_{o}>\sigma_{e}$.

- The narrower the range of tasks that workers with technical and social services can perform in general occupation, the larger labour productivity and the larger the sensitivity of labour productivity to unexpected shifts in the supply of labour with general education. Moreover, wage dispersion increases irrespective of the supply of workers with general education.

- The narrower the range of tasks general graduates can perform in the technical and social services occupations, the larger labour productivity and 


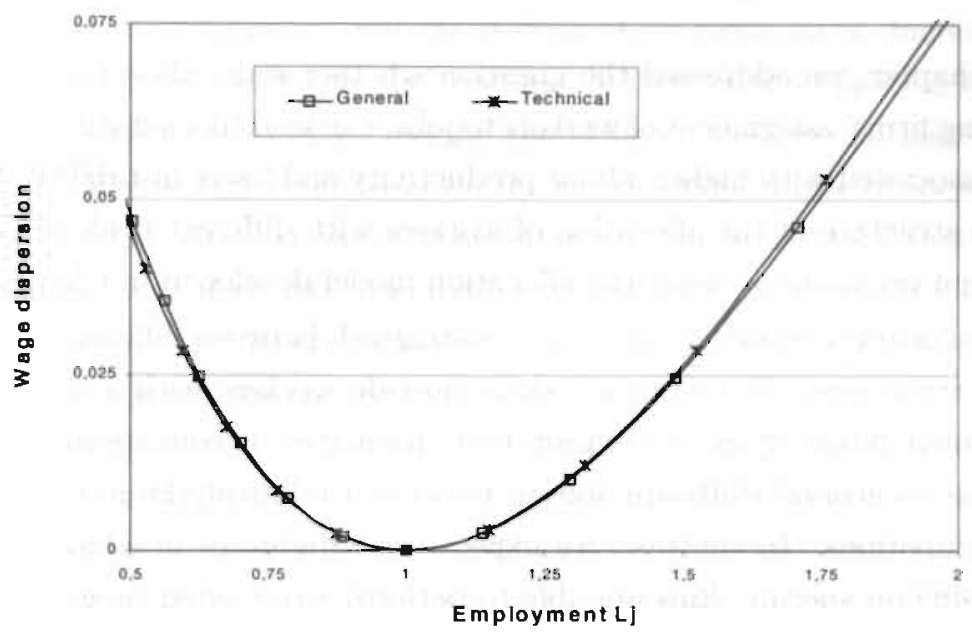

Figure 4.21: Wage dispersiou.

its sensitivity to shifts in the supply of workers with technical and social services education. However, wage dispersion is also larger for all supply of workers with general education.

- The larger the range of tasks that workers with technical and social services education can perform in each other's occupations, the smaller labour productivity and the smaller wage dispersion.

Moreover, since the ease to substitute between occupational outputs is larger than the ease to substitute between workers with the various educational fields, labour productivity in the Netherlands could be increased relatively more by a $x \%$ decrease in the range of tasks that workers with general education can perform outside the general occupation than by a $x \%$ decrease in the range of tasks that workers with technical and social services educational fields can perform in each other's occupations. The Netherlands may benefit from decreasing the range of tasks that workers with general education could perform outside general occupation while countries for which the ease to substitute occupational output is smaller relative to the ease of substitution between workers may benefit from decreasing the range of tasks that workers with technical and social services educational fields can perform in the general occupational field. 


\subsection{Summary and conclusion}

In this chapter, we addressed the question whether some allocation structures, underlying firms ${ }^{2}$ assignment of workers to jobs, can lead to a substitution process that is associated with higher labour productivity and lower instability. We analysed the structure of the allocation of workers with different fields of education to different occupations using the allocation model developed in Chapter 2.

The allocation model enabled us to distinguish between different types of allocation structures. Since general skills provide workers with a wide range of occupational possibilities, we expect that graduates in educational fields that emphasise on general skills are able to perform a relatively large range of tasks in all occupations. In contrast, we expect that graduates in educational fields emphasising on specific skills are able to perform a restricted range of the tasks in occupations outside their own occupational field. However, we expect that graduates in educational fields focusing on specific skills are relatively productive in general occupations. Since general skills are often needed to acquire more specific skills, workers with specific skills have a fair amount of general skills which enables these workers to perform quite some tasks in the general occupational field. The question arises what happens when the relative supply of labour shifts given the allocation structure. Since workers with general education can perform a rather large range of tasks in every occupation, they can easily switch occupations. We therefore expect that a shift in the supply of workers between two specific educational fields will lead to a reciprocal change in the wage rate of these two types of workers but will leave the wage of workers with general education unchanged.

We derived a sufficient condition for the type of allocation structure that satisfies this type of reciprocal shifts in a three educational fields-three occupations case and showed that these allocation structures are such that: 1) the range of tasks that workers with the education for which employment does not change, can perform outside their own occupation is evenly distributed and 2) the range of tasks that workers whose employment increases and workers whose employment decreases can perform in each other's occupation is equivalent and 3) the range of tasks that workers whose employment increases and workers whose employment decreases can perform in the occupation of workers whose employment does not change is equivalent. The family of allocation structures that satisfy the sufficient condition is therefore characterised by three productivity parame- 
ters. Simulations have shown that both labour productivity and wage dispersion are sensitive to the relative magnitude of these three parameters. Increasing the range of tasks that workers can perform outside their own occupation decreases labour productivity. The more specific the skills of workers the larger labour productivity. This result emphasises on the relative importance of specific skills for labour productivity. However, the larger the range of tasks that workers can perform outside their own occupation, the smaller the sensitivity of labour productivity and wage dispersion in case of unexpected supply shifts.

In order to address the question of the relevance of vocational general education in initial education, we used data on the Dutch labour market and estimated the elasticity of substitution parameters together with the allocation structure associated with workers with general education and workers with vocational specialisations in technical and social services at the intermediate level and three more or less related occupations. We found that the demand for workers with a general educational background is less elastic than the demand for workers with a vocational specialisation in technical and social services. This means that a relative decrease in the supply of graduates in general education induces a relatively large increase in their relative wage, a large decrease in labour productivity and a large increase in wage dispersion. Moreover, the estimated allocation structure indicates that 1) the range of tasks that workers with general education can perform in technical and social services occupations is evenly distributed and relatively large, 2) the range of tasks that workers with technical and social services educational fields can perform in each other's occupation is equal and relatively small and 3) the range of tasks that workers with technical education field can perform in the general occupation is relatively large and roughly equal to the range of tasks that workers with social services can perform. These results confirmed our expectation: the general educational field at the intermediate educational level in the Netherlands is very similar to our theoretical definition of general education whereas technical and social services educational fields correspond to our theoretical definition of specific education.

Using the results of the simulations, we can infer further on the relative importance of general education. We have shown that decreasing the range of tasks that workers with technical and social services can perform in the general occupation, by decreasing the amount of generic skills of technical and social services graduates, increases the long run labour productivity but would make labour productivity more sensitive to unexpected shifts in the supply of labour with 
general education. Moreover, it would increase wage dispersion irrespective of the supply of workers with general education. Decreasing the range of tasks general graduates can perform in the technical and social services occupations, that is increasing their amount of specific skills at the expense of their generic skills, would increase labour productivity but also increases the sensitivity of labour productivity to shifts in the supply of workers with technical and social services education. Moreover, wage dispersion would increase when the supply of workers with general education shifts. Finally, increasing the range of tasks that workers with technical and social services education can perform in each other's occupations, i.e. increasing their amount of generic skills, would decrease both labour productivity and wage dispersion.

From an educational policy perspective, we have shown that the skill content of a study in terms of specific and general skills matters for both labour productivity and the stability of the labour market. The more specific the skills of workers the larger labour productivity. However, the more generic the skills of workers, the larger the range of tasks these workers can perform outside their own occupation and the smaller the increase in wage dispersion in case of supply shifts. Moreover, the simulation results show that the flexibility of the labour market, measured by the ease to substitute between occupations and between workers with different educational backgrounds, should be accounted for when defining the skill content of the various educational fields. Indeed, the larger the ease to substitute between occupational outputs compared to the ease to substitute between workers with different educational backgrounds within occupations, the larger the percentage change in labour productivity associated to a decrease in the range of tasks that workers with general education can perform outside the general occupation and the smaller percentage change in labour productivity associated to a decrease in the range of tasks that workers with technical and social services can perform in the general occupation. This suggests that countries like the Netherlands, for which the ease to substitute between occupational outputs is large compared to the ease to substitute between workers within occupational fields, may benefit from decreasing the range of tasks that workers with general education could perform outside general occupation, by increasing the amount of skills that contribute to their productivity in the general occupational field at the expense of the general skills that contribute to their productivity in the other occupational fields. 


\section{Appendix A. Homogeneity restrictions}

Note that treating graduates from different educational specialisations as homogeneous (allocation model applied on levels only) is equivalent to using a linear or CES production function within each of the cross-level of education and occupation of the form:

$$
\begin{aligned}
H_{t} & =\sum_{i} H_{i t}=\sum_{i} \sum_{j} L_{i j t} \\
& =\sum_{i} \sum_{j} b_{i j} L_{i j t} \text { Linear-Linear function } \\
& =\sum_{i}\left(\sum_{j} a_{i j} L_{i j t}^{\beta}\right)^{1 / \beta} \text { Linear-CES function } \\
& =\left(\sum_{i}\left(\sum_{j} a_{i j} L_{i j t}^{\beta_{e}}\right)^{\beta_{o} / \beta_{e}}\right)^{1 / \beta_{o}} \text { CES-CES function }
\end{aligned}
$$

with the following restrictions: Linear-Linear production function with (1): $b_{i j}=$ $1 \forall i, j$ and Linear-CES production function with (1): $a_{i j}=1 \forall i, j$ and (2): $\beta=1$ and the CES-CES production function with (1): $a_{i j}=1 \forall i, j$ and (2): $\beta_{e}=\beta_{o}=1$. 


\section{Appendix B. Educational and occupational levels}

The levels of education attained and required levels of education are graded in 4 groups:

$$
\begin{aligned}
& 1=\text { elementary school SOI }(0,1 \text { and } 2) \text { or } \operatorname{ISCED}^{25}(0,1) \\
& 2=\text { lower vocational SOI }(3) \text { or } \operatorname{ISCED}(2) \\
& 3=\text { intermediate vocational SOI }(4) \text { or } \operatorname{ISCED}(3) \\
& 4=\text { higher vocational and university } \operatorname{SOI}(5,6 \text { and } 7) \text { or } \operatorname{ISCED~}(6,7)
\end{aligned}
$$

and the corresponding job levels (i.e. required level of education):

$1=$ elementary jobs SBC'92 (1)

$2=$ lower jobs $\operatorname{SBC} 92(2,3)$

$3=$ intermediate jobs $\mathrm{SBC} 92(4,5)$

$4=$ higher jobs SBC ' $92(6,7,8$ and 9$)$

where figures between brackets refer to the first digit of the SOI and SBC'92 codes.

\footnotetext{
${ }^{25}$ The ISCED classification (International Standard Classification of EDucation) distinguishes seven levels. This classification is usually used by the Center of Education Research and Innovation to produce OECD indicators of education systems (see OECD 2001).
} 


\section{Appendix C. Hamermesh's restrictions}

Hamermesh (1993), p. 72, notes that, in the multifactor case, the relative factordemand method should not be used to estimate $\sigma$ directly unless one imposes the restrictions that factor demand be homogeneous of degree zero in all factor prices.

A function $f\left(x_{1}, \ldots, x_{n}\right)$ is called homogeneous of degree zero if and only if it satisfies the following condition:

$$
f(c X)=f\left(c x_{1}, \ldots, c x_{n}\right)=f\left(x_{1}, \ldots, x_{n}\right)=f(X) \forall c \in \Re^{*}
$$

Consider equation 4.22 of Section 4.5 in a particular time period. Here we have:

$$
\begin{aligned}
l= & \ln \frac{L_{i j t}}{L_{g k t}}=\left(\sigma_{\epsilon}-\sigma_{o}\right) \times\left(\ln U C_{i}\left(w_{t}\right)-\ln U C_{g}\left(w_{t}\right)\right)+ \\
& \sigma_{\epsilon} \times\left(\ln a_{i j}-\ln a_{g k}+\ln w_{k t}-\ln w_{j t}\right)+\varepsilon_{i j t}
\end{aligned}
$$

$l$ is a function of $\left\langle w_{1}, \ldots, w_{n}\right\rangle$ of the form:

$$
\begin{aligned}
l\left(w_{1}, \ldots, w_{n}\right)= & \sigma_{\epsilon} \times\left(\ln a_{i j}-\ln a_{g k}+\ln w_{k}-\ln w_{j}\right)+ \\
& \left(\sigma_{e}-\sigma_{\theta}\right) \times\left(\ln U C_{i}\left(w_{1}, \ldots, w_{n}\right)-\ln U C_{g}\left(w_{1}, \ldots, w_{n}\right)\right\rangle \\
\forall i, g, j, k \in & \{1, \ldots, n\}
\end{aligned}
$$

Multiplying all inputs (factor prices) by a constant $c \in \Re^{*}$ gives:

$$
\begin{aligned}
l\left(c w_{1}, \ldots, c w_{n}\right)= & \sigma_{e} \times\left(\ln a_{i j}-\ln a_{g k}+\ln c \times w_{k}-\ln c \times w_{j}\right)+ \\
& \left(\sigma_{e}-\sigma_{o}\right) \times\left(\ln U C_{i}\left(c w_{1}, \ldots, c w_{n}\right)-\ln U C_{g}\left(c w_{1}, \ldots, c w_{n}\right)\right)
\end{aligned}
$$


where

$$
\begin{aligned}
\ln U C_{i}\left(c w_{1}, \ldots, c w_{n}\right) & =\ln \left(\sum_{j} a_{i j}^{\sigma_{e}} \cdot c^{1-\sigma_{e}} w_{j}^{1-\sigma_{e}}\right)^{1 /\left(1-\sigma_{e}\right)} \\
& =\ln c+\ln U C_{i}\left(w_{1}, \ldots, w_{n}\right)
\end{aligned}
$$

Hence:

$$
\begin{aligned}
l\left(c w_{1}, \ldots, c w_{n}\right)= & \sigma_{e} \times\left(\ln a_{j}-\ln a_{k}+\left(\ln w_{k}+\ln c\right)-\left(\ln c+\ln w_{j}\right)\right)+ \\
& \left(\sigma_{e}-\sigma_{o}\right) \times\left(\begin{array}{c}
\left(\ln U C_{i}\left(w_{1}, \ldots, w_{n}\right)+\ln c\right)- \\
\left(\ln c+\ln U C_{g}\left(w_{1}, \ldots, w_{n}\right)\right)
\end{array}\right) \\
\forall i, g, j, k \quad & \Leftrightarrow\{1, \ldots, n\} \text { and } c \in \Re^{*} \\
\Longleftrightarrow & l\left(w_{1}, \ldots, w_{n}\right) \\
l\left(c w_{1}, \ldots, c w_{n}\right) \quad & \\
\forall i, g, j, k & \in\{1, \ldots, n\} \text { and } c \in \Re^{*}
\end{aligned}
$$

Factor demand, as measured in equation 4.22 , is homogeneous of degree zero in all factor prices. 


\section{Appendix D. Derivation of the wage changes}

Linearising the shifts in employment by educational groups as a function of the changes in the wage rates gives:

$$
\begin{aligned}
\Delta L_{j} & =\sum_{i} \Delta L_{i j} \\
& \simeq \sum_{i} \sum_{k} \Delta w_{k} \frac{\partial L_{i j}(w)}{\partial w_{k}}
\end{aligned}
$$

where:

$$
\frac{\partial L_{i j}(w)}{\partial w_{k}}=L_{i j}\left(\begin{array}{c}
\sigma_{o} U C^{\sigma_{o}-1} \sum_{g} U C_{g}^{\sigma_{e}-\sigma_{o}}\left(\frac{a_{g k}}{w_{k}}\right)^{\sigma_{e}} \\
+\left(\sigma_{e}-\sigma_{o}\right) U C_{i}^{\sigma_{e}-1}\left(\frac{a_{i k}}{w_{k}}\right)^{\sigma_{e}}
\end{array}\right)
$$

and

$$
\frac{\partial L_{i j}(w)}{\partial w_{j}}=L_{i j}\left(\begin{array}{c}
\sigma_{o} U C^{\sigma_{o}-1} \sum_{g} U C_{g}^{\sigma_{e}-\sigma_{o}}\left(\frac{a_{g j}}{w_{j}}\right)^{\sigma_{e}} \\
+\left(\sigma_{e}-\sigma_{o}\right) U C_{i}^{\sigma_{e}-1}\left(\frac{a_{i j}}{w_{j}}\right)^{\sigma_{e}} \\
-\sigma_{e} w_{j}^{-1}
\end{array}\right)
$$

Solving the system defined by equation 4.24 for relative wage changes gives:

$$
\begin{aligned}
\Delta w_{1}-\Delta w_{3} & =-\frac{\partial L_{.2}}{\partial w_{2}} \Gamma \\
\Delta w_{1}-\Delta w_{2} & =\frac{\partial L_{.2}}{\partial w_{3}} \Gamma \\
\Delta w_{2}-\Delta w_{3} & =\frac{\partial L_{.2}}{\partial w_{1}} \Gamma
\end{aligned}
$$

where $\Gamma=\frac{\Delta L_{3}}{\frac{\partial L_{1}}{\partial w_{2}} \frac{\partial L_{3}}{\partial w_{2}}-\frac{\partial L_{2}}{\partial w_{1}} \frac{\partial L_{2}}{\partial w_{2}}}$

Because the system has only 2 degrees of freedom and we search for three unknowns ( 3 wage changes), the system has an infinite set of solutions. To solve the system, we focus on the set of solutions that minimise wage differentials. 
Since $\Delta w_{2} \in\left(\Delta w_{1},-\Delta w_{3}\right)$, imposing $\Delta w_{1}=-\Delta w_{3}$ minimises $\Delta w_{1}+\Delta w_{2}+\Delta w_{3}$. Doing so, the solution of the problems reads as in equation 4.13.

The parameters for which the reciprocal shifts in the educational composition of labour supply lead to changes in the wage rate of workers with education 1 and 3 only, i.e. $w_{2}$ remains constant, are such that:

$$
\begin{aligned}
\frac{\partial L_{2}}{\partial w_{3}} & =\frac{\partial L_{2}}{\partial w_{1}}=-\frac{1}{2} \frac{\partial L_{2}}{\partial w_{2}} \\
& \Leftrightarrow \\
\sum_{i} \frac{\partial L_{i 2}}{\partial w_{3}}-\sum_{i} \frac{\partial L_{i 2}}{\partial w_{1}} & =0
\end{aligned}
$$

where all derivatives are evaluated at the long run equilibrium wage rates, $w_{1}=w_{2}=w_{3}=w$.

Replacing the derivatives by their expression in terms of the parameters $a_{i j}$ the condition reads as:

$$
\sum_{g} \bar{L}_{g 2}\left(\begin{array}{c}
\sigma_{o} \overline{U C}^{\sigma_{q}-1}\left(\sum_{i} \overline{U C}_{i}^{\sigma_{e}-\sigma_{o}}\left(a_{i 3}^{\sigma_{e}}-a_{i 1}^{\sigma_{e}}\right)\right) \\
+\left(\sigma_{e}-\sigma_{o}\right) \overline{U C}_{g}^{\sigma_{e}-1}\left(a_{g 3}^{\sigma_{e}}-a_{g 1}^{\sigma_{e}}\right)
\end{array}\right)=0
$$

where

$$
\begin{aligned}
\overline{U C} & =U C(w)=\left(\sum_{i} \overline{U C}_{i}^{1-\sigma_{o}}\right)^{1 /\left(1-\sigma_{o}\right)} \\
\overline{U C}_{i} & =U C_{i}(w)=w\left(\sum_{j} a_{i j}^{\sigma_{e}}\right)^{1 /\left(1-\sigma_{e}\right)} \\
\bar{L}_{i j} & =H \times U C^{\sigma_{\circ}} U C_{i}^{\sigma_{e}-\sigma_{o}} a_{i j}^{\sigma_{e}}
\end{aligned}
$$

Using the notation $a_{i j}=\pi_{i j} / \sum_{j} \pi_{i j}$ and $\pi_{i i}=1$ and imposing $\pi_{13}=\pi_{31}$ and $\pi_{12}=\pi_{32}$, the condition simplifies to: 


$$
\bar{L}_{22}\left(\begin{array}{c}
\sigma_{o} \overline{U C}^{\sigma_{o}-1} \overline{U C}_{2}^{\sigma_{e}-\sigma_{o}}\left(a_{23}^{\sigma_{e}}-a_{21}^{\sigma_{e}}\right) \\
+\left(\sigma_{e}-\sigma_{o}\right) \overline{U C}_{2}^{\sigma_{e}-1}\left(a_{23}^{\sigma_{e}}-a_{21}^{\sigma_{e}}\right)
\end{array}\right)=0
$$

Hence, a sufficient (but not necessary) condition for $\Delta w_{2}=0$ is that $\pi_{13}=\pi_{31}$, $\pi_{12}=\pi_{32}$ and $\pi_{21}=\pi_{23}$. 


\section{Appendix E. Estimated short and long run de- mand}

Table 4.8: The long run allocation matrix in annual percentage and the estimates reallocation matrix for 1994, 1995 and 1996.

\begin{tabular}{|c|c|c|c|c|}
\hline \multirow[t]{2}{*}{ Occupational fields } & \multicolumn{3}{|c|}{ Educational fields } & \multirow[b]{2}{*}{$\begin{array}{c}\text { Total } \\
\%\end{array}$} \\
\hline & $\begin{array}{c}\text { General } \\
\%\end{array}$ & $\begin{array}{c}\text { Technical } \\
\%\end{array}$ & $\begin{array}{c}\text { Social services } \\
\%\end{array}$ & \\
\hline \multicolumn{5}{|l|}{ Long run } \\
\hline General & 32.8 & 6.3 & 6.7 & 45.8 \\
\hline TechnicaI & 3.4 & 23.4 & 2.0 & 28.8 \\
\hline Social services & 3.1 & 1.0 & 21.4 & 25.4 \\
\hline Total & 39.3 & 30.7 & 30.1 & 100 \\
\hline Wage & 1 & 1 & 1 & \\
\hline \multicolumn{5}{|l|}{1994} \\
\hline General & -1.8 & +0.2 & -0.1 & -1.7 \\
\hline Technical & -0.0 & +1.8 & +0.0 & +1.8 \\
\hline Social services & -0.2 & +0.0 & +0.1 & -0.1 \\
\hline Total & -2.0 & +2.0 & 0.0 & 0 \\
\hline Wage & 1 & $0.94(-0.06)$ & $0.97(-0.03)$ & \\
\hline \multicolumn{5}{|l|}{1995} \\
\hline General & -1.1 & +0.4 & -0.4 & -1.1 \\
\hline Technical & +0.1 & +2.9 & -0.1 & +2.9 \\
\hline Social services & -0.2 & +0.0 & -1.6 & -1.8 \\
\hline Total & -1.2 & +3.3 & -2.1 & 0 \\
\hline Wage & 1 & $0.93(-0.07)$ & $1.02(+0.02)$ & \\
\hline \multicolumn{5}{|l|}{1996} \\
\hline General & -1.7 & +0.3 & -0.2 & -1.6 \\
\hline Technical & -0.0 & +2.3 & -0.0 & +2.3 \\
\hline Social services & -0.2 & +0.0 & -0.5 & -0.7 \\
\hline Total & -1.9 & +2.6 & -0.7 & 0 \\
\hline Wage & 1 & $0.93(-0.07)$ & $0.98(-0.02)$ & \\
\hline
\end{tabular}

Short run minus long run wage between (parentheses). 


\section{Appendix F. Wald-test on earnings regressions specification}

Table 4.9: Wald-test on earnings regression specifications by year.

\begin{tabular}{|c|c|c|c|c|c|c|c|c|c|}
\hline \multirow[b]{3}{*}{ ESS } & \multicolumn{3}{|c|}{94} & \multicolumn{3}{|c|}{95} & \multicolumn{3}{|c|}{96} \\
\hline & $\mathrm{HC}$ & $\mathrm{TH}$ & ASS & $\mathrm{HC}$ & $\mathrm{TH}$ & ASS & $\mathrm{HC}$ & $\mathrm{TH}$ & ASS \\
\hline & 58.59 & 58.18 & 58.17 & 16.86 & $1 \overline{6} .92$ & 16.77 & 18.20 & 18.27 & 18.09 \\
\hline $\mathrm{N}$ & 535 & 535 & 535 & 495 & 495 & 495 & 506 & 506 & 506 \\
\hline df & 14 & 14 & 16 & 14 & 14 & 16 & 13 & 13 & 15 \\
\hline$R_{a d j}^{2}$ & 0.585 & 0.587 & 0.586 & 0.802 & 0.801 & 0.801 & 0.786 & 0.785 & 0.785 \\
\hline $\begin{array}{l}F_{H C} \\
F_{T H}\end{array}$ & 2.05 & 0.03 & & 1.31 & 2.21 & & 1.55 & 2.47 & \\
\hline
\end{tabular}

Table 4.10: Wald-test on earnings regression specifications for the pooled sample.

\begin{tabular}{l|rrr}
\hline \hline & \multicolumn{3}{|c}{ Pool } \\
& \multicolumn{1}{|c|}{ HC } & \multicolumn{1}{c}{ TH } & \multicolumn{1}{c}{ ASS } \\
\cline { 2 - 4 } ESS & 94.59 & 94.37 & 93.99 \\
$\mathrm{~N}$ & 1536 & 1536 & 1536 \\
df. & 20 & 20 & 26 \\
$R_{\text {adj }}^{2}$ & 0.703 & 0.703 & 0.702 \\
\cline { 2 - 4 }$F_{H C}$ & 1.61 & & \\
$F_{T H}$ & & 1.01 & \\
\hline \hline
\end{tabular}




\section{Appendix G. Descriptive statistics of the data}

Table 4.11: Descriptive statistics of the data.

\begin{tabular}{l|rrrrrr|rr}
\hline \hline & \multicolumn{1}{|c|}{1994} & \multicolumn{1}{c|}{1995} & \multicolumn{1}{|l}{ Pool } \\
Variables & Mean & Std & Mean & Std & Mean & Std & Mean & Std \\
\hline Earnings & 2653 & 1447 & 2724 & 892 & 2836 & 944 & 2736 & 1133 \\
Age & 36.9 & 8.8 & 38.5 & 8.8 & 39.6 & 8.6 & 38.3 & 8.8 \\
Female & 0.32 & 0.47 & 0.30 & 0.46 & 0.30 & 0.46 & 0.30 & 0.46 \\
Hours & 37.0 & 9.7 & 36.8 & 9.2 & 37.0 & 9.5 & 36.9 & 9.5 \\
Tenure & 10.6 & 8.7 & 11.3 & 9.1 & 12.5 & 9.2 & 11.5 & 9.0 \\
Education & & & & & & & & \\
General & 0.36 & 0.48 & 0.38 & 0.48 & 0.39 & 0.49 & 0.38 & 0.49 \\
Technical. & 0.34 & 0.47 & 0.34 & 0.47 & 0.33 & 0.47 & 0.33 & 0.47 \\
Social services & 0.30 & 0.46 & 0.28 & 0.45 & 0.28 & 0.45 & 0.29 & 0.45 \\
Occupation & & & & & & & & \\
General & 0.43 & 0.49 & 0.45 & 0.50 & 0.45 & 0.50 & 0.45 & 0.50 \\
Technical. & 0.32 & 0.46 & 0.32 & 0.47 & 0.31 & 0.46 & 0.31 & 0.46 \\
Social services & 0.25 & 0.43 & 0.23 & 0.42 & 0.24 & 0.43 & 0.24 & 0.43 \\
N & 535 & & 495 & & 506 & & 1536 & \\
\hline \hline
\end{tabular}




\section{Chapter 5}

\section{Do large firms have more}

\section{possibilities to substitute labour than small firms?}

\subsection{Introduction}

In the allocation model developed in Chapter 2, the way in which firms assign workers to tasks is the determinant factor of the substitution process. In Chapter 4 we showed that the structure of workers' productivity in the various occupations, underlying the way in which firms assign workers to tasks, can lead to a substitution process associated with a higher labour productivity and a lower wage inequality. However, empirical analyses show tremendous heterogeneity in output, productivity and input mix across firms (see Abowd et al. (1999), Baily et al. (1992) and Olley and Pakes (1996) for instance). A possible explanation of the heterogeneity in output, productivity and labour composition between firms is that firms have different modes of production. These modes of production relate input quantities to output and productivity and are captured by the concept of production function. The heterogeneity in output, productivity and input-mix raises the question whether firms have the same production function whereas the impact of the substitution process on output and productivity suggests that if there are differences in the production function these differences may relate to the substitution possibilities of firms.

In this chapter, we therefore analyse the modes of production of firms and investigate whether the differences in the modes of production, i.e. differences in 
the production function, are related to the differences in the substitution possibilities between firms. Perhaps the most challenging observation is the positive effect of a firm's size on its productivity (e.g. Idson and Oi (1999) and Haltiwanger et al. (1999)), capital intensity, (e.g. Oi (1983)) and the skill composition of its workforce (see Oi (1983) and Haltiwanger et al. (1999)). In this chapter we advance the hypothesis that the differences in labour productivity, capital intensity and the skill composition of the workforce observed between small and large firms lie in the differences in the production function. Following Klump and De La Granville (2000) the differences in the capital intensity between large and small firms can be explained by a larger elasticity of substitution between labour and capital in large firms. We argue that in a similar way the differences in the skill composition of the workforce between large and small firms can be explained by a larger elasticity of substitution between skilled and unskilled labour. To explain the differences in the skill composition between large and small firms we prove two theorems. We prove that i) if two firms are described by CES production functions differing only by their elasticity of substitution between skilled and unskilled labour, at an equivalent labour force composition the firm with the higher elasticity of substitution will have the higher labour productivity. Moreover, we prove that if the two firms also initially share a common skill intensity and face the same skill-biased technological change, the firm with the highest elasticity of substitution between skilled and unskilled labour will have a larger rate of change in the relative demand for skilled workers. Hence, skill-biased technological change results in a larger change in the demand for skilled workers in firms with higher elasticity of substitution between skilled and unskilled workers. In turn, the larger labour productivity observed in large firms can be explained by a larger elasticity of substitution between inputs. Using matched employer-employee data for Denmark, we evaluate the extent to which the elasticities of substitution between capital and labour and between skill-groups differ between large and small firms and whether these differences explain the firm-size effects on labour productivity, capital intensity and the skill composition of the workforce.

Our main findings are that large firms indeed have higher elasticities of substitution between skilled workers in skilled jobs and all other inputs than small firms in all industries. These differences in elasticities of substitution are of the magnitude to explain the higher labour productivity, capital intensity and skill intensity observed in large firms. As the skill segregation hypothesis suggests (see 


\subsection{INTRODUCTION}

Haltiwanger et al. (1999)), we find that large firms employ more overeducated workers than small firms. We relate the tendency of large firms to employ a relatively overeducated workforce to an ant versus cicada $a^{1}$ behaviour. The larger productivity enables large firms to build in a reserve capacity of skilled workers in periods of low wages for skilled people in order to anticipate demand or supply shocks in the labour market for skilled workers. If the wage of skilled workers increases, large firms are affected less since they already retain internal reserves of skilled workers. ${ }^{2}$

The question of differences in the production function between firms is related to the literature on the relation between firm-size and labour productivity. In this literature, the firm-size effect on labour productivity is often explained by the efficiency wage theory proposed by Solow (1979) in which productivity is a function of workers' effort. Idson and Oi (1999) advance the hypothesis that differences in workers' work effort between firms of different size is at the origin of the observed productivity differences between firm-size categories. Workers in large firms have less idle time and hence are more productive which allows them to command higher wages in a competitive labour market. Idson and $\mathrm{Oi}$ (1999) find that the inter-size range for the change in labour productivity is about 0.17 log-points in the US manufacturing industry in 1992 and is accompanied by a wage-size elasticity of 0.075 . However, the firm-size wage premium becomes insignificant when they include labour productivity measures in the set of explanatory variables. From these results Idson and Oi conclude that the firm-size wage premium is indeed due to a higher productivity of workers employed in large firms. However, Idson and $\mathrm{Oi}$ do not control for the characteristics of workers neither in the wage regression nor in the labour productivity regression. Since skill intensity and labour productivity both increase with firm-size the true effect of labour productivity on the firm-size wage premium is over-estimated in their analysis as inclicated by Bayard and Troske (1999). The higher labour productivity related to workers' effort accounts for at most half of the firm-size wage

\footnotetext{
${ }^{1}$ See De La Fontaine (1668). In this fable Jean De La Fontaine tells the story of an ant that builds in food reserves during summer, as it abounds, for consumption during winter when food is scarce and a cicada that spends the summer playing the guitar and starves during winter.

${ }^{2} \mathrm{By}$ analogy to the labour hoarding explanation of procyclical productivity; see e.g. Fair (1985), Fay and Medoff (1985) and Sbordone (1996). Changes in labour utilisation allow the firm to react to unexpected changes in product demand without laying off workers. Workers can be allocated to non-production activities such as maintenance and training rather than being layed off (Fay and Medoff (1985)).
} 
premium once controls for skills and other workers' characteristics are included. Moreover, Haltiwanger et al. (1999) find that it is not merely because firms of different employment size systematically employ a different skill-mix of workers that their labour productivity significantly differs. For the same workforce composition, larger firms have higher labour productivity. The positive relationship between firm-size and labour productivity and input mix reflects complex differences in the modes of production between large and small firms. This suggests that large and small firms choose different modes of production, requiring a different workers' mix, and lock in. Thereby, changes in workforce composition reflect transitory shocks in the labour market that yield fluctuations around the long run levels of workforce compositions these firms have chosen. ${ }^{3}$

The differences in the production function between firms leading to differences in the labour productivity, capital to labour ratio and skill workforce composition may be characterised by differences in the ease to substitute between factors inputs. Indeed, De La Grandville (1989) shows that there is a relation between the output increase due to a factor price change and the elasticity of substitution between factors of production. Following this argument, Klump and De La Grandville (2000) prove that a higher elasticity of substitution will result into a. higher level of labour productivity in the steady-state. Intuitively, differences in the ease to substitute between the various input factors across firms as an explanation of the size effect in labour productivity seems, on a theoretical basis, consistent. Indeed, the magnitude of the elasticity of substitution actually determines the range of possibilities available to employers. The higher this elasticity, the greater the opportunities for employers to produce a given level of output with different factor combinations.

Yet, the higher skill intensity in large firms has been subject to various interpretations in the literature. The differences in the skill-composition of the

\footnotetext{
${ }^{3}$ Though this heterogeneity across firms is consistent with a conjecture that different firms choose different modes of production (Haltiwanger et al. (1999), Idson and Oi (1999) and Bayard and Troske (1999) for instance), only few attempts have been made in directly comparing the shape of the production function across firms. In the exhaustive survey of empirical estimations of production functions by Hamermesh (1993) only two studies distinguish between groups of firms within industries. Klotz et al. (1980) estimate a translog production function for high and low productive manufacturing firms in 1967 using three inputs: capital, production and non-production workers. Field (1988) estimates a translog production function for large and small farms in the cotton industry in 1860, using land, slaves and free workers as inputs. Since 1993, to our knowledge, only Lever (1996) for the Ducth manufacturing industry and Dhawan (2001) with U.S. data estimate production function parameters for different firm categories.
} 
workforce between firms of different sizes might emerge from different sources. ${ }^{4}$ Building on an assignment hypothesis (see Sattinger (1993)), Haltiwanger et al. (1999) argue that firms choose different modes of production resulting in skill segregation. This skill segregation hypothesis implies that different firms employ workers with different educational attainment to do a job of a given level of complexity. Yet, as Idson and Oi (1999) acknowledge, large firms adopt new technologies earlier which probably results in a larger amount of complex jobs. Therefore, the larger proportion of high skilled workers in larger firms might correspond with a conjecture that in large firms the distribution of jobs by their level of complexity is relatively more skewed to the right. Large firms have more complex jobs than smaller firms and therefore employ systematically more skilled workers. However, strictly speaking, Haltiwanger et al. do not use an assignment model. Their labour productivity regression ${ }^{5}$ takes the form of a human capital specification, i.e. a firm's workforce is decomposed along educational attainment regardless of the occupational structure, and they do not test empirically for the skill segregation hypothesis. In the presence of skill segregation, large firms systematically employ more overeducated workers than small firms. Therefore, building on the allocation model developed in Chapter 2, for each firm, workers are grouped according to their educational attainment and their occupational level.

Following the elasticity hypothesis of Klump and De La Grandville (2000) differences in the ease to substitute between the various factors of production may be at the origin of the differences in the skill composition of the workforce and capital intensity across firms. Klump and De La Grandville (2000) prove that a higher elasticity of substitution between capital and labour will result into

\footnotetext{
${ }^{4}$ In the literature on job requirements, authors argue that since jobs differ with respect to the level of skills needed for satisfactory performance, employers classify jobs according to the minimally 'required' levels of education and work experience. Herewith, the minimally required levels of education and experience define the hiring standards of firms. These hiring standards are then used as instruments to control for the duration of the vacancies. Since the pool of applicants might significantly differ in terins of their skill levels between firms of different sizes, large firms might have incentives to set higher hiring standards than small firms. Therefore, large firms may employ more skilled workers simply because they observe more favourable poois of applicants which enable employers in large firms to set higher hiring standards than small firms. Van Ours and Ridder (1991), however, do not find such evidence for the Netherlands:

${ }^{5}$ Haltiwanger et al.'s (1999) analysis reads as a production function estimation where ex ante assumptions are made on the elasticities of substitution. Therein, the elasticity of substitution between each pair of labour inputs is constant and equal to unity regardless of the firm's employment size (Cobb-Douglas production function).
} 
a higher capital intensity in the steady-state. This results can be used to explain differences in the capital to labour ratio between firms. Indeed, the larger capital to labour ratio observed in large firms possibly emerge from a larger elasticity of substitution between capital and labour input in these large firms. Mloreover, the elasticity hypothesis would be consistent with the observed larger skill intensity in large firms if the ease to substitute between workers with different skill-levels increases with firm size. ${ }^{6}$

The structure of this chapter is as follows. In Section 5.2, a theoretical setting is developed to show the relationship between elasticity of substitution, labour productivity and skill-composition. On the basis of four theorems, two by Klump and De La Grandville (2000) and two proven in this chapter, we show that the magnitude of the elasticity of substitution between inputs relates to the level of labour productivity, capital intensity and skill composition of the workforce. Section 5.3 describes the data. In Section 5.4, we first describe our quantitative approach to measure the elasticities of substitution between labour types, differentiated by education and occupation, and capital for firms of different employment size and in different industries and present in the following subsection the estimates of the elasticities of substitution by industry and firm-size. As predicted by our theoretical model, we find that large firms have higher elasticities of substitution between skilled labour with all other inputs (unskilled labour and capital). To check whether this result is merely driven by specific characteristics of the data we use, we replicate the analyses of Idson and Oi and Haltiwanger et al. with our data. The results of these replication analyses are in line with Idson and Oi and Haltiwanger et al. so that we conclude that our results not driven by specific characteristics of our data. Some final remarks and conclusions appear in Section 5.5.

\footnotetext{
${ }^{6}$ Klotz et al. (1980) find that plants with large labour productivity have a larger elasticity of substitution between blue and white collar-workers than plants with a lower labour productivity (highest quartile elasticity equals 6 , lowest quartile equals 2 ). However, their study does not include capital input. Lever (1996) on the other hand finds a slightly higher (but not significant) elasticity of substitution between capital and labour in large firms but does not differentiate between different types of labour.
} 


\subsection{Elasticities of substitution: Four theorems}

De La Grandville (1989) sheds some light on the property of the elasticity of substitution: the increase in the production due to a decrease in one factor price is an increasing function of the elasticity of substitution between the factors of production. In order to illustrate this relationship, we define a theoretical setting as follows.

Consider two firms that maximise profits. Both firms' produce the same output, $H$, by combining quantities of two factors of production, $q_{1}$ and $q_{2}$. The two firms' production functions are distinguished by their elasticity of substitution (firm 1 has an elasticity of substitution equal to 1, i.e. a Cobb-Douglas production function, and firm $\sigma$ has an elasticity of substitution equal to $\sigma$, i.e. a CES production function) only and share initially the same baseline values for the quantities of each input, $q_{1}^{0}$ and $q_{2}^{0}$, output level, $H^{0}$ and cost-constraint, $C^{0}$.

The production function of firm 1 takes the form of a homogeneous of degree one Cobb-Douglas production function and reads as follows:

$$
H_{1}\left(q_{1}(w, C), q_{2}(w, C)\right)=\bar{\alpha} \times q_{1}^{\bar{\psi}}(w, C) \times q_{2}^{1-\bar{\psi}}(w, C)
$$

where $w=<w_{1}, w_{2}>$ are the respective prices of inputs $q_{1}$ and $q_{2}$ and $C$ is the cost constraint. The bar above production parameters indicates that the parameters are normalised to some baseline values as De La Grandville (1989) did.

The production function of firm $\sigma$ takes the form of a homogeneous of degree one CES production function and reads as follows:

$$
H_{\sigma}\left(q_{1}(w, C), q_{2}(w, C)\right)=\bar{\gamma}\left(\bar{\delta} \times q_{1}^{(\sigma-1) / \sigma}(w, C)+(1-\bar{\delta}) \times q_{2}^{(\sigma-1) / \sigma}(w, C)\right)^{\sigma /(\sigma-1)}
$$

where $\bar{\alpha}, \bar{\psi}, \bar{\gamma}$ and $\bar{\delta}$ are such that

$$
H_{1}^{0}\left(q_{1}^{0}\left(w^{0}, C^{0}\right), q_{2}^{0}\left(w^{0}, C^{0}\right)\right)=H_{\sigma}^{0}\left(q_{1}^{0}\left(w^{0}, C^{0}\right), q_{2}^{0}\left(w^{0}, C^{0}\right)\right) \text {. }
$$

The elasticities of substitution between input $q_{1}$ and $q_{2}$ are 1 for firm 1 and $\sigma$ for firm $\sigma$, where $\sigma$ is assumed to be larger than 1 without loss of generality. 
Let us start with a short-run analysis of the impact of the elasticity of substitution on the optimal output level. The evidence of the positive relationship between the magnitude of the increase in the maximum production level associated to a factor price change and the magnitude of the elasticity of substitution is depicted in Figure 5.1. Both firms share initially in point $A$ the same quantities of inputs $q_{1}^{0}$ and $q_{2}^{0}$, and the same cost constraint $C^{0}$. The short-run expansion path for both firms is reached at point $A$ for input prices $w^{0}$, where both isoquants and the cost constraint are tangent. At point $A$ both firms' production levels are one unit since we have normalised their production functions. The figure shows what happens to the respective production levels at given total costs if one of the input prices decreases, for instance the price of input $q_{1}$. First, given total costs, $C^{0}$, the new cost constraint, shared by both firms, is depicted by the (dashed) downward sloping line $C^{1}$. Since firm $\sigma$ has a higher elasticity of substitution, the substitution effect is larger in firm $\sigma$ and the new input ratio $q_{2}^{1} / q_{1}^{1}$ is smaller in firm $\sigma$ than in firm 1. This is seen in the graph by the flatter ray from the origin passing through point $B_{\sigma}$ on the original isoquant curve $H_{\sigma}^{0}$ where the tangent and the new cost constraint share the same slope. Furthermore, given total costs, we know that the new maximum production level must be such that the new cost constraint is tangent to the associated isoquant. The new short-run expansion path for firm $\sigma$ at input prices $w^{1}$ is achieved by moving on the ray from the origin to point $B_{\sigma}^{\prime}$ where it crosses the new cost constraint. The new maximum production level of firm $\sigma$ is defined by the (dashed) isoquant $\dot{H}_{\sigma}^{1}$ and maximum production level of firm 1 is defined by the (dashed) isoquant $H_{1}^{1}$. The derivation of the new equilibrium point for firm 1, i.e. $B_{1}^{\prime}$, is similar. Graphically, we observe that the intersection of the new isoquant $\left(H_{1}^{1}\right.$ and $\left.H_{\sigma}^{1}\right)$ with the initial ray from the origin moves farther out as the elasticity of substitution increases (respectively $A^{\prime}$ for firm 1 and $A^{\prime \prime}$ for firm $\sigma$ ). The properties of the isoquant imply that at time 1 , firm $\sigma$ achieves a higher production level than firm 1 .

Moreover, the property of the elasticity of substitution is of crucial importance for the growth of firms. Consider the production function of the two firms depicted above and suppose $q_{2}$ is capital input, and $q_{1}$ is labour input. The labour productivity of each firm can be written as follows:

For firm 1: 


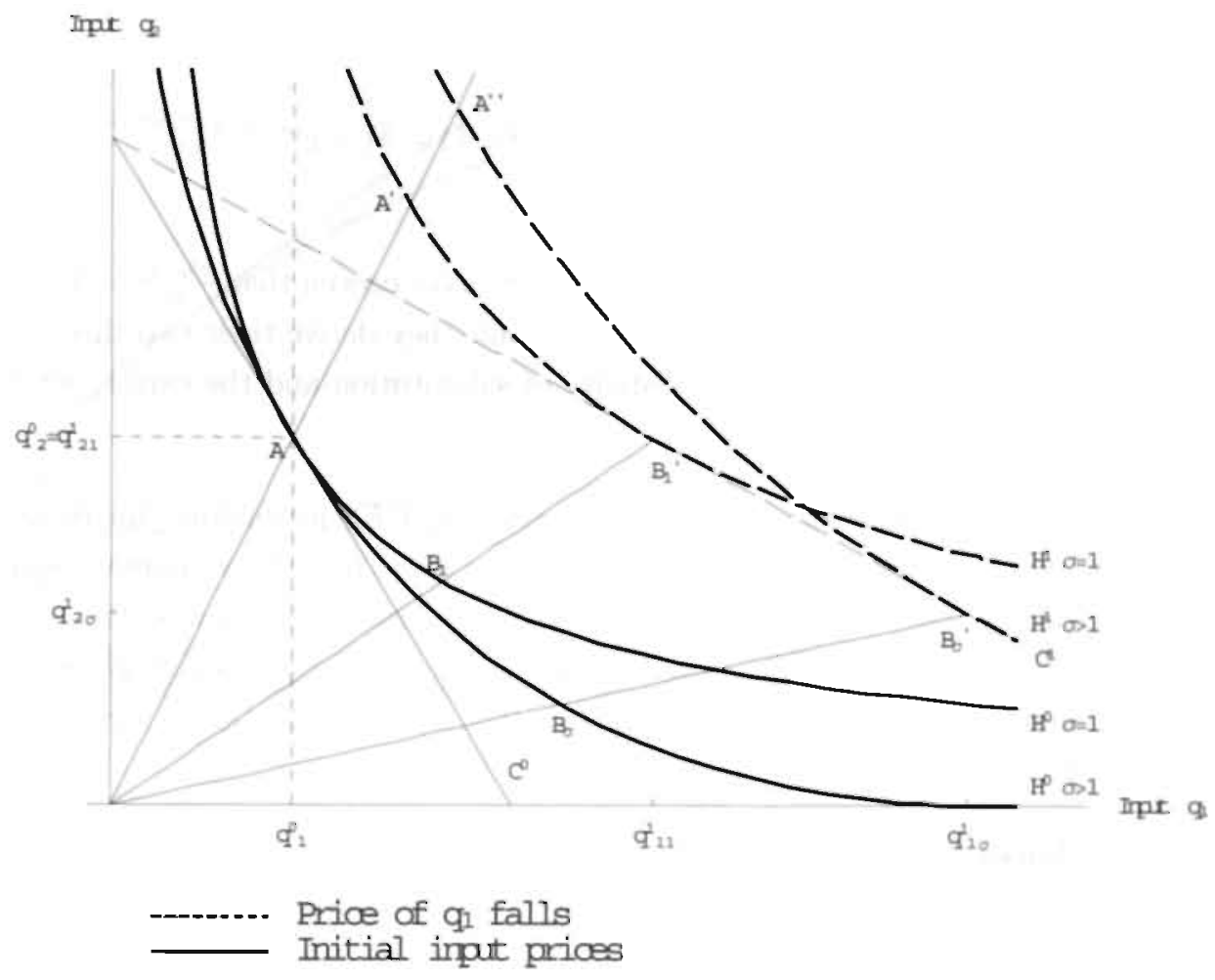

Figure 5.1: The demand curve for input $q_{1}$ and. $q_{2}$ and the relationship between the elasticity of substitution and the change in the maximum production level at given total cost associated to a decrease in one input price. 


$$
\frac{H_{1}}{q_{1}}(k, 1)=h_{1}(k)=\bar{\alpha} \times k^{1-\bar{\psi}}
$$

where $k=\frac{q_{2}}{q_{1}}$ is the capital intensity and $h_{1}()$ is labour productivity function.

For firm $\sigma$ :

$$
\frac{H_{\sigma}}{q_{1}}(k, 1)=h_{\sigma}(k)=\bar{\gamma}\left(\bar{\delta}+(1-\bar{\delta}) \times k^{(\sigma-1) / \sigma}\right)^{\sigma /(\sigma-1)}
$$

Klump and De La Grandville (2000) have proven that $\frac{\partial h_{\sigma}(k)}{\partial \sigma}>0$ for all $k \neq \bar{k}$ and $\frac{\partial h_{\sigma}}{\partial \sigma}=0$ for $k=\bar{k}$. From this result they derive their two theorems on the relationship between the elasticity of substitution and the capital intensity and labour productivity.

Theorem 1 If two firms are described by CES production functions differing only by their elasticity of substitution and share initially a common capital-labour ratio $\bar{k}$, the same employment growth $\dot{L}$, and investment rate $s$, then at any stage of its development the firm with the higher elasticity of substitution will have a higher level of labour productivity. (Cf: Klump and De La Grandville (2000) p.285)

Theorem 2 If two firms are described by CES production functions differing only by their elasticity of substitution and share initially a common capital-labour ratio $\bar{k}$, the same employment growth $\dot{L}$, and invesiment rate $s$, and if the levels of the elasticities of substitution guarantee the existence of steady states, then the firm with the higher elasticity of substitution between capital and labour will have a higher capital intensity and higher labour productivity in the steady state. (Cf: Klump and De La Grandville (2000) p. 286)

The firm's labour productivity is an increasing function of its elasticity of substitution. If the production functions of the two firms only differ by their elasticity of substitution, at an equivalent value of capital intensity, any value, the firm with the highest elasticity of substitution has a higher level of labour productivity. This theorem is depicted in Figure 5.2. For any vertical line, the intersection of this line with the labour productivity function shifts upward as 


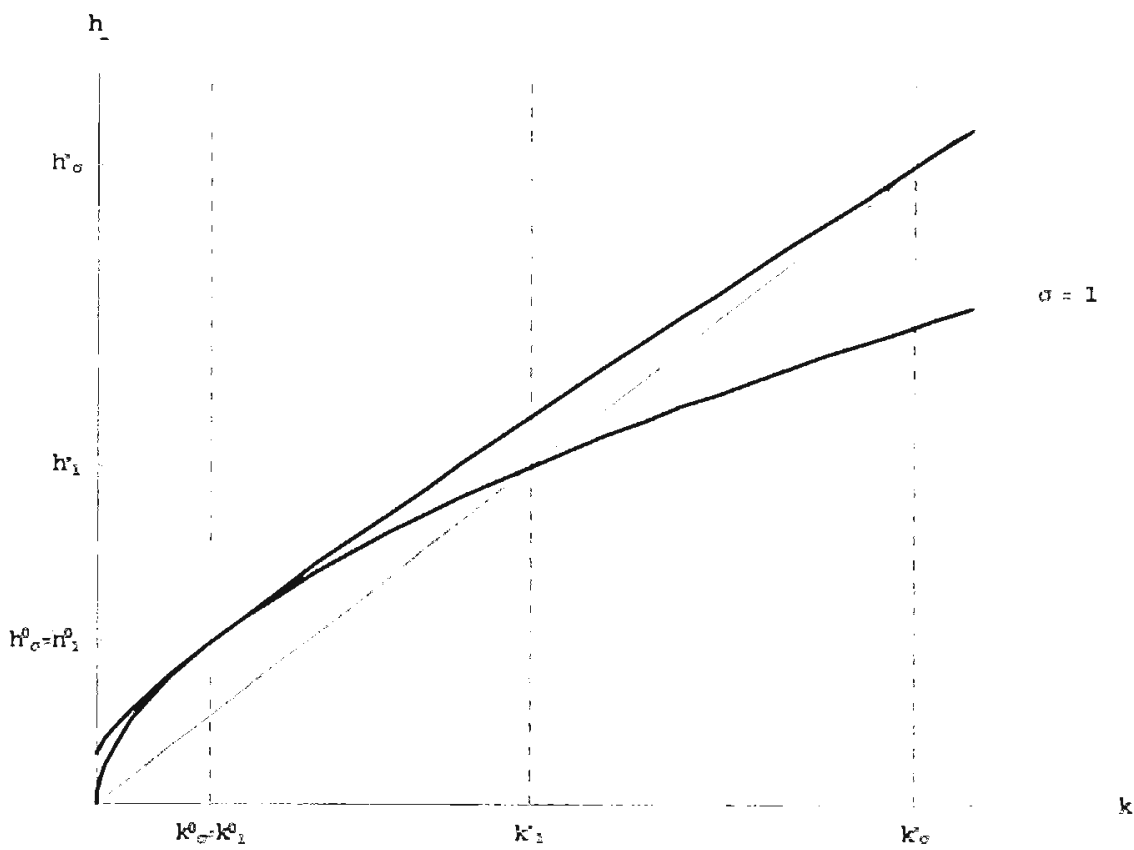

Figure 5.2: At equivalent capital intensity, a higher elasticity of substitution between capital and labour implies a higher labour productivity.

the elasticity of substitution increases. Furthermore, if both firms share the same investment rate and labour force growth, the firm with the highest elasticity of substitution will have the highest labour productivity and capital intensity in the steady-state. Indeed, the intersection of the labour productivity curve of firm $\sigma$ with a common ray from the origin will be situated above and to the right of the intersection with the labour productivity curve of firm 1. In Figure 5.2, the intersection of any ray from the origin with both labour productivity curves is such that the firm with the highest elasticity of substitution, firm $\sigma$, has a higher capital intensity, $k_{1}^{*}<k_{\sigma}^{*}$, and a larger labour productivity, $h_{\sigma}^{*}=h_{\sigma}\left(k_{\sigma}^{*}\right)>$ $h_{1}\left(\dot{k}_{1}^{*}\right)=h_{1}^{*}$.

Suppose now that both inputs $q_{1}$ and $q_{2}$ are labour inputs differentiated by skills and $q_{1}$ and $q_{2}$ are respectively the number of unskilled and skilled workers. The elasticity of substitution considered here are labour-labour elasticities of substitution. Having normalised the production function of both firms, firm 1 
and firm $\sigma$, we can derive the long run labour productivity of both firms as a function of the proportion of skilled workers in each firm, denoted $p\left(p=\frac{q_{2}}{q_{1}+q_{2}}\right)$.

Consider that firms maximises profits and produces output, $H$, by combining unskilled and skilled labour, say $L_{u} \equiv q_{1}$ and $L_{s} \equiv q_{2}$. The production function of the firms takes the form of a homogeneous of degree one CES production function:

$$
H_{\sigma}\left(L_{u}, L_{s}\right)=\bar{\gamma}\left(\bar{\delta} \times L_{u}^{(\sigma-1) / \sigma}+(1-\bar{\delta}) \times L_{s}^{(\sigma-1) / \sigma}\right)^{\sigma /(\sigma-1)}
$$

where $\bar{\gamma}$ and $\bar{\delta}$ are technology parameters and $\sigma$ is the elasticity of substitution between skilled and unskilled labour.

The long run labour productivity of the firms is derived as a function of the proportion of skilled workers in the firm, $p=\frac{L_{s}}{L_{u}+L_{s}}$.

$$
\frac{H_{\sigma}}{L_{u}+L_{s}}(p, 1-p)=g_{\sigma}(p)=\bar{\gamma}\left(\bar{\delta}(1-p)^{(\sigma-1) / \sigma}+(1-\bar{\delta}) \times p^{(\sigma-1) / \sigma}\right)^{\sigma /(\sigma-1)}
$$

We are now set to prove our two theorems.

Theorem 3 If two firms are described by CES production functions differing only by their elasticity of substitution between skilled and unskilled labour, at equivalent labour force composition $p$, any $p$, the firm with the higher elasticity of substitution will have the higher labour productivity.

Proof. Once recognised that $k=\frac{p}{1-p}\left(p=\frac{k}{k+1}\right)$ and $g_{-}(p)=g_{-}\left(\frac{k}{k+1}\right)=$ $h_{-}(k) \frac{1}{k+1}$ derivation of the function $g$ with respect to the elasticity of substitution becomes trivial:

$$
\frac{\partial g}{\partial \sigma}=\frac{1}{k+1} \frac{\partial h}{\partial \sigma}
$$

Since $p=\frac{k}{k+1}>0$ for all $k>0$ we conclude that $\frac{\partial g}{\partial \sigma} \geq 0$ for all $p$ and equal to zero for $p=\bar{p}$. This result, illustrated in Figure 5.3, implies that at equivalent 


\subsection{ELASTICITIES OF SUBSTITUTION: FOUR THEOREMS}

labour force composition, the higher the elasticity of substitution between skilled and unskilled labour the higher labour productivity.

Also, the differences in the skill composition can be explained by differences in the ease to substitute between skill-categories in the presence of skill-biased technological change as the following theorem states. ${ }^{7}$

Theorem 4 If two firms are described by CES production functions differing only by their elasticity of substitution and share initially a common skill intensity, i.e. $L_{s} / L_{u}$ and a skilled labour augmenting technological change characterised by the same function $m(t)$ (same rate of skilled labour augmenting $L_{s}$, i.e. $m^{\prime}$ ), then, the firm with the higher elasticity of substitution between skilled and unskilled labour will have a larger rate of change in the relative demand for skilled workers $L_{s} / L_{u}$ and vice versa.

Proof. To prove this, consider a CES production function with two labour inputs, $L_{u}$ and $L_{s}$, with non-neutral, $L_{s}$ augmenting technological change.

$$
H_{\sigma}\left(L_{u t}, L_{s t}\right)=\bar{\gamma}\left(\bar{\delta} L_{u t}^{(\sigma-1) / \sigma}+(1-\bar{\delta}) \times\left(m(t) L_{s t}\right)^{(\sigma-1) / \sigma}\right)^{\sigma /(\sigma-1)}
$$

where $m^{\prime}=(1 / m)(d m / d t)$ is the rate of skilled labour $L_{s}$, augmenting technological change at time $t$ and $m>0$ and $m^{\prime}>0$.

Deriving equation 5.8 with respect to each input factor yields the marginal productivity of $L_{u}$ and $L_{s}$ :

$$
\begin{aligned}
& \partial H_{\sigma} / \partial L_{u}=\bar{\delta}\left(\frac{Y_{t}}{L_{u t}}\right)^{1 / \sigma}=w_{u t} \\
& \partial H_{\sigma} / \partial L_{s}=(1-\bar{\delta})\left(\frac{Y_{t}}{L_{s t}}\right)^{1 / \sigma} m^{(\sigma-1) / \sigma}(t)=w_{s t}
\end{aligned}
$$

where $w_{v t}$ and $w_{s t}$ are the wage rates of unskilled and skilled workers respectively.

\footnotetext{
${ }^{7}$ Among others, Bound and Johnson (1992), Berman et al. (1994), Autor et al. (1998), Berman et, al. (1998) and Machin and Van Reenen (1998) show that technological developments are skill biased. New technologies, such as computers, require skills that are more expensive to acquire than existing skills. Since it is less costly for skilled workers to acquire the new skills, skilled workers are the first to use the new technology. In turn, their marginal productivity raises compared to unskilled workers (see Dume et al. (2000) for instance).
} 
The relative demand for skilled workers $L_{s}$ reads as:

$$
q_{t}=\frac{L_{s t}}{L_{u t}}=\left(\frac{\bar{\delta}}{1-\bar{\delta}}\right)^{-\sigma}\left(\frac{w_{s t}}{w_{u t}}\right)^{-\sigma} m^{-1+\sigma}(t)
$$

Writing $\dot{q}$ the rate of change in the relative demand for skilled workers $L_{s}$, and assuming constant wages, we have:

$$
\dot{q}=(\sigma-1) \frac{m^{\prime}}{m}
$$

Deriving equation 5.12 with respect to $\sigma$ yields:

$$
\frac{\partial \dot{q}}{\partial \sigma}=\frac{m^{\prime}}{m}
$$

Since both $m^{\prime}$ and $m$ are strictly positive, the derivative of the rate of change of the relative demand for skilled workers $L_{s}$ associated to the skilled augmenting technological change, is strictly positive.

Hence, if two firms are described by CES production functions that differ only by their elasticity of substitution and share initially a common skill intensity, i.e. $L_{s} / L_{u}$ and a skilled labour augmenting technological change characterised by the same function $m(t)$ (same rate of skilled labour augmenting $L_{s}$, i.e. $m^{\prime}$ ), then, the firm with the highest elasticity of substitution between skilled and unskilled labour will have a larger rate of change in the relative demand for skilled workers $L_{s} / L_{u}$. Skilled-biased technological change results in a larger change in the demand for skilled workers in firms with higher elasticity of substitution between skilled and unskilled workers. ${ }^{8}$

Also the differences in the skill composition can be explained by differences in the ease to substitute between skill-categories under skill-biased technological change.

Hence, if two firms are described by CES production function differing only by their elasticity of substitution and share initially a common skill intensity, i.e.

\footnotetext{
${ }^{8}$ Reciprocally, the change in the demand for unskilled workers will be larger, the larger the elasticity of substitution between skilled and unskilled workers given an unskilled labour augmenting technological change.
} 


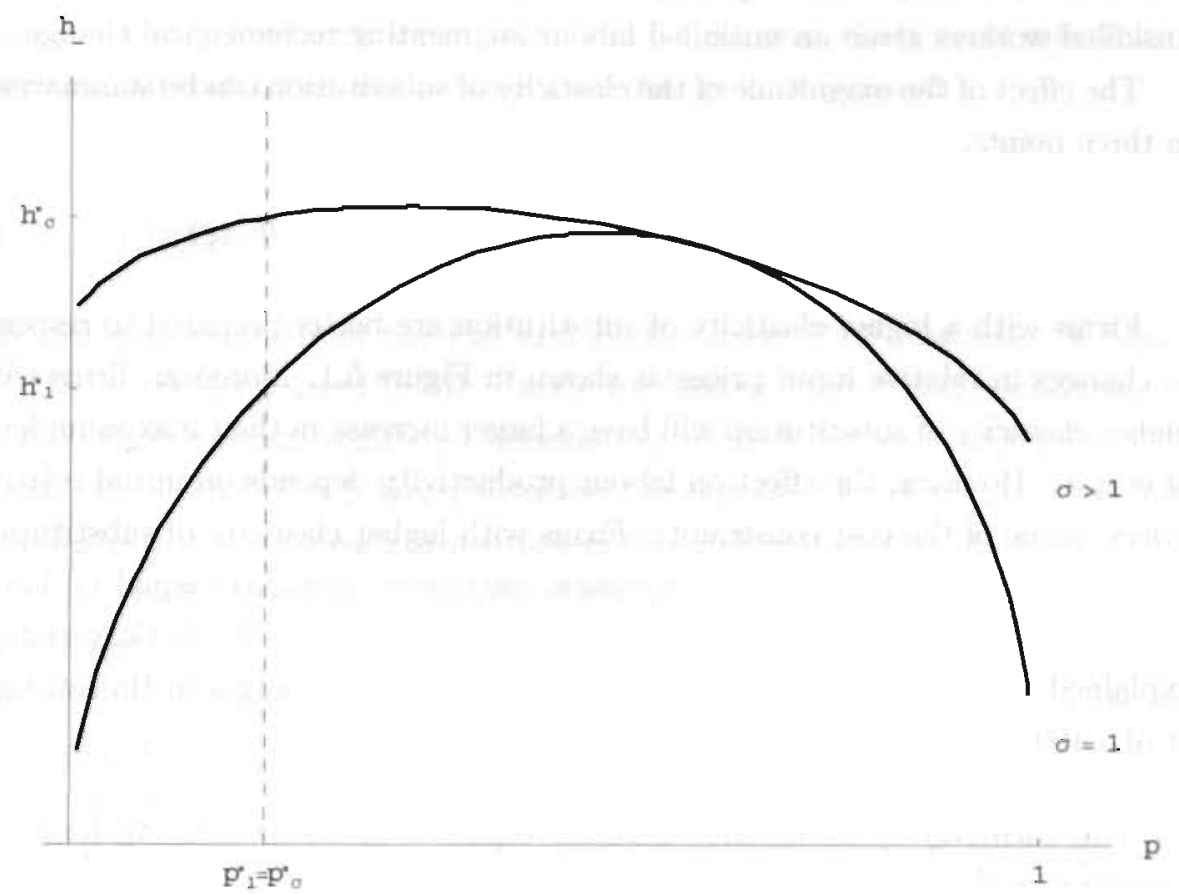

Figure 5.3: At equivalent workforce composition, a higher elasticity of substitution between skilled and unskilled workers implies a higher labour productivity. 
$q_{2} / q_{1}$ and a skilled labour augmenting technological change characterised by the same function $g(t)$ (same rate of skilled labour augmenting $q_{2}$, i.e. $g^{\prime}$ ), then, the firm with the highest elasticity of substitution between skilled and unskilled labour will have a larger rate of change in the relative demand for skilled workers $q_{2} / q_{1}$. Skilled-biased technological change results in a larger change in the demand for skilled workers in firms with higher elasticity of substitution between skilled and unskilled workers. Reciprocally, the change in the demand for unskilled workers will be larger, the larger the elasticity of substitution between skilled and unskilled workers given an unskilled labour augmenting technological change.

The effect of the magnitude of the elasticity of substitution can be summarised in three points.

\section{A) The elasticity of substitution and short run expansion path.}

Firms with a higher elasticity of substitution are better prepared to respond to changes in relative input prices as shown in Figure 5.1. Moreover, firms with higher elasticity of substitution will have a larger increase in their maximum level of output. However, the effect on labour productivity depends on initial relative prices (slope of the cost constraint). Firms with higher elasticity of substitution could reach the new short-run expansion path with a higher, equal or lower labour productivity change. This last results could explain the little variation explained by workforce changes and labour productivity changes in Haltiwanger et al. (1999).

B) The elasticity of substitution between capital and labour and the long run expansion path.

At any stage of its development and at equivalent capital intensity, the firm with the highest elasticity of substitution enjoys a higher labour productivity. When two firms have the same investment rate and employment growth but different elasticities of substitution between capital and labour, the one with the highest elasticity will reach its steady-state at a higher capital intensity and with a higher labour productivity. Both implications coincide with a conjecture that large firms have a higher elasticity of substitution between capital and labour.

C) The skilled labour unskilled labour elasticity of substitution and the long run expansion path. 
At equivalent workforce composition, the firm with the highest elasticity of substitution between skilled and unskilled workers enjoys a higher labour productivity. The labour productivity gap found between large and small firms after controlling for workforce composition may coincide with a conjecture that large firms enjoy a larger labour-labour elasticity of substitution. Moreover, given skillbiased technological change, the firm with the highest elasticity of substitution between skilled and unskilled workers will have a higher rate of change in the relative demand for skilled workers. The larger skill intensity in large firms may coincide with the conjecture that large firms have higher elasticity of substitution between skill categories and technological change is skill-biased.

\subsection{Data}

We use data drawn from the Pay and Performance (P\&P) database of Statistics Denmark maintained by the Centre for Labour market and Social research (CLS). P\&P contains registered information on all firms and residents in Denmark. At the end of each year (November) workers and firms are matched. This enables us to derive for each firm an exhaustive and precise decomposition of their workforce along demographic variables, educational background and occupational attainment.

Individuals selected are those employed in the private sector during the period 1992-1995. The classical demographic variables such as gender, age but also a direct measure of experience, constructed by backward inspection of previous professional status since 1964, are available. The educational background information refers to the highest educational attainment of individuals and is coded according to the Danish educational classification conceptually similar to the International Standard Classification of EDucation (ISCED) decomposition. This data is re-coded into three educational levels: lower education (no schooling and elementary schools), intermediate education (high-school and vocational high-schools) and higher education (college, advanced technical schools and Universities). ${ }^{9}$ Similarly, the occupation of each worker is classified according to the Danish occupational codes and re-coded into three levels: low-skilled occupations, intermediary skilled occupations and high-skilled and managerial occupations.

\footnotetext{
${ }^{9}$ See Bingley and Westergaard-Nielsen (1998).
} 
Table 5.1: Firms' shares and employment shares by industry and firm-size (average 1992-'95).

\begin{tabular}{l|rrr|r}
\hline \hline Industry & Manufacturing & Utilities & Construction & Total \\
Firms & 2,925 & 920 & 2,220 & 6,065 \\
& $\%$ & $\%$ & $\%$ & $\%$ \\
$0-20$ & 13 & 26 & 17 & 15 \\
$20-49$ & 47 & 53 & 55 & 51 \\
$50-99$ & 19 & 12 & 17 & 17 \\
$100+$ & 21 & 9 & 11 & 15 \\
& & & & \\
Employment & 301,136 & 51,130 & 135,738 & 488,004 \\
& $\%$ & $\%$ & $\%$ & $\%$ \\
$0-20$ & 2 & 7 & 5 & 3 \\
$20-49$ & 15 & 29 & 28 & 22 \\
$50-99$ & 13 & 15 & 18 & 15 \\
$100+$ & 70 & 49 & 49 & 60 \\
\hline \hline
\end{tabular}

Since each worker is assigned a firm identification number we aggregate workers' characteristics into summary measures for each firm. ${ }^{10}$ As a result, our data has the firm as unit of observation. This data combines firms' workforce composition with capital stock, labour costs and value-added. The employment size of each firm is obtained by simply counting the number of workers matched to the firm. ${ }^{11}$ The industry codes are used to group firms into distinct industries. In this paper we focus on the three largest industries in our data: Manufacturing, Utilities and Construction. ${ }^{12}$

Table 5.1 shows the distribution of firms and employment shares by industry and firm-size categary. The data covers $6,1.00$ firms and roughly 488,000 workers for each year over the period 1992-1995. In the empirical analyses of this paper we have selected the firms with at least 20 employees. Though this implies dropping

\footnotetext{
${ }^{10}$ These summary measures are the proportions of females, the proportion of workers with less than 5 years of experience, between 5 and 10 years and more than 10 years of experience and the relative proportions of workers by educational and occupational levels as well as the proportions by cross-cell of education and occupation (allocation matrix of education by occupation).

${ }^{11}$ Full time equivalents are also available. Using this variable did not affect the estimated results.

${ }^{12}$ The sector of industry Transport and Telecommunication, ranked fourth on both the employment size and the firms density scale, was very unstable during the period 92-95 as the rates of firm-deaths and mergers of firms in this sector were very high.
} 
out $15 \%$ of the firms, only $3 \%$ of the workforce in the private sector is avoided.

To illustrate labour productivity and capital intensity differences across firmsize, we derive labour productivity as the ratio of value added by the number of employees and capital intensity as the ratio of capital by the number of employees of each firm in each industry. The (log) average labour productivity and capital intensity by firm-size and industry in the period 92-95 are reported in Table 5.2. The table clearly illustrates that both labour productivity and capital intensity increase with firm-size.

Table 5.2: Firms' labour productivity and capital intensity by industry and firmsize.

\begin{tabular}{l|rrr}
\hline \hline Firm-size & $20-49$ & $50-99$ & $100+$ \\
Industry & & & \\
Manufacturing & & & \\
$\log$ labour productivity & 8.72 & 9.53 & 11.39 \\
log capital intensity & 5.12 & 5.28 & 5.94 \\
Utilities & & & \\
log labour productivity & 8.41 & 9.30 & 10.99 \\
log capital intensity & 4.36 & 4.45 & 5.11 \\
Construction & & & \\
log labour productivity & 8.71 & 9.61 & 11.31 \\
$\log$ capital intensity & 5.48 & 5.67 & 6.12 \\
\hline \hline
\end{tabular}

Table 5.3 presents summary statistics of the workforce composition of firms by industry and employment size. As observed in other studies (Oi (1983) and Haltiwanger et al. (1999)), the proportion of skilled workers increases with the employment size in all industries. The proportion of workers with a high level of education differs between small and large firms by roughly $4 \%$ points in all industries.

As mentioned in the introduction, these differences in the skill composition of the workforce between firms of different sizes might emerge from different sources. Building on an assignment hypothesis (see Sattinger (1993)), Haltiwanger et al. argue that firms choose different modes of production resulting in skill segregation. Yet, as Idson and Oi (1999) acknowledge, large firms adopt new technologies earlier which probably results in a larger amount of complex jobs. Therefore, the larger proportion of high skilled workers in larger firms might correspond with a conjecture that in large firms the distribution of jobs by their level of complexity 
Table 5.3: Workforce composition by industry and firm-size.

\begin{tabular}{|c|c|c|c|c|c|c|c|c|c|}
\hline Industry & \multicolumn{3}{|c|}{ Manufacturing } & \multicolumn{3}{|c|}{ Construction } & \multicolumn{3}{|c|}{ Utilities } \\
\hline Firm-size & $\begin{array}{r}20-49 \\
\%\end{array}$ & $\begin{array}{r}50-99 \\
\%\end{array}$ & $\begin{array}{r}100+ \\
\%\end{array}$ & $\begin{array}{r}20-49 \\
\%\end{array}$ & $\begin{array}{r}50-99 \\
\%\end{array}$ & $\begin{array}{r}100+ \\
\%\end{array}$ & $\begin{array}{r}20-49 \\
\%\end{array}$ & $\begin{array}{r}50-99 \\
\%\end{array}$ & $\begin{array}{r}100+ \\
\%\end{array}$ \\
\hline $\begin{array}{l}\text { Female } \\
\text { Age: }\end{array}$ & 28 & 29 & 32 & 10 & 9 & 7 & 33 & 36 & 39 \\
\hline Young & 37 & 35 & 30 & 33 & 34 & 33 & 43 & 43 & 42 \\
\hline $\begin{array}{l}\text { Old } \\
\text { Experience: }\end{array}$ & 6 & 6 & 7 & 6 & 6 & 6 & 5 & 5 & 6 \\
\hline Few & 24 & 22 & 18 & 19 & 20 & 19 & 28 & 29 & 29 \\
\hline $\begin{array}{l}\text { Large } \\
\text { Education: }\end{array}$ & 59 & 60 & 64 & 64 & 64 & 64 & 56 & 55 & 55 \\
\hline Low & 35 & 35 & 36 & 24 & 25 & 25 & 29 & 28 & 30 \\
\hline Medium & 57 & 55 & 52 & 68 & 66 & 64 & 65 & 64 & 58 \\
\hline High & 8 & 10 & 12 & 8 & 9 & 11 & 6 & 8 & 13 \\
\hline
\end{tabular}

is relatively more skewed to the right. Large firms have more complex jobs than smaller firms and therefore employ systematically more skilled workers.

Classifying jobs by the level of skills 'required' and looking at the allocation of workers, differentiated by their educational attainment, to jobs of different levels of complexity (education required) enables us to indicate differences between firm-size categories in the extent of workers who are over or undereducated for their jobs (see Hartog (1992 and 2000)) in Table 5.4. Under the hypothesis that large firms have more complex jobs the distribution of workers into the three categories should be independent of the size of employment. The larger amount of workers with high skills observed in large firms should be allocated to the larger amount of complex jobs large firms have such that the proportion of workers being undereducated, overeducated or having the required educational level for their jobs should roughly be identical across employers. On the other hand, skill segregation will result into differences in the proportion of workers overeducated for their jobs across employers. Table 5.4 presents striking stylised facts on the differences in the allocation of workers between firm-size categories in the three industries. In all industries, large firms tend to allocate relatively more workers to occupations in which workers' educational level is above the 'required' job level. The inter firm-size changes in the proportion of workers who 
are overeducated for their job varies between $0.3 \%$ points in the Utilities sector and $1.3 \%$ points in the Manufacturing industry. This shows that a conjecture that large firms have more complex jobs is definitively not the only explanation why large firms employ more skilled workers.

Table 5.4: Firms allocation of workers by industry and firm-size.

\begin{tabular}{l|rrr|rrr}
\hline \hline $\begin{array}{l}\text { Firm-size } \\
\text { Industry }\end{array}$ & $20-49$ & $50-99$ & $100+$ & $20-49->50-99$ & $\begin{array}{r}50-99->100+ \\
\text { \%-points }\end{array}$ & $\begin{array}{l}\text { Inter-size } \\
\text { range } \\
\text { \%-points }\end{array}$ \\
$\begin{array}{l}\text { Manufacturing } \\
\text { Overeducation }\end{array}$ & 16.0 & 17.4 & 18.6 & 1.4 & 1.2 & 1.3 \\
$\begin{array}{l}\text { Undereducation } \\
\text { Match }\end{array}$ & 18.8 & 17.4 & 16.3 & -1.4 & -1.7 & -1.3 \\
Utilities & 65.2 & 65.2 & 65.1 & 0.0 & -0.1 & 0.0 \\
$\begin{array}{l}\text { Overeducation } \\
\text { Undereducation }\end{array}$ & 13.1 & 12.9 & 13.6 & -0.2 & 0.7 & 0.3 \\
Match & 15.8 & 15.3 & 14.4 & -0.5 & -0.9 & -0.7 \\
Construction & 71.1 & 71.8 & 72.0 & 0.6 & 0.2 & 0.4 \\
Overeducation & 16.2 & 17.1 & 17.3 & & & \\
Undereducation & 24.6 & 24.1 & 24.6 & -0.5 & 0.2 & 0.6 \\
Match & 59.2 & 58.8 & 58.1 & -0.4 & -0.5 & 0.0 \\
\hline \hline
\end{tabular}

The tendency of large firms to employ a relatively overeducated workforce can be interpreted as an ant versus cicada behaviour. Large firms build in a reserve capacity of skilled workers in periods of surplus of skilled people in order to anticipate either demand or supply shocks in the labour market for skilled workers. In case of excess demand for skilled workers, large firms are affected less since they already retain internal reserves of skilled workers. In periods of a tight labour market for skilled workers, large firms could therefore easily recruit unskilled workers instead of skilled workers, allocate the newly recruited workers to low skill jobs and internally reallocate the skilled workers that are working in these low skill jobs to high skill jobs. 


\subsection{Empirical results}

\subsubsection{Production function and firm size}

In order to derive elasticities of substitution, we estimate a production function separately for each firm-size category and industry. The analysis is done for each sector of industry separately since the skill-composition of the workforce and capital intensity that are related to the size effect on labour productivity vary systematically across industries.

We approximate the $\mathrm{N}$-factor ${ }^{13}$ production function for each firm-size category and industry, $H=F\left(L_{11}, \ldots, L_{n n}, K\right)$, by a translog form: ${ }^{14}$

$$
\begin{aligned}
\ln H= & \alpha_{0}+\alpha_{A} \ln A+\alpha_{K} \ln K+\sum_{i, j} \alpha_{i j} \ln L_{i j} \\
& +\frac{1}{2} \sum_{i, j} \beta_{K, i j} \ln K \ln L_{i j}+\frac{1}{2} \sum_{i, j} \sum_{g, k} \beta_{i j, g k} \ln L_{i j} \ln L_{g k} \\
& +\beta_{K, A} \ln K \ln A+\sum_{i, j} \beta_{i j, A} \ln L_{i j} \ln A+\frac{1}{2} \beta_{A, A} \ln ^{2} A
\end{aligned}
$$

where $H$ is output, $L_{i j}$ are labour inputs (number of workers with education $j$ working in occupation $i, i=<1, \ldots, n>$ and $j=<1, \ldots, n>),{ }^{15} K$ is capital stock, $A$ is a time dependent technological index, the Greek letters are technology parameters.

We choose for the translog production function form rather than a nestedCES production function since the translog production function does not require to impose ex ante restrictions on the substitutability between the various labour inputs and capital and offers the most flexible functional form. Nested-CES production functions require to choose for the way in which capital and labour inputs are nested. ${ }^{16}$

\footnotetext{
${ }^{13}$ Let the first $N-1$ input factors be labour inputs differentiated by education, indexed by $j \in\langle 1, \ldots, n\rangle$, and occupation, indexed by $i \in\langle 1, \ldots, n\rangle$, and the $N^{\text {th }}$ be capital stock.

${ }^{14} \mathrm{We}$ have dropped firm and time indexes for the sake of convenience.

${ }^{15}$ Note that $N=n^{2}+1$.

${ }^{16}$ In the previous chapters we used a CES production function as it offers a convenient way to derive theoretical results and to estimate relative demand equations. In this chapter, we are
} 
We assume that the production function of specification (1) is well-behaved so that it is homogeneous of degree one in inputs quantities. This implies imposing the following restrictions on the parameters:

$$
\begin{aligned}
\alpha_{K}+\sum_{i, j} \alpha_{i j} & =1 \\
\sum_{i, j}\left(\beta_{K, i j}+\sum_{g, k} \beta_{i j, g k}\right) & =\sum_{i, j} \beta_{i j, K}=\sum_{i, j} \beta_{i j, g k}=\sum_{i, j} \beta_{K, i j}=\sum_{i, j} \beta_{g k, i j}^{\prime}=0 \\
\beta_{i j, g k} & =\beta_{g k, i j} \text { and } \beta_{K, i j}=\beta_{i j, K} \\
\sum_{i} \beta_{i j, A}+\beta_{K, A} & =0
\end{aligned}
$$

Note that our model can be viewed as a generalisation of the model of Haltiwanger et al. Therein, second order and interaction terms are absent (CobbDouglas production function) and all firms have the same production function except for the technological parameters $\alpha_{0}$ and $\alpha_{A}$. All $\beta$ 's parameters are equal to 0 (i.e. the elasticities of substitution equal unity for each pair of inputs in all firms.

With the assumption of competitive input markets, $\partial H / \partial L_{i j}=w_{i j}$ and $\partial H / \partial K=r$, the factor share equations are derived from the $N$ output elasticity equations as follows:

$$
\begin{aligned}
\partial H / \partial L_{i j} & =w_{i j} L_{i j} / H=S_{i j}, \forall i, j \\
\partial H / \partial K & =r K / H=S_{K}
\end{aligned}
$$

where $w_{i j}$ and $S_{i j}$ are respectively the price and cost share of factor $i j$ and $r$ and $S_{K}$ the price and cost share of capital.

Equating the costs shares to the logarithmic marginal products yields:

interested in estimating the shape of the production function. To this aim, the translog form should be prefered for its flexible functional form. 


$$
\begin{aligned}
& S_{i j}=\alpha_{i j}+\beta_{i j, K} \ln K+\sum_{g k} \beta_{i j, g k} \ln L_{g k}+\gamma_{i j, A} \ln A, \forall i, j \\
& S_{K}=\alpha_{K}+\beta_{K, K} \ln K+\sum_{g k} \beta_{K, g k} \ln L_{g k}+\gamma_{K, A} \ln A
\end{aligned}
$$

Any deviations of the cost shares from the logarithmic marginal products are assumed to be errors in cost minimising behaviour captured in the empirical estimation by a classical additive disturbance for each of the cost shares equations.

As we are interested in considering the effects of exogenous changes in factor prices on factor quantities, we derive the Allen partial Elasticities of Substitution. (AES), denoted $A E S_{i j, g k}$ and $A E S_{K, i j}$, and defined as $A E S_{i j, g k}=\left|G_{i j, g k}\right| /|G|$ where $|G|$ is the determinant of the symmetric matrix $G$ defined as follows:

$$
G=\left[\begin{array}{cccc}
0 & S_{K} & S_{g k} & S_{n n} \\
S_{K} & \beta_{K, K}+S_{K}^{2}-S_{K} & & \beta_{K, n n}+S_{n n} \times S_{K} \\
S_{g k} & & \beta_{g k, g k}+S_{g k}^{2}-S_{g k} & \\
S_{i j} & & \beta_{g k, i j}+S_{g k} \times S_{i j} & \\
S_{n n} & \beta_{K, n n}+S_{n n} \times S_{K} & & \beta_{n n, n n}+S_{n n}^{2}-S_{n n}
\end{array}\right]
$$

and $\left|G_{i j, g k}\right|$ is the cofactor of $G_{i j, g k}$ in $G$.

These partial elasticities of substitution register the effect on the relative quantity of two factors, say $i j$ and $g k$, of a change in the relative price of these two factors where output and prices of other factors are held constant. ${ }^{17}$ However, Blackorby and Russel (1989) demonstrate that this concept suffers serious shortcomings. They show that for more than two inputs, the AES are not a measure of the curvature of the production function and therefore are not a complete measure

${ }^{17}$ See Allen (1938). 
of substitution. Therefore, they propose the concept of elasticity of substitution developed by Morishima (1969) that does not suffer these shortcomings.

The Morishima Elasticities of Substitution (MES), given the positive linear homogeneity of the production function (see Blackorby and Russel (1981)), are defined by:

$$
M E S_{i j, g k}=S_{i j}\left(A E S_{g k, i j}-A E S_{i j, i j}\right), \forall(i j, g k) \in N-1 \times N-1
$$

The MES measure the proportional effect of changing the relative price of input $i j$ and $g k$ on the relative quantity of factors $i j$ and $g k$. The MES are divided in two parts: the proportional effect on the quantity of input $g k$ of varying the price of input $i j$ and the proportional effect on the quantity of $i j$ of varying the price of input $i j$.

\subsubsection{Elasticities of substitution}

We estimate simultaneously the equation of the translog production ${ }^{18}$ (equation 5.14) and the share equations ${ }^{19} 5.21$ and 5.22 using the iterative Zellner method

\footnotetext{
${ }^{18}$ It is usually argued that factor prices rather than factor quantities should be considered as exogenous when using firm-level data and therefore a cost function should be estimated rather than a production function. As Varian (1984) p. 174 explains:

...if the inanagers observe variables omitted in the model, then they certainly take that information into account when they determine their optimal choice of inputs.
}

The estimates of the model will then be biased. This problem can be solved using a cost function as prices are exogenous and not determined by the managers. However, estimating a cost function requires to assume fixed output level. The resulting parameter estimates represent substitution possibilities along an isoquant but ignore the scale effects on output. As De La Grandville (1989) shows, the magnitude of the elasticity of substitution determines the magnitude of the scale effect as well. The larger the elasticity of substitution, i.e. the larger. the substitution effect (trivial) and the larger the scale effect. In order to take scale effects into account we estimate a production function rather than a cost function. Because of the endogeneity of input levels, an estimation procedure using instrument variables is required. To avoid problems inherent in choosing instrumental variables, the Zellner method is prefered. Berndt and Christensen (1973) indeed find no significant differences in estimates between the Zellner method and the three stage least squares.

${ }^{19}$ One share equation, arbitrarily chosen, was dropped since identification problems results from the homogeneity restrictions. The translog parameters are though independent of the choice of which share equation to drop since we use the iterative Zellner-efficient estimation 
(see Chen and Tang (1987) for the estimation of a similar set of equations using firm-level data). ${ }^{20}$ For both, occupation and education, intermediate and higher levels are merged in one group in order to preserve representativeness of firms within each firm-size categories as for more than $70 \%$ of our small firms no observations are found in at least one of the cells of the allocation matrix defined with three educational levels and three occupational levels. When merging intermediate and high levels, only $20 \%$ of the small firms are dropped.

Tables 5.5, 5.6 and 5.7 present the Morishima elasticities of substitution and factor demand elasticities, i.e. $\eta_{i j, i j}$, by firm-size in the Manufacturing, Construction and Utilities industry respectively. The Morishima elasticities refer to a $1 \%$ change in relative factor prices initiated by a change in the price of the input figuring in the first column.

From the Morishima elasticities of substitution two patterns emerge. First, the differences in the magnitude of the MES between skilled workers in skilled jobs and capital across firm-size categories are striking. In the three industries, the percentage change in the relative quantity of skilled workers in skilled jobs and capital in response to a $1 \%$ change in the relative wages, initiated by a change in the wage rate only, is larger in large firms. This suggests that large firms can adjust an increase in the relative price of skilled workers working in skilled jobs with a larger change in the relative quantities of these workers to capital stock than smaller firms. Secondly, the magnitudes of the labour-labour elasticities of substitution in the three industries are clearly related to the size of the firm. The MES between skilled workers in skilled jobs and all other labour inputs, associated to a change in the wage rate of skilled workers in skilled jobs, are larger in large firms.

The direction of the differences in the MES between skilled workers in skilled jobs and all other inputs across firm-size categories is consistent with the observation that large firms have a higher skill intensity than small firms given skill-biased technological change. Indeed, as theorem 4 states the rate of change in the relative demand for skilled workers under skill-biased technological change is positively related to the magnitude of the elasticity of substitution between skilled and unskilled labour. At an equivalent rate of skilled labour augmenting (unskilled labour saving), the larger the elasticity of substitution, the larger the

(see Berndt and Christensen (1973).

${ }^{20}$ See Zellner (1962 and 1963). 
Table 5.5: Morishima elasticities of substitution and factor demand elasticities by firm-size in the Manufacturing industry, evaluated at the normalised mean share.

\begin{tabular}{l|rrrrr}
\hline \hline$\overline{\text { Firm-size }}$ & \multicolumn{1}{|c}{$K$} & $\overline{L_{11}}$ & $L_{12}$ & $\bar{L}_{21}$ & $\bar{L}_{22}$ \\
$20-49$ & & & & & \\
\hline$K$ & & 1.89 & 1.87 & 1.96 & 1.79 \\
$L_{11}$ & 1.73 & & 1.63 & 1.69 & 1.67 \\
$L_{12}$ & 1.66 & 1.58 & & 1.67 & 1.58 \\
$L_{21}$ & 1.85 & 1.75 & 1.79 & & 1.68 \\
$L_{22}$ & 1.48 & 1.50 & 1.43 & 1.40 & \\
\hline$\eta_{i j, i j}$ & -1.50 & -1.39 & -1.35 & -1.49 & -0.99 \\
\hline $50-99$ & & & & & \\
\hline$K$ & & 1.69 & 1.66 & 1.75 & 1.65 \\
$L_{11}$ & 1.67 & & 1.61 & 1.68 & 1.66 \\
$L_{12}$ & 1.61 & 1.57 & & 1.73 & 1.58 \\
$L_{21}$ & 1.87 & 1.83 & 1.91 & & 1.78 \\
$L_{22}$ & 1.53 & 1.58 & 1.49 & 1.51 & \\
\hline$\eta_{i j, i j}$ & -1.35 & -1.38 & -1.36 & -1.54 & -1.04 \\
\hline $100+$ & & & & & \\
\hline$K$ & & 1.56 & 1.56 & 1.71 & 1.54 \\
$L_{11}$ & 1.63 & & 1.55 & 1.81 & 1.66 \\
$L_{12}$ & 1.66 & 1.58 & & 1.90 & 1.66 \\
$L_{21}$ & 2.28 & 2.33 & 2.40 & & 2.22 \\
$L_{22}$ & 1.52 & 1.62 & 1.56 & 1.66 & \\
\hline$\eta_{i j, i j}$ & -1.24 & -1.39 & -1.42 & -1.90 & -1.09 \\
\hline \hline
\end{tabular}

$L_{i j}$ is the number of workers with education $j$ working in occupation $i$.

rate of change in the relative demand for skilled workers. When firms of different size share the same rate of skill-augmenting, differences in the magnitude of their elasticity of substitution between skilled workers and unskilled-workers generate differences in their rate of change in skilled labour demand. Since large firms have larger elasticities of substitution between skilled and unskilled workers in skilled jobs and technological change is skill-biased, large firms have a larger increase of the demand for skilled workers which generates differences in the skill intensity across firms of different employment size.

Overall results are consistent with empirical regularities observed in other empirical research. ${ }^{21}$ First, in absolute values, the factor demand elasticity for

\footnotetext{
${ }^{21}$ See Hamermesh (1993) Table 3.7 and 3.8 .
} 
Table 5.6: Morishima elasticities of substitution and factor demand elasticities by firm-size in the Construction industry, evaluated at the normalised mean share.

\begin{tabular}{l|rrrrr}
\hline \hline $\begin{array}{l}\text { Firnn-size } \\
20-49\end{array}$ & $K$ & $\overline{L_{11}}$ & $L_{12}$ & $L_{21}$ & $L_{22}$ \\
\hline $\bar{K}$ & & 2.33 & 2.51 & 2.56 & 2.01 \\
$L_{11}$ & 2.01 & & 1.92 & 1.87 & 1.85 \\
$L_{12}$ & 2.41 & 2.17 & & 2.21 & 2.11 \\
$L_{21}$ & 2.51 & 2.19 & 2.27 & & 2.19 \\
$L_{22}$ & 1.23 & 1.48 & 1.47 & 1.53 & \\
\hline$\eta_{i j, i j}$ & -1.84 & -1.56 & -1.87 & -1.93 & -0.92 \\
\hline $50-99$ & & & & & \\
\hline $\bar{K}$ & & 1.87 & 1.94 & 2.13 & 1.76 \\
$L_{11}$ & 1.66 & & 1.57 & 1.66 & 1.61 \\
$L_{12}$ & 1.88 & 1.76 & & 2.01 & 1.76 \\
$L_{21}$ & 2.48 & 2.28 & 2.45 & & 2.28 \\
$L_{22}$ & 1.39 & 1.50 & 1.44 & 1.60 & \\
\hline$\eta_{i j, i j}$ & -1.52 & -1.34 & -1.56 & -2.01 & -0.97 \\
\hline $100+$ & & & & & \\
\hline$K$ & & 1.62 & 1.91 & 1.89 & 1.66 \\
$L_{11}$ & 1.43 & & 1.40 & 1.64 & 1.48 \\
$L_{12}$ & 2.19 & 1.95 & & 2.47 & 2.02 \\
$L_{21}$ & 2.63 & 2.62 & 2.91 & & 2.58 \\
$L_{22}$ & 1.50 & 1.55 & 1.53 & 1.76 & \\
\hline$\eta_{i j, i j}$ & -1.39 & -1.25 & -1.81 & -2.27 & -1.04 \\
\hline \hline
\end{tabular}

unskilled-workers in low skilled jobs is larger than that for skilled workers in skilled jobs in all industries and all firm-size categories. ${ }^{22}$ The results show that each labour group is substitute with physical capital in all firm-size categories and all industries. Surprisingly, the results suggest that skilled workers in skilled jobs (allocation cell $\langle 2,2\rangle$ ) are p-substitute with capital. However, we find a larger degree of p-substitutability between unskilled-workers in low skilled jobs and capital than between skilled workers in skilled jobs and capital.

In all industries, we observe persistent patterns between the magnitude of both factor demand elasticities and elasticities of substitution and the size of firms. The magnitude of the own-price factor demand elasticities, in absolute values, decreases with firm-size for capital and unskilled-workers in low skilled

${ }^{22}$ See Hamermesh (1993) Table 3.7. 
Table 5.7: Morishima elasticities of substitution and factor demand elasticities by firm-size in the Utilities industry, evaluated at the normalised mean share.

\begin{tabular}{l|rrrrr}
\hline \hline Firm-size & \multicolumn{1}{|l}{$K$} & \multicolumn{1}{c}{$L_{11}$} & \multicolumn{1}{l}{$L_{12}$} & \multicolumn{1}{l}{$L_{21}$} & \multicolumn{1}{c}{$L_{22}$} \\
$20-49$ & & & & & \\
\hline$K$ & & 1.88 & 1.90 & 2.04 & 1.76 \\
$L_{11}$ & 2.00 & & 2.12 & 2.09 & 1.93 \\
$L_{12}$ & 2.04 & 2.15 & & 2.09 & 1.98 \\
$L_{21}$ & 2.26 & 2.23 & 2.20 & & 2.10 \\
$L_{22}$ & 1.46 & 1.51 & 1.55 & 1.55 & \\
\hline$\eta_{i j, i j}$ & -1.50 & -1.69 & -1.71 & -1.85 & -1.03 \\
\hline $50-99$ & & & & & \\
\hline$K$ & & 1.67 & 1.69 & 1.80 & 1.67 \\
$L_{11}$ & 1.78 & & 1.95 & 1.89 & 1.76 \\
$L_{12}$ & 1.89 & 2.04 & & 1.99 & 1.89 \\
$L_{21}$ & 1.97 & 1.97 & 1.98 & & 1.87 \\
$L_{22}$ & 1.55 & 1.52 & 1.58 & 1.53 & \\
\hline$\eta_{i j, i j}$ & -1.36 & -1.52 & -1.62 & -1.65 & -1.09 \\
\hline $100+$ & & & & & \\
\hline$K$ & & 1.43 & 1.55 & 1.71 & 1.46 \\
$L_{11}$ & 1.64 & & 1.81 & 1.96 & 1.69 \\
$L_{12}$ & 1.97 & 2.05 & & 2.17 & 2.00 \\
$L_{21}$ & 2.56 & 2.63 & 2.62 & & 2.55 \\
$L_{22}$ & 1.53 & 1.58 & 1.71 & 1.86 & \\
\hline$\eta_{i j, i j}$ & -1.20 & -1.44 & -1.70 & -2.20 & -1.14 \\
\hline \hline
\end{tabular}

jobs $^{23}$ while it increases for skilled workers in skilled jobs and to some extent for unskilled-workers in skilled jobs. The differences in magnitude of the ownprice factor demand elasticities of skilled workers in skilled jobs between large and smaller firms suggest that large firms could accommodate a change in the relative wage of skilled workers in skilled jobs more easily than smaller firms.

\subsubsection{Robustness check}

As predicted by our theoretical model, we find that large firms have higher elasticities of substitution between skilled labour with all other inputs (unskilled labour and capital). To check whether this result is driven by the data we use

\footnotetext{
${ }^{23}$ Klotz et al. (1980) find similar results for U.S. manufacturing plants in 1967 .
} 
or really consistent with our theoretical model, we reproduce the analyses of Idson and Oi (1999) and Haltiwanger et al. (2000) with our data. These analyses consist of log-linear regressions relating firms' workforce characteristics to their labour productivity, separately for each industry. All data are deviations from year means such that we control for price variation and variations in capital usage. ${ }^{24}$ Since the number of firms varies across size categories, least squares and means are weighted by the relative number of firms in each firm-size category. Our measure of labour productivity is the log of value-added per employee in firm $f$ in period $t, Y_{f t}=\ln \frac{H_{f t}}{L_{f t}}$. The size variables, $S_{1, f t}, S_{2, f t}$ and $S_{3, f t}$, are dummies corresponding to firm-size $20-49\left(S_{1, f t}=1\right.$ for $L_{f t} \in[20,49]$ and 0 otherwise, where $L_{f t}$ is total employment of firm $f$ in period $t$ ) and 50-99 and 100 and more respectively. Firm's workforce is further decomposed into the proportion of female $D_{1, f i}$, the proportion of young and old workers, $D_{2, f t}$ and $D_{3, f t}$ respectively and the proportion of workers with less than 5 years of experience and more than 10 years of experience, $D_{4, f t}$ and $D_{5, f t}$ respectively. $P_{j, f t}(j=1,2,3$ are educational levels) capture the distribution of firms' workforce by educational levels $\left(P_{j, f t}=L_{j, f t} / L_{f t}\right)$.

The first model (Model I) is a regression of firms' labour productivity on firm size only and is conceptually comparable to Idson and Oi (1999)'s estimation of the size-output elasticity in the US manufacturing industry.

Model (I):

$$
Y_{f t}=b_{0}+b_{1} S_{1, f t}+b_{2} S_{2, f t}+e_{f t}
$$

where $e_{f t}$ are error terms satisfying the classical assumptions of linear regression.

The results of the estimation of Model I are reported in column (I) of Table 5.8, 5.9 and 5.10. The results indicate that large firms have a higher measure of labour productivity than smaller firms. In the manufacturing industry, the labour productivity of firms with more than 100 employees exceeds the labour productivity of medium-size firms by $13 \%$ and that of small-size firms by $18 \%$.

\footnotetext{
${ }^{24}$ Including capital in the set of explanatory variables, in order to get closer to a production function (Cobb-Douglas), increases the percentage of the variation in labour productivity explained but the magnitude and significativity change neither for the size-effect nor for workforce composition parameters.
} 
These results are similar to size-output elasticity of 0.172 in the manufacturing industry in 1992 (see Idson and Oi (1999)).

To replicate Haltiwanger et al.'s regression, Model I is extended by including workforce characteristics in the set of explanatory variables. Firms' workforce is decomposed into educational attainment as well as sex, age and experience categories. This model is conceptually equivalent to Haltiwanger et al.'s regression and the underlying production function has a Cobb-Douglas shape. The elasticity of substitution between all pairs of inputs is therefore assumed to be equal to 1.

Model (II):

$$
Y_{f t}=b_{0}+b_{1} S_{1, f t}+b_{2} S_{2, f t}+\sum_{d} c_{d} D_{d, f t}+\sum_{j} d_{j} P_{j, f t}+e_{f t}
$$

Results of the estimation of Model (II) are reported in column (II) of Table 5.8, 5.9 and 5.10. The results show that differences in the workforce characteristics account for roughly $20 \%$ of the variation in labour productivity across employers. Moreover, the results indicate that firms employing more educated-workers are more productive as predicted by the human capital theory. The inter firm-size productivity differences are persistent even when controls for workforce composition are included. The firm-size coefficients remains significant after including control for workforce composition. This means that the labour productivity gap between firms of different employment size cannot be imputed completely to systematic differences in the skill-mix of their workforce. These results are in line with Haltiwanger et al.'s results for the US industries.

In a third regression, control for the firm's allocation of workers to occupations is included by adding to the previous regressions information on the allocation of workers. The underlying production function can be seen as a special case of the theoretical model developed in Chapter 2, i.e. equation 2.7 where $\sigma_{o}=\sigma_{e}=1$. The model reads as follows:

Model (III):

$$
Y_{f t}=b_{0}+b_{1} S_{1, f t}+b_{2} S_{2, f t}+\sum_{d} c_{d} D_{d, f t}+\sum_{i} \sum_{j} d_{i j} P_{i j, f t}+e_{f t}
$$


where $i=1,2,3$ are occupational levels and $P_{i j, f t}\left(P_{i j, f t}=L_{i j, f t} / L_{f t}\right)$ is the proportion of workers with educational level $j$ allocated to occupational level $i$ in firm $f$ at time $t$.

Table 5.8: Productivity regressions in the manufacturing industry.

\begin{tabular}{|c|c|c|c|c|c|c|}
\hline Firm-size & (I) & & (II) & & (III) & \\
\hline $20-49$ & -0.18 & ** & -0.09 & $* *$ & -0.10 & ** \\
\hline 50-99 & -0.13 & ** & -0.07 & $* *$ & -0.08 & ** \\
\hline Female & & & -0.10 & $* *$ & -0.27 & $* *$ \\
\hline age $<30$ & & & 0.15 & & 0.28 & $* *$ \\
\hline $30 \leq$ age $<55$ & & & -0.39 & $* *$ & -0.48 & ** \\
\hline $\exp <5$ & & & -1.00 & $* *$ & -0.99 & ** \\
\hline $\exp \geq 10$ & & & 0.31 & $* *$ & 0.35 & ** \\
\hline \multicolumn{7}{|l|}{ Allocation } \\
\hline$P_{12}$ & & & & & 0.64 & ** \\
\hline$P_{13}$ & & & & & 2.42 & $* *$ \\
\hline$P_{21}$ & & & & & -0.19 & * \\
\hline$P_{22}$ & & & & & -0.03 & \\
\hline$P_{23}$ & & & & & 2.65 & ** \\
\hline$P_{31}$ & & & & & 2.46 & ** \\
\hline$P_{32}$ & & & & & 1.71 & $* *$ \\
\hline$P_{33}$ & & & & & 0.74 & ** \\
\hline \multicolumn{7}{|l|}{ Education } \\
\hline$P_{.1}$ & & & -0.11 & $* *$ & & \\
\hline$P_{.3}$ & & & 1.02 & $* *$ & & \\
\hline$R^{2}$ & 0.023 & & 0.178 & & 0.236 & \\
\hline Wald- $t$ & & & 133 & $* *$ & & \\
\hline
\end{tabular}

* sig $5 \%$

** $\operatorname{sig} 1 \%$

$P_{i j}$ is the proportion of workers with educational level $j$ allocated to occupational level $i$.

$P_{. j}$ is the proportion of workers with educational level $j$.

As shown in column (III) of Table 5.8, 5.9 and 5.10, in all industries, replacing the human capital specification by an allocation specification adds significant explanatory power (See Wald-tests) but leaves the firm-size effect unaffected. Though systematic differences in the allocation across employers of different size do not explain the nature of the employment-size productivity differentials completely, the results indicate that variations in allocation are significantly related to differences in productivity levels across employers. Differences in the allocation 
Table 5.9: Productivity regressions in the utilities industry.

\begin{tabular}{|c|c|c|c|c|c|c|}
\hline Firm-size & (I) & & (II) & & (III) & \\
\hline $20-49$ & -0.08 & $* *$ & 0.07 & $* *$ & 0.07 & ** \\
\hline $50-99$ & -0.03 & & 0.07 & $* *$ & 0.07 & ** \\
\hline Female & & & 0.00 & & -0.13 & \\
\hline age $<30$ & & & -0.02 & & 0.06 & \\
\hline $30 \leq$ age $<55$ & & & -0.74 & $* *$ & -0.72 & $* *$ \\
\hline $\exp <5$ & & & -0.25 & & -0.26 & \\
\hline $\exp \geq 10$ & & & 0.38 & & 0.42 & * \\
\hline \multicolumn{7}{|l|}{ Allocation } \\
\hline$P_{12}$ & & & & & 0.49 & $* *$ \\
\hline$P_{13}$ & & & & & 2.67 & ** \\
\hline$P_{21}$ & & & & & 0.53 & ** \\
\hline$P_{22}$ & & & & & 0.18 & * \\
\hline$P_{23}$ & & & & & 1.62 & $* *$ \\
\hline$P_{31}$ & & & & & 0.94 & * \\
\hline$P_{32}$ & & & & & 0.75 & * \\
\hline$P_{33}$ & & & & & 2.08 & ** \\
\hline \multicolumn{7}{|l|}{ Education } \\
\hline$P_{1}$ & & & -0.05 & & & \\
\hline$P_{3}$ & & & 1.76 & $* *$ & & \\
\hline$R^{2}$ & 0.006 & & 0.166 & & 0.175 & \\
\hline Wald-t & & & 5.4 & $* *$ & & \\
\hline
\end{tabular}

of workers to jobs does explain part of the differences in labour productivity between different firms. The most striking result is that firms which employ workers which are overeducated for their jobs are more productive. In the manufacturing, utilities and construction industries, this pattern is persistent. Firms allocating $1 \%$ point more workers with an intermediate educational level in low-skill jobs than the industry-mean have a labour productivity exceeding the industry-mean by $0.5 \%$, ceteris paribus. In all industries, the firms for which the proportion of workers with high educational level working in low-skill jobs exceeds the industrymean by $1 \%$ point, enjoy a labour productivity that exceeds the industry-mean by about $2.5 \%$. These results, especially the significant effect of overeducation of nonproduction workers (i.e. occupational levels 2 and 3 ), are consistent with Black and Lynch (2001) finding that firms with a larger average educational level 
Table 5.10: Productivity regressions in the conctruction industry.

\begin{tabular}{|c|c|c|c|c|c|c|}
\hline Firm-size & (I) & & (II) & & (III) & \\
\hline $20-49$ & -0.14 & $* *$ & -0.12 & $* *$ & -0.11 & $* *$ \\
\hline 50-99 & -0.06 & $*$ & -0.04 & & -0.04 & \\
\hline Female & & & 0.12 & * & 0.10 & $*$ \\
\hline age $<30$ & & & 0.94 & $* *$ & 0.97 & $* *$ \\
\hline $30 \leq$ age $<55$ & & & 0.56 & $*$ & 0.57 & $*$ \\
\hline$e x p<5$ & & & -0.97 & $* *$ & -0.96 & ** \\
\hline $\exp \geq 10$ & & & 1.03 & $* *$ & 0.99 & $* *$ \\
\hline \multicolumn{7}{|l|}{ Allocation } \\
\hline$P_{12}$ & & & & & 0.46 & $* *$ \\
\hline$P_{13}$ & & & & & 2.93 & $* *$ \\
\hline$P_{21}$ & & & & & -0.38 & $*$ \\
\hline$P_{22}$ & & & & & -0.10 & \\
\hline$P_{23}$ & & & & & 2.64 & $* *$ \\
\hline$P_{31}$ & & & & & 1.24 & $* *$ \\
\hline$P_{32}$ & & & & & 0.64 & $* *$ \\
\hline$P_{33}$ & & & & & 0.85 & ** \\
\hline \multicolumn{7}{|l|}{ Education } \\
\hline$P_{.1}$ & & & -0.07 & & & \\
\hline$P_{3}$ & & & 1.35 & ** & & \\
\hline$R^{2}$ & $\overline{0.00 \overline{7}}$ & & $\overline{0.201}$ & & $0 . \overline{218}$ & \\
\hline Wald-t & & & 27.2 & *** & & \\
\hline
\end{tabular}

of nonproduction workers have a larger labour productivity.

Both Model (II) and (III) indicate that at equivalent workforce composition, large firms enjoy a larger labour productivity. This labour productivity gap found between large and small firms after controlling for workforce composition may coincide with a conjecture that large firms enjoy a larger labour-labour elasticity of substitution. Indeed, in Section 5.2 we have shown that at equivalent workforce composition firms with a higher labour-labour elasticity of substitution enjoy a larger labour productivity.

To complete the replication of Haltiwanger et al., we evaluate the extent to which changes in workforce composition reflect transitory shocks in the labour market that yield fluctuations around the long run levels of workforce compositions firms have chosen. Regressions of four-year labour productivity changes on 
Table 5.11: Productivity growth regressions by industry.

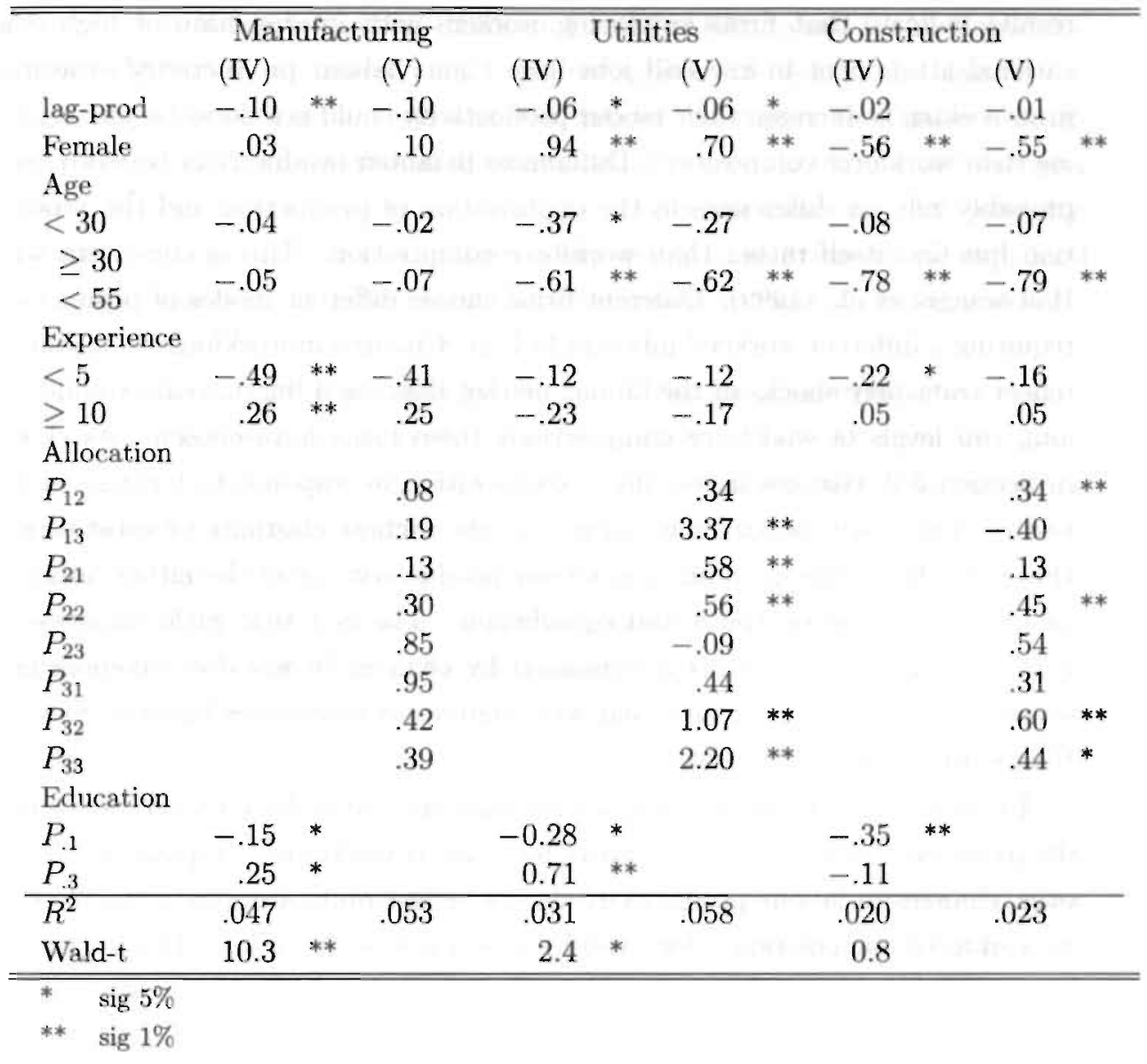

changes in the workforce composition are run. Model (IV) is the human capital version (the dynamic version of Model (II)) and Model (V) is the allocation specification (the dynamic version of Model (III)).

Results are reported in Table 5.11. The results indicate that though labour productivity levels are explained for a great deal by workforce composition, changes in the workers mix of firms explain very little of the variation in labour productivity changes. The results are in line with those obtained by Haltiwanger et al. (1999) for US data. Moreover, even though the allocation specification adds significant power, the coefficients do not show systematic results across in- 
dustries. Changes in the workforce composition and allocation of workers to jobs do not explain much of the labour productivity changes. Though the previous results indicate that firms employing workers with intermediate or high educational attainment in low-skill jobs have higher labour productivity measures, firms seeking to increase their labour productivity could not do so by just changing their workforce composition. Differences in labour productivity between firms probably rely on differences in the organisation of production and the production function itself rather than workforce composition. This is consistent with Haltiwanger et al. (1999). Different firms choose different modes of production, requiring a different workers' mix and lock in. Changes in workforce composition reflect transitory shocks in the labour market that yield fluctuations around the long run levels of workforce compositions these firms have chosen. As shown in Section 5.2, changes in workforce composition in response to increase in the relative wages will be larger in firms with the highest elasticity of substitution. However, the resulting changes in labour productivity could be either larger or smaller depending on the initial equilibrium. The fact that little variation in labour productivity changes is explained by changes in workforce composition across employers might correspond with significant differences between firms in their elasticities of substitution.

Results of this subsection clearly show that large firms have higher labour productivity even when we control for differences in workforce composition. Moreover, changes in labour productivity do not reflect quite accurately the changes in workforce composition. Both results are in line with those of Haltiwanger et al. for the US economy and coincide with a conjecture that firms differ in their modes of production. In this chapter we have shown that these differences in the production function consist of differences in the elasticities of substitution between skill groups of workers and capital.

\subsection{Summary and conclusion}

In this chapter, we analysed the production function between firms and investigated whether these differences are related to the differences in the substitution possibilities between firms. We advanced the hypothesis that the differences in labour productivity, capital intensity and the skill composition of the workforce observed between small and large firms are due to the differences in the produc- 
tion function. We argued that the differences in capital intensity between large and small firms can be explained by a larger elasticity of substitution between labour and capital in large firms (theorem 1 and 2 of Klump and De La Grandville (2000)). Moreover, we proved that i) ceteris paribus, the higher the elasticity of substitution between skilled and unskilled labour, the higher the labour productivity and ii) that given skill-biased technological change, the larger the elasticity of substitution between skilled and unskilled labour the larger the skill intensity. In turn, the larger labour productivity observed in large firms can be explained by a larger elasticity of substitution between inputs in case of skill-biased technological change.

In all three industries we analysed, we found that the magnitude of the elasticities of substitution between skilled workers in skilled jobs with all other labour inputs and capital is larger in large firms. This suggests that large firms can better adjust their input mix to changes in the relative wage of skilled workers working in skilled jobs than small firms. These differences explain the higher labour productivity and capital intensity observed in large firms. Moreover, the higher elasticity of substitution between skilled and unskilled labour in large firms explains the higher skill intensity in large firms.

As the skill segregation hypothesis suggests, we found that large firms employ more overeducated workers than small firms. We related the tendency of large firms to employ a relatively overeducated workforce to an 'ant versus cicada' behaviour. The larger productivity enables large firms to build in a reserve capacity of skilled workers in periods of low wages for skilled people in order to anticipate demand or supply shocks in the labour market for skilled workers. If the wage of skilled workers increases, large firms are affected less since they already retain an internal reserve of skilled workers. 
CHAPTER 5. SUBSTITUTION AT THE FIRM-LEVEL 


\section{Chapter 6}

\section{Conclusions}

\subsection{Main findings}

The aim of this study was twofold. One was to yield an understanding of what happens when substitution takes place in the labour market. The other was to understand why some labour markets are more flexible than others. Although the specialisation of labour is an important feature, in the labour market no one is irreplaceable. We argued that if a worker leaves, the firm would perhaps shuffle some tasks and look for a new worker but production will be almost unaffected. This (re-)assignment of tasks to workers generates flexibility in the labour market such that shifts in the demand for and supply of the various types of workers can be absorbed more easily. However, as this flexibility is probably not unlimited, we addressed the question: what are the determinants of the possibilities to substitute workers with different skills. Understanding the mechanism by which tasks are divided in the labour market may therefore contribute to our insight on why some labour markets are more flexible than others.

The first main result of this study is that a simple two-level production function can be used to model the assignment of the tasks of several occupations to workers with various educational backgrounds. The second main insight is that the substitution process that takes place in the labour market is consistently explained by the assigument of workers to jobs. The skill content of the various studies is an important determinant of the assignment of workers to tasks as it sizes the range of tasks that workers with the various educational backgrounds can perform in the various occupations, i.e. the allocation structure. The third main result of the study is that when it is easy to substitute between 
occupational outputs, productivity will benefit more from an educational system with three vocational specialisations. In contrast, when it is easier to substitute between workers within occupations, productivity will benefit more from an educational system with two vocational specialisations and one general educational field. The fourth main insight of the study is that differences in the shape of the production function and in particular differences in the substitution possibilities between large and small firms in the same industry contribute significantly to the differences in output, productivity and the allocation of workers to occupations observed between large and small firms.

\subsection{Summary}

To understand how the assignment of heterogeneous workers to heterogemeous jobs affects the substitution between groups of workers, we developed an allocation model in Chapter 2. The model provided some insight on how the assignment of heterogeneous workers to heterogeneous jobs relates to the substitution process observed in the labour market. The model is an extension of Rosen's (1978) tasks assignment model in which each occupation has a different continuum of tasks. We showed that the assignment of workers with various educational backgrounds to heterogeneous tasks in several occupations can be formalised in an allocation model by estimating a two-level Constant Elasticity of Substitution (CES) production function.

The model presented admits two noteworthy special cases. Using a one level CES production function and differentiating workers according to their education only (or their accupation orly) is comparable to the model of Rosen (1978). Using a two-level Cobb-Douglas-Linear production. function leads to the production function used in Tinbergen (1973).

The model we developed showed that when the relative wage of workers with a particular education increases, these workers will be assigned a smaller range of tasks in all occupations, i.e. only the tasks in which they are good at. Moreover, when the range of tasks that workers with a particular education perform in their specific occupation decreases more than the range of tasks these workers perform in other occupations then, it becomes less (more) efficient to produce intermediate output in the specific occuparion of these workers provided that the parameter of substitution between occupational output is larger (respectively snaller) than 
unity.

We generalised this model by releasing the assumption that within educational groups workers are homogeneous. In this model workers and jobs are, by analogy to Tinbergen (1956), heterogeneous with respect to both the skills workers have and the skills jobs require. However, we emphasised the demand for labour by solving for the assignment of workers to jobs that maximises firms' production function. We have shown, using an extension of Rosen's (1978) specification of the demand for workers per unit of output, that the assignment of heterogeneous workers to heterogeneous jobs can be formalised in an allocation model by estimating a two-level CES production function where a distinction is made between the various educational backgrounds of workers and the various occupations.

In Chapter 3, we tested the relevance of our allocation model in explaining the substitution process between different types of workers. We approached this question by comparing the allocation of workers with different educational fields to various occupations and wages across countries. Across countries, differences in the relative supply of labour should coincide with wage differentials if the substitution process between the various types of labour occurs freely in each country. However, we argued that workers who graduated in the same field of study in different countries differ in the range of tasks they can perform in the various occupations. These differences are due to differences in the educational system between countries. For instance, the knowledge taught in the various educational fields in France is different from the knowledge taught in similar studies in the UK. These differences in the skill content of educational fields generate differences in the range of tasks graduates in France and the UK can perform in the various occupations. An important implication is that the content of a study determines the assignment possibilities and therefore the substitution process in the labour market. The analysis pursued in Chapter 3 and the ensuing empirical results highlighted the relevance of our allocationı model in explaining the substitution process that takes place in the labour market. Empirical results indeed show that cross-country differences in allocation are to a large extent (50\%) due to differences in the allocation structure. Moreover, once these differences in the allocation structure are controlled for, we found that wage differentials across countries coincide with at least $64 \%$ of the differences in the employment of workers with various educational fields in the various occupations. The remaining $36 \%$ can be imputed to unobserved factors, that may be related to labour market institutional factors like wage-setting, pay norms and minimum wage. 
The differences in the allocation structure between countries indicate that the choice for the structure of the educational system is the result of an optimalisation process. Therefore, in Chapter 4 , we addressed the question to what extent the knowledge taught in each field of education affects the long run labour productivity and labour market instability.

The allocation model enabled us to distinguish between different structures of the educational system. We argued that a shift in the supply of workers between two specific educational fields should to lead to a reciprocal change in the wage rate of these two types of workers but should leave the wage of workers with general education unchanged. We derived a sufficient condition for the allocation structure to satisfy this type of reciprocal shifts in a three educational fields-three occupations case. The family of allocation structures that satisfies this type of reciprocal shifts, is characterised by three productivity parameters. The first parameter indicates the range of tasks that workers with the education for which employment does not change, can perform outside their own occupation. The second parameter indicates the range of tasks that workers whose employment increases and workers whose employment decreases can perform in each other's occupation. The last parameter indicates the range of tasks that workers whose employment increases and workers whose employment decreases can perform in the occupation of workers whose employment does not change. Simulations show that labour productivity and wage dispersion are sensitive to the relative magnitude of the three parameters. Increasing the range of tasks that workers can perform outside their own occupation decreases labour productivity. However, the larger the range of tasks that workers can perform outside their own occupation, the smaller the increase in wage dispersion in case of supply shifts.

To address the question of the relevance of vocational education in initial education, we used data on the Dutch labour market and estimated the elasticity of substitution parameters together with the allocation structure associated to workers with general, technical and social services studies at the intermediate level, working in three more or less related occupations. We found that the demand for workers with a general educational background is less elastic than the demand for workers with technical and social services vocational specialisations. This result indicates that a relative decrease in the supply of graduates of general education induces a relatively large increase in the relative wage of these graduates, a large decrease in labour productivity and a large increase in wage dispersion. 
We have shown that the skill content of a study in terms of specific and general skills matters for both labour productivity and wage inequality. The more specific the skills of workers, the larger labour productivity. However, the more generic the skills of workers, the larger the range of tasks these workers can perform outside their own occupation and the smaller the increase in wage inequality in case of supply shifts. Moreover, we show that the flexibility of the labour market, measured by the parameters indicating the ease to substitute between workers with different educational backgrounds within occupations and the ease to substitute between occupational output should be accounted for when the skill content of the various educational fields is defined. When the parameter indicating the ease to substitute between occupational output is large compared to the parameter indicating the ease to substitute between workers with different educational fields, like in the Netherlands, the economy may benefit from decreasing the range of tasks that workers with general education could perform outside the general occupation, by increasing the amount of skills that contribute to their productivity in the general occupation at the expense of the general skills that contribute to their productivity in the other occupational fields.

In the allocation model developed in Chapter 2, the substitution process is determined by the way in which firms assign workers to tasks. The structure of workers' productivity in the various occupations, underlying the way in which firms assign workers to tasks, can lead to a substitution process associated with a higher labour productivity and a lower wage inequality. In Chapter 5, we analysed whether the tremendous heterogeneity observed between small and large firms in terms of output, productivity and input mix is explained by differences in the modes of production. The heterogeneity in output, productivity and input-mix raises the question whether small and large firms have the same production function whereas the impact of the substitution process on output and productivity suggests that if there are differences in the production function these differences may relate to the substitution possibilities of firms. We argued that the differences in capital intensity between large and small firms can be explained by a larger elasticity of substitution between labour and capital in large firms and we proved that the higher the elasticity of substitution between skilled and unskilled labour, the higher the labour productivity and the larger the skill intensity in case of skill-biased technological change. In turn, the larger labour productivity observed in large firms can be explained by a larger elasticity of substitution between inputs. 
We used matched employer-employee data for the Danish manufacturing, construction and utilities industries between 1992-1995 to estimate production functions for firms of different sizes in each industry. In all three industries, the magnitude of the estimated elasticities of substitution between skilled workers in skilled jobs with all other labour inputs and capital is larger in large firms. These differences explain the higher labour productivity and capital intensity observed in large firms. Moreover, at sight of the skill-biased nature of the technological developments observed since the last decades, the higher elasticity of substitution between skilled and unskilled labour in large firms could explain the higher skill intensity in large firms.

As the skill segregation hypothesis suggests, we found that large firms employ more overeducated workers than small firms. We related the tendency of large firms to employ a relatively overeducated workforce to an 'ant versus cicada' behaviour. This larger productivity enables large firms to build in a reserve capacity of skilled workers in periods of low wages for skilled people in order to anticipate demand or supply shocks in the labour market for skilled workers. If the wage of skilled workers increases, large firms are affected less since they already retain an internal reserve of skilled workers.

\subsection{Future research}

This study has answered two important questions on the flexibility of the labour market: i) what happens when substitution takes place in the labour market and. ii) why some labour markets are more flexible than others. However, the study leaves room for relevant future research in various directions:

- In Chapter 3 and 4, we focused our analyses on the various fields of education and occupation in order to acknowledge the large variations observed in wages and allocation between the various fields of education at a particular level. In Chapter 5, due to data restrictions, only the levels of education and occupation are considered. A general model including both vertical and horizontal educational and occupational scales would be a natural continuation of the analyses of Chapter 3 and 4 . Such a general model would provide more information on the relative importance of vertical substitution compared to horizontal substitution than the magnitudes of the respective elasticities of substitution. This is particularly relevant in the 
light of the findings of Dolton and Makepeace (1990) and Borghans and Heijke (1998). Both studies find that for some educational categories the education with the most similar occupational field is situated at a different level of education in the same vocational specialisation (indicating the relevance of vertical substitution) while for other educational categories the most similar education is found at the same level (horizontal substitution).

- The direct implications of the model in Chapter 4 are that if two countries are differentiated by their ease to substitute between workers with various educational backgrounds only then, the country with a smaller elasticity of substitution between workers with the various educational backgrounds will benefit relatively more from adopting a vocational educational system whereas the country with a larger elasticity will benefit relatively more from adopting an educational system that focuses on generic skills. This result emphasises the relationship between the educational system of a country and the flexibility of the labour market and calls for replications of the empirical analysis of Chapter 4 with US and German data as it could contribute to explaining the fundamental differences in both educational systems. Indeed, since the US educational system is usually referred to as producing generic skills in abundance whereas the dual educational system in Germany produces school-leavers with vocational skills, based on the theoretical implications of the model in Chapter 4 we would expect that the ease to substitute between workers with various educational backgrounds in the US exceeds that of Germany conditional on the ease to substitute between occupational output.

- A general criticism of labour demand analyses resides in the fact that most studies do not observe what actually occurs in the workplace. However, in the 90's more longitudinal data with detailed information on a random set of workplaces became available. This enables research on the workfloor level within firms. In Chapter 5, we actually 'got our hands dirty' (Hamermesh (1993) p. 401), and measured production functions at the workplace level. However, though we were able to shed some light on the differences in the production function between large and small firms that generate the observed differences in labour productivity, capital intensity, skill composition and allocation of workers, we did not infer further on how workers use their time on the job, how they are supervised and therefore what exactly 
generates the larger substitution possibility for large firms. Although there is a growing body of empirical and theoretical literature on the impact of Total Quality Management (TQM), see Black and Lynch (2001) and High Performance Workplace (HPW), see Ichniowski and Shaw (2003), on productivity and wages, to our knowledge none of these studies have analysed their impact on the ease to substitute between inputs. ${ }^{1}$ This would be an interesting and challenging extension of Chapter 5.

- Finally, the idea of using the allocation model developed in this study in the context of regional labour mobility is very appealing. Think of an allocation model of the type depicted in Chapter 4 . Replace workers' education by workers' region of origin and workers' occupation by the region in which workers are employed. Suppose there are three regions, North, Centre and South. When shortages of labour are observed in the northern region, and labour surpluses characterise the local labour market in the southern region, the model developed in this study could be used in order to underpin the regional substitution process. In other words, would workers move from South to work in North (direct substitution) or would workers move from South to Centre, replace some workers from the Centre who themselves would move to North (indirect substitution). ${ }^{2}$ Such an analysis is highly relevant for analysing; the (re-)allocation of workers between the various member states of the European Union, as a reallocation of labour between. EU countries should be a major adjustment process if countries in the Euro-area are affected by different exogenous shocks to the economy. If for instance the three regions are France, Belgium and the Netherlands, one would expect indirect reallocation of labour surpluses in France to labour shortages in the Netherlands, for as long as the range of tasks that French workers can perform in each country, the $\alpha_{i j}$ parameters, depend on whether French workers, workers from $j$, can talk Dutch, language of $i$. The use of a neutral language, English for instance, could shift the reallocation from an indirect route to a direct route between the Netherlands and France. Half of the way back to direct reallocation is already available since Dutch workers

\footnotetext{
${ }^{1}$ Black and Lynch (2001) use a. Cobb-Douglas production function where the ease to substitute between production and nomproduction workers is equal to unit for all firms regardless of their Human Resources Management (HRM) system.

${ }^{2}$ See among others, Creedy (1974) and Pissarides and Wadsworth (1989) and Davis and Patterson (2000).
} 
do talk English. However, English is not as spread a skill in France as it is in the Netherlands. This asymmetry guarantees indirect substitution. 
CHAPTER 6. CONCLUSIONS 


\section{References}

Abowd, J., F. Kramarz, and D. Margolis (1999): "High Wage Workers and High Wage Firms," Econometrica, 67(2), 251-333.

Acemoglu, D. (2002): "Technical Change, Inequality and the Labor Market," Journal of Economic Literature, 40(1), 7-72.

(2003): "Cross-Country Inequality Trends," Economic Journal, 113, $121-49$.

Al-Shamsi, F. (2001): "Capital-Labor Substitutability in Labor Importing Economy: The Case of the United Arab Emirates," Middle East Business and Economic Review, 13(1), 44-51.

Alba-Ramirez, A. (1993): "Mismatch in the Spanish Labor Market?," Journal of Human Resources, 28(2), 259-78.

ALLEN, R. (1938): Mathematical Analysis for Economists. London: Macmillan.

Allen, S. (1986): "Union Work Rules and Efficiency in the Building Trades," Journal of Labor Economics, 4(2), 212-42.

Ashenfelter, O., and R. Layard (1986): Handbook of Labor Economics, vol. 1. Amsterdam: North-Holland, 1st edn.

Autor, D., F. Katz, And A. Krueger (1998): "Computing Inequality: Have Computers Changed the Labor Market?" Quarterly Journal of Economics, 113(4), 1169-213.

Baily, M., C. Hulten, and D. Campbell (1992): "Productivity Dynamics in Manufacturing Plants," Brookings Papers on Economic Activity, Microeconomics, pp. 187-249. 
Battu, H., C. Belfield, And P. Sloane (1999): "Overeducation Among Graduates: A Cohort View," Education Economics, 7(1), 21-38.

Bayard, K., And K. Troske (1999): "Examining the Employer-Size Wage Premium in the Manufacturing, Retail Trade, and Service Industries Using Employer-Employee Matched Data," American Economic Review, 89(2), 99103.

BerG, I. (1970): Education and Jobs: The Great Training Robbery. New York: Praeger.

Berman, E., J. Bound, and Z. Griliches (1994): "Changes in the Demand for Skilled Labor Within US Manufacturing: Evidence from Annual Survey of Manufactures," Quarterly Journal of Economics, 109(1), 367-97.

Berman, E., J. Bound, and S. Machin (1998): "Implications of Skill-Biased Technological Change: International Evidence," Quarterly Journal of Economics, 113(4), 1245-79.

Berndt, E., And L. Christensen (1973): "The Translog Function and the Substitution of Equipment, Structures, and Labor in U.S. Manufacturing 192968," Journal of Econometrics, 1(1), 81-114.

- (1974): "Testing for the Existence of an Aggregate Index Labor Input," American Economic Review, 64(3), 391-404.

Berndt, E., And D. Wood (1975): "Technology, Prices and the Derived Demand for Energy," Review of Economics and Statistics, 57(3), 259-68.

Bingley, P., and N. Westergaard-Nielsen (1998): "Three Elements of Personnel Policy: Worker Flows, Retention and Pay," Centre for Labour Market and Social Research, Working Paper, 98-16.

BisHOP, J. (1995): "Vocational Education and at-Risk Youth in the United States," Vocational Training European Journal, 6, 34-42.

BLACK, S., AND L. LYNCH (2001): "How to Compete: The Impact of Workplace Practices and Information Technology on Productivity," Review of Economics and Statistics, $83(3), 434-45$. 
Blackorby, C., And R. Russel (1981): "The Morishima Elasticity of Substitution; Symmetry, Constancy, Separability, and its Relationship to the Hicks and Allen Elasticities," Review of Economic Studies, 48(1), 147-58.

(1989): "Will the Real. Elasticity of Substitution Please Stand Up? (A Comparison of the Allen/Uzawa and Miroshima Elasticities)," American Economic Review, 79(4), 882-88.

Blanchflower, D., N. Millward, and A. Oswald (1991): "Unionism and Employment Behaviour," Economic Journal, 101(407), 815-34.

Blau, F., And L. Kahn (1996): "International Differences in Male Wage Inequality: Institutions Versus Market Forces," Journal of Political Economy, 104(4), 791-837.

Borghans, L., And A. DE Grip (2000): The Overeducated Worker? Cheltenham: Edward Elgar Publishing.

Borghans, L., And H. HeiJke (1998): "Flexibility and Structure of the Dutch Labour Market," in Towards a Transparent Labour Market for Educational Decisions, ed. by H. Heijke, and L. Borghans, pp. 119-50. Aldershot: Ashgate.

Boumahdi, R., and J. Plassard (1992): "Another Look on Earnings Functions: Testing for the Demand Side," Economics Letters, 38(1), 73-76.

Bound, J., And G. JoHnson (1992): "Changes in the Structure of Wages During the 1980's: An Evaluation of Alternative Explanations," American Economic Review, 82(3), 371-92.

Bresson, G., F. Kramarz, and P. Sevestre (1992): "Heterogenous Labor and the Dynamics of Aggregate Labor Demand: Some Estimations Using Panel Data," Empirical Economics, 17(1), $153-67$.

Brogan, R., and E. Erickson (1975): "Capital-Skill Complementarity and Labor Earnings," Southern Economic Journal, 42(1), 83-8.

BüCHEL, F. (2002): "The Effects of Overeducation on Productivity in Germany: The Firms' Viewpoint," Economics of Education Review, 21(3), 263-75. 
Buchel, F., A. De Grip, and A. Mertens (2003): Overeducation in Errope: Current Issues in Theory and Policy. Cheltenham UK: Edward Elgar, Forthcoming.

CARD, D. (1986): "Efficient Contracts with Costly Adjustment," American Economic Review, 76(5), 1045-71.

Card, D., and J. Dinardo (2002): "Skill Biased Technological Change and Rising Wage Inequality: Some Problems and Puzzles," NBER Working Paper, 8769.

Card, D., F. Kramarz, ani T. Lemieux (1999): "Changes in the Relative Structure of Wages and Employment: A Comparison of the United States, Canada and France," Canadian Joumal of Economics, 32(4), 843-77.

Card, D., And T. Lemieux (1996): "Wage Dispersion, Returns to Skill and Black-White Differentials," Journal of Econometrics, 74(2), 319-61.

- (2001): "Can Falling Supply Explain the Rising Return to College for Younger Men? A Cohort-Based Analysis," Quarterly Journal of Economics, $116(2), 705-46$.

Chen, T., And D. TANG (1987): "Offshore Assembly and Short-Run LaborLabor Substitution," Weltwirtschaftliches-Archiv, 123(1), 140-8.

Clark, K., And D. Leslie (1994): "Labour Quality and Aggregate Real-Wage Dynamics," Applied Economics, 26(9), 865-75.

Conn, E., and S. Khan (1995): "The Wage Effects of Overschooling Revisted," Labour Economics, 2(1), 67-76.

Comay, Y., A. Melnik, and M. Poliatschek (1973): "The Option Value of Education and the Optimal Path for Investment in Human Capital," International Economic Review, 14(2), 421-35.

Cremdy, J. (1974): "Inter-Regional Mobility: A Cross-Section Analysis," Scottish Journal of Political Economy, 21(1), 41-53.

Daly, M., F. Búchel, and G. Duncan (2000): "Premiums and Penalties for Surplus and Deficit Education: Evidence from the United States and Germany," Economics of Education Review, 19, 169-78. 
Davis, J., and D. Patterson (2000): "Regional Mobility of Economists," Journal of Labor Research, 21(4), 641-7.

DE GRIP, A. (1989): "The Economics of Overeducation: Comment," Economics of Education Review, 8(2), 205-7.

DE La Fontaine, J. (1668): "La Cigale et La Fourmi," in Fables, chap. Livre I, Fable 1.

de La Grandville, O. (1989): "In Quest of the Slutsky Diamond," American Economic Review, 79(3), 468-81.

de Oliveira, M., M. Santos, and B. KiKer (2000): "The Role Human Capital and Technological Change in Overeducation," Economics of Education Review, 19(2), 199-206.

Devroye, D., and R. Freeman (2001): "Does Inequality in Skills Explain Inequality of Earnings Across Countries?," NBER working paper, 8140.

Dhawan, R. (2001): "Firm Size and Productivity Differential: Theory and Evidence from a Panel of US Firms," Journal of Economic Behavior and Organization, 44(3), 269-93.

Dhrymes, P. (1969): "A Model of Short-Run Labor Adjustment," in The Brookings Model: Some Further Results, ed. by J. Duesenberry. Chicago: Rand McNaliy.

Diamond, P. (1981): "Mobility Costs, Frictional Unemployment and Efficiency," Journal of Political Economy, 89, 798-812.

Diewert, W., and T. Wales (1987): "Flexible Functional Forms and Global Curvature Conditions," Econometrica, 55(1), 43-68.

Dinardo, J., N. Fortin, And T. Lemieux (1996): "Labor Market Institutions and the Distribution of Wages, 1979-1992: A Semi-Parametric Approach," Econometrica, 64(5), 1001-44.

Dolton, P., and G. Makepeace (1990): "The Eamings of Economics Graduates," Economic Journal, 100(399), 237-50. 
Dolton, P., And A. Vignoles (2000): "The Incidence and Effects of Overeducation in the U.K. Graduate Labour Market," Economics of Education Review, $19(2), 179-98$.

(2002): "Is a Broader Curriculum Better?," Economics of Education Review, 21(5), 415-29.

Dothan, U., And J. Williams (1981): "Education as an Option," Journal of Business, 54(1), 117-39.

Dougherty, C. (1972): "Estimates of Labor Aggregation Functions," Journal of Political Economy, 80(6), 1101-19.

Dougherty, C., and M. Selowsky (1973): "Measuring the Effects of the Misallocation of Labour," Review of Economics and Statistics, 55(3), 386-90.

Duncan, G., and S. Hoffman (1981): "The Incidence and Wage Effects of Overeducation," Economics of Education Review, 1(1), 75-86.

Dunne, T., L. Foster, J. Haltiwanger, and K. Troske (2000): "Wage and Productivity Dispersion in U.S. Manufacturing: The Role of Computer: Investment," NBER, working paper $\gamma_{465 .}$

Dupuy, A., AND A. DE GRIP (2002): "Do Large Firms Have More Opportunities to Substitute Labour Than Small Firms?", CLS Working Paper Series, 02-01.

Evans, G., And R. Lindley (1973): "The Use of RAS and Related Models in Manupower Forecasting," Economics of Planning, 13(1-2), 53-73.

FAIR, R. (1985): "Excess Labour and the Business Cycle," American Economic Review, 75(1), 239-45.

Fallon, P., and P. LAyard (1975): "Capital-Skill Complementarity, Income Distribution, and Output Accounting," Journal of Political Economy, 83(2), 279-301.

FAY, J., And J. Medoff (1985): "Labour and Output over the Business Cycle," American Economic Review, 75(4), 638-55.

FIELD, E. (1988): "Free and Slave Labor in the Antebellum South: Perfect Substitutes or Different Inputs?," Review of Economics and Statistics, 70(4), 654-59. 
Fuer, R., D. Hamermesh, and A. Rees (1996): The Economics of Work and Pay. New York: HarperCollins, 6th edn.

Freeman, R. (1976): The Over-Educated American. NewYork: Academic Press.

Freeman, R., and R. Schettkat (2001): "Skill Compression, Wage Differentials, and Employment: Germany vs The U.S.," Oxford Economic Papers, $53(3), 582-603$.

Gould, E. (2002): "Rising Wage Inequality, Comparative Advantage, and the Growing Importance of General Skills in the United States," Journal of Labor Economics, 20(1), 105-47.

Grant, J. (1979): "Labor Substitution in U.S. Manufacturing," Ph.D. thesis, Michigan State University.

Green, F., S. Mcintosh, and A. Vignoles (1999): "Overeducation and Skills: Clarifying the Concepts," London School of Economics Discussion Paper, 435,54 .

Griffin, P., And A. Cox-Edwards (1993): "Rates of Return to Education in Brazil: Do Labour Market Conditions Matter?," Economics of Education Review, 12(3), 245-55.

Griliches, Z. (1969): "Capital-Skill Complementarity," Review of Economics and Statistics, 51(4), 465-8.

Groot, W. (1996): "The Incidence of, and Returns to Overeducation in the U.K.," Applied Economics, 28(10), 1345-50.

Groot, W., and H. Van Den Brink-Maasen (2000): "Skill Mismatches in the Dutch Labor Market," International Journal of Manpower, 21(7-8), 58495 .

GruBB, W. (1997): "The Returns to Education in the Sub-Bacalaureate Labour Market, 1984-1990," Economics of Education Review, 16(3), 231-45.

Gyapong, A., and K. Gyimah-Brempong (1988): "Factor Substitution, Price Elasticity of Factor Demand and Returns to Scale in Police Production," Southern Economic Journal, 54(4), 863-78. 
Haltiwanger, J., J. Lane, and J. Spletzer (1999): "Productivity Differences Across Employers: The Roles of Employers Size, Age and Human Capital," American Economic Review, 89(2), 94-98.

Hamermesh, D. (1983): "New Measures of Labor Cost: Implications for Demand Elasticities and Nominal Wage Growth," in The Measurement of Labor Cost, ed. by J. Triplett. Amsterdam: North-Holland.

(1986): "The Demand for Labor in the Long Run.," in Hand'book of Labor Economics., ed. by O. Ashenfelter, and R. Layard, pp. 429-71. Amsterdam: North-Holland.

— (1992): "The Demand for Labor in the Long Run.," in Handbook of Labor Economics, ed. by O. Ashenfelter, and R. Layard, pp. 429-71. Amsterdam: North-Holland.

—_ (1993): Labor Demand. Princeton, New Jersey: Princeton University Press.

Hamermesh, D., and J. Grant (1979): "Econometric Studies of Labor-Labor Substitution and their Implications for Policy," Journal of Human. Resources, $14(4), 518-42$.

Hartog, J. (1980): "Earnings and Capability Requirements," Review of Economics and Statistics, 62(2), 230-40.

- (1985): "Earnings Function: Testing the Demand Side," Economics Letters, 19, 281-85.

(1992): Capabilities, Allocation and Earnings. Boston: Kluwer Academic Publishers.

(2000): "Over-Education and Earnings: Where are We, Where Should We Go," Economics of Education Review, 19(2), 131-47.

(2001): "On Human Capital and Individual Capabilities," Scholar Working Paper Series, WP 22.

Hartog, J., and H. Oosterbeek (1988): "Education, Allocation and Earnings in the Netherlands: Overschooling?" Economics of Education Review, 7(2), 185-94. 
Hartog, J., And M. Tsang (1987): "Estimating, Testing and Applying a Comparative Advantage Earnings Function for the U.S. 1969 - 1973 - 1977," Research Memorandum No. 8709, University of Amsterdam.

Heckman, J., And B. Honore (1990): "The Empirical Content of the Roy Model," Econometrica, 58(5), 1121-49.

Heckman, J., and G. Sedlacek (1985): "Heterogeneity, Aggregation and Market Wage Functions: An Empirical Model of Self-Selection in the Labor Market," Journal of Political Economy, 93(6), 1077-125.

(1990): "Self-Selection and the Distribution of Hourly Wages," Journal of Labor Economics, 8(1), S329 63.

HeiJke, H., And L. Borghans (1998): Towards a Transparent Labour Market for Educational Decisions. Aldershot: Ashgate.

Hicks, J. (1964): The Theory of Wages. London: Macmillan, 2nd edn.

(1970): "Elasticity of Substitution Again: Substitutes and Complements," Oxford Economic Papers, 22(3), 289-96.

IChniowski, C., And K. Shaw (2003): "Beyond Incentive Pay: Insiders' Estimates of the Value of Complementary Human Resource Management Practices," Journal of Economic Perspectives, 17(1), 155-80.

IDson, T., AND W. OI (1999): "Workers Are More Productive in Large Firms," American Economic Review, 89(2), 104-108.

James, E., N. Alsalam, J. Conaty, and D. To (1989): "College Quality and Future Earnings: Where Should You Send Your Child to College?," American Economic Review, 79, 247-52.

Johnson, G. (1970): "The Demand for Labor by Educational Category," Southern Economic Journal, 37(2), 190-204.

(1997): "Changes in Earnings Inequality: The Role of Demand Shifts," Journal of Economic Perspectives, 11(2), 41-54.

Johnson, G., and F. Stafford (1974): "The Earnings and Promotion of Women Faculty," American Economic Review, 64(6), 888-903. 
Jovanovic, B. (1979): "Job Matching and the Theory of Turnover," Journal of Political Economy, 87, 972-90.

Judge, G., W. Griffiths, and R. Hill (1985): The Theory and Practice of Econometrics. New York: Wiley, 2nd edn.

Juhn, C., K. Murphy, And B. Pierce (1993): "Wage Inequality and the Rise in Returns to Skill," Journal of Political Economy, 101(3), 410-42.

Kadas, S., and E. KlafzKy (1976): "Estimation of the Parameters in the Gravity Model for Trip Distribution: A New Method and Solution Algorithm," Regional Science and Urban Economics, 6(4), 439-57.

KANG, S., AND J. Bishop (1989): "Vocational and Academic Education in High School: Complements or Substitutes?," Economics of Education Review, 8(2), $133-48$.

KatZ, L., AND K. Murphy (1992): "Changes in Relative Wages, 1963-1987: Supply and Demand Factors," Quarterly Journal of Economics, 107(1), 35-78.

Katz, L., and A. Revenga (1989): "Changes in the Structure of Wages: The United States vs Japan," Journal of the Japanese and International Economy, $3(4), 522-53$.

Kiker, B., M. Santos, and M. De Oliveira (1997): "Overeducation and Undereducation: Evidence for Portugal," Economics of Education Review, 16(2), $111-25$.

Kiotz, B., R. Madoo, and R. Hanson (1980): "A Study of High and Low Labor Productivity Establishment in U.S. Manufacturing," in New Developments in Productivity Measurement and Analysis, ed. by J. Kendrick, and B. Vaccara. Chicago: University of Chicago Press.

Klump, R., and O. De La Grandville (2000): "Economic Growth and the Elasticity of Substitution: Two Theorems and Some Suggestions," American Economic Review, 90(1), 282-91.

Kruseli, P., L. Ohanian, V. Ríos-Rull, and G. Violante (2000): "Capital-Skill Complementarity and Inequality: A Macroeconomic Analysis," Econometrica, 68(5), 1029-53. 
Leuven, E., H. Oosterbeek, and H. Van Ophem (2004): "Explaining International Differences in Male Wage Inequality by Differences in Demand and Supply of Skill," Economic Journal, forthcoming.

Lever, M. (1996): "Firm. Size and Employment Determination in Dutch Manufacturing Industries," Small Business Economics, 8(5), 389-96.

LevY, D. (1990): "Aggregate Output, Capital and Labor in the Post-War U.S. Economy," Economics Letters, 33(1), 41-5.

Levy, F., and R. Murnane (1996): "With What Skills are Computers Complements?" American Economic Review, 86(2), 258-62.

MacDonald, G. (1982): "A Market Equilibrium Theory of Job Assignment and Sequential Accumulation of Information," American Economic Review, 72(5), $1038-55$.

MaChin, S., and J. Van Reenen (1998): "Technology and Changes in Skill Structure: Evidence from Seven OECD Countries," Quarterly Journal of Economics, 113(4), 1215-44.

Mairesse, J., And B. Dormont (1985): "Labor and Investment Demand at the Firm Level: A Comparison of French, German and U.S. Manufacturing, 1970-79," European Economic Review, 28(1-2), 201-31.

Marshali, A. (1920): Principles of Economics. London: Macmillan, 8th edn.

Mincer, J. (1993): Studies in Human Capital. Aldershot: Edward Elgar.

MorRison, C. (1988): "Quasi-Fixed Inputs in U.S. and Japanese Manufacturing: A Generalized Leontief Restricted Cast Approach," Review of Economics and Statistics, $70(2), 275-87$.

Mortensen, D. (1986): "Job Search and Labor Market Analysis," in Handbook of Labor Economics, ed. by O. Ashenfelter, and R. Layard, vol. 2. Amsterdam: Northe Holland.

Murphy, K., A. Shleifer, and R. Vishny (1991): "The Allocation of Talent: Implications for Growth," Quarterly Journal of Economics, 106(2), 503-30. 
Murphy, K., and F. Welch (1992): "The Structure of Wages," Quarterly Joumal of Economics, 107(1), 35-78.

Muysken, J., H. Mombert, and H. Rieder (2003): "The Impact of Education and Mismatch on Wages: Germany, 1984-2000," Mimeo.

Muysken, J., AND J. Ruholl (2001): "The Impact of Education and Mismatch on Wages: The Netherlands, 1986-1998," MERIT Working Paper series, University of Maastricht, 30.

Newbery, D., And J. Stiglitz (1981): The Theory of Commodity Price Stabilization. Clarendon Press: Oxford.

NG, Y. (2001): "Overeducation and Undereducation and their Effect on Earnings: Evidence from Hong Kong, 1986-1996," Pacific Economic Review, 6(3), 401-18.

Nickell, S., AND B. Bell (1996): "Changes in the Distribution of Wages and Unemployment in OECD Countries," American Economic Review, Papers and Proceedings, 86(2), 302-8.

OECD (2001): Education at a Glance: OECD Indicators. Paris: OECD publications.

Or, W. (1983): "Heterogeneous Firms and the Organization of Production," Economic Inquiry, 21(2), 147-71.

Olley, G., And A. Pakes (1996): "The Dynamics of Productivity in the Telecommunications Equipment Industry," Econometrica, 64(6), 1263-97.

Pincus, F. (1980): "The False Promise of Community Colleges: Class Conflict and Vocational Education," Harvard Educational Review, 50, 332-61.

PIssarides, C. (1984): "Search Intensity, Job Advertising, and Efficiency," Journal of Labor Economics, 2, 128-43.

Pissarides, C., and J. Wadsworth (1989): "Unemployment and the InterRegional Mobility of Labour," Economic Journal, 99(397), 739-55.

Ramcharran, H. (2001a): "Productivity, Returns to Scale and the Elasticity of Factor Substitution in the USA Apparel Industry," International Journal of Production Economics, 73(3), 285-91. 
(2001b): "Estimating Productivity and Returns to Scale in the US Textile Industry," Empirical Economics, 26(3), 515-24.

Rosen, S. (1968): "Short-Run Employment Variation on Class-I Railroads in the United States, 1947-1963," Econometrica, 36, 511-29.

50.

Rox, A. (1950): "The Distribution of Earnings and of Individual Output," Economic Journal, 60(3), 489-505.

(1951): "Some Thoughts on the Distribution of Earnings," Oxford Economic Papers, 3(1), 135-46.

Rumberger, R. (1987): "The Impact of Surplus Schooling on Productivity and Earnings," Journal of Human Resources, 22(1), 24-50.

SaLOP, S. (1979): "A Model of the Natural Rate of Unemployment," American Economic Review, 69(1), 117-25.

SATO, K. (1967): "A Two-Level CES Production Function," Review of Economic Studies, 34, 201-18.

SAttinger, M. (1975): "Comparative Advantage and the Distribution of Earnings and Abilities," Econometrica, 43(3), 455-68.

(1978): "Comparative Advantage in Individuals," Review of Economics and Statistics, 60(2), 259-67.

(1979): "Comparative Advantage and the Distributions of Earnings and Abilities," Econometrica, 43(3), 455-68.

(1980): Capital and the Distribution of Labor Earnings. Amsterdam: North-Holland.

(1993): "Assignment Models of the Distribution of Earnings," Journal of Economic Literature, 31(2), 831-80.

Sbordone, A. (1996): "Cyclical Productivity in a Model of Labor Hoarding," Joumal of Monetary Economics, 38(2), 331-61. 
SICherman, N. (1991): "Overeducation in the Labor Market," Labor Economics, 9(2), 101-22.

Sloane, P., H. Battu, and P. Seaman (1999): "Overeducation, Undereducation and the British Labour Market," Applied Economics, 31(11), 1437-53.

Slutsky, E. (1915): "Sulla Teoria Del Bilancio Del Consumatore," Giornale degli Economisti, 51, 1-26.

SoLOW, R. (1979): "Another Possible Source of Wage Stickiness," Journal of Macrocconomics, $1(1), 79-82$.

Stone, R., And A. BRown (1964): A Computable Model of Economic Growth, vol. 1 of the series "A Programme for Growth". London: Chapman and Hall.

Teulings, C. (1995a): "A Generalized Assignment Model of Workers to Jobs for the U.S. Economy," Tinbergen Institute, Discussion Paper, TI 95-67,.

(1995b): "The Wage Distribution in a Model of the Assignment of Skills to Jobs," Journal of Political Economy, 103(2), 180-215.

(2002): "Comparative Advantage, Relative Wages, and the Accumulation of Human Capital," Timbergen Imstitate Discussion Paper; (TI 2002)$081 / 3)$.

Teulings, C., and J. Hartog (1998): Corporatism or Competition? Cambridge: Cambridge University Press.

Tinbergen, J. (1956): "On the Theary of Income Distribution," Weltwirtschaftiches Archiv, 77(1), 156-75.

(1973): "Labour with Different Types of Skills and Jobs as Production Factors," De Economist, 121(3), 213-24.

- (1974): "Substitution of Graduate by Other Labour," Kyklos, 27(2), $217-26$.

- (1975a): Income Distribution: Analysis and Policies. Amsterdam: North-Holland.

(1975b): "Substitution of Academically Trained by Other Manpower," Weltwirtschaftliches Archiv, 111(3), 466-76. 
Tinbergen, J. (1977): "Income Distribution: Second Thoughts," De Economist, 125(3), 315-39.

Tinbergen, J. (1982): "The Scarcity Earnings Theory Mlustrated by Rumberger's Skill Requirements Study," Erasmus University Rotterdam, Discussion Paper, $8202 / \mathrm{G}$.

(1984): "Allocation of Workers over Jobs," De Economist, 132(1), 23 -9.

Tsang, M. (1987): "The Impact of Underutilisation of Education on Productivity: A Case Study of the U.S. Bell Companies," Economics of Education Review, 6(2), 23954.

TsanG, M., AND H. Levin (1985): "The Economics of Overeducation," Economics of Education Review, 4(2), 93-104.

(1989): "The Economics of Education: Reply," Economics of Education Review, 8(2), 209.

VAHEY, S. (2000): "The Great Canadian Training Robbery: Evidence on the Returns to Educational Mismatch," Economics of Education Review, 19(2), 219-27.

Van Batenburg, P., and J. Tinbergen (1984): "Income Distribution: A Correction and a Generalization," Weltwirtschaftliches Archiv, 120(2), 361-5.

VAn Eiss, P., AND L. Borghans (1996): "The Use of RAS in Manpower Forecasting: A Microeconomic Approach," Economic Modelling, 13, 257-87.

VAN OURS, J., AND G. RIDder (1991): "Job Requirements and the Recrtitiment of New Employees," Economics Letters, 36(2), 213-18.

VARIAN, H. (1984): Microeconomic Analysis. New York: Norton and Company, 2nd edn.

Verdugo, R., And J. Schneider (1994): "Gender Inequality in FemaleDominated Occupations: The Earnings of Male and Female Teachers," Economics of Education Review, 13(3), 251-64.

Verdugo, R., And N. Verdugo (1989): "The Impact of Surplus Schooling on Earnings," Journal of Human Resources, 24(4), 629-43. 
Vroom, V. (1964): Work and Motivation. New York: John Wiley and Sons.

Welch, F. (1970): "Education in Production," Journal of Political Economy, $78(1), 35-59$.

Willis, R. (1986): "Wage Determinants: A Survey and Reinterpretation of Human Capital Earnings Functions," in Handbook of Labor Economics, ed. by O. Ashenfelter, and R. Layard, pp. 525 602. Amsterdam: North-Holland.

Willis, R., And S. Rosen (1979): "Education and Self-Selection," Journal of Political Economy, 87(5), S7-S36.

Wilms, W. (1974): "Public and Proprietary Vocational Training: A Study of Effectiveness," Center for Research and Development in Higher Education, University of California, Berkeley.

Zellner, A. (1962): "An Efficient Method of Estimating Seemingly Unrelated Regressions and Tests for Aggregation Bias," Journal of the American Statistical Association, 57, 585-612.

(1963): "Estimators for Seemingly Unrelated Regression Equations: Some Exact Finite Sample Results," Journal of the American Statistical Association, 58, 977-92. 


\section{Summary in Dutch}

Het doel van deze studie is tweevoudig: het ene is om inzicht te brengen in wat er gebeurt als er op de arbeidsmarkt substitutieprocessen plaatsvinden. Het andere doel is te begrijpen waarom sommige arbeidsmarkten flexibeler zijn dan anderen. Hoewel de specialisatie van arbeid een belangrijke eigenschap is, is op de arbeidsmarkt, niemand onvervangbaar. Wij beweren dat als een arbeidskracht weggaat, het bedrijf misschien enkele taken zal verschuiven en een nieuwe arbeidskracht zal zoeken maar de productie zal hierdoor vrijwel onaangetast blijven. Deze (her-) toewijzing van taken aan arbeidskrachten creëert een dusdanige flexibiliteit op de arbeidsmarkt waardoor de verschuivingen in de vraag naar en de aanbod van de diverse soorten arbeidskracht gemakkelijker kunnen worden geabsorbeerd. Maar, aangezien deze flexibiliteit waarschijnlijk niet onbeperkt is, stellen wij de vraag: wat zijn de beslissende factoren in de mogelijkheden om arbeidskrachten met verschillende vaardigheden te substitueren. Begrip van het mechanisme waardoor de taken op de arbeidsmarkt verdeeld worden geeft inzicht in de vraag waarom sommige arbeidsmarkten flexibeler zijn dan anderen.

Om te begrijpen hoe de toewijzing van taken in heterogene banen aan heterogene arbeidskrachten de substitutie tussen groepen arbeidskrachten beïnvloedt, wordt in Hoofdstuk 2 een allocatiemodel ontwikkeld. Het model laat zien hoe de toewijzing van heterogene arbeidskrachten aan heterogene banen verbonden is met het substitutieproces dat op de arbeidsmarkt wordt waargenomen. Het model is een uitbreiding van het 'taaktoewijzingsmodel' (task assignment model) van Rosen (1978) waarin elk beroep een verschillend continuüm van taken heeft. Wij tonen aan dat de toewijzing van arbeidskrachten met uiteenlopende opleidingsachtergronden naar heterogene taken in verschillende beroepen in een allocatiemodel kan worden geformaliseerd door een 2-niveau Constante Elasticiteit Substitutie (CES) productie functie te schatten.

Het gepresenteerde model laat twee opmerkelijke speciale gevallen toe. Het 
gebruiken van een 1-niveau CES productie functie waarin alleen een onderscheid wordt gemaakt tussen arbeidskrachten naar opleidingsachtergrond (of beroep) is vergelijkbaar met het model van Rosen (1978). Het gebruiken van een 2niveau Cobb-Douglas-Lineaire productie functie leidt tot de productie functie die gebruikt wordt door Tinbergen (1973).

Het gepresenteerde model laat zien dat wanneer het relatieve loon van arbeidskrachten met een bepaalde opleidingsachtergrond toeneemt, ze een kleiner aantal taken in alle beroepen zullen worden toevertrouwd, i.e. slechts de taken waarin zij heel goed zijn. Wanneer het aantal verschillende taken die arbeidskrachten met een bepaalde opleidingsachtergrond in hun specifieke beroep uitvoeren meer afneemt dan het aantal taken dat deze arbeidskrachten uitvoeren in andere beroepen, dan wordt het minder efficiënt om output in het specifieke beroep van deze arbeidskrachten te produceren op voorwaarde dat de parameter van substitutie tussen beroepsoutput groter is dan 1. Het omgekeerde is het geval waarbij de parameter van subsitutie tussen beroepsoutput kleiner is dan 1.

We generaliseren dit model door de veronderstelling dat binnen opleidingsgroepen, arbeidskrachten homogeen zijn los te laten. In dit model, zijn arbeidskrachten en banen, naar analogie met Tinbergen (1956), heterogeen met betrekking tot respectievelijk de vaardigheden die arbeidskrachten hebben en de vaardigheden die de verschillende beroepen vereisen. Wij benadrukken echter de vraag naar arbeid door de toewijzing van arbeidskrachten aan banen die de productiefunctie van bedrijven maximaliseert op te lossen. Door het gebruiken van een uitbreiding van Rosen's (1978) specificatie van de vraag naar arbeidskrachten per eenheid output, tonen wij aan dat de toewijzing van heterogene arbeidskrachten aan heterogene banen in een allocatiemodel kan worden geformaliseerd door het schatten van een 2-niveau CES productie functie, waarbij een onderscheid wordt gemaakt tussen de diverse opleidingsachtergronden van arbeidskrachten en de diverse beroepen.

In Hoofdstuk 3, testen wij de relevantie van ons allocatiemodel voor het verklaren van het substitutieproces tussen verschillende soorten arbeidskracht. Wij doen dit door het vergelijken van de allocatie van arbeidskrachten met verschillende opleidingsrichtingen naar diverse beroepen en lonen in verschillende landen. Als het substitutieproces tussen de diverse soorten arbeidskrachten in alle landen onbelemmerd plaatsvindt, zouden de verschillen tussen het relatieve aanbod van arbeidskrachten moeten samenvallen met de loonverschillen. We tonen echter aan dat arbeidskrachten-met een diploma in dezelfde studierichting maar in verschil- 
lende landen, verschillen in het aantal verschillende taken die zij in de diverse beroepen kunnen uitvoeren. Deze verschillen zijn toe te schrijven aan verschillen in het onderwijssysteem tussen landen. Zo verschilt de kennis die op de diverse opleidingsrichtingen in Frankrijk wordt onderwezen van de kennis die in gelijkwaardige studies in het Verenigd Koninkrijk wordt onderwezen. Deze verschillen in de inhoud van een bepaalde opleidingsrichting veroorzaken verschillen in het aantal verschillende taken dat gediplomeerden in Frankrijk en het VK kunnen uitvoeren in de diverse beroepen. Een belangrijke implicatie is dat de inhoud van een studie de 'taak-toewijzingsmogelijkheden' en daarmee het substitutieproces op de arbeidsmarkt bepaalt. De analyse die in Hoofdstuk 3 wordt uitgevoerd en de daaruit vloeiende empirische resultaten benadrukten de relevantie van ons allocatiemodel bij het verklaren van het substitutieproces dat op de arbeidsmarkt plaatsvindt. De empirische resultaten tonen inderdaad aan dat de verschillen in allocatie tussen landen in hoge en belangrijke mate $(50 \%)$ de verschillen in de allocatiestructuur volgen. Zodra voor deze verschillen in de allocatiestructuur wordt gecontroleerd, vinden wij dat de loonverschillen tussen landen met minstens $64 \%$ van de verschillen in de aanwending van arbeidskrachten met diverse opleidingsachtergronden in diverse beroepen samenvallen. De resterende $36 \%$ kan aan niet waargenomen factoren worden toegeschreven, die gerelateerd kunnen zijn aan institutionele factoren zoals vastgestelde salarisschalen of minimumlonen.

De verschillen in de allocatiestructuur tussen landen wijzen erop dat de keus voor de structuur van het onderwijssysteem het resultaat is van een optimaliseringsproces. Daarom stellen wij in Hoofdstuk 4 de vraag in welke mate de kennis die in elke studierichting wordt anderwezen de arbeidsproductiviteit en de arbeidsmarkt instabiliteit op de lange termijn beïnvloedt.

Wij stellen dat een verschuiving in het aanbod van arbeidskrachten met twee specifieke beroepsopleidingsrichtingen tot een verandering in het relatieve loon van deze twee soorten arbeidskracht zou moeten leiden, maar het loon van arbeidskrachten met een algemene: opleidingsrichting onveranderd zou moeten laten. Wij leiden een toerijkende voorwaarde voor de allocatiestructuur af, waarbij voldaan wordt aan dit type wederzijdige verschuiving in het geval van 3opleidingsrichtingen/3-beroepen. Allocatiestructuren die aan dit type verschuivingen voldoen worden gekenmerkt door drie productiviteitsparameters. De eerste parameter duidt op het aantal taken die arbeidskrachten met een opleidingsrichting waarvoor de werkgelegenheid niet verandert, buiten hun eigen beroep kunnen uitvoeren. De tweede parameter heeft betrekking op het aantal taken die 
de arbeidskrachten waarvoor de werkgelegenheid toeneemt en de arbeidskrachten waaryoor de werkgelegenheid daalt in elkaars beroep kunnen uitoefenen. De derde parameter wijst op het aantal taken die de arbeidskrachten waarvoor de werkgelegenheid toeneent en de arbeidskrachten waarvoor de werkgelegenheid daalt, kunnen uitvoeren in het beroep van de arbeidskrachten waarvoor de werkgelegenheid niet verandert. De simulaties tonen aan dat zowel de arbeidsproductiviteit als de loonspreiding gevoelig zijn voor de relatieve omvang van de drie parameters. Het vergroten van het aantal taken die arbeidskrachten buiten hun eigen beroep kunnen uitvoeren vermindert de arbeidsproductiviteit. Echter, des te groter het aantal taken die arbeidskrachten buiten hun eigen beroep kunnen uitvoeren, des te kleiner de toename van de loonspreiding wanneer er sprake is van verschuivingen in de samenstelling van het arbeidsaanbod.

Om de relevantie van het beroepsonderwijs in initieel onderwijs te onderzoeken, gebruiken we Nederlandse arbeidsmarkt gegevens. Wij schatten de elasticiteit van substitutieparameters en de allocatiestructuurparameters voor arbeidskrachten met algemene, technische en sociale-en-diensten studies op het middelbaar (HAVO/VWO en MBO) niveau, die in drie min of meer aan de opleidingsrichting verwante beroepen werken. We zien dat de vraag naar arbeidskrachten met een algemene/administratieve opleidingsachtergrond minder elastisch is dan de vraag naar arbeidskrachten met technische en sociale-endiensten beroepsspecialisaties. Dit resultaat wijst erop dat een relatieve daling van gediplomeerden met een algemene opleiding een vrij hoge toename van het relatieve loon van deze gediplomeerden, een grote daling van de gemiddelde arbeidsproductiviteit en een hoge toename van loonspreiding veroorzaakt.

We tonen aan dat de inhoud van een studie in termen van specifieke en algemene vaardigheden voor zowel arbeidsproductiviteit als loonongelijkheid van belang is. Hoe specifieker de vaardigheden van arbeidskrachten hoe groter de arbeidsproductiviteit. Niettemin, hoe algemener de vaardigheden van arbeidskrachten hoe groter het aantal taken dat deze arbeidskrachten buiten hun eigen beroep kunnen uitvoeren en hoe kleiner de toename van de loonongelijkheid in het geval van aanbodverschuivingen. Voorts tonen wij aan dat er rekening zou moeten worden gehouden met de flexibiliteit van de arbeidsmarkt wanneer de inhoud van de diverse opleidingsrichtingen wordt vastgesteld. Wanneer, zoals in Nederland het geval is, de parameter van substitutie-elasticiteit tussen beroepsoutput groot is in vergelijking met de parameter van substitutie-elasticiteit tussen arbeidskrachten met verschillende opleidingsrichtingen kan de economie profiteren 
van het verminderen van het aantal taken dat arbeidskrachten met een algemene opleiding buiten het algemene beroep kunnen uitvoeren, door de vaardigheden te verhogen die tot hun productiviteit in het algemene beroep bijdragen ten koste van de algemene vaardigheden die tot hun productiviteit op de andere beroepsrichtingen bijdragen.

In het allocatiemodel dat in Hoofdstuk 2 wordt ontwikkeld, wordt het substitutieproces bepaald door de manier waarop bedrijven aan arbeidskrachten hun taken toewijzen. De structuur van de productiviteit van arbeidskrachten in de diverse beroepen kan tot een substitutieproces leiden met een hogere arbeidsproductiviteit en een lagere loonongelijkheid. In Hoofdstuk 5 analyseren we of de grote verschillen die tussen kleine en grote bedrijven in termen van output, productiviteit en de inputs in het productieproces verklaard kunnen worden door verschillen in de wijze van productie. Deze verschillen wijzen er op dat kleine en grote bedrijven niet dezelfde productiefunctie hebben. Wij stellen dat de verschillen in kapitaalintensiteit tussen grote en kleine bedrijven kunnen worden verklaard door een grotere substitutieelasticiteit tussen arbeidskracht en kapitaal in grote bedrijven. Ook, laten wij zien dat hoe hoger de substitutieelasticiteit tussen geschoolde en ongeschoolde arbeidskrachten, hoe groter het werkgelegenheidsaandeel van de geschoolde arbeidskrachten in het geval. van 'skill-biased' technologische verandering. Bovendien, kan de hogere arbeidsproductiviteit die in grote bedrijven wordt waargenomen door een grotere substitutieelasticiteit tussen inputs worden verklaard.

Om productiefuncties voor bedrijven van verschillende grootte in elke industrietak te schatten, gebruiken wij 'matched employer-employee' gegevens voor de Deense industrie, bouwsector en nutsbedrijven tussen 1992-1995. In alle drie de bedrijfssectoren is de omvang van de geschatte substitutieelasticiteit tussen geschoolde arbeidskrachten in hoge functies met alle andere arbeidsinput en het kapitaal groter in grote bedrijven. Deze verschillen verklaren de hogere arbeidsproductiviteit en de kapitaalintensiteit die in grote bedrijven wordt waargenomen. Gegeven het 'skill-biased' karakter van de technologische ontwikkelingen die in de laatste decennia wordt waargenomen, kan de hogere substitutieelasticiteit tussen geschoolde en ongeschoolde arbeidskrachten in grote bedrijven de hogere proportie van geschoolde arbeidskracht in grote bedrijven verklaren.

In overeenkomst met de 'skill segregation' hypothese, vinden we dat er in grote bedrijven meer overgeschoolde arbeidskrachten werkzaam zijn. Dit kan 
gezien worden als een vorm van 'ant versus cicada' gedrag. De hogere productiviteit stelt grote bedrijven in staat om een reservecapaciteit van geschoolde arbeidskrachten op te bouwen tijdens periodes van lage lonen voor geschoolde arbeidskrachten. Daardoor kunnen grote bedrijven bij vraag- of aanbodschokken op de arbeidsmarkt voor geschoolde arbeidskrachten voorzien in hun behoefte aan geschoold personeel. Bij het stijgen van het loon van geschoolde arbeidskrachten, worden grote bedrijven minder beïnvloed aangezien zij reeds een interne reserve van geschoolde arbeidskrachten in huis hadden.

Samenvattend, leiden de analyses in dit proefschrift tot vier belangrijk resultaten. Het eerste belangrijke resultaat van deze proefschriftstudie is dat een eenvoudige productiefunctie op twee niveaus de toewijzing van arbeidskrachten met uiteenlopende onderwijsachtergronden aan de taken van verschillenden beroepen in kaart kan worden gebracht. Het tweede belangrijke inzicht is dat het substitutieproces dat op de arbeidsmarkt plaatsvindt op consistente wijze verklaard kan worden op basis van het allocatiemodel waarin arbeidskrachten met uiteenlopende opleidingsachtergronden worden toegewezen aan verschillende banen. De inhoud van de diverse opleidingen is een belangrijke determinant in de toewijzing van arbeidskrachten aan taken aangezien de inhoud van een opleiding het aantal taken die arbeidskrachten met een opleidingsachtergrond in de diverse beroepen kunnen uitvoeren bepaalt, i.e. de allocatiestructuur. Het derde belangrijke resultaat van deze proefschriftstudie is dat wanneer het makkelijk is om de output van de verschillende beroepen onderling te vervangen, een onderwijssysteem met beroepsspecialisaties tot een hogere productiviteit zal leiden. Wanneer het daarentegen gemakkelijker is om tussen arbeidskrachten binnen beroepen te substitueren, een onderwijssysteem met twee beroepsspecialisaties en één algemene opleidingsrichting tot een hogere productiviteit zal leiden. Het vierde belangrijke inzicht dat de studie oplevert is dat de verschillen in de vorm van de productiefunctie en in het bijzonder verschillen in de substitutiemogelijkheden tussen grote en kleine bedrijven in dezelfde bedrijfssector een belangrijk oorzaak zijn van de verschillen in output, productiviteit en de allocatie van arbeidskracht. 


\section{Conventions}

Some notational conventions are needed to ease the reader's mind throughout this study.

- Variahles:

- $H$ is the level of output produced either by a firm or the economy and when indexed by occupation (see index conventions) represents intermediate output produced in that particular occupation.

- $h$ is the labour productivity measured in units of output per worker.

- $L$ is the labour demand measured as the number of workers employed and will often be indexed by education and occupation (see index conventions).

- $K$ is the level of capital engaged in the production of output.

- $k$ is the capital intensity measured in units of capital per worker.

- $C$ are the input costs engaged to produce output.

- $w$ is the wage rate of workers and will be indexed by education.

- $U C$ is the unitary cost function and when indexed by occupation represents the unitary cost function in a particular occupation.

$-t$ stands for the level of skills a worker possesses and when indexed on $r$ refers to the skill of type $r$.

- $s$ stands for the level of skills required to do a task and when indexed on $r$ refers to the skill of type $r$. 
- Parameters:

- $a$ and $\pi$ represent productivity parameters defined by the technology used to produce output and therefore are parameters of the production function. These parameters will be indexed by education and occupation such that they reflect the range of tasks of an occupation workers with each educational background can perform. The $a$ parameters sum to unity in each occupation while the largest $\pi$ in each occupation is equal to unity.

- $\beta$ is a technology parameter that expresses the ease to substitute between the various inputs.

$-\sigma$ is the parameter of substitution elasticity.

- Indexes:

${ }_{-}{ }_{i}$ indexes occupations or when relevant tasks, and therefore refer to a demand side index. When a comparison between two occupations or tasks is needed, the second index is $g$.

${ }_{-}{ }_{j}$ indexes education or when relevant individual workers and therefore refer to a supply side index. When a comparison between two educational groups or workers is needed, the second index is $k$.

${ }{ }_{r}$ indexes the types of skill. 


\section{Curriculum vitae}

Arnaud Dupuy (4 August 1974) went to high-school in Grenoble (Ecole des Pupilles de l'Air (EPA), 1990-1992), France where he got his Baccalaureat C (Mathematics and Sciences) with honors. He studied Econometrics and Applied Economics at the Grenoble University and got his 'Maitrise des Sciences Techniques' with honors. From September 1997 to June 1998 he followed various econometric courses at the Maastricht University via the Erasmus exchange program which resulted in the 'Diplôme d'economiste Bilingue.' He started his Ph.D. thesis in August 1998 at the Research Centre for Education and the Labour Market (ROA), Maastricht University. In May 2001, he received a grant from the Marie Curie funding for a three-month stay at the Centre for Labour market and Social research (CLS) in Aarhus Business School, Denmark. Since February 2001 he is a Research fellow at the ROA. 
CURRICULUM VITAE 


\section{ROA Dissertation Series}

1. Lex Borghans (1993), Educational Choice and Labour Market Information, Maastricht: Centre for Education and the Labour Market (ROA).

2. Frank Cörvers (1999), The Impact of Human Capital on International Competitiveness and Trade Performance of Manufacturing Sectors, Maastricht: Centre for Education and the Labour Market (ROA).

3. Ben Kriechel (2003), Heterogeneity among Displaced Workers, Maastricht: Centre for Education and the Labour Market (ROA).

4. Arnaud Dupuy (2004), Assignment and Substitution in the Labour Market, Maastricht: Centre for Education and the Labour Market (ROA). 
